\title{
Uncovering Local Endemism in the Kimberley, Western Australia: Description of New Species of the Genus Amplirhagada Iredale, 1933 (Pulmonata: Camaenidae)
}

\author{
FRANK KÖHLER \\ Department of Environment and Conservation of Western Australia, Science Division, \\ Wildlife Place, Woodvale WA 6026, Australia; and \\ Australian Museum, 6 College Street, Sydney NSW 2010, Australia \\ frank.koehler@austmus.gov.au
}

\begin{abstract}
In this work twenty-six species of the camaenid land snail Amplirhagada, which is endemic to the Kimberley region in Western Australia, are newly described. In addition, the anatomy of two further species, A. katerana and A. combeana, is described and a further, yet undescribed species is reported from Boongaree Island based on dry shell material. Most of these species occur on islands of the Bonaparte Archipelago off the mainland coast. The patterns of distribution and differentiation of these island species are comparable, however, with those found on the mainland. Mainland species are usually restricted to single rainforest patches. Frequently, single patches harbour only one or two congeneric species. Similarly, smaller islands usually support one endemic Amplirhagada species whereas on larger islands up to four species are found to occur in sympatry. Species are distinguishable particularly by the characteristic anatomy of the inner penial wall. Sympatric species generally exhibit marked morphological differences in shells and genital anatomy. A molecular phylogeny based on partial sequences of the mitochondrial cytochrome c oxidase unit 1 gene (COI) reveals a basal polytomy among species of the genus, which are generally genetically well differentiated. Relationships among species in the molecular tree mainly reflect geographical patterns.
\end{abstract}

KÖHLER, FRANK, 2010. Uncovering local endemism in the Kimberley, Western Australia: description of new species of the genus Amplirhagada Iredale, 1933 (Pulmonata: Camaenidae). Records of the Australian Museum 62(2): 217-284.

Camaenid land snails of the genus Amplirhagada Iredale, 1933, are endemic to the Kimberley region of Western Australia, where they have radiated extensively. Thirty species are currently considered valid, most of which usually occupy small distributional ranges along the Kimberley coast from the Buccaneer Archipelago in the south to Kalumburu in the north as well as in inland areas of the Napier, Harding, and King Leopold Ranges, the Drysdale
River Reserve, Mt Elizabeth Station and the region south of Wyndham (Solem, 1981a, 1988). Many of these species are restricted to single localities, such as rainforest patches or more open woodlands (Solem, 1991). Supposed exceptions, with species occupying larger ranges, are likely to result from the inadequate delimitation of morphologically cryptic species (Solem, 1981a). Earlier accounts were predominantly based on dry shells (e.g., Smith, 1894; Iredale, 1933, 


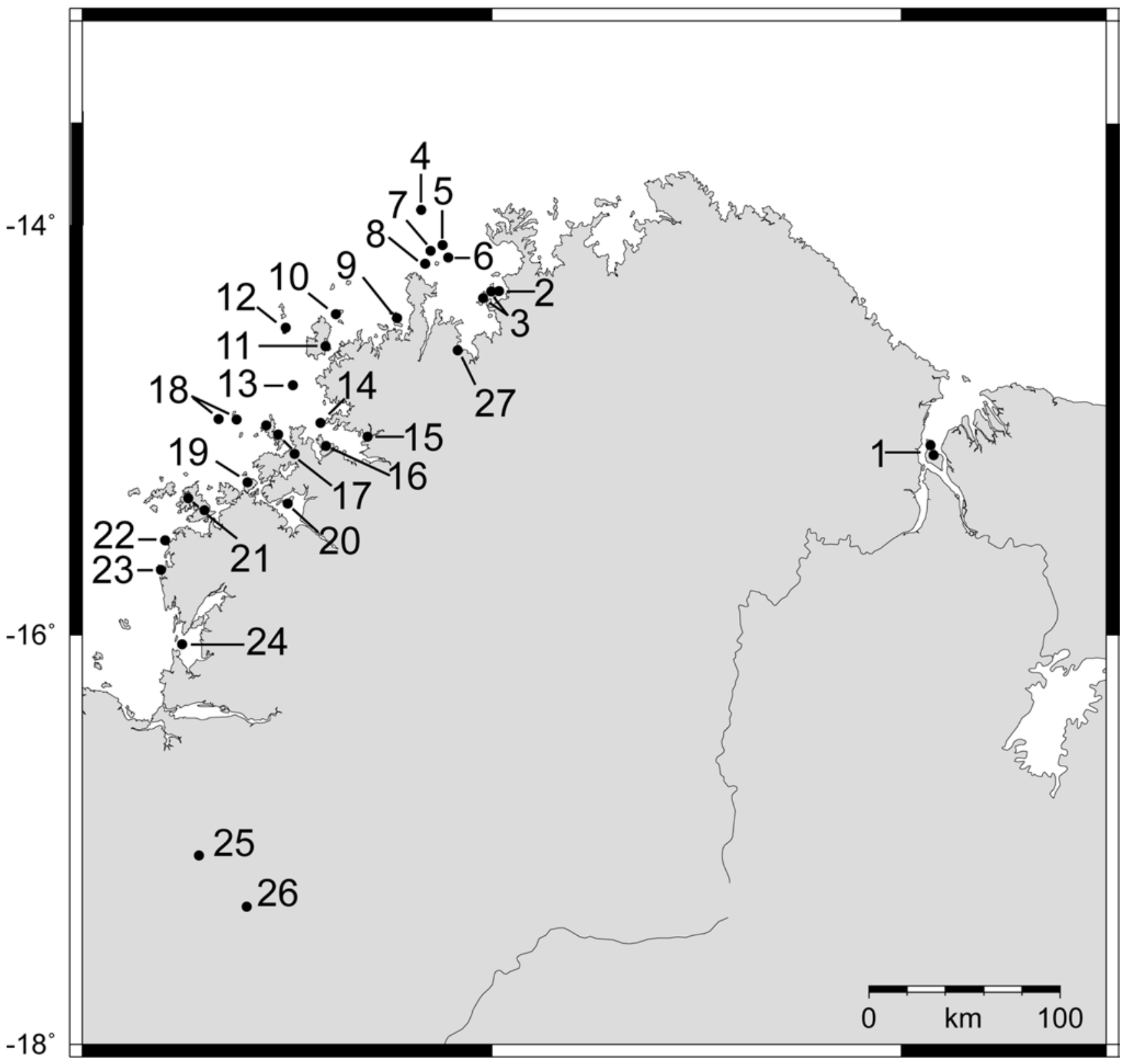

Figure 1. Distribution of Amplirhagada species in the Kimberley region, northwestern Australia. (1) A. euroa n.sp., Adolphus Island. (2) A. solemiana n.sp., Middle Osborn Island. (3) A. indistincta n.sp., Southwest Osborn Island, Kidney Island. (4) A. combeana, Cassini Island. (5) A. mckenziei n.sp., Oliver Island. (6) A. ponderi n.sp., Kingsmill Island. (7) A. montesquieuana n.sp., Fenelon Island. (8) A. descartesana n.sp., Descartes Island. (9) A. katerana, Katers Island. (10) A. puescheli n.sp., unnamed island near Prudhoe Island. (11) A. decora n.sp., A. kessneri n.sp., Bigge Island. (12) A. berthierana n.sp., Berthier Island. (13) A. lamarckiana n.sp., Lamarck Island. (14) A. anderdonensis n.sp., unnamed island, Anderdon Islands. (15) A. tricenaria n.sp., Prince Frederick Harbour, north of Hunter River mouth. (16) A. regia n.sp., A. boongareensis n.sp., A. gibsoni n.sp., and Amplirhagada sp., Boongaree Island. (17) A. yorkensis n.sp., Coronation Island. (18) A. buffonensis n.sp., Buffon Island. (19) A. uwinsensis n.sp., Uwins Island. (20) A. sphaeroidea n.sp., St. Andrews Island. (21) A. basilica n.sp., and A. camdenensis n.sp., Augustus Island. (22) A. kimberleyana n.sp., NW of Wilson Point. (23) A. gemina n.sp., $1.5 \mathrm{~km}$ SE of Hall Point. (24) A. dubitabile n.sp., Steep Island. (25) A. napierana, north Napier ranges. (26) A. percita, Napier ranges. (27) A. castra, A. mitchelliana, and A. varia, Mitchell Plateau.

1938, 1939). However, Solem (1981a, 1988) demonstrated that Amplirhagada species frequently show only subtle differences in shell features, such as colour, shape, and sculpture. In addition, shells are prone to homoplasy, which renders the delimitation of species by shell features alone difficult or impossible. In fact, proper species delimitation requires the study of genital anatomy, which was identified as a convenient source of key morphological characters for the recognition of species not only in this genus but also in other camaenid genera (Solem, 1979, 1981a, 1981b, 1984, 1985; Willan et al., 2009; Köhler, 2010). In Amplirhagada structure of the inner penial wall and development of the main stimulatory pilaster provide particularly valuable diagnostic characters for delimiting species (Solem, 1988). 
A comparative study, mainly of the genital anatomy, enabled Solem (1981a) to identify a large number of species that were unrecognized by previous authors, who relied exclusively on shell features. Solem showed that relatively restricted areas in the Kimberley, such as the Mitchell Plateau, may support a surprisingly large number of species that can be differentiated on morphological criteria only by their genital anatomy. Solem's milestone publications on the Camaenidae in Western Australia (Solem, 1979, 1981a, 1981b, 1984, 1985, 1988, 1991; Solem \& Christensen, 1984) highlighted the remarkable diversity and patterns of local endemism within this group of land snails. Even though he published extensively on Western Australian Camaenidae, Solem was not able to approach a complete documentation of their extant diversity (Cameron et al., 2005).

In addition to thirty named species of Amplirhagada, Solem (1991) listed 25 undescribed species from rainforest patches and woodlands throughout the Kimberley region. When Alan Solem died in 1990 he left numerous examples of undescribed Amplirhagada species that are currently housed in the Field Museum in Chicago. Given the poor documentation of camaenid land snails from vast areas, such as most of the islands off the Kimberley coast, and with documented but undescribed material being kept in the collections of various museums, many more species undoubtedly remain to be discovered (Solem, 1988). Taking this high proportion of undiscovered diversity into consideration; Amplirhagada is surely the most species diverse camaenid genus in northwestern Australia, with only a small fraction of its actual species diversity having been described.

The aim of the present work is to enhance the documentation of diversity of this endemic genus in the Western Australian Kimberley region. Special attention is paid to islands off the Kimberley coast, which have previously been neglected. Twenty-seven Amplirhagada species are newly described herein based on a comparative study of samples from various sources. The core material was collected in 2007-2008 during the Kimberley Island Survey of the Department of Environment and Conservation, Western Australia. This material is supplemented by samples that were collected as early as 1987 and are housed in museum collections.

In addition to the study of morphological differentiation, molecular phylogenies have been reconstructed based on sequences of a partial fragment of the mitochondrial cytochrome c oxidase gene (COI) in order to compare rates of genetic and morphological differentiation and to assess the diagnostic value of anatomical characters in a phylogenetic context.

\section{Material and methods}

This study is primarily based on ethanol preserved specimens and supplementary dry shell material collected during the Kimberley Island Survey (KIS) of the Department of Environment and Conservation, Western Australia (DEC) in 2007-2009, the Kimberley Rainforest Survey of the then Department of Conservation and Land Management, Western Australia (RFS) in 1987-1988 and additional field work conducted between 1988 and 2002 by various parties. Types and other voucher material are deposited in the Western Australian Museum, Perth (WAM), the Field Museum of Natural History, Chicago (FMNH), and the Australian Museum, Sydney (AMS).

Morphological descriptions focus on characters of the shell, the mantle cavity, the genital organs, and the radula. Morphometric shell parameters, such as height of shell $(\mathrm{H})$, diameter of shell (D), height of last whorl (LW), and width of umbilicus $(\mathrm{U})$ were measured with callipers precise to $0.1 \mathrm{~mm}$. The numbers of whorls $(\mathrm{N})$, including the protoconch, were counted as described Barker (1999: Fig. 6). The parameter "angle of aperture" describes the angle formed between aperture and the horizontal in degrees when the shell is in an upright position. The morphometric shell parameters $\mathrm{H}, \mathrm{D}, \mathrm{LW}, \mathrm{U}, \mathrm{N}$, $\mathrm{H} / \mathrm{D}$ were subjected to morphometric analyses when considered necessary for the delimitation of species with similar shells.

Anatomy of mantle and genital organs was studied using a binocular microscope with drawing mirror. If not stated otherwise, the final inking of drawings was done by Martin Püschel (Sydney). Radulae and jaws were extracted manually, cleaned by soaking in $10 \% \mathrm{KOH}$ solution for about six hours followed by rinsing in water and ethanol. They were mounted on carbon specimen tabs for electron scanning microscopy. Radular tooth formula gives the numbers of teeth as follows: $\mathrm{C}$ (central row of teeth)+number of lateral rows of teeth+number of transitional rows of teeth+number of marginal rows of teeth. The anatomy was studied in two (in small series) to five specimens per sample in order to confirm that morphological observations are consistently found among conspecific specimens.

DNA was extracted from small pieces of foot muscle by use of a QIAGEN DNA extraction kit for animal tissue following the standard procedure of the manual. A fragment of the mitochondrial cytochrome c oxidase gene (COI) was amplified by PCR using the standard primers LCO1490 and HCO2198 of Folmer et al. (1994). Reactions were performed under standard conditions with an annealing temperature of $50^{\circ} \mathrm{C}$. Phylogenetic trees were reconstructed by application of Maximum Likelihood (ML) using the software TREEFINDER version October 2008 (Jobb et al., 2004), Bayesian Inference (BI) using the software MRBAYES 3.1.2 (Ronquist \& Huelsenbeck, 2003), and Maximum Parsimony using the Ratchet implemented in WINCLADA (Nixon, 1999) with 1,000 iterations, 10 trees kept at each step. Nodal support of topologies was inferred by applying MP bootstrapping (Felsenstein, 1985) or by calculating Bayesian posterior clade probabilities (Larget \& Simon, 1999) and Expected-Likelihood Weights of Local Rearrangements of tree topology (LR-ELW) (Strimmer $\&$ Rambaut, 2002). Pair-wise genetic distances were calculated with the software DAMBE (Xia \& Xie, 2001). Sequences have been deposited with GenBank under the accessions GU302247 to GU302299. 


\section{Systematic descriptions}

\section{Gastropoda}

Heterobranchia

Stylommatophora

Camaenidae Pilsbry, 1895

\section{Amplirhagada Iredale, 1933}

Amplirhagada Iredale, 1933: 52; Solem, 1981a: 147-320; Solem, 1988: 28-32; Solem, 1991: 187-202. Type species Helix (Hadra) sykesi Smith, 1894 by original designation. Tenuigada Iredale, 1939: 68. Type species Tenuigada percita Iredale, 1939 by original designation.

\section{Diagnosis}

Rock or free sealer with medium sized $(15-30 \mathrm{~mm}$ in diameter), thin and translucent to moderately thick, broadly conical to dome-shaped shell with moderately to strongly elevated spire. Umbilicus concealed by columellar reflection or narrowly open. Protoconch with weak to strongly developed radially elongated pustulations; transition to teleoconch inconspicuous. Teleoconch with very weak axial growth lines that may become almost invisible on last whorl or sculptured by well-developed, regular axial lirae. Last whorl moderate to wide in cross-section; periphery well rounded to slightly angulate (often transitions are found within single populations). Shell colour usually variable even within populations, background often yellowish brown to horn, frequently with darker, brown bands located below suture and on periphery of whorl; some species are uniform in colour. Genitalia typically; development depends on seasonal activity and maturity. Penis with well-developed sheath, extending entire length, thin proximally, thick distally. No well-developed epiphallus present. Penial retractor muscle attached at apex of penial complex. Vas deferens entering sheath from halfway up to almost apically; entering penial chamber through verge. Inner penial wall supports characteristic pustulation and basal pilasters; a main stimulatory pilaster varies in development from undifferentiated to very large, cone-shaped. Spermatheca relatively simple, short reaching base of spermoviduct; duct and head usually well differentiated; inner spermathecal and vaginal wall with longitudinal pilasters that vary in development and finer structure. Albumen gland elongate. Hermaphroditic duct tightly undulating. Radula rectangular in shape, usually between 3.5 and $5.5 \mathrm{~mm}$ long with 120-170 rows of teeth. Tooth formula variable, $\mathrm{C}+12-20+3-4+15-22$.

\section{Amplirhagada euroa n.sp.}

Type locality (Fig. 1). Western Australia, eastern Kimberley, Cambridge Gulf, eastern section of Adolphus Island, $15^{\circ} 06^{\prime} 32^{\prime \prime S} 128^{\circ} 09^{\prime} 08^{\prime \prime E}$; KIS 3-113. East-facing gully with ephemeral stream and patches of vine thicket, fig trees. Scree on very steep slopes. In loose soil under large boulders (leg. V. Kessner, 7 August 2008).

Type material. Holotype WAM S34601 (Pl. 1.1). Paratypes AMS C463680 (6 preserved specimens, as holotype), WAM S37083 (12 preserved specimens, as holotype), WAM S37390 (3 shells, $15^{\circ} 06^{\prime} 18^{\prime \prime} \mathrm{S}$ $128^{\circ} 09^{\prime} 04^{\prime \prime E}$ ), WAM S37391 (shell, $15^{\circ} 06^{\prime} 35^{\prime \prime S} 128^{\circ} 09^{\prime} 57^{\prime \prime E}$ ), AMS C463723 (6 shells, $15^{\circ} 06^{\prime} 32^{\prime \prime S} 128^{\circ} 09^{\prime} 08^{\prime \prime}$ ). WAM S37392 (11 shells, $15^{\circ} 06^{\prime} 32^{\prime \prime} \mathrm{S} 128^{\circ} 09^{\prime} 08^{\prime \prime E}$ ), WAM S37393 (3 shells, north of Adolphus Island, $\left.15^{\circ} 04^{\prime} 19^{\prime \prime} \mathrm{S} 128^{\circ} 08^{\prime} 18^{\prime \prime E}\right)$.

Etymology. From euroa (Latin = eastern), for this species occurring at the easternmost limits of the known range of the genus.

Sealing strategy. Rock sealer.

Shell (Fig. 2A-B, Pl. 1.1-2). Broadly conical with low to medium high spire, thin to translucent. Periphery evenly rounded to slightly angulate; upper and basal sectors of whorls rounded. Umbilicus open, narrowly winding, 50-90 percent concealed by columellar reflection. Background colour yellowish brown with chestnut brown, thin to moderately broad, diffuse to well defined sub-sutural and mid-whorl bands, clearly visible on last whorls only; ventral colour brownish horn to whitish; outer lip colour tends to be lighter than shell till whitish; inner lip translucent. Protoconch c. $3 \mathrm{~mm}$ in diameter, comprising about 1.7 whorls, with faint, indistinct axial riblets. Teleoconch with fine axial lirae, curved if viewed from above, pointed in cross-section, irregularly spaced, spaces as wide as thickness of lirae. Lirae evenly distributed across whorl diameter, with reduced height underneath suture; present on all whorls. Angle of aperture $45^{\circ}$. Outer lip simple rounded, sharp, slightly to well expanded, slightly reflected; basal node absent or very weak; palatal node absent. Parietal wall of inner lip absent or inconspicuous.

Pallial morphology. Pallial cavity deep, extending one whorl; mottled or spotted black mantle pigmentation. Kidney extending about half of pallial cavity.

Genital morphology (Figs. 3-4). Penis straight, more or less of same length as anterior part of oviduct. Vas deferens coils before entering penis. Penial retractor muscle shorter than penis complex. Penial verge short, less than $1 / 5$ of length of penial chamber, slender with rounded tip. Penial wall pustules normal to elongated, arranged in rows over entire length of inner penial wall. Main stimulatory pilaster large, cone-shaped, comprising entire length of inner penial wall; sculptured by ridges with smooth, flattened pustules. Vas deferens entering penial sheath in upper third. Vagina of medium length, posteriorly inflated; inner vaginal wall supports undulating longitudinal pilasters. Spermatheca short, reaching base of spermoviduct; duct wide, inner wall with smooth longitudinal pilasters; head globular to elongately inflated, connected with oviduct by connective tissue, wall of head delicate, smooth. Free oviduct rather straight comprising about half of length of anterior part of oviduct. Spermoviduct longer than anterior part of oviduct. Talon embedded in albumen gland close to anterior end of albumen gland.

Radular morphology (Fig. 2C-E). Rectangular. Tooth formula $\mathrm{C}+12-13+3-4+20-21$. Average number of rows of teeth $146 \pm 7$ with $36.2 \pm 0.7$ rows of teeth per $\mathrm{mm}(\mathrm{n}=2)$. Central teeth with sharply pointed triangular mesocones, shorter than base of tooth; ectocones vestigial. Lateral teeth with bluntly pointed triangular mesocones, length equal to 

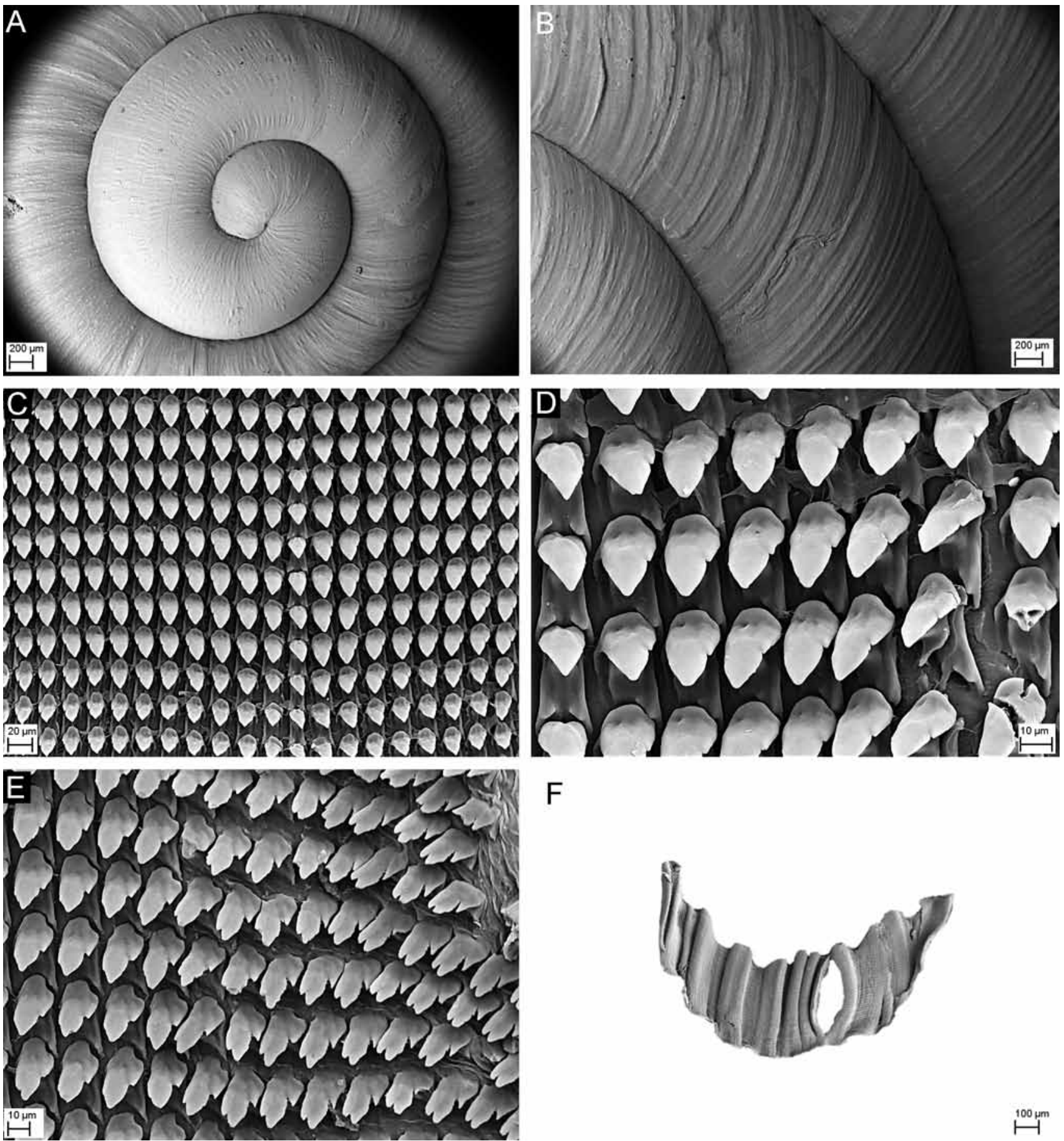

$\mathrm{F}$

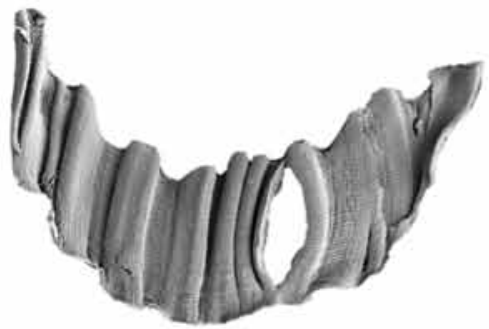

$\stackrel{100 \mu \mathrm{m}}{\longmapsto}$

Figure 2. SEM photographs of Amplirhagada euroa n.sp., paratype AMS C463680: (A) apical whorl viewed from above (scale 200 $\mu$ ); $(B)$ penultimate whorls viewed from above (scale $200 \mu \mathrm{m}) ;(C)$ central and lateral radular teeth (scale $20 \mu \mathrm{m})$; $(D)$ details of central and lateral teeth (scale $10 \mu \mathrm{m}) ;(E)$ details of outer lateral and inner marginal teeth (scale $10 \mu \mathrm{m}) ;(F)$ jaw (scale $100 \mu \mathrm{m})$.

base of tooth; small ectocones; endocones absent. Marginal teeth multicuspic, mesocone and endocone similar in length, ectocone smaller than endocone, occasionally subdivided.

Comparative remarks. Amplirhagada euroa is geographically well separated from most other congeneric species. Amplirhagada cambridgensis Solem, 1988 (from the western bank of Cambridge Sound) and A. questronana Solem, 1981a (from El Questro Station near Wyndham, c. $100 \mathrm{~km} \mathrm{~S}$ of Adolphus
Island) occur in closer proximity. The shell of $A$. cambridgensis is very similar but this species differs in the morphology of the inner penial wall with pustules being arranged to form corrugated longitudinal pilasters. Amplirhagada euroa differs from $A$. questronana by umbilicus forming a chink instead of being open and by its long main stimulatory pilaster that supports flattened pustules (A. questronana has a short pilaster with corrugations). Otherwise, both species have rather similar shells with regard to shape and size. 


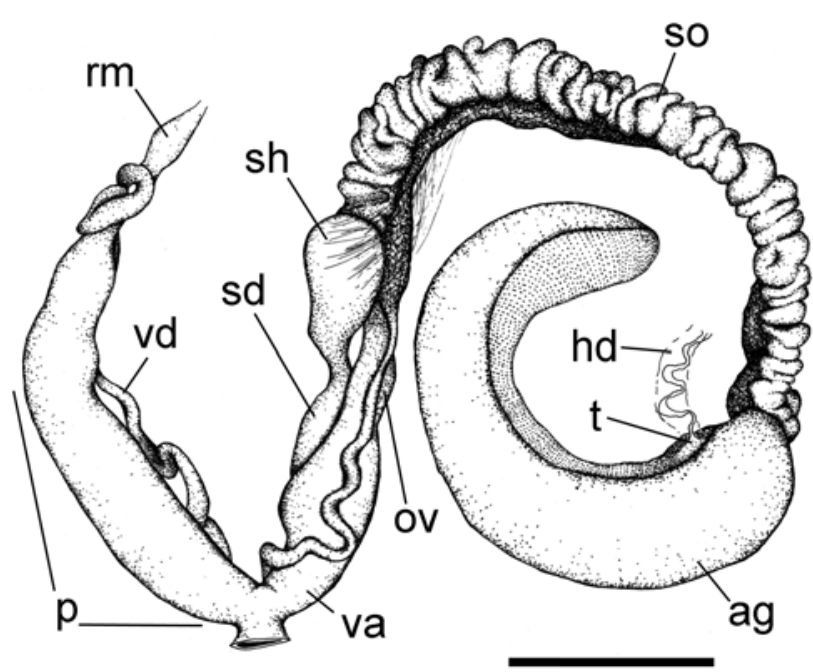

Figure 3. Genitalia of Amplirhagada euroa n.sp., paratype AMS C463680 (7 August, scale $10 \mathrm{~mm}$ ). Labelling of structures: ag, albumen gland; hd, hermaphroditic duct; $p$, penial complex (penis and penis sheath); ov, oviduct (free anterior part); rm, penial retractor muscle; sd, spermathecal duct; sh, spermathecal head; sp, spermoviduct (uterus, prostate); $t$, talon; va, vagina; vd, vas deferens.

\section{Amplirhagada solemiana n.sp.}

Type locality (Fig. 1). Western Australia, northwestern Kimberley, Bonaparte Archipelago, Admiralty Gulf, west coast of Middle Osborn Island, $14^{\circ} 18^{\prime} 18^{\prime \prime S} 125^{\circ} 59^{\prime} 35^{\prime \prime E}$; KIS 2-030. Small vine thicket at base of hill, west facing slopes. Common on trees and bushes (leg. V. Kessner, 13 February 2008).

Type material. Holotype WAM S34602 (Pl. 1.3). Paratypes AMS C463681 (8 preserved specimens, as holotype), WAM S36860 (20

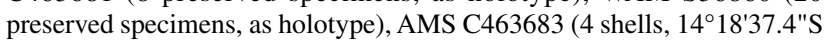
$125^{\circ} 59^{\prime} 18.4^{\prime \prime E}$ ), WAM S36572 (10 shells, $\left.14^{\circ} 18^{\prime} 37.4^{\prime \prime S} 125^{\circ} 59^{\prime} 18.4^{\prime \prime E}\right)$, AMS C463682 (2 preserved specimens, east coast, $14^{\circ} 18^{\prime} 53.5^{\prime \prime} \mathrm{S}$ $126^{\circ} 02^{\prime} 06.7^{\prime \prime E}$ ), WAM S36859 (6 preserved specimens, east coast, $\left.14^{\circ} 18^{\prime} 53.5^{\prime \prime S} 126^{\circ} 02^{\prime} 06.7^{\prime \prime E}\right)$.

Additional, non-type material. WAM S36471, WAM S36566-71, WAM S36573, WAM S36585-99, WAM S36858, WAM S36861, WAM S36971, AMS C463684-5 (Middle Osborn Island).

Etymology. Named in honour of Alan Solem, in recognition of his achievements in camaenid systematics.

\section{Sealing strategy. Rock sealer.}

Shell (Fig. 5A-E, Pl. 1.3-4). Semi-globose with moderately high spire. Thin to solid, translucent. Periphery evenly rounded to slightly angulate; upper and basal sectors of whorls well rounded. Umbilicus open, forming a chink, to $80-90$ percent concealed by columellar reflection. Background colour horn to yellowish brown, with brown, well defined to diffuse, moderately broad, sub-sutural and

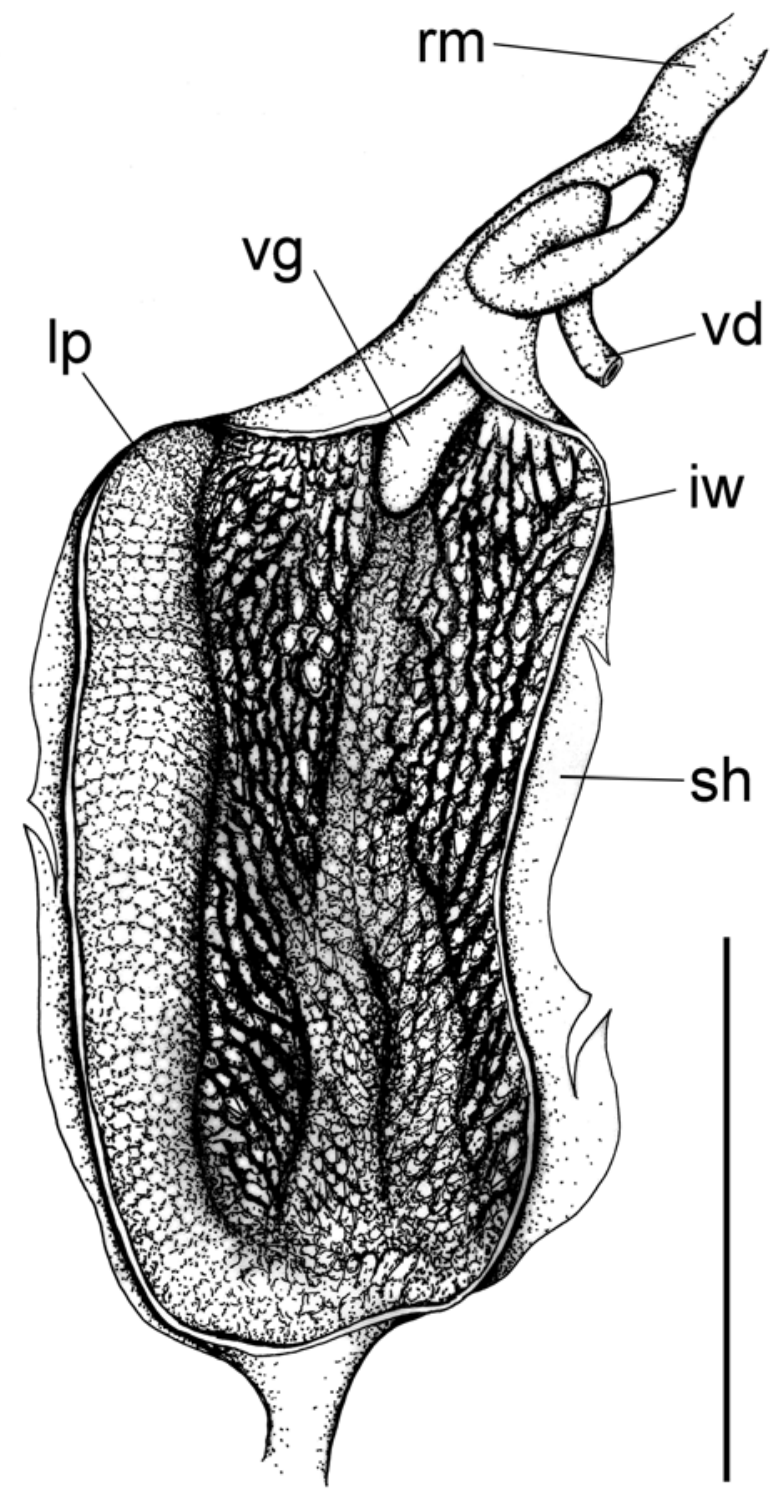

Figure 4. Interior of penial chamber of Amplirhagada euroa n.sp., paratype AMS C463680 (7 August, scale $5 \mathrm{~mm}$ ). Labelling of structures: iw, inner penial wall; lp, longitudinal (main) pilaster; rm, penial retractor muscle; sh, penial sheath; vd, vas deferens; $\mathrm{vg}$, penial verge.

mid-whorl bands, visible on entire shell; ventral and outer lip colour horn; inner lip translucent, pale. Protoconch c. 1.8 $\mathrm{mm}$ in diameter, comprising about 1.5 whorls, sculptured by comparatively strong axial ribs. Teleoconch sculptured by coarse, regular lirae, rounded in cross-section; spaces equal to thickness of lirae; sculpture evenly distributed across whorls of shell and across whorl diameter, height of lirae reduced underneath suture. Angle of aperture $45^{\circ}$; outer lip sharp to moderately thick, rounded, slightly expanded, slightly reflected; basal and palatal node absent. Parietal wall of inner lip inconspicuous.

Figure 5 (facing page). SEM photographs of Amplirhagada solemiana n.sp. (A-E). Shell, paratype AMS C463683: $(A)$ apical whorl viewed from above (scale $200 \mu \mathrm{m}) ;(B)$ first four whorls viewed from above (scale $1 \mathrm{~mm}) ;(C)$ shell, lateral view (scale $1 \mathrm{~mm}) ;(D)$ details of axial sculpture on last whorl, lateral view (scale $1 \mathrm{~mm}$ ); $(E)$ close-up of axial lirae on last whorl (scale $100 \mu \mathrm{m})$. ( $F-I)$ Radula, paratype AMS C463681: $(F)$ rows of central and lateral teeth (Scale $20 \mu \mathrm{m}) ;(G)$ details if central and lateral teeth (scale $20 \mu \mathrm{m}) ;(H)$ outer lateral and inner marginal teeth (scale $10 \mu \mathrm{m}) ;(I)$ middle and outer marginal teeth (scale $10 \mu \mathrm{m})$. $(J)$ jaw, paratype AMS C463681 (scale $100 \mu \mathrm{m})$. 

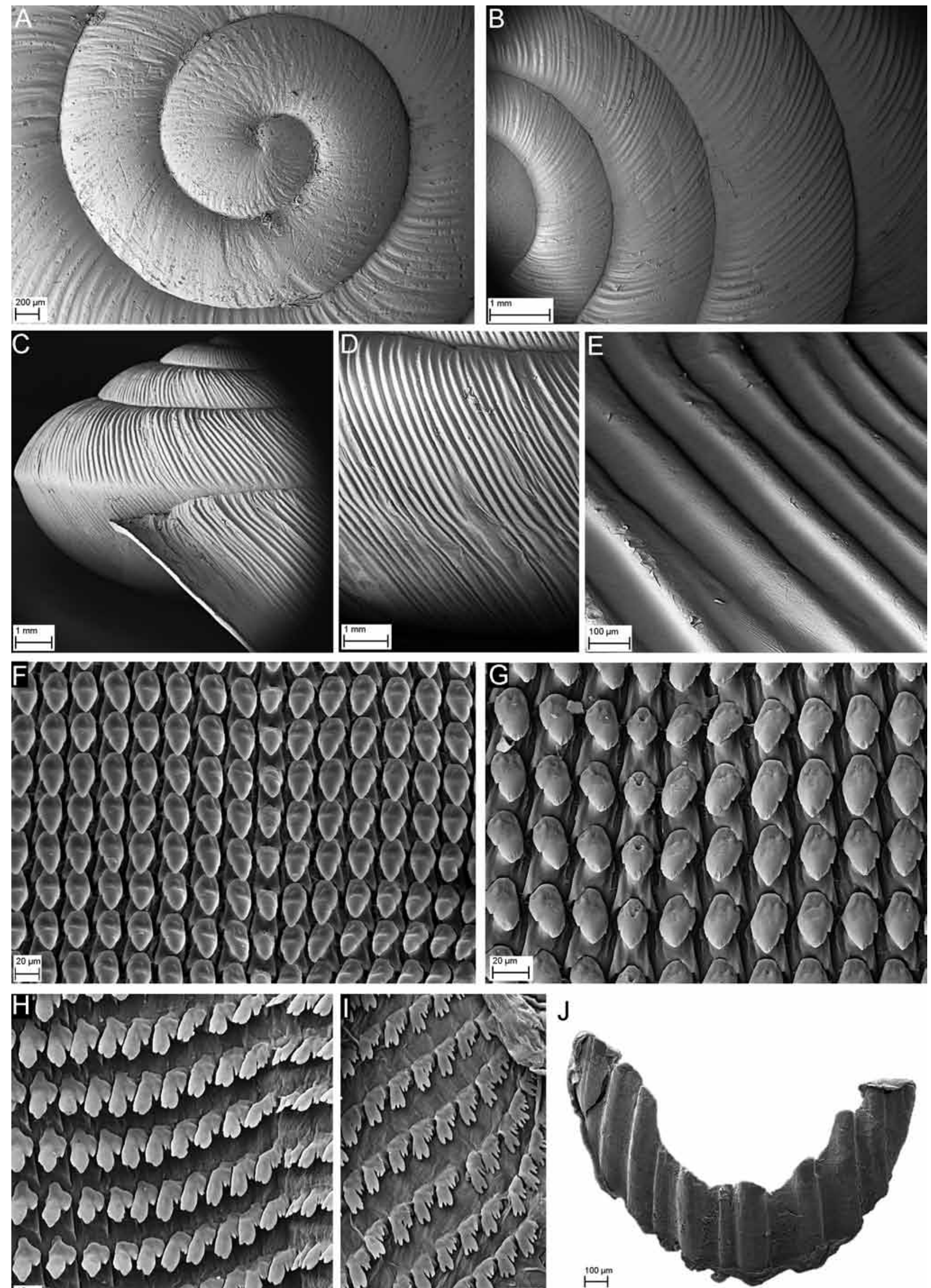

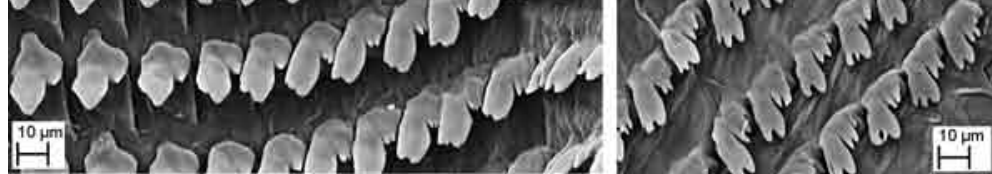
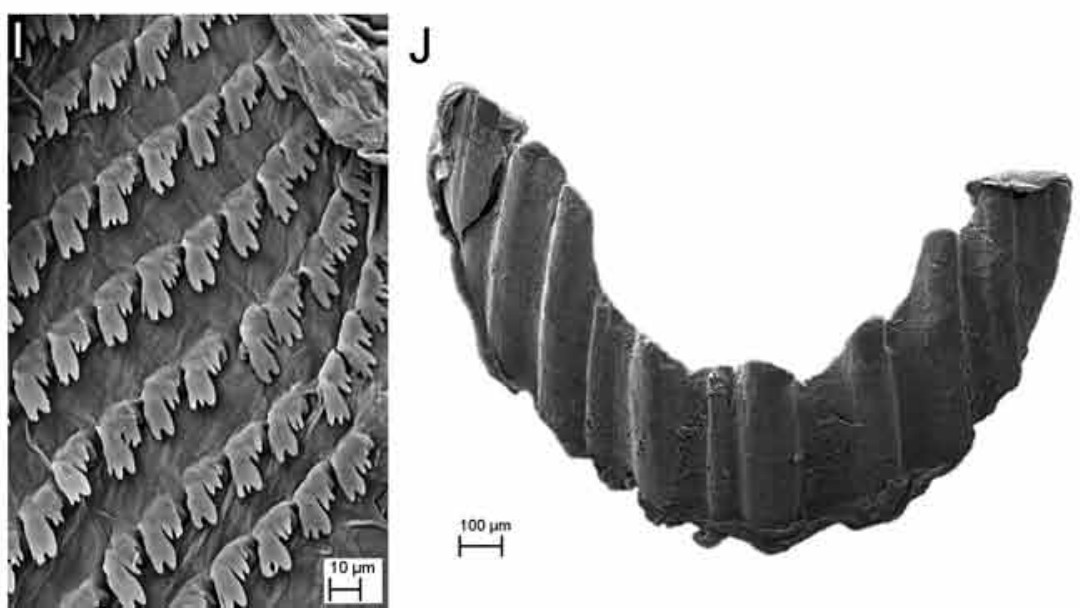


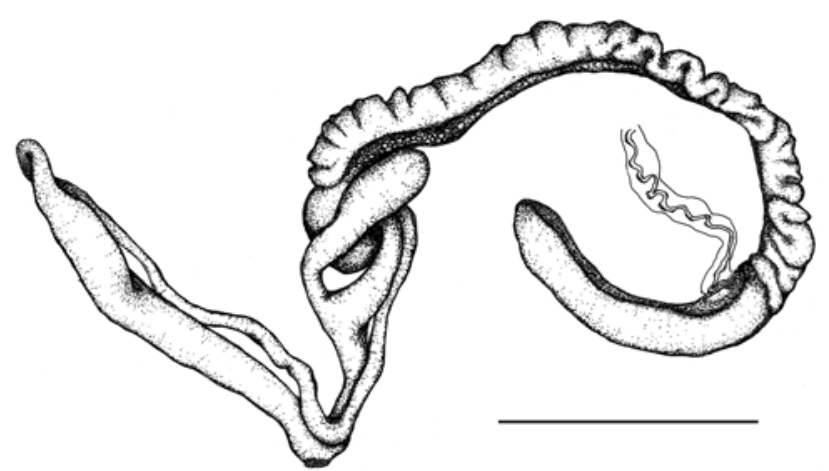

Figure 6. Genitalia of Amplirhagada solemiana n.sp., paratype WAM S36581 (13 February, scale $10 \mathrm{~mm}$ ). Compare with Fig. 3 for labelling of structures.

Pallial morphology. Pallial cavity deep, extending one whorl. Pigmentation on mantle consists of sparsely spaced dark grey-black spots. Kidney extending about half of pallial cavity or slightly more.

Genital morphology (Figs. 6-7). Penis straight to slightly curved; same length as anterior part of oviduct or slightly longer. Vas deferens forms simple loop before entering penis. Penial retractor muscle about as long as penis. Penial verge long to very long (c. $1 / 3$ to $1 / 2$ of penial chamber), slender to spatulate with pointed tip. Pustulation comprising entire length of inner penial wall; pustules small to moderate in size, densely arranged in rows, some of which form four to five corrugated longitudinal pilasters along entire length of penial chamber; main stimulatory pilaster not differentiated. Vas deferens entering penial sheath apically. Vagina of medium length, tubular or posteriorly inflated. Inner vaginal wall densely ciliated, ciliae arranged to form smooth longitudinal pilasters, pilasters may be weakly developed. Spermathecal duct of medium thickness; internally with smooth longitudinal pilasters. Spermathecal head elongately inflated, connected with oviduct by connective tissue; inside entirely smooth; wall moderately thick. Length of free oviduct equivalent to about half of anterior part of oviduct; coiled underneath entrance to spermoviduct. Spermoviduct longer than anterior part of oviduct. Talon embedded in albumen gland close to anterior end.

Radular morphology (Fig. 5F-I). Rectangular. Tooth formula $\mathrm{C}+9-12+3-4+19-21$. Average number of rows of teeth $131 \pm 22$ with $29.9 \pm 0.6$ rows per $\mathrm{mm}(\mathrm{n}=3)$.

Central teeth with bluntly pointed, ovate mesocones, shorter than base of tooth; ectocones vestigial. Lateral teeth with bluntly pointed ovate mesocones, length equal to base of tooth; small ectocones; endocones absent. Marginal teeth multicuspic, mesocone and endocone similar in length, ectocone smaller than endocone, occasionally subdivided.

Comparative remarks. Shells are close to Amplirhagada imitata (E. A. Smith, 1894) in overall shape, colouration, and sculpture, but see Fig. 8. The type locality of A. imitata was restricted to Baudin Island by Solem (1981a). Amplirhagada imitata and A. solemiana exhibit the most sharply defined and prominent axial sculpture among all congeners except for A. indistincta. The anatomy of A. imitata is unknown for only dry shells were available to Solem (1981a). In between

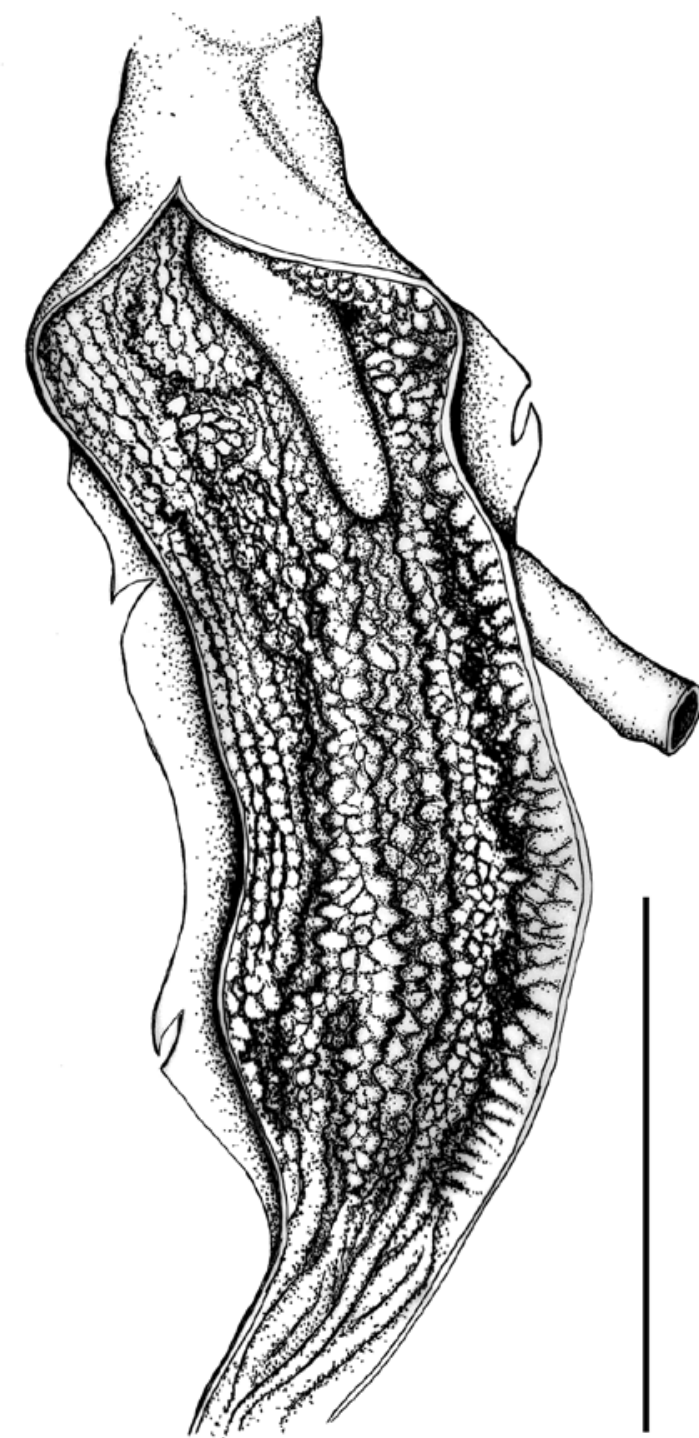

Figure 7. Interior of penial chamber of Amplirhagada solemiana n.sp., paratype AMS C463681 (13 February, scale 3 mm). Compare with Fig. 4 for labelling of structures.

Baudin Island (A. imitata) and the two Osborn Islands (A. solemiana and $A$. indistincta) there are numerous other islands that are occupied by Amplirhagada species (e.g., Kingsmill, Corneille, Fenelon, and Descartes Islands) (Fig. 1). Given the usually very restricted occurrence of Amplirhagada species and the marked genetic differentiation of $A$. solemiana and $A$. indistincta, it is considered very unlikely that either of them could be conspecific with A. imitata from Baudin Island, which is located in a considerable distance (c. $50 \mathrm{~km}$ NW of Osborn Islands). Based on shell features only, Solem (1981a) also synonymized A. burrowsena Iredale, 1938 from Vansittart Bay (c. $80 \mathrm{~km}$ E of Baudin Is) with A. imitata and reported this species to further occur in rainforest patches on the mainland (RFS 03/3, 11/1). These reports, however, almost certainly refer to extralimital populations. Species such as $A$. imitata, A. solemiana, A. indistincta, A. burrowsena and likely an undescribed species from the rainforest patches on the mainland may possibly form a group of sibling species that are not clearly differentiated by means of their shell morphology as is also known from the species group of A. mitchelliana Solem, 1981 from the Mitchell Plateau. 


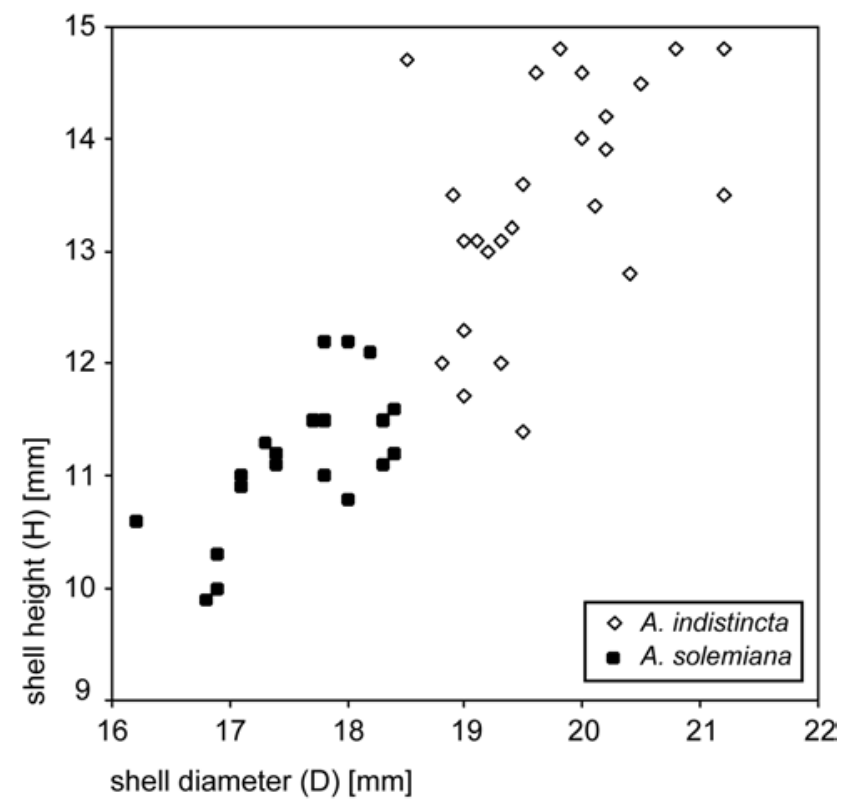

Figure 8. Comparison of $A$. solemiana and A. indistincta by means of shell parameters. Scatter-plot showing the ratio of shell height $(H)$ versus diameter $(D)$.

\section{Amplirhagada indistincta n.sp.}

Type locality (Fig. 1). Western Australia, northwestern Kimberley, Bonaparte Archipelago, Admiralty Gulf, West coast of South West Osborn Island, 14²2'26"S 125 56'13"E; KIS 3-7. Isolated vine thicket patch on dune behind sand beach, on trees, under logs (leg. V. Kessner, 29 July 2007).

Type material. Holotype WAM S34603 (Pl. 1.5). Paratypes AMS C463686 (5 preserved specimens, as holotype), WAM S36617 (10 preserved specimens, as holotype), AMS C463688 (5 shells, 14²2'26"S $125^{\circ} 56^{\prime} 13^{\prime \prime E}$ ),WAM S36575 (15 shells, $\left.14^{\circ} 22^{\prime} 26^{\prime \prime S} 125^{\circ} 56^{\prime} 13^{\prime \prime E}\right)$, AMS C463687 (20 preserved specimens, $14^{\circ} 22^{\prime} 26.5^{\prime \prime S} 125^{\circ} 56^{\prime} 17.8^{\prime \prime} \mathrm{E}$ ), WAM S36865 (40 preserved specimens, $14^{\circ} 22^{\prime} 26.5^{\prime \prime} \mathrm{S} 125^{\circ} 56^{\prime} 17.8^{\prime \prime} \mathrm{E}$ ), AMS C463689 (11 shells, east coast, $14^{\circ} 22^{\prime} 47.3^{\prime \prime}$ S $125^{\circ} 56^{\prime} 00.6^{\prime \prime E}$ ), WAM S36962 ( 25 shells, east coast, $\left.14^{\circ} 22^{\prime} 47.3^{\prime \prime S} 125^{\circ} 56^{\prime} 00.6^{\prime \prime} \mathrm{E}\right)$.

Additional, non-type material. WAM S28521, WAM S36491-501, WAM S36574, WAM S36577, WAM S36612-16, WAM S36618-25, WAM S36863-4, WAM S36866, AMS C463690-1 (South West Osborn Island); WAM S41454, AMS C463724 (Kidney Island; $14.329^{\circ} \mathrm{S} 125.985^{\circ} \mathrm{E}$ ).

Etymology. From indistincta $($ Latin $=$ indistinct) referring to the close morphological resemblance with A. solemiana.

Sealing strategy. Rock sealer.

Shell (Fig. 11A-D, Pl. 1.5-6). Semi-globose to broadly conical with moderate to high spire; solid to thick, not translucent. Periphery well rounded to slightly angulate. Umbilicus completely concealed by columellar reflection. Background colour yellowish to brownish white; with thin to moderately broad brown to yellowish brown sub-sutural and mid-whorls bands that are visible on most whorls, subsutural band diffuse, mid-whorl band well marked; ventral colour whitish to greyish white; outer lip colour differs from shell, whitish; inner lip translucent, white. Protoconch

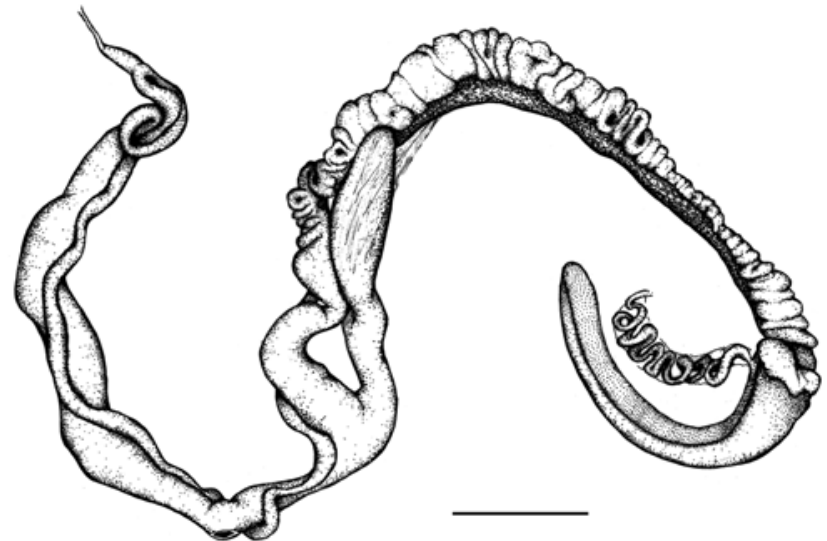

Figure 9. Genitalia of Amplirhagada indistincta n.sp., paratype AMS C463687 (11 February, scale 10 mm). Compare with Fig. 3 for labelling of structures.

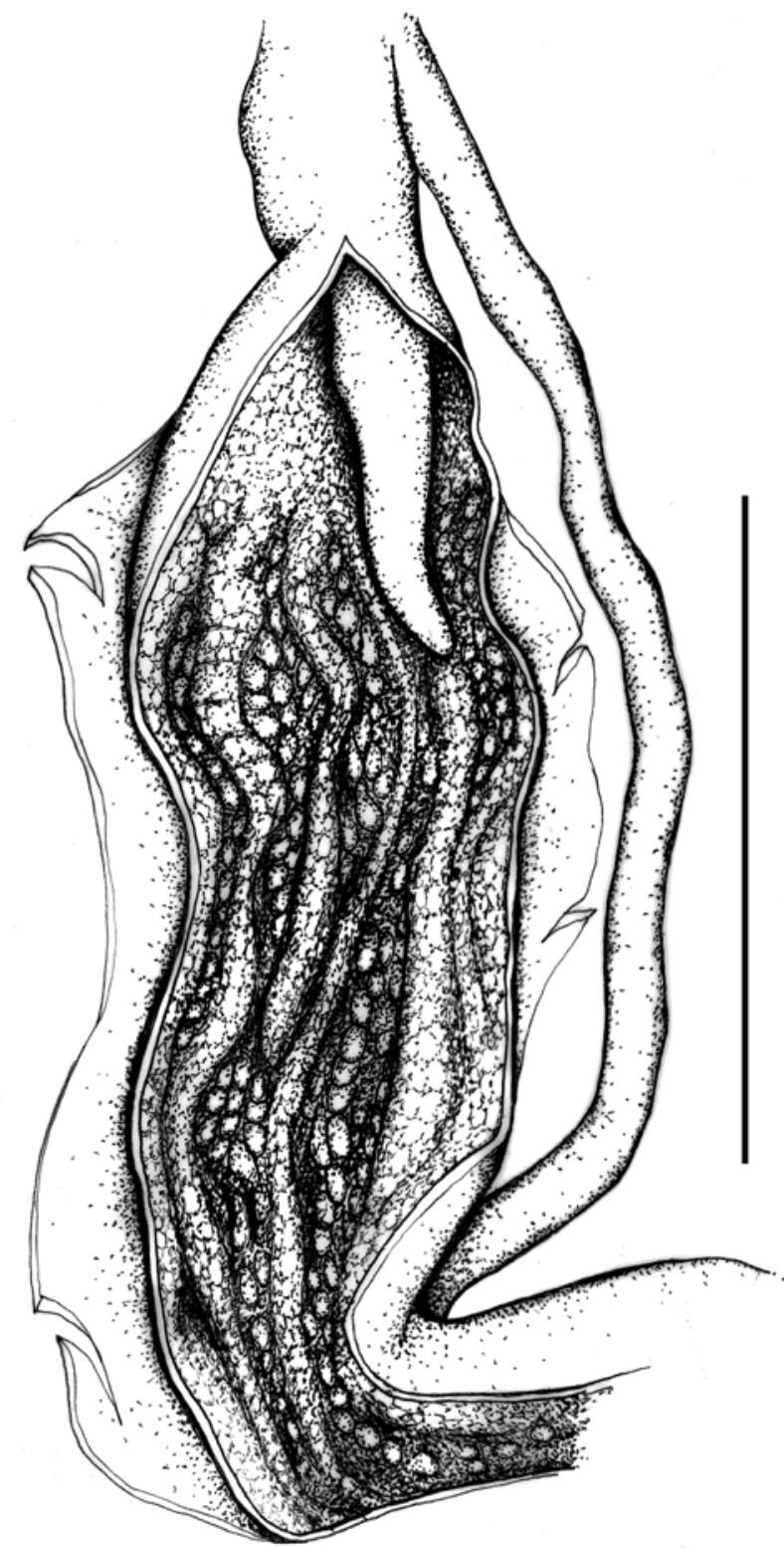

Figure 10. Interior of penial chamber of Amplirhagada indistincta n.sp., paratype AMS C463687 (11 February, scale $5 \mathrm{~mm}$ ). Compare with Fig. 4 for labelling of structures. 

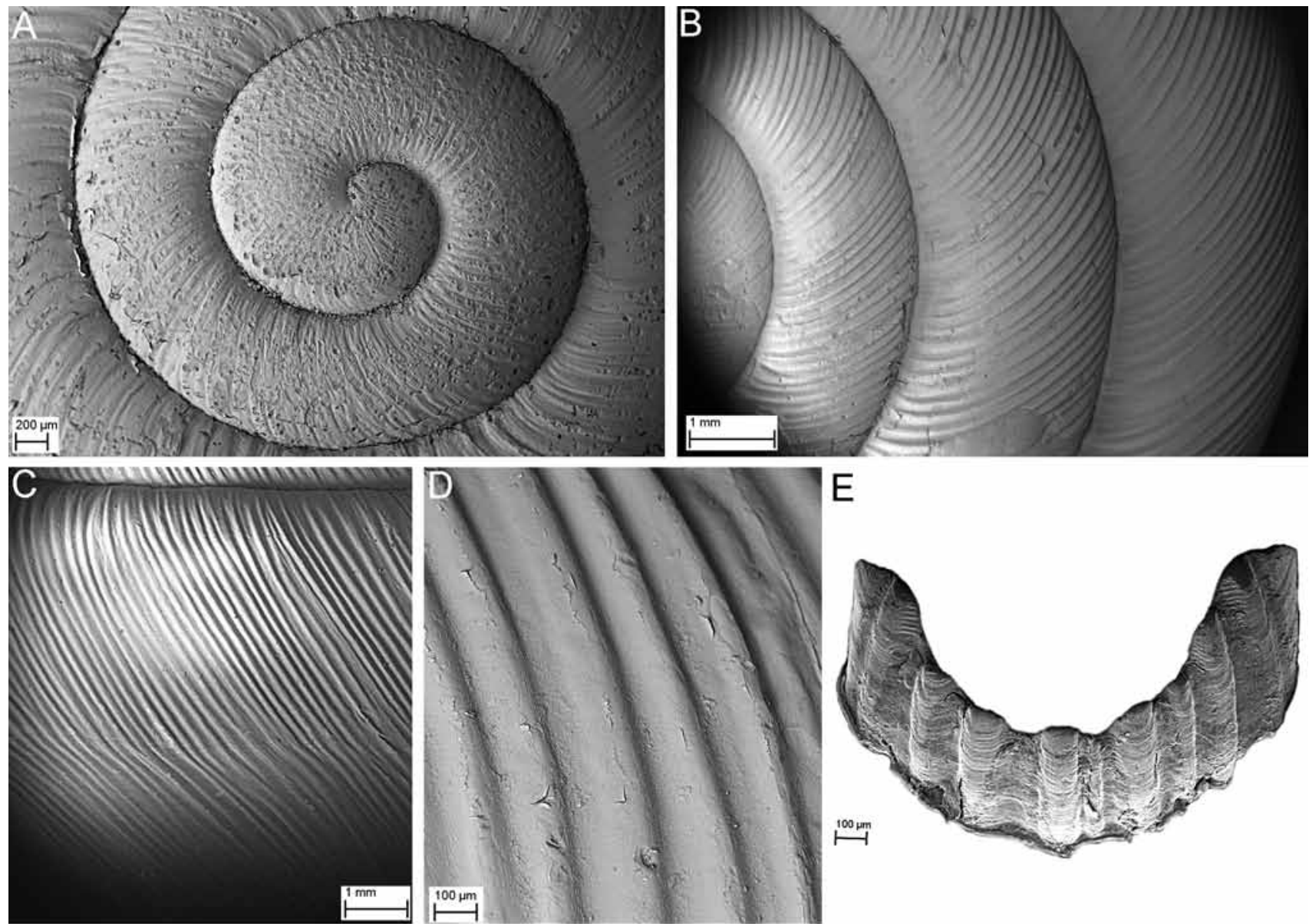

E
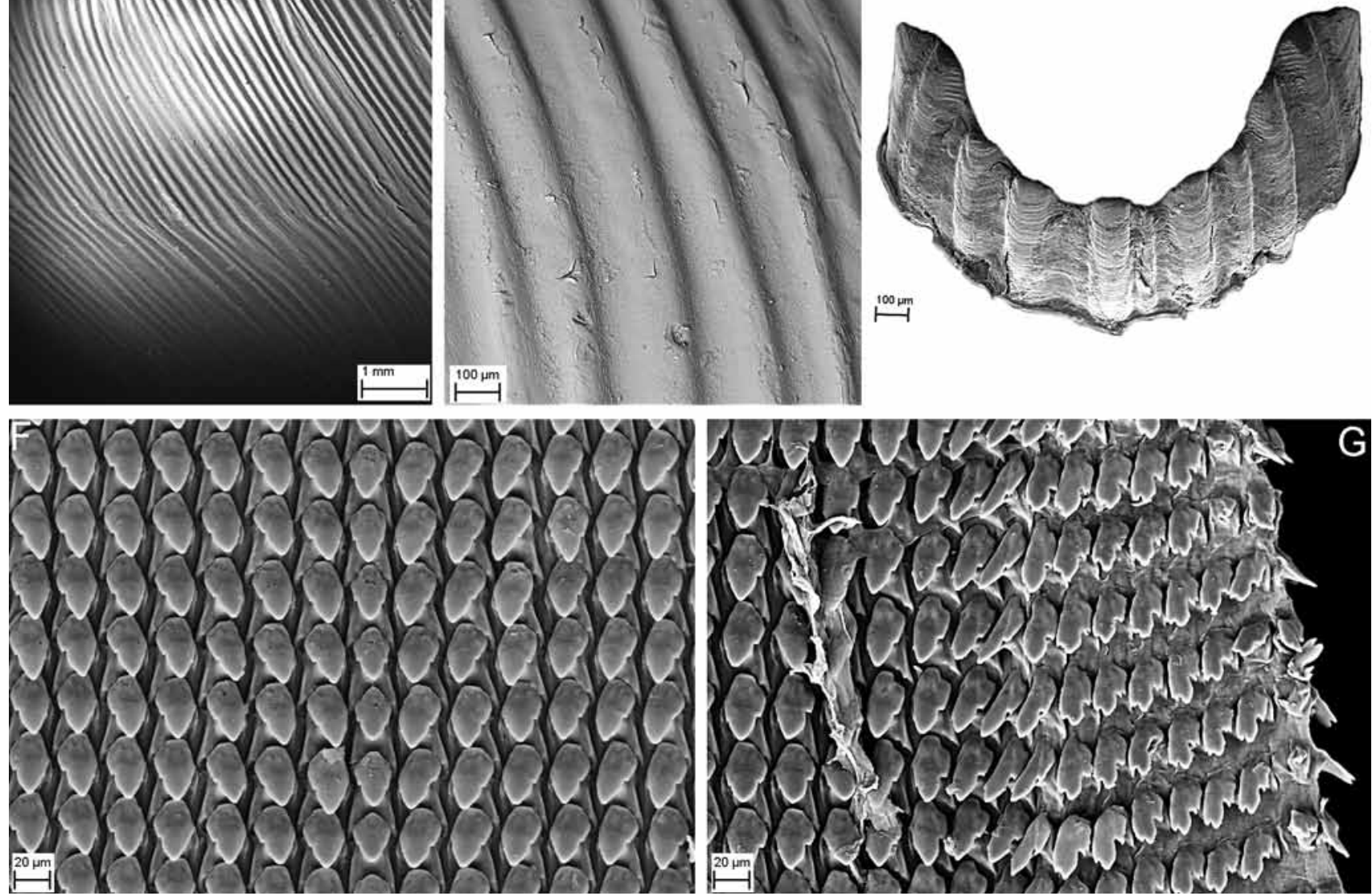

Figure 11. SEM photographs of Amplirhagada indistincta n.sp. (A-D) Shell: $(A)$ apical whorl viewed from above, paratype AMS C463688 (scale $200 \mu \mathrm{m}$ ); (B) first four whorls viewed from above, paratype AMS C463689 (scale $1 \mathrm{~mm}$ ); (C) details of axial sculpture on last whorl, lateral view, paratype AMS C463689 (scale $1 \mathrm{~mm}$ ); $(D)$ close-up of sculpture on last whorl, paratype AMS C463689 (scale $100 \mu \mathrm{m}) ;(E)$ jaw, paratype AMS C463687 (scale $100 \mu \mathrm{m})$. $(F-G)$ Radula, paratype AMS C463687: $(F)$ rows of central and lateral teeth (Scale 20 $\mu \mathrm{m})$; $(G)$ outer lateral and inner marginal teeth (scale $10 \mu \mathrm{m})$.

c. $2 \mathrm{~mm}$ in diameter, comprising about 1.5 whorls, with strong axial sculpture. Teleoconch sculptured by coarse, regular, curved, in cross-section rounded lirae; sculpture evenly distributed across shell and whorl diameter; spaces between lirae equal to thickness of lirae, height of lirae reduced underneath suture. Angle of aperture $30^{\circ}$; outer lip rounded, sharp to moderately thick, expanded, slightly reflected; basal node of lip weak, palatal node absent. Parietal wall of inner lip inconspicuous.
Pallial morphology. Pallial cavity deep, extending one whorl. Pigmentation on mantle consists of sparsely distributed dark brown to black spots. Kidney extending more than half of pallial cavity.

Genital morphology (Figs. 9-10). Penis straight to slightly curved; same length as anterior part of oviduct or slightly longer. Vas deferens forms simple loop before entering penis. Penial retractor muscle about as long as penis. Penial verge 


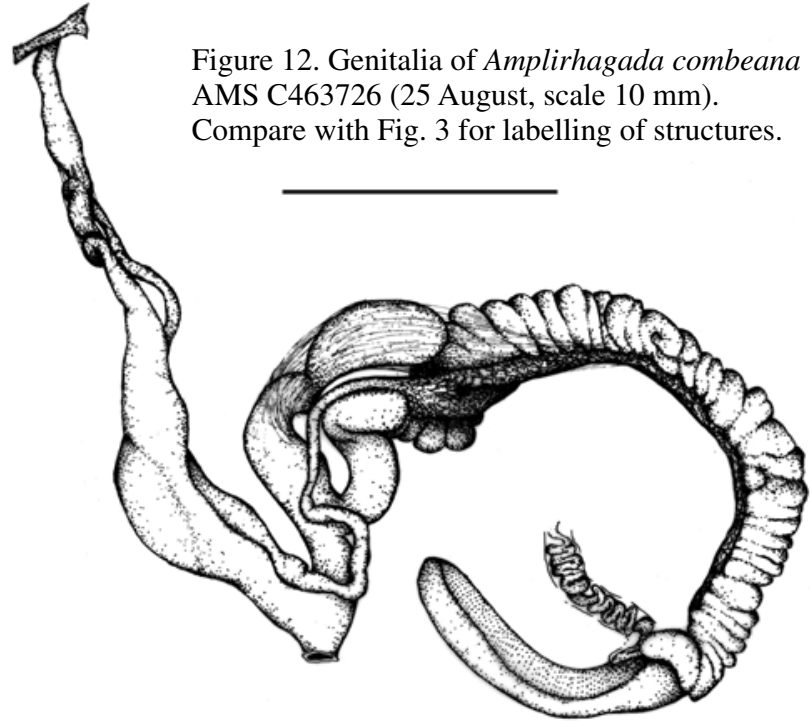

long to very long (c. $1 / 3$ to $1 / 2$ of penial chamber), slender to spatulate with pointed tip. Pustulation comprising entire length of inner penial wall; penial wall pustules small to moderate in size, densely arranged in rows, some of which form four to five longitudinal pilasters along entire length of penial chamber; main stimulatory pilaster not differentiated. Vas deferens entering penial sheath apically. Vagina of medium length, tubular or posteriorly inflated. Inner vaginal wall densely ciliated, ciliae arranged to form smooth longitudinal pilasters, pilasters may be weakly developed. Spermathecal duct of medium thickness; internally with smooth longitudinal pilasters. Spermathecal head elongately inflated, connected with oviduct by connective tissue; inside entirely smooth; wall moderately thick. Length of free oviduct equivalent to about half of anterior part of oviduct; coiled underneath entrance to spermoviduct. Spermoviduct longer than anterior part of oviduct. Talon embedded in albumen gland close to anterior end.

Radular morphology (Fig. 11F-G). Rectangular. Tooth formula $\mathrm{C}+12+3-4+20-21$. Average number of rows of teeth $126 \pm 14$ with $26.3 \pm 1.5$ rows per $\mathrm{mm}(\mathrm{n}=2)$. Central teeth with bluntly pointed, ovate mesocones, shorter than base of tooth; ectocones vestigial. Lateral teeth with bluntly pointed, ovate mesocones, shorter than base of tooth; ectocones small, endocones absent. Marginal teeth multicuspic; ectocones shorter and narrower than mesocones, split into two denticles; endocones of approximately same size as ectocones.

Comparative remarks. Most similar to A. solemiana in shell and genital anatomy. Shells of $A$. indistincta are larger than those of $A$. solemiana (Table 1); a one-way ANOVA revealed that both species differ significantly in the shell parameters H, D, and H/D (Fig. 8). Specimens from Kidney Island, which is located in between Middle and Southwest Osborn Island, tend to have slightly larger and more robust shells than specimens from the type locality. In the molecular phylogeny they cluster closely together with $A$. indistincta and are therefore considered conspecific because their anatomy corresponds with the specimens from Southwest Osborn Island. Amplirhagada solemiana and A. indistincta exhibit a virtually identical genital anatomy but cluster as clearly distinct lineages in the mitochondrial phylogeny (see below). For relationship with $A$. imitata see under A. solemiana.

\section{Amplirhagada combeana Iredale, 1938}

Helix (Hadra) imitata var. cassiniensis Smith, 1894: 92, pl. 7, fig. 16 (Cassini Island). Amplirhagada combeana Iredale, 1938: 113 (nomen novum), Solem, 1981a: 310-312, pl. 12b, figs. $71 \mathrm{~h}-\mathrm{i})$.

Nomenclatural remarks. The original specific epithet "cassiniensis" employed by Smith (1894) is preoccupied and has been replaced with "combeana" by Iredale (1938), who elevated the taxon to the rank of an independent species. Solem (1981a: 310-312) described details of the shell but was not able to describe the anatomy because no preserved material was available.

Material examined. WAM S41450, AMS C463725 (Western Australia, northwestern Kimberley, Bonaparte Archipelago, Cassini Island, $\left.13^{\circ} 57^{\prime} 04^{\prime \prime S} 125^{\circ} 38^{\prime} 39^{\prime \prime}\right)$, WAM S41455, AMS C463726 (1357'22"S 1253'ㄱ'E) (Fig. 1).

Sealing strategy. Rock sealer.

Shell (Fig. 14A-C, Pl. 1.7). Broadly conical with low to medium spire; solid (not translucent). Periphery well rounded to slightly angulate. Umbilicus completely concealed by columellar reflection or forming a chink. Background colour horn to yellowish brown; with diffuse to well defined, thin to moderately broad, chestnut brown sub-sutural and

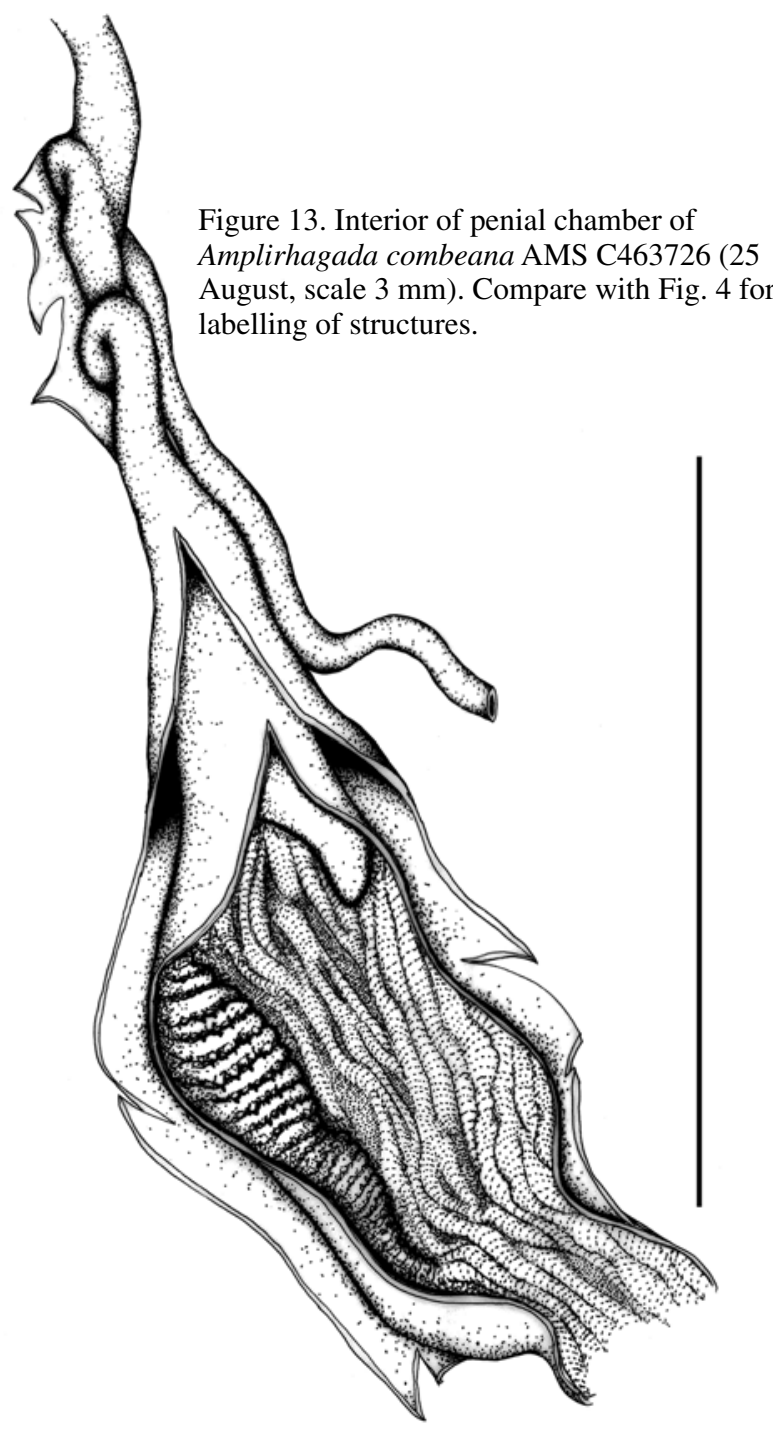



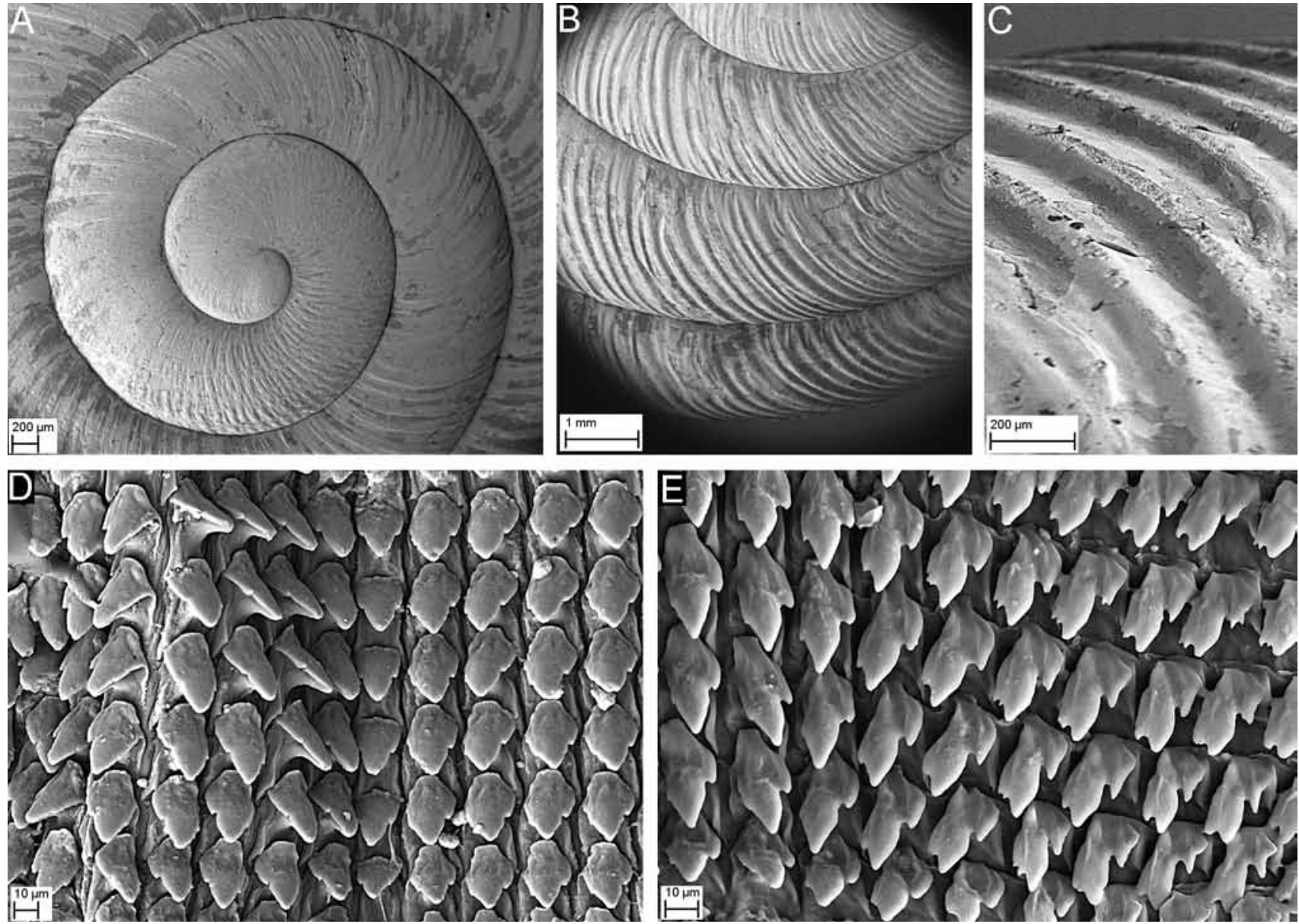

Figure 14. SEM photographs of Amplirhagada combeana, AMS C463725. (A-C) Shell: $(A)$ apical whorl viewed from above (scale 200 $\mu \mathrm{m}) ;(B)$ first four whorls viewed from above (scale $1 \mathrm{~mm}) ;(C)$ details of axial sculpture on last whorl (scale $100 \mu \mathrm{m})$. $(D-E)$ Radula: $(D)$ close-up of central and lateral radular teeth (Scale $10 \mu \mathrm{m}) ;(E)$ outer lateral and inner marginal teeth (scale $10 \mu \mathrm{m})$.

mid-whorl bands that are most conspicuous on last whorl; ventral colour horn; outer lip colour same as shell; inner lip translucent. Protoconch c. $1.7 \mathrm{~mm}$ in diameter with 1.5 whorls, comparatively strong axial sculpture. Teleoconch sculptured by coarse, curved, in cross-section rounded, irregularly spaced lirae; spaces equal to thickness of lirae; lirae evenly distributed across shell and whorl diameter, height reduced underneath suture. Angle of aperture $30^{\circ}$; outer lip rounded, moderately thick, expanded, slightly reflected; basal node of lip weak, palatal node absent.

Pallial morphology. Pallial cavity moderately deep, extending $\mathbf{3} / \mathbf{4}$ whorl. Pigmentation on mantle consists of sparse greyish patches or spots. Kidney extending not more than half of pallial cavity.

Genital morphology (Figs. 12-13). Penis straight; more or less of same length as anterior part of oviduct or longer. Vas deferens forms simple loop before entering penis. Penial retractor muscle shorter than penis. Penial verge short $(<1 / 8$ penial chamber), broad with pointed to rounded tip. Penial wall covered by a number of smooth longitudinal pilasters; pustulation absent. Main stimulatory pilaster welldifferentiated, extending apical to median portion of penial chamber, cone-shaped, corrugated by ridges that support little hooks. Vas deferens entering penial sheath in upper third. Vagina of medium thickness, posteriorly inflated. Inner vaginal wall with smooth, longitudinal pilasters. Spermathecal duct moderately thick, inside with smooth longitudinal pilasters. Spermathecal head globular, connected with oviduct by connective tissue, inside entirely smooth with delicate wall. Free oviduct comprising about half of anterior part of oviduct; coiled underneath entrance to spermoviduct. Spermoviduct longer than anterior part of oviduct. Talon embedded in albumen gland at junction with spermoviduct.

Radular morphology (Fig. 14D-E). Rectangular. Tooth formula $\mathrm{C}+12+2-3+18-20$ with $162.5 \pm 3.5$ rows of teeth, $33.5 \pm 1.9$ rows per $\mathrm{mm}(\mathrm{n}=2)$. Central teeth with bluntly pointed, triangular to ovate mesocones, shorter than base of tooth; ectocones well developed. Lateral teeth with bluntly pointed, triangular to ovate mesocones; length equal to base of tooth; ectocones well developed, endocones vestigial. Marginal multicuspic; ectocones shorter and narrower than mesocones; endocones approximately same size as ectocones; divided into two denticles.

Comparative remarks. This species differs from all previous species by the absence of penial wall pustules and the presence of a well-developed main stimulatory pilaster. Axial sculpture is not as regular as in A. solemiana and A. indistincta but more pronounced as in A. euroa. With respect to penial morphology $A$. solemiana and $A$. indistincta differ most markedly by absence of a well-differentiated main stimulatory pilaster. For comparison with A. mckenziei and A. montesquieuana see below, with other species see Solem (1981a: 310). 


\section{Amplirhagada mckenziei n.sp.}

Type locality (Fig. 1). Western Australia, northwestern Kimberley, Bonaparte Archipelago, Admiralty Gulf, Montesquieu Islands, Oliver Island, $14^{\circ} 05^{\prime} 42^{\prime \prime} \mathrm{S} 125^{\circ} 44^{\prime} 30^{\prime \prime E}$; KC-062 (leg. V. Kessner \& A. Longbottom, 18 June 1988).

Type material. Holotype WAM S34604 (Pl. 1.8). Paratypes WAM S41488 (3 preserved specimens), FMNH 219253 (3 preserved specimens).

Additional, non-type material. AMS C463727, FMNH 219250, WAM S41487 (Western Australia, northwestern Kimberley, Bonaparte Archipelago, Admiralty Gulf, Montesquieu Islands, unnamed island SE of Oliver Island, $14^{\circ} 05^{\prime} 55^{\prime \prime S} 125^{\circ} 44^{\prime} 50 " \mathrm{E}$; KC-061).

Etymology. Named in honour of Norman L. McKenzie, Western Australian Department of Environment and Conservation, in recognition of his promotion of malacological research in Western Australia.

Sealing strategy. Rock sealer.

Shell (Fig. 17A-C, Pl. 1.8-9). Broadly conical to almost flat with low to medium spire. Thin to solid, translucent. Periphery rounded. Umbilicus concealed by columellar reflection to 50-100 percent, forming a chink or narrowly winding opening. Background colour brownish horn, ventrally lighter; with diffuse to well marked, thin, yellowish brown sub-sutural and mid-whorl bands that are most conspicuous on last whorl; outer lip colour same as shell; inner lip translucent, whitish. Protoconch c. $2.2 \mathrm{~mm}$ in diameter with 1.5 whorls, sculptured by strong axial elements. Teleoconch with coarse axial lirae; curved when viewed from above; rounded in cross-section with irregular spacing; spaces equal to thickness of lirae; distributed evenly across shell and across whorl diameter, reduced underneath suture. Angle of aperture $30^{\circ}$; outer lip rounded, sharp to moderately thick, slightly expanded, not or slightly reflected; basal node absent or weak; palatal node absent. Parietal wall of inner lip inconspicuous.

Pallial morphology. Pallial cavity short, extending half whorl. Mantle pigmentation consists of blackish spots. Kidney extending more than half of pallial cavity.

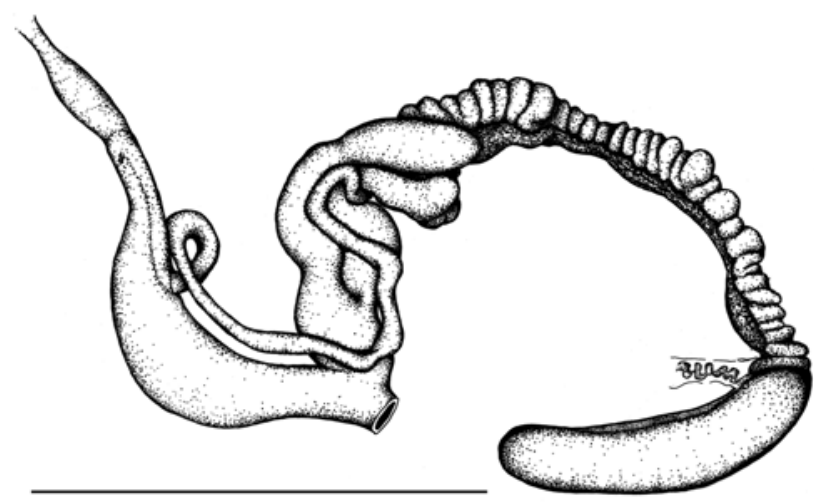

Figure 15. Genitalia of Amplirhagada mckenziei n.sp., paratype WAM S41488 (18 July, scale $10 \mathrm{~mm}$ ). Compare with Fig. 3 for labelling of structures.
Genital morphology (Figs. 15-16). Penis straight, slightly longer than anterior part of oviduct. Vas deferens forms simple loop before entering penis. Penial retractor muscle shorter than penis. Penial verge very short (barely visible) to short ( $<1 / 8$ penial chamber), slender to spatulate with pointed tip. Penial wall pustules small, arranged in rows over entire length of inner penial wall. Main stimulatory pilaster welldifferentiated, relatively thin, cone-shaped, sculptured by ridges with little hooks, on apical portion of inner penial wall. Vas deferens rather straight to undulated, rather thick, entering penial sheath in upper third of penis. Vagina rather thick, tubular to posteriorly inflated. Inner vaginal wall with smooth longitudinal pilasters. Spermathecal duct wide, with smooth longitudinal pilasters inside. Spermathecal head globular to elongately inflated, connected with oviduct by connective tissue; inside entirely smooth with thin wall. Free oviduct more or less straight comprising less than half to about half of length anterior part of oviduct of anterior part of oviduct. Spermoviduct of same length as anterior part of oviduct. Talon embedded in albumen gland at junction with spermoviduct.

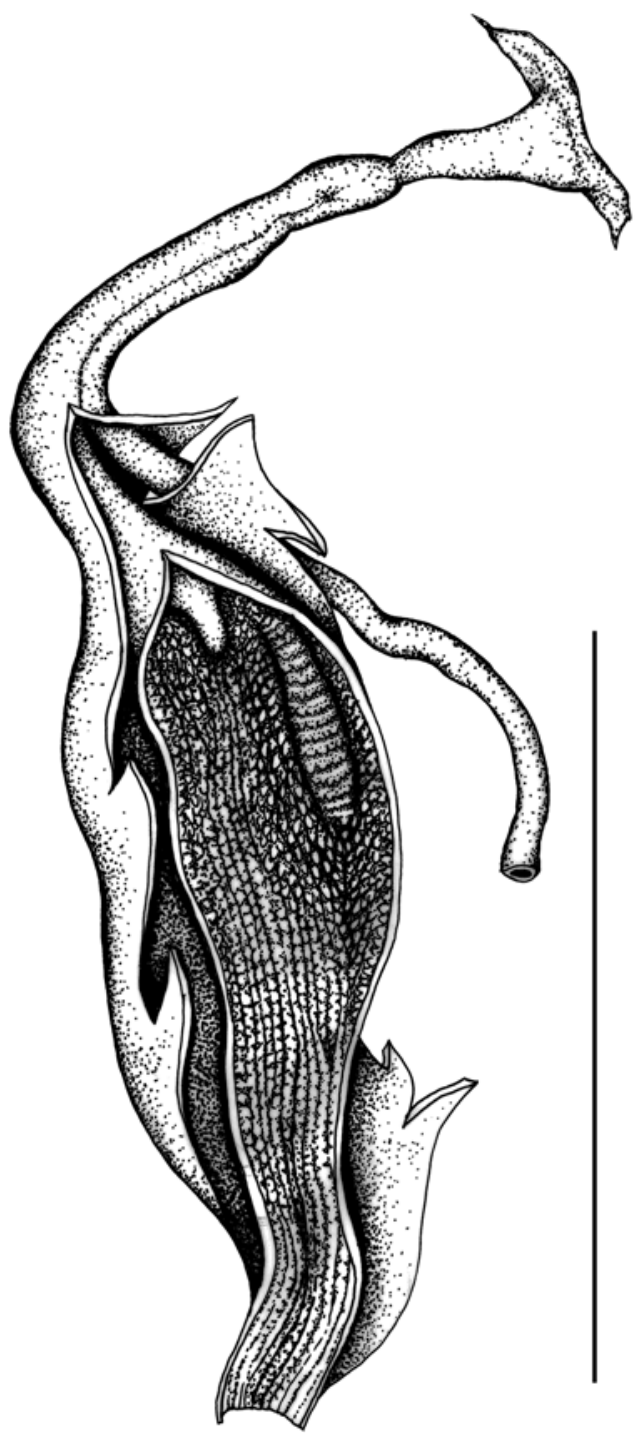

Figure 16. Interior of penial chamber of Amplirhagada mckenziei n.sp., paratype FMNH 219253 (18 July, scale $10 \mathrm{~mm}$ ). Compare with Fig. 4 for labelling of structures. 

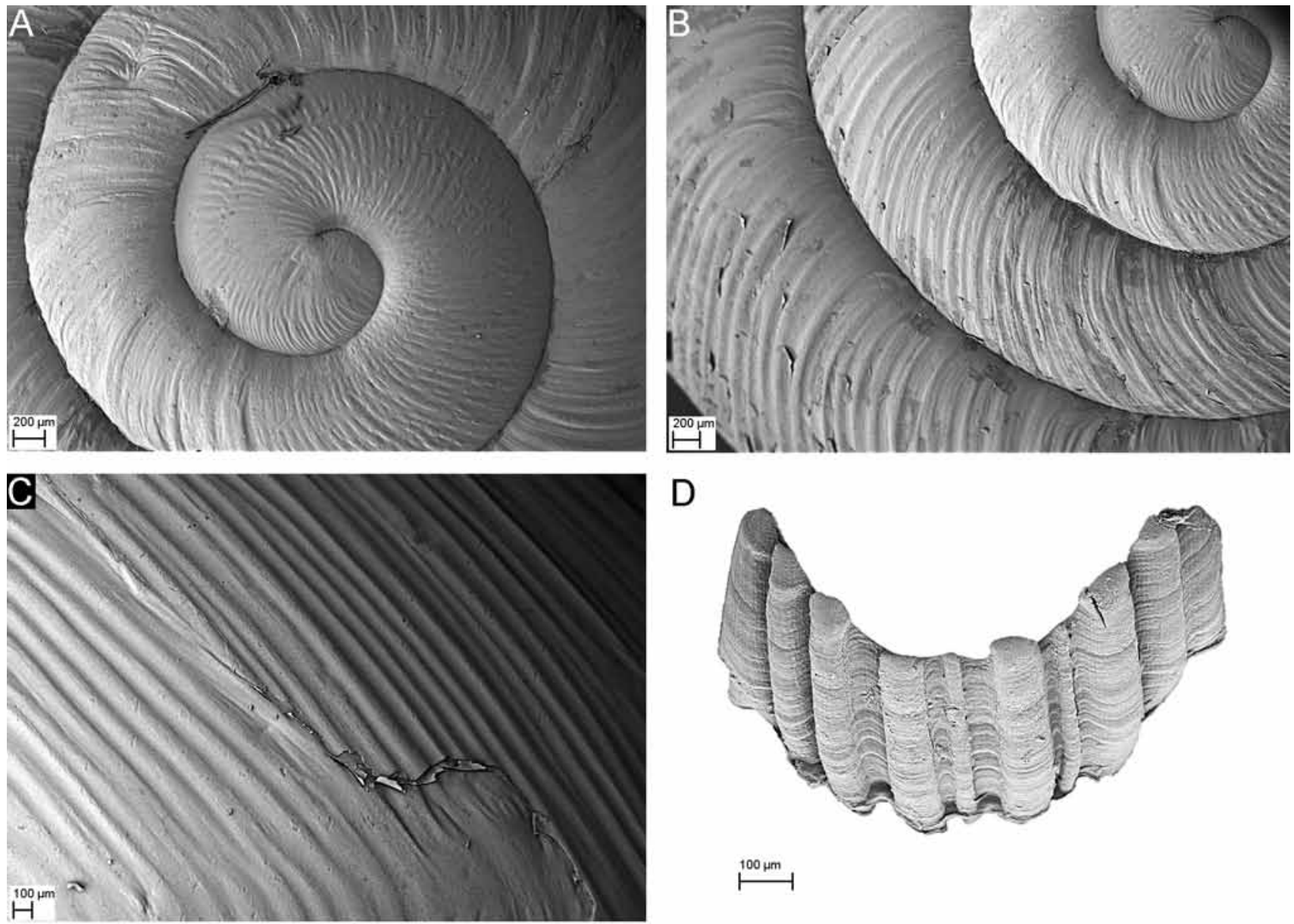

$\stackrel{100 \mu \mathrm{m}}{\longmapsto}$
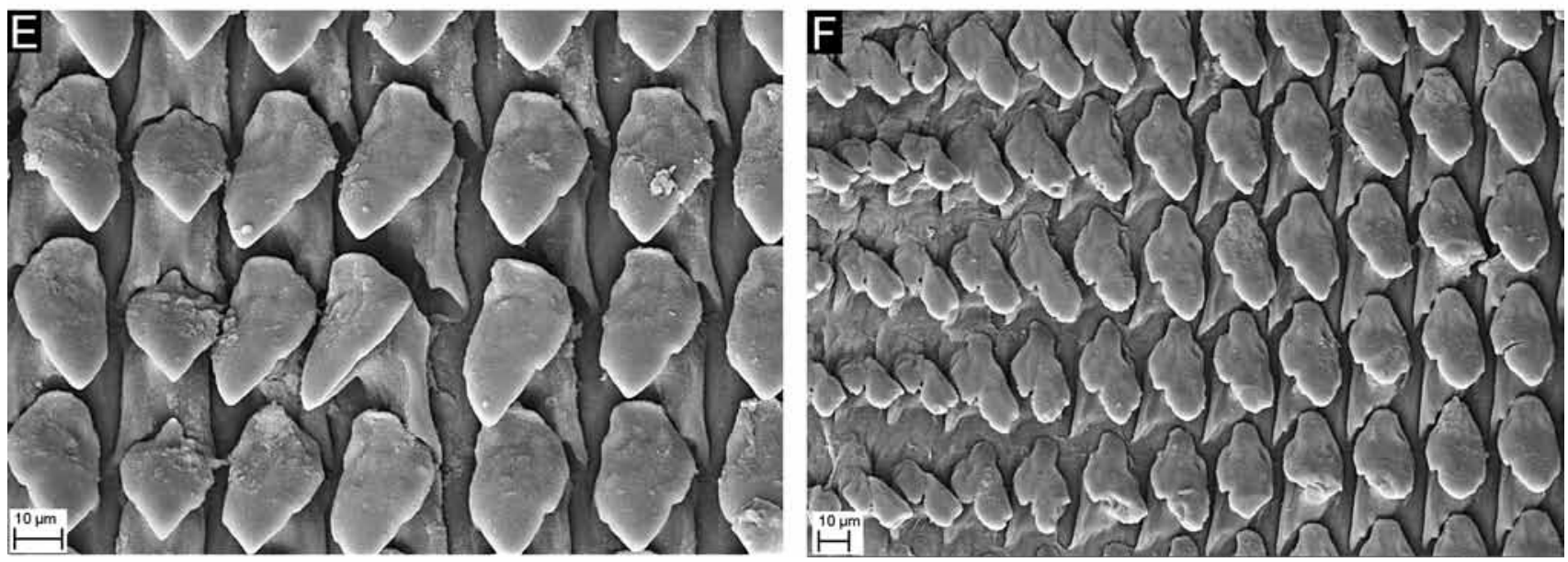

Figure 17. SEM photographs of Amplirhagada mckenziei n.sp., paratypes WAM S41488. $(A-C)$ Shell: $(A)$ apical whorl viewed from above (scale $200 \mu \mathrm{m}$ ); $(B)$ first four whorls viewed from above (scale $200 \mu \mathrm{m}$ ); $(C)$ details of axial sculpture on last whorl (scale $100 \mu \mathrm{m}$ ). $(D)$ Jaw (scale $100 \mu \mathrm{m}) .(E-F)$ Radula: $(E)$ close-up of central and inner lateral radular teeth (Scale $10 \mu \mathrm{m})$; $(E)$ outer lateral and inner marginal teeth (scale $10 \mu \mathrm{m})$.

Radular morphology (Fig. 17E-F). Rectangular. Tooth formula $\mathrm{C}+12-18+2-3+18-20$. With in average $135 \pm 12.5$ rows of teeth, $31.2 \pm 1.2$ rows per $\mathrm{mm}(\mathrm{n}=2)$. Central teeth with sharply pointed, triangular mesocones, shorter than base of tooth; ectocones vestigial. Lateral teeth with sharply pointed, triangular mesocones, length equal to base of tooth; ectocones tiny, endocones vestigial. Marginal teeth with triangular to ovate mesocones; ectocones shorter and narrower than mesocones; endocones reduced in size.
Comparative remarks. The studied museum material was labelled as "Amplirhagada sp. 72" by Solem. This species is closely related to A. montesquieuana (see below) and A. combeana, both inhabiting islands in relative proximity. Amplirhagada combeana is similar in exhibiting a relatively pronounced but irregular axial sculpture but differs in having smaller main stimulatory pilaster, penial verge and no penial wall pustules. 


\section{Amplirhagada ponderi n.sp.}

Type locality (Fig. 1). Western Australia, northwestern Kimberley, Bonaparte Archipelago, Admiralty Gulf, Kingsmill Island, $14^{\circ} 09^{\prime 24}$ "S 125 46'16"E; KC-067 (leg. V. Kessner \& A. Longbottom, 19 July 1988).

Type material. Holotype WAM S34605 (Pl. 1.10). Paratype WAM S41489 (1 preserved specimen), FMNH 219268 (1 preserved specimen).

Etymology. Named in honour of Winston F. Ponder, senior fellow of the Australian Museum, in recognition of his achievements in malacological research.

Shell (Pl. 1.10). Broadly conical, with low spire; thin (translucent) to solid. Periphery slightly angulate; upper and basal sectors of whorls rounded. Umbilicus open, narrowly winding, c. 40-60 percent concealed by columellar reflection. Background colour yellowish brown to horn; with diffuse, thin, light brown sub-sutural and mid-whorl bands being most conspicuous on last whorl; ventral colour whitish horn; outer lip colour same as shell; inner lip colour horn to translucent. Protoconch and teleoconch smooth except for growth lines. Angle of aperture $45^{\circ}$; outer lip rounded, sharp to moderately thick, expanded, slightly reflected; basal node of lip weak to moderately developed; palatal node absent. Parietal wall of inner lip inconspicuous.

Pallial morphology. Pallial cavity moderately deep, extending $3 / 4$ whorl. Blackish mottled pigmentation on mantle. Kidney extending half of pallial cavity.

Genital morphology (Figs. 18-19). Penis bent; much longer than anterior part of oviduct. Vas deferens forms complex coiling before entering penis. Penial retractor muscle stubby, much shorter than penis. Penial verge medium sized to long $(1 / 8-1 / 3$ of penial chamber), slender to spatulate with pointed tip. Penial wall pustules very small, arranged in rows over entire length of inner penial wall. Main stimulatory pilaster well-differentiated, narrow and quite long comprising apical to median portion of penial chamber; corrugated by ridges of undifferentiated pustules that support little hooks. Vas deferens entering

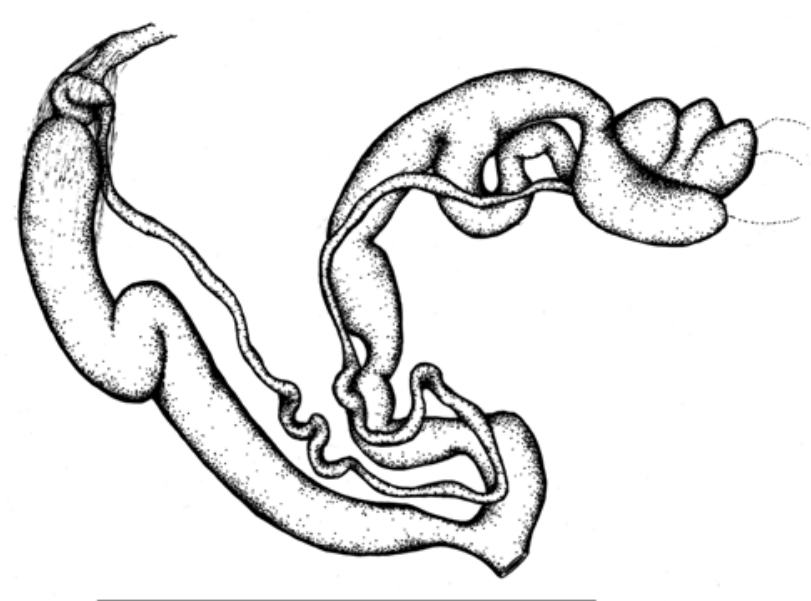

Figure 18. Genitalia of Amplirhagada ponderi n.sp., paratype FMNH 219268 (19 July, scale 10 mm). Compare with Fig. 3 for labelling of structures. penial sheath in upper third. Vagina relatively long, tubular, posteriorly slightly inflated. Inner vaginal wall with smooth longitudinal pilasters. Spermathecal duct moderately thick with smooth longitudinal pilasters inside. Spermathecal head elongately inflated, connected with oviduct by connective tissue, entirely smooth inside; wall delicate. Length of free oviduct less than half of anterior part of oviduct, zig-zagfolded underneath entrance to spermoviduct. Posterior part of genitalia unknown.

Radular morphology (Fig. 20A-C). Rectangular. Tooth formula $\mathrm{C}+16+3+18$. Average number of rows of teeth 165 (n $=1)$ with 35.6 rows per $\mathrm{mm}(\mathrm{n}=1)$. Central teeth with sharply pointed, elongate to triangular mesocones, shorter than base of tooth; ectocones vestigial. Lateral teeth with sharply pointed, elongate to triangular mesocones, not exceeding base of tooth; ectocones well developed, endocones vestigial. Marginal teeth with elongate to triangular mesocones; ectocones shorter and narrower than mesocones; endocones reduced in size.

Comparative remarks. The studied museum material was labelled as "Amplirhagada sp. 73" by Solem. The shell of this species is similar to those of other species from the Montesquieu Islands, such as A. mckenziei, A. montesquieuana or A. puescheli (for comparison with the latter two see below), and is not readily differentiated from the former in shell characters alone. The inner penial wall

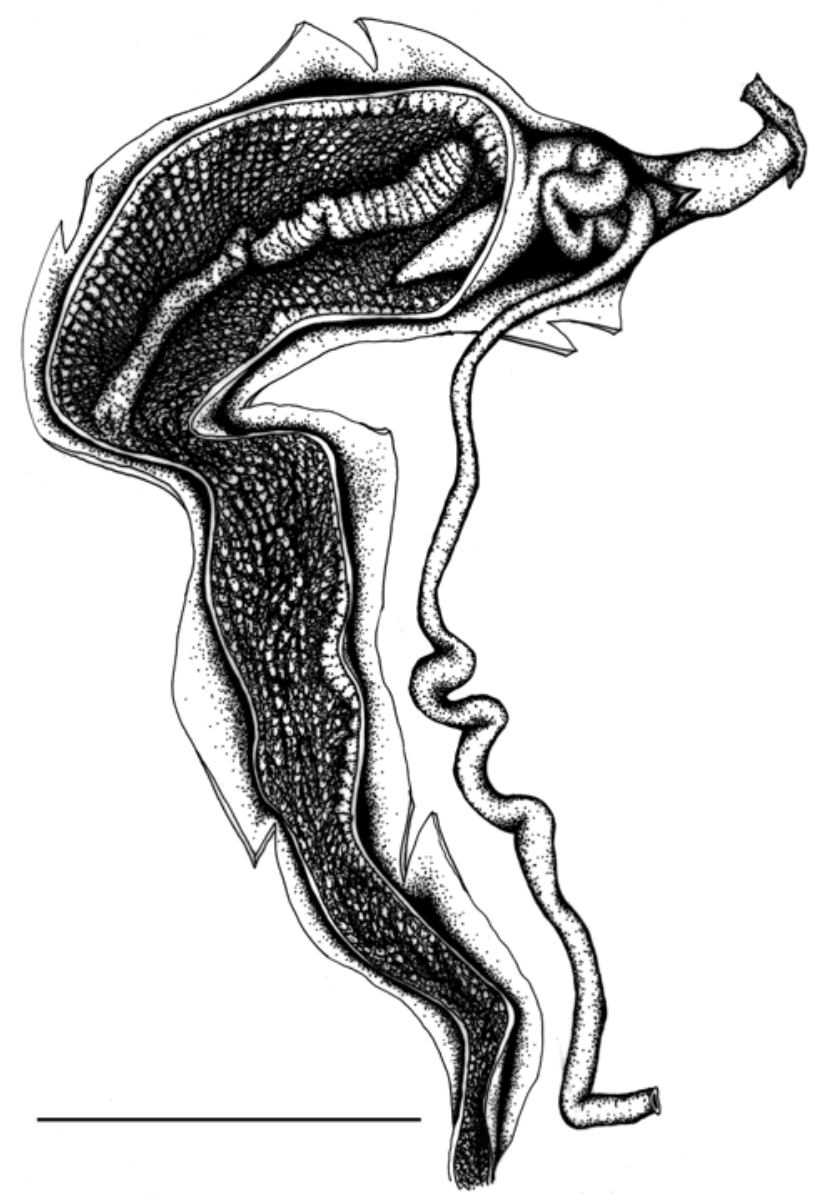

Figure 19. Interior of penial chamber of Amplirhagada ponderi n.sp., paratype FMNH 219268 (19 July, scale 5 mm). Compare with Fig. 4 for labelling of structures. 

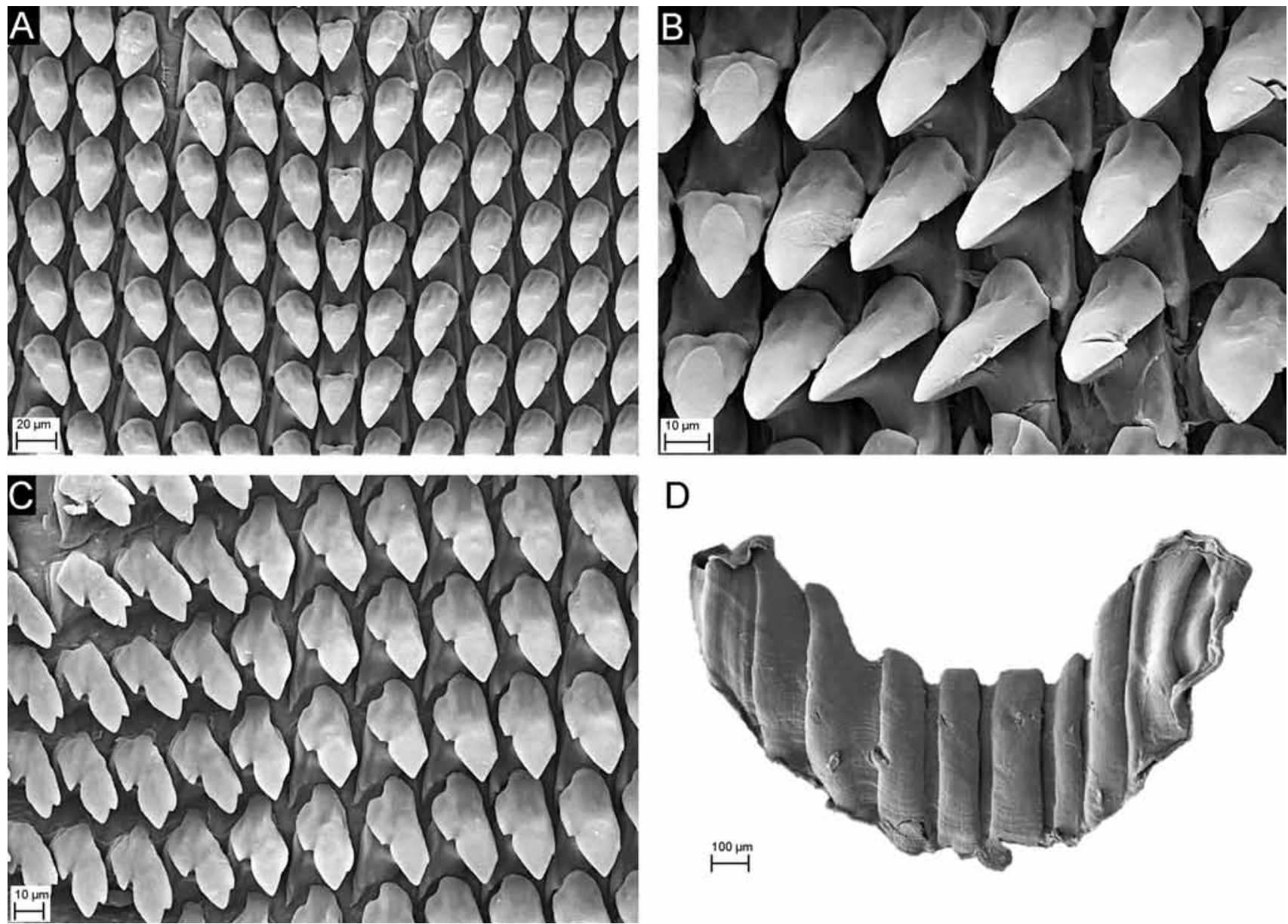

Figure 20. SEM photographs of the radula of Amplirhagada ponderi n.sp., paratype FMNH 219268: $(A)$ central and inner lateral teeth (Scale $20 \mu \mathrm{m}) ;(B)$ close-up of inner lateral teeth $($ scale $10 \mu \mathrm{m}) ;(C)$ outer lateral and inner marginal teeth $($ scale $10 \mu \mathrm{m}) ;(D)$ jaw $(\mathrm{scale} 100 \mu \mathrm{m})$.

of $A$. ponderi, however, is very characteristic. It differs from A. mckenziei most markedly by its much longer and narrow main pilaster, which extends almost to the anterior end of the penial chamber. The penis of A. ponderi is proportionally longer. For comparison with other species from the Montesquieu Islands see below. Phylogenetically, A. ponderi is more closely related to A. varia, A. solemiana, and $A$. indistincta. From all these it differs by possessing a well-developed, corrugated main pilaster.

\section{Amplirhagada montesquieuana n.sp.}

Type locality (Fig. 1). Western Australia, northwestern Kimberley, Bonaparte Archipelago, Admiralty Gulf, Fenelon Island, $14^{\circ} 08^{\prime} 16^{\prime \prime} \mathrm{S} 125^{\circ} 41^{\prime} 55^{\prime} \mathrm{E}$; FERT 04 (leg. Harvey, 28.08.2002).

Type material. Holotype WAM S34606 (Pl. 1.11). Paratypes AMS C463748 (9 preserved specimens), WAM S41453 (15 preserved specimens)

Etymology. In reference to Montesquieu Islands, to which Fenelon Island belongs.

\section{Sealing strategy. Rock sealer.}

Shell (Fig. 21A-B, Pl. 1.11). Broadly conical with low spire; thin (translucent). Whorls evenly rounded in cross-section. Umbilicus open, forming a chink to narrowly winding opening, 80-95 percent concealed by columellar reflection. Background colour whitish or yellowish to golden brown; with diffuse, thin, brown sub-sutural and mid-whorl bands most conspicuous on last whorl; ventral colour whitish; outer lip colour same as shell or lighter; inner lip whitish and translucent. Protoconch c. $2 \mathrm{~mm}$ in diameter with 1.5 whorls, sculptured by fine but distinct axial lirae. Teleoconch with coarse axial lirae, rounded in cross-section with regular spacing, spaces equal to thickness of lirae. Sculpture evenly distributed across shell and whorl diameter, height reduced underneath suture. Angle of aperture $30^{\circ}$, outer lip rounded, sharp to moderately thick, slightly expanded and reflected; basal node of lip weak, palatal node absent. Parietal wall of inner lip inconspicuous.

Pallial morphology. Pallial cavity moderately deep, extending $3 / 4$ whorl. Mantle with mottled, black pigmentation. Kidney extending about half of pallial cavity.

Genital morphology (Figs. 22-23). Penis straight, of more or less same length as anterior part of oviduct to slightly longer. Vas deferens coils once before entering penis. Penial retractor muscle clearly shorter than penis. Penial verge very short, slender to spatulate, with pointed tip. Penial wall pustules of normal size, slightly elongated, arranged in sparsely distributed, distinct rows over entire length of inner penial wall. Towards base of penial chamber, pustules fuse to form corrugated, narrow pilasters. Main stimulatory pilaster 

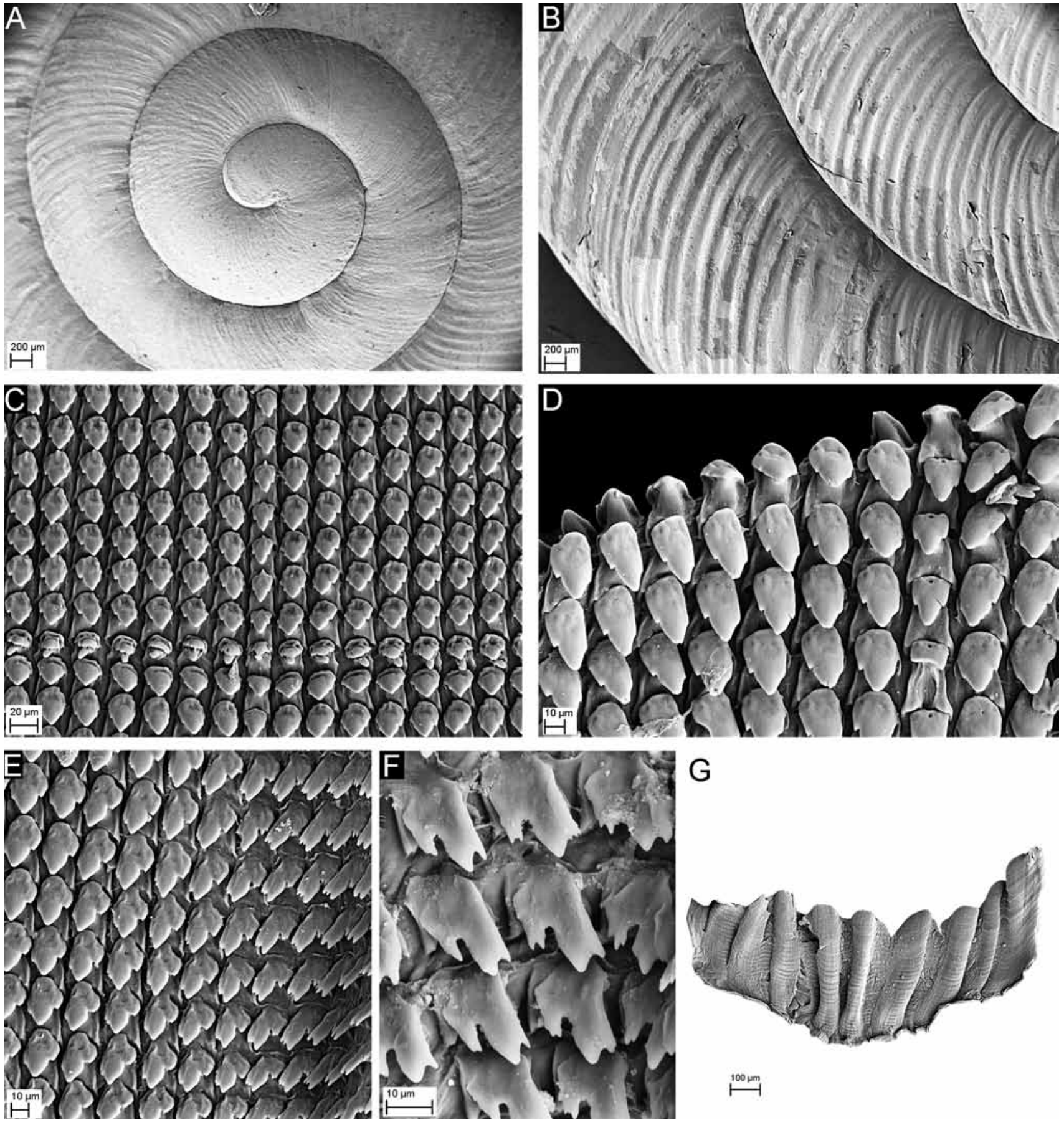

Figure 21. SEM photographs of Amplirhagada montesquieuana n.sp., paratypes AMS C463748. $(A-B)$ Shell: $(A)$ apical whorl viewed from above (scale $200 \mu \mathrm{m}) ;(B)$ sculpture on last two whorls viewed from above (scale $200 \mu \mathrm{m})$. $(C-F)$ Radula: $(C)$ central and lateral teeth $($ Scale $20 \mu \mathrm{m}) ;(D)$ close-up of central and inner lateral teeth $($ scale $10 \mu \mathrm{m}) ;(E)$ outer lateral and inner marginal teeth $($ scale $10 \mu \mathrm{m})$; $(F)$ close-up of middle marginal teeth (scale $10 \mu \mathrm{m})$. $(G)$ Jaw (scale $100 \mu \mathrm{m})$.

differentiated, forming cone-shaped, prominent ridge covered by enlarged pustules at apical to median portion of penial chamber. Pilaster ridges carry little toe-shaped extensions that support hooks. Vas deferens entering penial sheath in upper third. Vagina moderately long, tubular. Inner vaginal wall with smooth longitudinal pilasters. Spermathecal duct wide; inner wall with transversely structured, longitudinal pilasters. Spermathecal head globular to elongate, connected with oviduct by connective tissue; wall delicate. Free oviduct comprising \pm half of anterior part of oviduct, rather straight. Spermoviduct longer than anterior part of oviduct. Talon embedded in albumen gland at junction with spermoviduct.

Radular morphology (Fig. 21C-F). Rectangular. Tooth formula $\mathrm{C}+11+4+14$. Average number of rows of teeth $150 \pm 32.5$ with $38.1 \pm 0.3$ rows per $\mathrm{mm}(\mathrm{n}=2)$. Central teeth with sharply pointed, triangular mesocones, shorter than base of tooth; ectocones small. Lateral teeth with bluntly pointed, triangular mesocones, length equal to base of tooth; ectocones well developed, endocones vestigial. Marginal teeth with elongate mesocones; ectocones shorter and narrower than mesocones, split into two denticles; endocones reduced in size. 


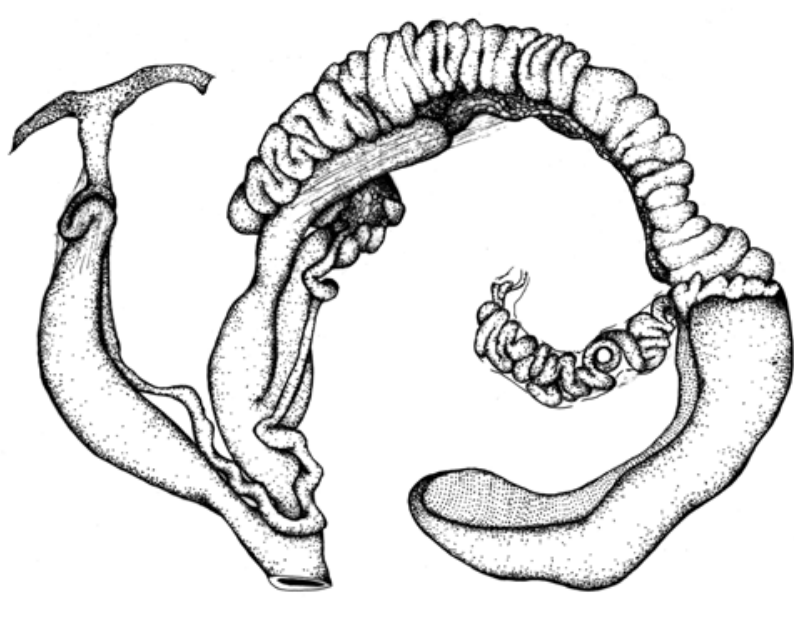

Figure 22. Genitalia of Amplirhagada montesquieuana n.sp., paratype AMS C463748 (28 August, scale $10 \mathrm{~mm}$ ). Compare with Fig. 3 for labelling of structures.

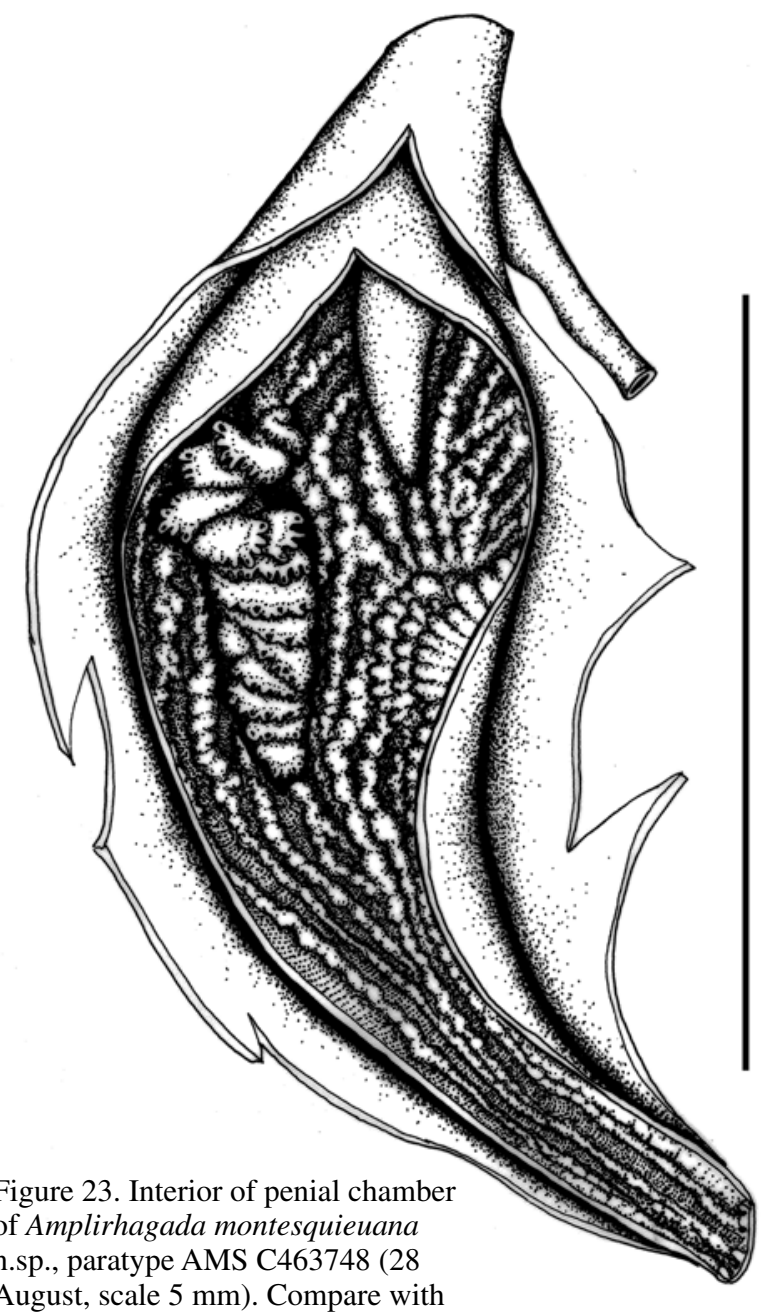

August, scale $5 \mathrm{~mm}$ ). Compare with

Fig. 4 for labelling of structures.

Comparative remarks. The shell of this species is smaller than that of other species from the Montesquieu Islands but otherwise difficult to differentiate by means of colour, sculpture and shape (Table 1). Its axial sculpture is more regular than that of A. combeana and A. mckenziei. From A. mckenziei it also differs by a smaller and comparatively flatter shell; a one-way ANOVA revealed that both species differ significantly in the shell parameters $\mathrm{H}, \mathrm{D}, \mathrm{FW}$ and $\mathrm{H} / \mathrm{D}$. The inner penial wall is characteristic by its rather sparsely distributed rows of pustules that give rise to corrugated, narrow, longitudinal pilasters towards the base of the penial chamber, and the shape and development of the main stimulatory pilaster being shorter and broader than in A. ponderi and larger than in A. mckenziei. The possession of well-developed "toe-shaped" extensions of the pilaster ridges is unique amongst species from Montesquieu Islands.

\section{Amplirhagada descartesana n.sp.}

Type locality (Fig. 1). Western Australia, northwestern Kimberley, Admiralty Gulf, Institute Islands, Descartes Island, $14^{\circ} 10^{\prime} 26^{\prime \prime S} 125^{\circ} 40^{\prime} 38^{\prime \prime E}$; KC-071 (leg. V. Kessner $\&$ A. Longbottom, 19 July 1988).

Type material. Holotype WAM S34607 (Pl. 1.12). Paratypes WAM S41491 (4 preserved specimens, as holotype), FMNH 219276 (5 preserved specimens, as holotype), FMNH 219272 (16 preserved specimens, unnamed island SW of Descartes Island, $14^{\circ} 10^{\prime} 45^{\prime \prime S} 125^{\circ} 40^{\prime} 00^{\prime \prime} \mathrm{E}, \mathrm{KC} / 070$ ), WAM S41490 (10 preserved specimens, same as FMNH 219272), AMS C463749 (7 preserved specimens, same as FMNH 219272).

Additional, non-type material. WAM S41452 (Descartes Island, $\left.125^{\circ} 40^{\prime} 47^{\prime \prime} \mathrm{E} 14^{\circ} 09^{\prime} 50^{\prime \prime S}\right)$.

Etymology. In reference to Descartes Island, where this species occurs.

Shell (Fig. 24A-D, Pl. 1.12). Semi-globose to broadly conical with medium high spire; thin (translucent) to solid. Periphery evenly rounded to slightly angulate; upper and basal sectors of whorls rounded. Umbilicus forming a chink to narrowly winding opening, 30-100 percent concealed by columellar reflection. Background colour brownish horn; uniform or banded; if present sub-sutural and mid-whorl bands diffuse, thin, brown, on last whorl(s) only; ventral colour, outer and inner lip colour whitish to cream. Protoconch c. $2.8 \mathrm{~mm}$ in diameter with 1.7 whorls, almost smooth, sculptured by faint axial lirae. Teleoconch sculptured by coarse lirae, rounded in cross-section, regularly spaced, spaces equal to thickness of lirae, evenly distributed across shell and whorl diameter even, reduced underneath suture. Angle of aperture $45^{\circ}$, outer lip rounded, moderately thick, slightly expanded, slightly reflected; basal node absent or weak, palatal node absent. Parietal wall of inner lip inconspicuous.

Pallial morphology. Pallial cavity moderately deep, extending $3 / 4$ whorl. Mottled pigmentation on mantle dark grey. Kidney extending about half of pallial cavity.

Genital morphology (Figs. 25-26). Penis straight to slightly curved, longer than anterior part of oviduct. Vas deferens forms simple loop before entering penis. Penial retractor muscle shorter than penis. Penial verge short ( $<1 / 4$ penial chamber), slender to spatulate, with pointed tip. Penial wall pustules present, of average size, slightly elongated, arranged in rows across entire length of inner penial wall. Main stimulatory pilaster well-differentiated, large, cone-shaped, sculptured by smooth horizontal ridges, comprising entire length of penial chamber. Vas deferens entering penial sheath in upper third. Vagina comparatively 

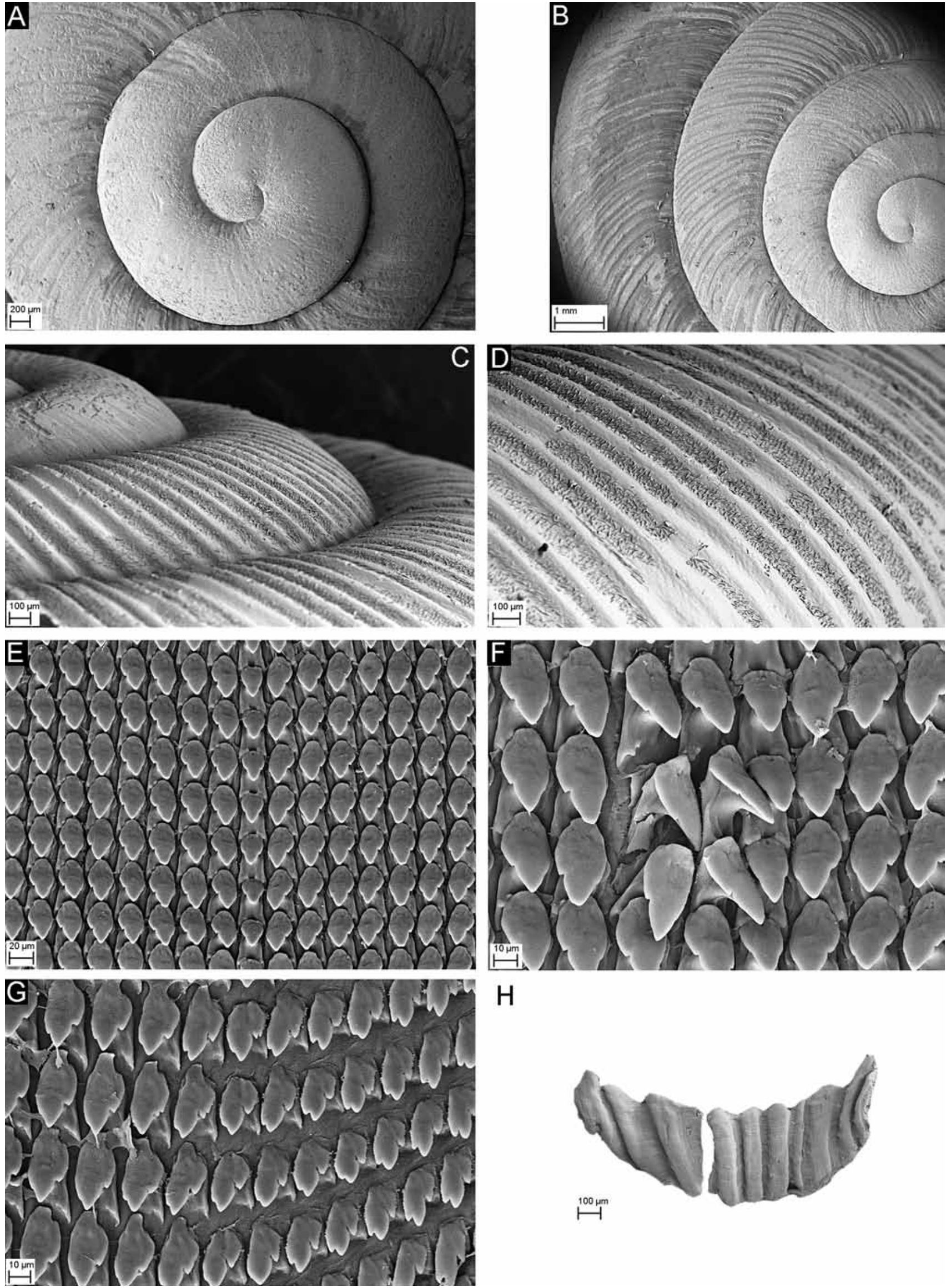

$\mathrm{H}$

Figure 24. SEM photographs of Amplirhagada descartesana n.sp., paratype AMS C463749. (A-D) Shell: $(A)$ apical whorl viewed from above (scale $200 \mu \mathrm{m}) ;(B)$ sculpture on first four whorls viewed from above (scale $1 \mathrm{~mm}) ;(C)$ sculpture, lateral view (scale $100 \mu \mathrm{m}) ;(D)$ close-up of sculpture, obliquely from above (scale $100 \mu \mathrm{m}) .(E-G)$ Radula: $(E)$ central and lateral teeth (Scale $20 \mu \mathrm{m}) ;(F)$ close-up of central and inner lateral teeth (scale $10 \mu \mathrm{m}) ;(G)$ outer lateral and inner marginal teeth (scale $10 \mu \mathrm{m})$. $(H)$ Jaw (scale $100 \mu \mathrm{m})$. 


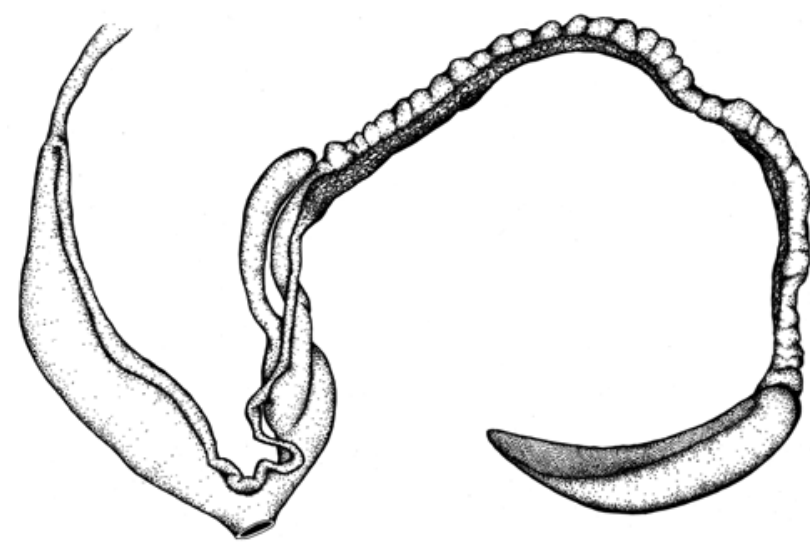

Figure 25. Genitalia of Amplirhagada descartesana n.sp., paratype WAM S41491 (20 July, scale $10 \mathrm{~mm}$ ). Compare with Fig. 3 for labelling of structures.

short to moderately long, posteriorly inflated. Inner vaginal wall with smooth longitudinal pilasters. Spermathecal duct comparatively wide, internally with smooth longitudinal pilasters. Spermathecal head elongately inflated, connected with oviduct by connective tissue, internally smooth, with delicate wall. Free oviduct comprising about half of anterior part of oviduct, rather straight. Spermoviduct clearly longer than anterior part of oviduct. Talon embedded in albumen gland close to anterior end.

Radular morphology (Fig. 24E-G). Rectangular. Tooth formula $\mathrm{C}+16-17+3-4+18-20$. In average with $139 \pm 5.5$ rows of teeth, $31.4 \pm 0.2$ rows per $\mathrm{mm}(\mathrm{n}=2)$. Central teeth with bluntly pointed, triangular mesocones, shorter than base of tooth; ectocones small. Lateral teeth with bluntly pointed, triangular mesocones, length equal to base of tooth; ectocones small, endocones vestigial. Marginal teeth with elongate mesocones; ectocones shorter and narrower than mesocones, divided into two denticles; endocones smaller than ectocones.

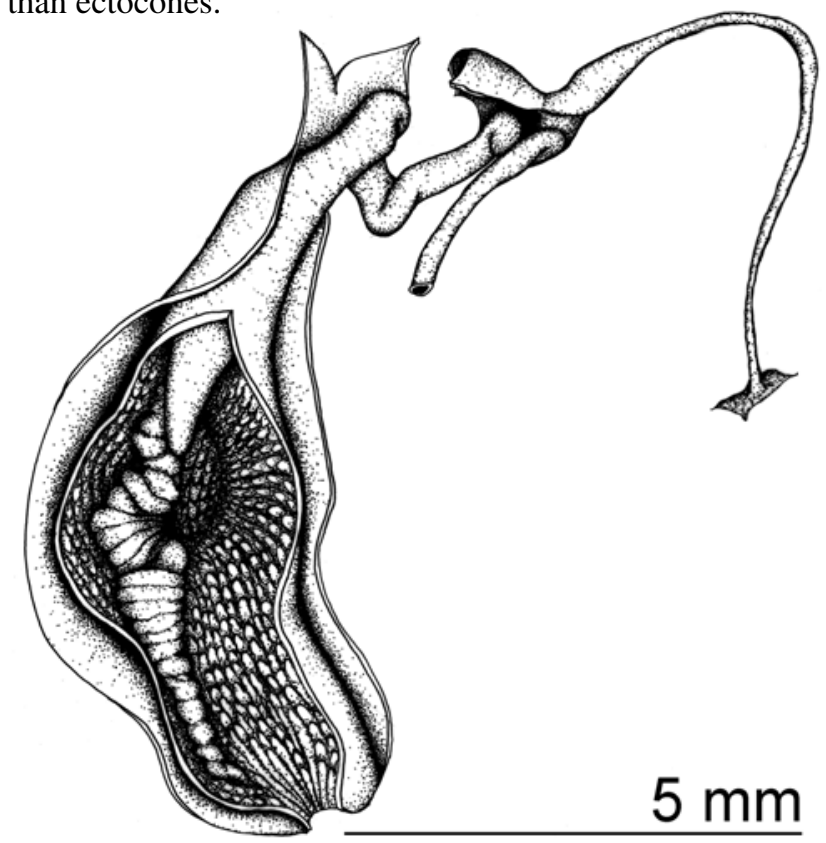

Figure 26. Interior of penial chamber of Amplirhagada descartesana n.sp., paratype FMNH 219276 (20 July, scale 5 $\mathrm{mm}$ ). Compare with Fig. 4 for labelling of structures.
Comparative remarks. The present material has been labelled as "Amplirhagada sp. 74" by Solem. The species is most readily distinguished from other species from the Montesquieu Islands by its more turreted shell. Similar to $A$. montesquieuana, its axial sculpture is more regular than that of A. combeana and A. mckenziei. From A. montesquieuana it differs by its larger size and more conical shape. The main stimulatory pilaster is similar to that in A. montesquieuana in shape but lacks "hooked toes"; broader than pilaster in A. ponderi and A. mckenziei; penial wall pustulation differs markedly from that in A. montesquieuana.

\section{Amplirhagada katerana Solem, 1981}

\author{
Amplirhagada katerana Solem, 1981a: 198-201, figs. 37d, \\ 41a, 43e-f.
}

Material examined. AMS C463692, WAM S36601 (preserved specimens, Bonaparte Archipelago, Montague Sound, Kater's Island, 14²6'51.6"S $125^{\circ} 31^{\prime} 07.1^{\prime \prime E}$ ), WAM S36878 (preserved specimens, $14^{\circ} 26^{\prime} 52^{\prime \prime} \mathrm{S}$ $125^{\circ} 31^{\prime} 13^{\prime \prime E}$ ), AMS C463695, WAM S36879 (preserved specimens, $14^{\circ} 26^{\prime} 49^{\prime \prime S} 125^{\circ} 31^{\prime} 15^{\prime \prime E}$ ), AMS C463696, WAM S36880 (preserved specimens, $14^{\circ} 26^{\prime} 56.8^{\prime \prime S} 125^{\circ} 31^{\prime} 11.0^{\prime \prime E}$ ) (Fig. 1).

\section{Sealing strategy. Free sealer.}

Shell (Fig. 27A-C, Pl. 1.13). Semi-globose with medium spire; solid. Periphery evenly rounded to angulate. Umbilicus forming a chink or narrowly winding opening, 80-90 percent concealed by columellar reflection. Background colour horn; with diffuse to well marked, dark brown, moderately to very thick sub-sutural and mod-whorl bands; bands may fuse with each other concealing background colour completely; ventral colour, outer lip and inner lip horn. Protoconch c. $2.3 \mathrm{~mm}$ in diameter, comprising 2 whorls, sculptured by fine, indistinct axial lirae. Teleoconch smooth except for axial growth lines. Angle of aperture $30^{\circ}$; outer lip rounded, sharp to moderately thick, slightly expanded, not or slightly reflected, basal and palatal node absent. Parietal wall of inner lip inconspicuous.

Pallial morphology. Pallial cavity deep, comprising one whorl. Mottled pigmentation on mantle dark greyish brown. Kidney extending about half of pallial cavity.

Genital morphology (Figs. 28-29). Penis straight, of about same length as anterior part of oviduct. Vas deferens forms simple loop or coils before entering penis. Penial retractor muscle shorter than penis of same length. Penial sheath evenly thick. Penial verge short ( $1 / 8-1 / 4$ of penial chamber), broad, with pointed tip. Penial wall covered by small pustules, arranged in rows over entire length of inner penial wall. Main stimulatory pilaster not differentiated. Three pilasters are formed by rows of thickened pustules comprising entire length of inner penial wall. Vas deferens slightly undulated, entering penial sheath close to apical portion. Vagina elongated, tubular. Inner vaginal wall with smooth longitudinal pilasters. Spermathecal duct and head not well-differentiated; duct moderately thick, internally with smooth longitudinal pilasters; head globular to elongately inflated, internally smooth, with delicate wall; only tip of head connected with oviduct by connective 

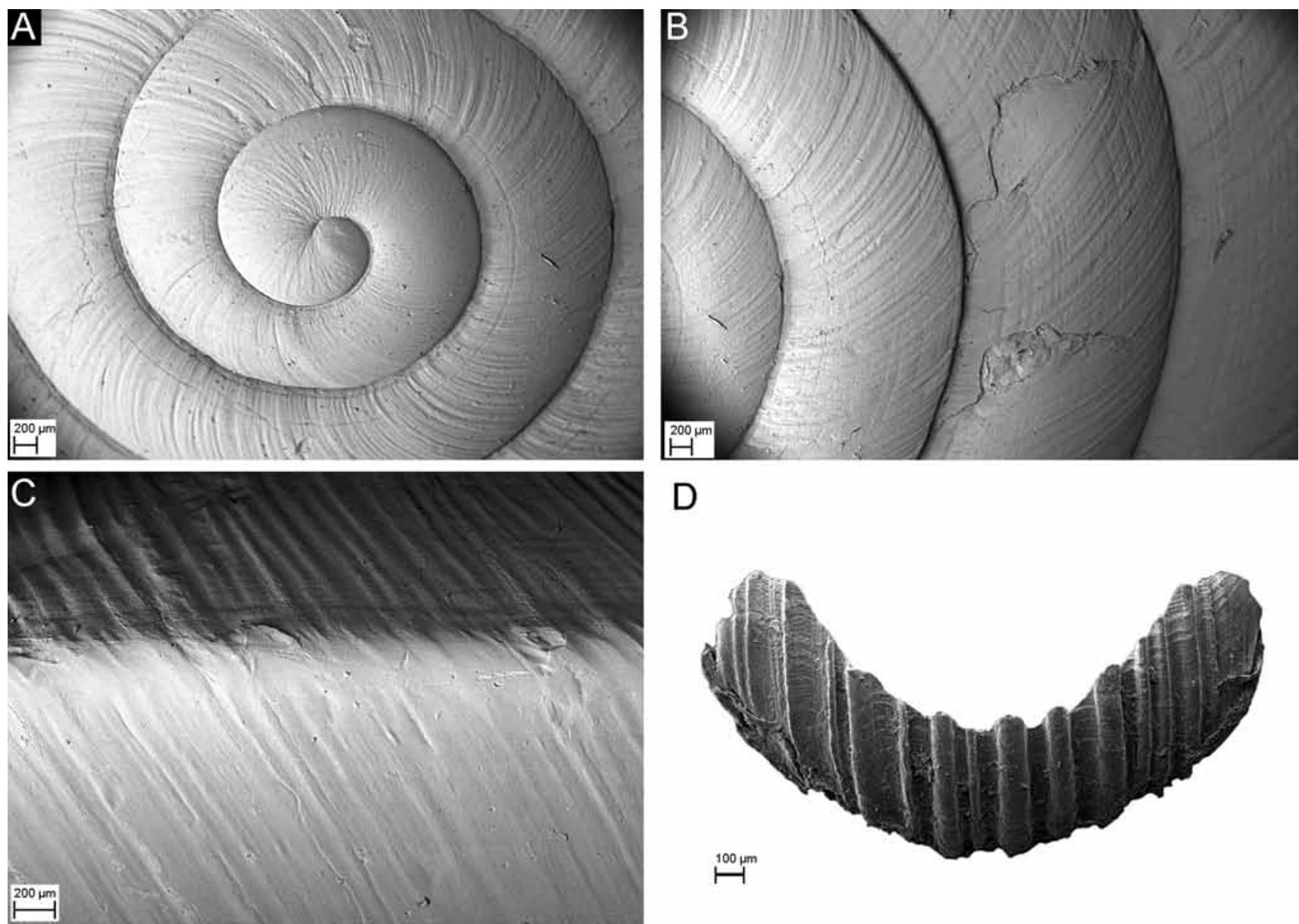

D
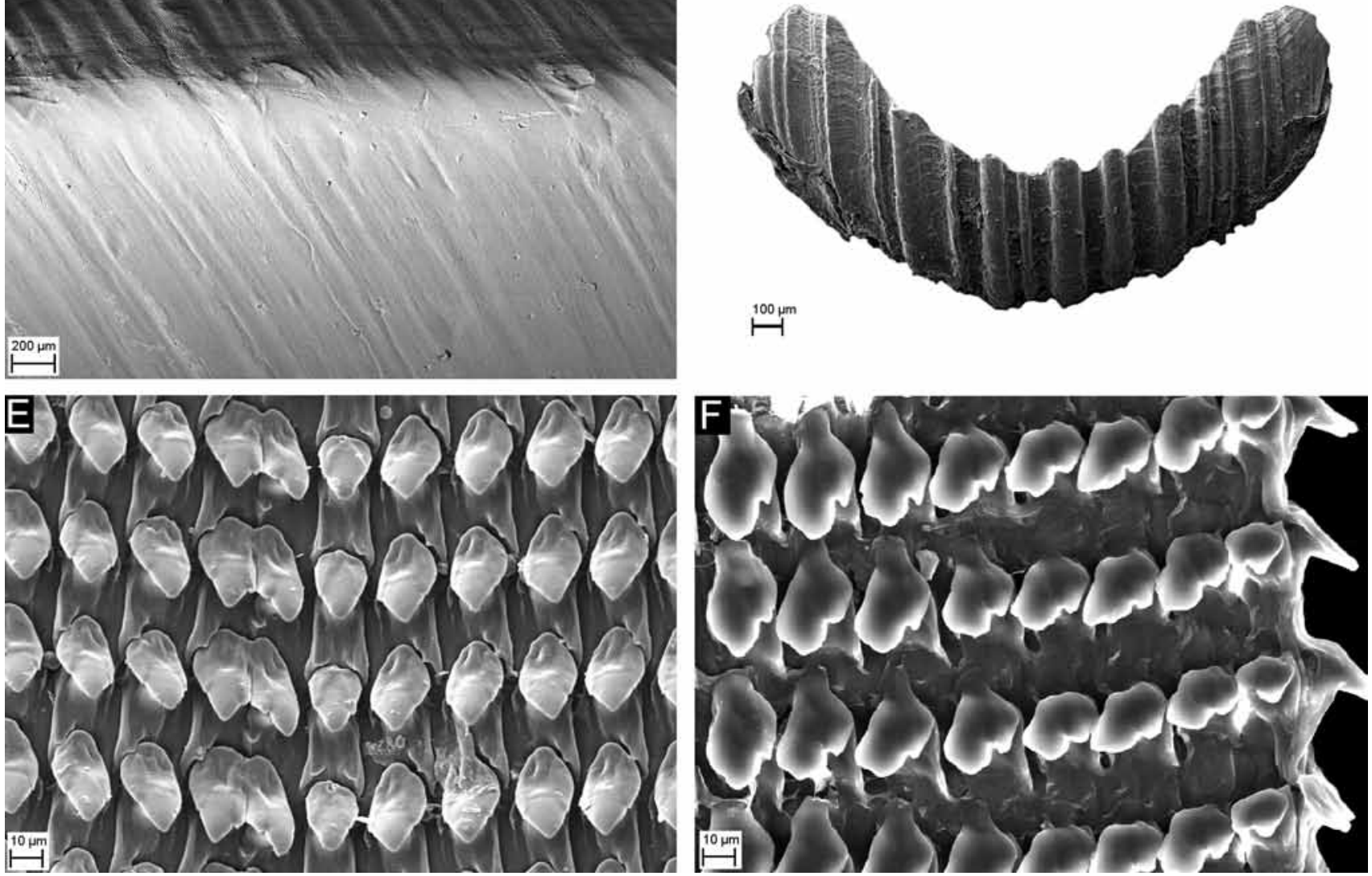

Figure 27. SEM photographs of Amplirhagada katerana. (A-C) Shell, AMS C463697: $(A)$ apical whorl viewed from above (scale 200 $\mu \mathrm{m}) ;(B)$ sculpture on first three whorls viewed from above (scale $200 \mu \mathrm{m}) ;(C)$ close-up of the peripheral keel and sculpture on last whorl (scale $200 \mu \mathrm{m})$. (D) Jaw, WAM S36603 (scale $100 \mu \mathrm{m})$. (E-F) Radula, WAM S36603: $(E)$ close-up of central and inner lateral teeth (scale $10 \mu \mathrm{m}) ;(F)$ close-up of middle marginal teeth (scale $10 \mu \mathrm{m})$.

tissue. Free oviduct comprising more than half of anterior part of oviduct, more or less straight. Spermoviduct slightly longer than anterior part of oviduct. Talon embedded in albumen gland close to anterior end of albumen gland.

Radular morphology (Fig. 27E-F). Rectangular. Tooth formula $\mathrm{C}+14-20+3-4+15-22$. In aerage with $126 \pm 7.0$ rows of teeth, $30.7 \pm 0.1$ rows per $\mathrm{mm}(\mathrm{n}=2)$. Central teeth with bluntly pointed, triangular mesocones, shorter than base of tooth; ectocones vestigial. Lateral teeth with bluntly pointed, triangular mesocones, shorter than base of tooth; ectocones and endocones vestigial. Marginal teeth with rounded mesocones; ectocones shorter and narrower than mesocones, simple; endocones vestigial.

Comparative remarks. Shell more conical in shape and whorls more flattened in diameter than in any species listed so far. Dark brown colour of most shells with pronounced different ventral colour is very characteristic. Penial interior with three longitudinal pilasters formed by enlarged wall pustules is peculiar to this species. For comparison with other species also see Solem (1981a: 198-199). 


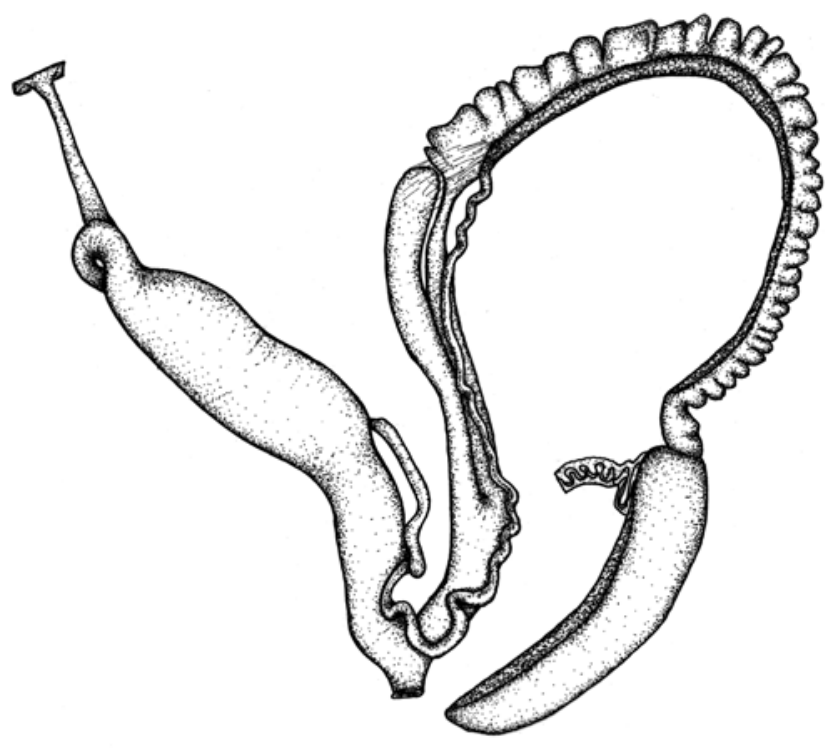

Figure 28. Genitalia of Amplirhagada katerana AMS C463692 (27 July, scale $10 \mathrm{~mm}$ ). Compare with Fig. 3 for labelling of structures.
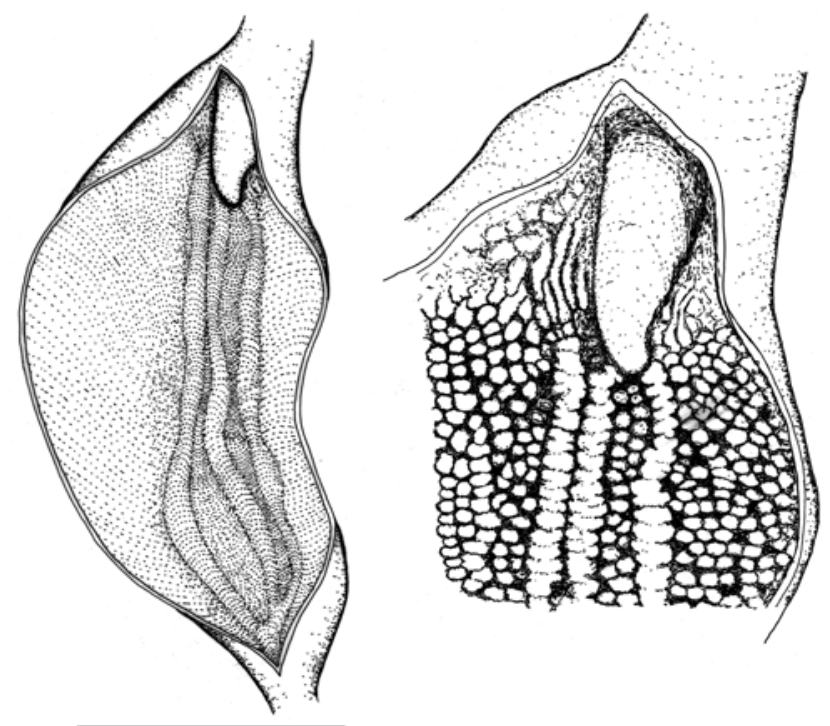

Figure 29. Interior of penial chamber of Amplirhagada katerana AMS C463692 (27 July, scale $5 \mathrm{~mm}$ ) (general overview and magnification of pustulation; drawing F.K.). Compare with Fig. 4 for labelling of structures.

\section{Amplirhagada puescheli n.sp.}

Type locality (Fig. 1). Western Australia, Kimberley, Bonaparte Archipelago, Montague Sound, unnamed island near Prudhoe Island, $14^{\circ} 25^{\prime} 19^{\prime \prime} \mathrm{S} 125^{\circ} 14^{\prime} 23^{\prime \prime} \mathrm{E}$; KC-075 (leg. V. Kessner \& A. Longbottom, 21 July 1988).

Type material. Holotype WAM S34608 (P1. 1.14). Paratypes AMS C463750 (8 preserved specimens), FMNH 219290 (18 preserved specimens), WAM S41486 (10 preserved specimens).

Etymology. Named in honour of Martin Püschel, acknowledging his indispensable help with producing most illustrations used in this publication.

Shell (Fig. 32A-C, Pl. 1.14). Broadly conical with low to medium spire; thin to solid (translucent). Periphery slightly angulate; upper and basal sectors of whorls rounded. Umbilicus forming a chink or narrowly winding opening, 30-90 percent concealed by columellar reflection. Background colour horn to yellowish brown; with diffuse to well marked, brown sub-sutural and mid-whorl bands being most conspicuous on last whorls; ventral colour horn; outer lip colour same as shell; inner lip translucent, whitish. Protoconch c. $2.5 \mathrm{~mm}$ in diameter, comprising 1.5 whorls, smooth. Teleoconch smooth except of faint axial growth

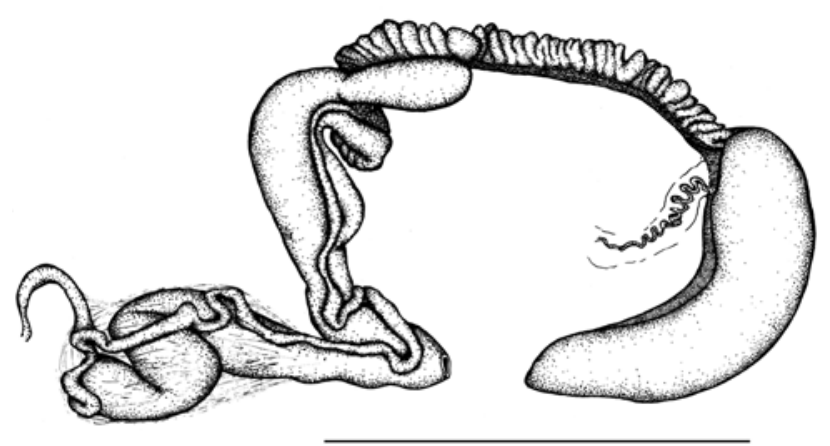

Figure 30. Genitalia of Amplirhagada puescheli n.sp., paratype AMS C463750 (21 July, scale $10 \mathrm{~mm}$ ). Compare with Fig. 3 for labelling of structures.

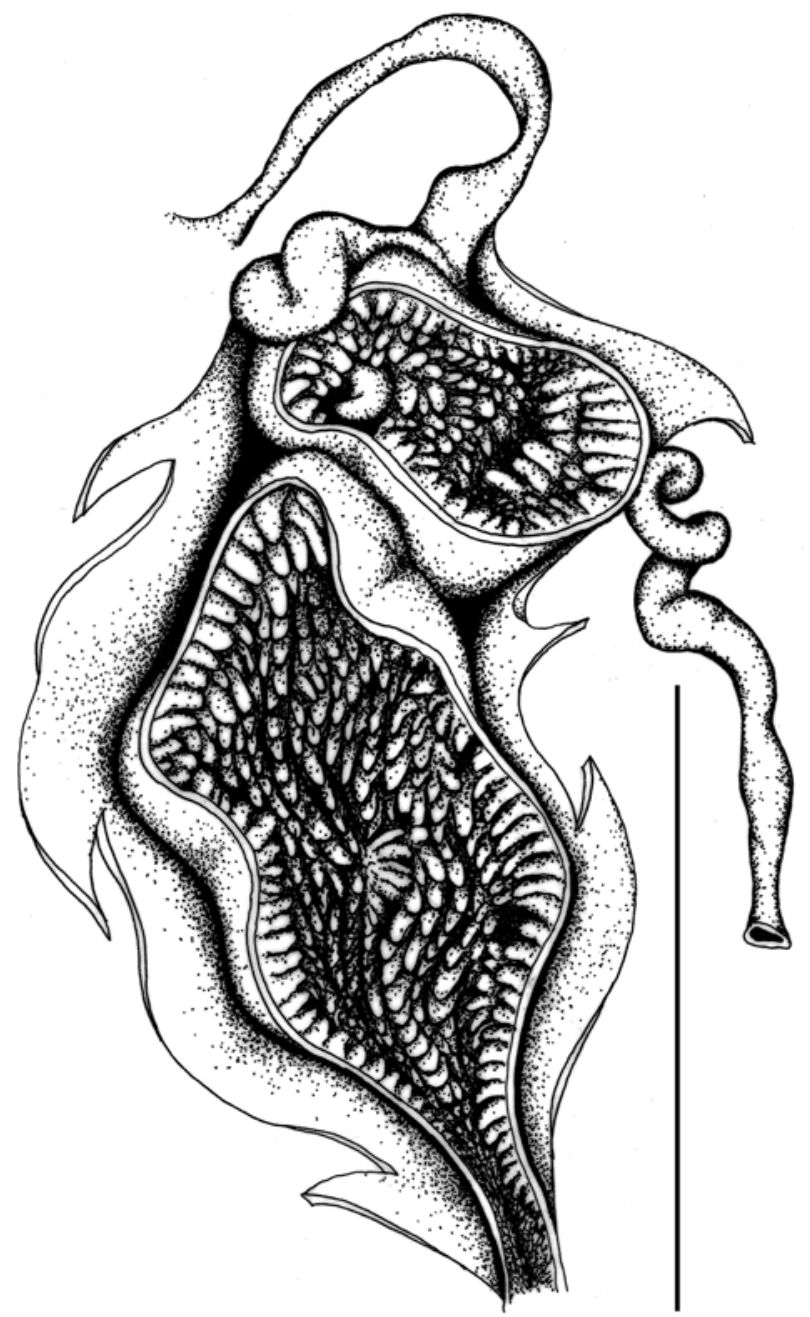

Figure 31. Interior of penial chamber of Amplirhagada puescheli n.sp., paratype AMS C463750 (21 July, scale $5 \mathrm{~mm}$ ). Compare with Fig. 4 for labelling of structures. 

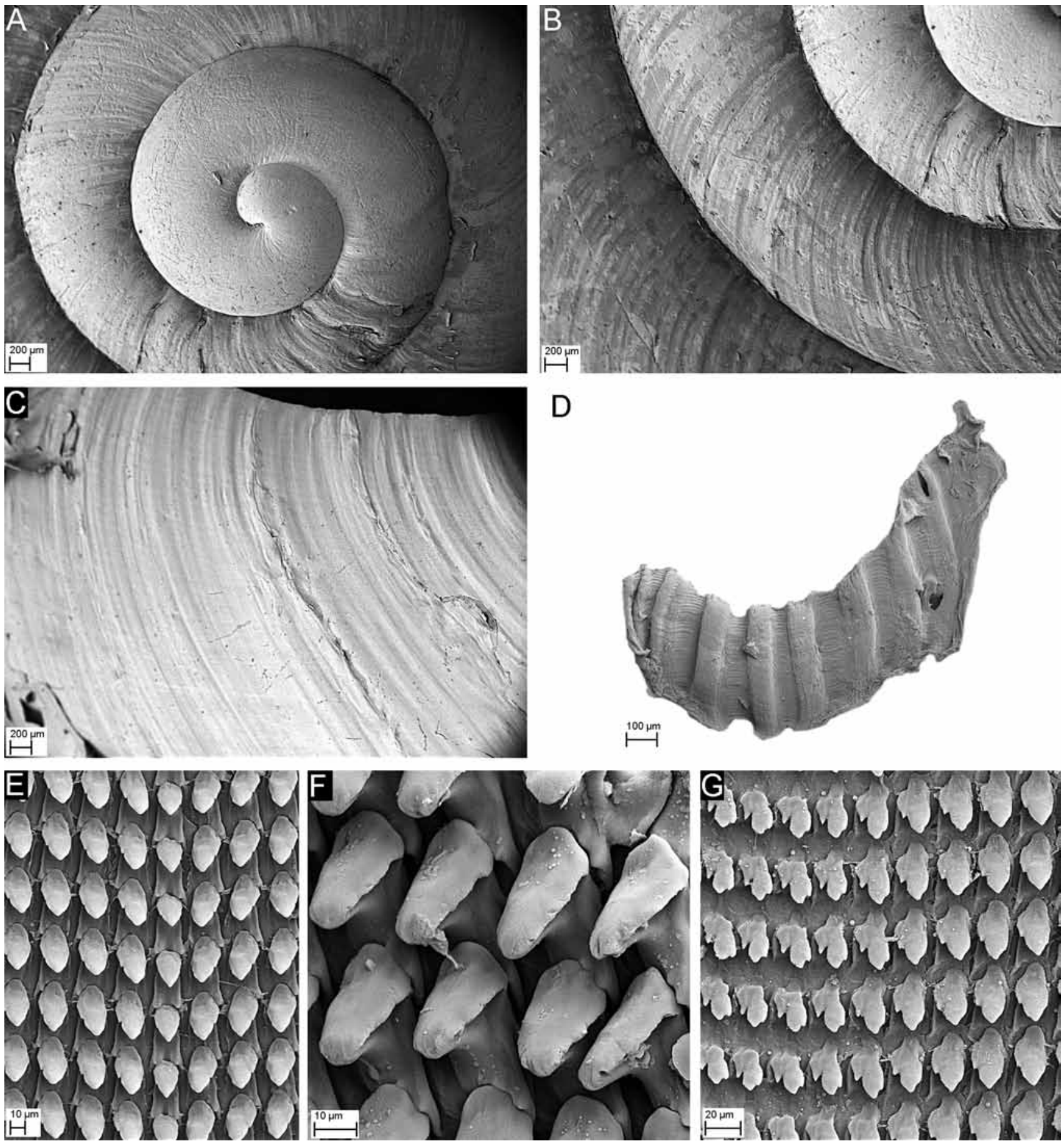

Figure 32. SEM photographs of Amplirhagada puescheli, paratype AMS C463750. (A-C) Shell: $(A)$ apical whorl viewed from above (scale $200 \mu \mathrm{m}) ;(B)$ sculpture on first three whorls viewed from above (scale $200 \mu \mathrm{m}) ;(C)$ sculpture on last whorl (scale $200 \mu \mathrm{m})$. $(D)$ Jaw, broken (scale $100 \mu \mathrm{m}) .(E-G)$ Radula: $(E)$ central and inner lateral teeth (scale $10 \mu \mathrm{m})$; $(F)$ close-up of lateral teeth (scale $10 \mu \mathrm{m})$; $(G)$ outer lateral and inner marginal teeth (scale $20 \mu \mathrm{m}$ ).

lines. Angle of aperture $30^{\circ}$; outer lip rounded, sharp, slightly expanded, slightly reflected; basal node of lip absent weak; palatal node absent. Parietal wall of inner lip inconspicuous.

Pallial morphology. Pallial cavity moderately deep, extending $3 / 4$ whorl. Mantle pigmentation consist of black spots. Kidney extending half of pallial cavity or more.

Genital morphology (Figs. 30-31). Penis curved or sharply bent, of more or less of same length as anterior part of oviduct. Vas deferens coils before entering penis. Penial retractor muscle shorter than penis. Penial verge tiny (barely visible), slender to spatulate with pointed tip. Penial wall pustules small, elongated, arranged in rows over entire length of inner penial wall. Main stimulatory pilaster absent. Vas deferens entering penial sheath in upper third. Vagina moderately wide, posteriorly inflated; inner vaginal wall with undulating longitudinal pilasters. Spermatheca long, clearly extending over base of spermoviduct. Spermathecal duct internally with undulating longitudinal pilasters. Spermathecal head globular to elongately inflated, connected with oviduct by connective tissue, internally smooth with 
delicate to thin wall. Free oviduct shorter than half of anterior part of oviduct, more or less straight. Spermoviduct of same length as anterior part of oviduct. Talon embedded in albumen gland close to anterior end of albumen gland.

Radular morphology (Fig. 32E-G). Rectangular. Tooth formula C+12-15+2-3+19-20. In Average with $156 \pm 10$ rows of teeth, $32.5 \pm 0.4$ rows per $\mathrm{mm}(\mathrm{n}=2)$. Central teeth with sharply pointed, triangular mesocones, shorter than base of tooth; ectocones absent. Lateral teeth with bluntly pointed, triangular mesocones, length equal to base of tooth; ectocones and endocones vestigial. Marginal teeth with triangular to rounded mesocones; ectocones shorter and narrower than mesocones, simple, pointed; endocones greatly reduced.

Comparative remarks. The present material has been labelled as "Amplirhagada sp. 70" by Solem. Shell is rather generic and similar to a number of species especially from islands in the Admiralty Gulf. It differs by its sharply bent penis with strongly developed pustulation of inner whorl and absence of well-differentiated main pilaster and a rather tiny verge.

\section{Amplirhagada decora n.sp.}

Type locality (Fig. 1). Western Australia, northwestern Kimberley, Bonaparte Archipelago, Bigge Island, $4.3 \mathrm{~km}$ north of Savage Hill, $14^{\circ} 35^{\prime} 15^{\prime \prime S} 125^{\circ} 11^{\prime} 05^{\prime \prime E}$; KIS 1-41. Vine thicket on lower and mid slopes north of small stream, dolerite, on trees and bushes in wetter sections (leg. V. Kessner, 17 February 2008).

Type material. Holotype WAM S34609 (Pl. 1.15). Paratypes AMS C463698 (8 preserved specimens, as holotype), WAM S36873 (17 preserved specimens, as holotype), AMS C463699 (4 preserved specimens, $14^{\circ} 35^{\prime} 13.3^{\prime \prime S} 125^{\circ} 11^{\prime} 10.5^{\prime \prime E}$ ), WAM S36874 (9 preserved specimens,

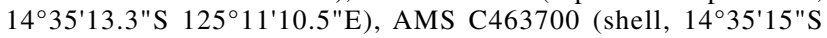
$125^{\circ} 11^{\prime} 05^{\prime \prime E}$ ), WAM S36963 ( 2 shells, $14^{\circ} 35^{\prime} 15^{\prime \prime S ~} 125^{\circ} 11^{\prime} 05^{\prime \prime E}$ ).

Additional, non-type material. WAM S36461-7, WAM S36652-4, WAM S36872 (Bigge Island).

Etymology. From decora (Latin = elegant, beautiful) in reference to its beautiful shell.

Shell (Fig. 35A-C, Pl. 1.15). Globose, with medium to high spire; solid. Periphery angulate; upper sector of whorls flattened to rounded; basal sector rounded. Umbilicus completely concealed by columellar reflection. Background colour brownish horn; with well defined, dark brown, moderately broad sub-sutural and mid-whorl bands being most conspicuous on last whorls; ventral colour horn; outer lip colour same as shell; inner lip translucent. Protoconch c. $2 \mathrm{~mm}$ in diameter, comprising 1.5 whorls, sculptured by fine, indistinct axial lirae. Teleoconch with fine axial lirae, rounded in cross-section, regularly spaced, spaces equal to thickness of lirae, lirae distributed evenly across shell surface, reduced underneath suture. Angle of aperture $30^{\circ}$, outer lip rounded, sharp to moderately thick, not or slightly expanded, not reflected; basal and palatal node absent. Parietal wall of inner lip absent.

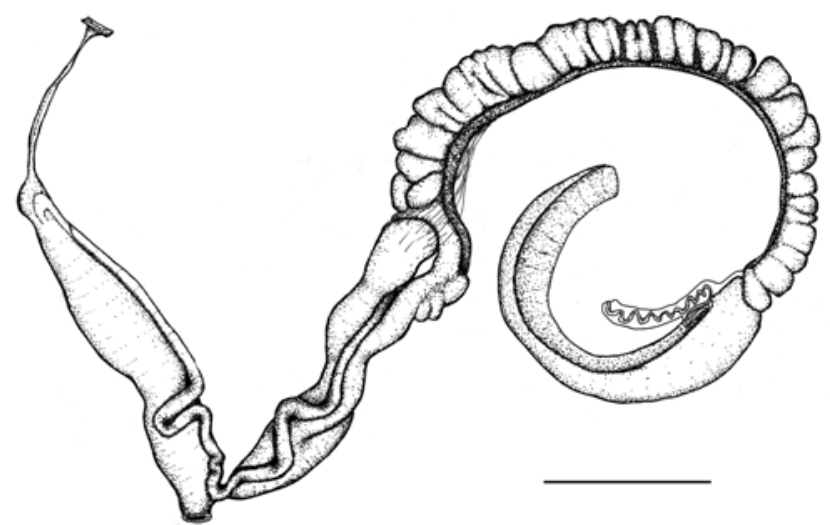

Figure 33. Genitalia of Amplirhagada decora n.sp., paratype AMS C463699 (17 February, scale 10 mm) (drawing F.K.). Compare with Fig. 3 for labelling of structures.

Pallial morphology. Pallial cavity deep, extending one whorl. Mottled pigmentation on mantle dark grey. Kidney extending about half of pallial cavity.

Genital morphology (Figs. 33-34). Penis straight, of more or less same length as anterior pert of oviduct. Vas deferens forms simple loop before entering penis. Penial retractor muscle of about same length as penis. Penial sheath evenly thin. Penial verge tiny (barely visible), with truncated tip. Penial wall pustules of average size, densely arranged

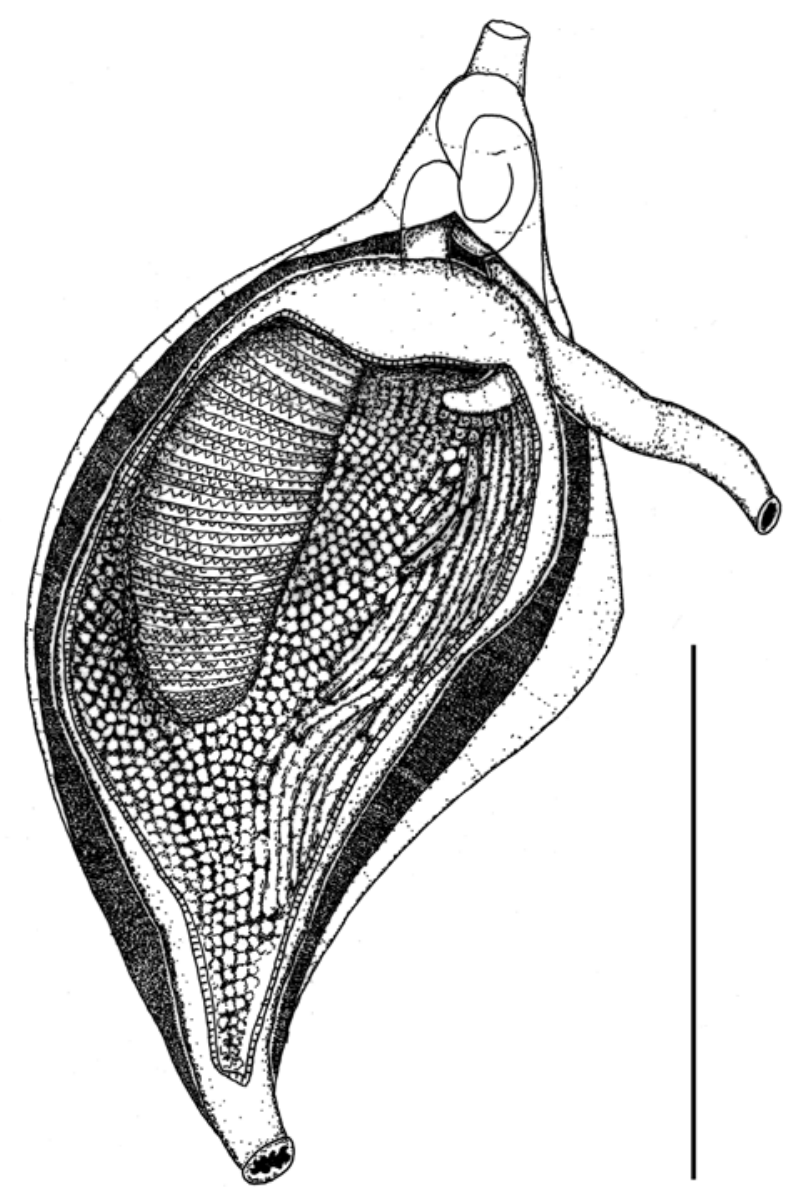

Figure 34. Interior of penial chamber of Amplirhagada decora n.sp., paratype AMS C463698 (17 February, scale $5 \mathrm{~mm}$ ) (drawing F.K.). Compare with Fig. 4 for labelling of structures. 

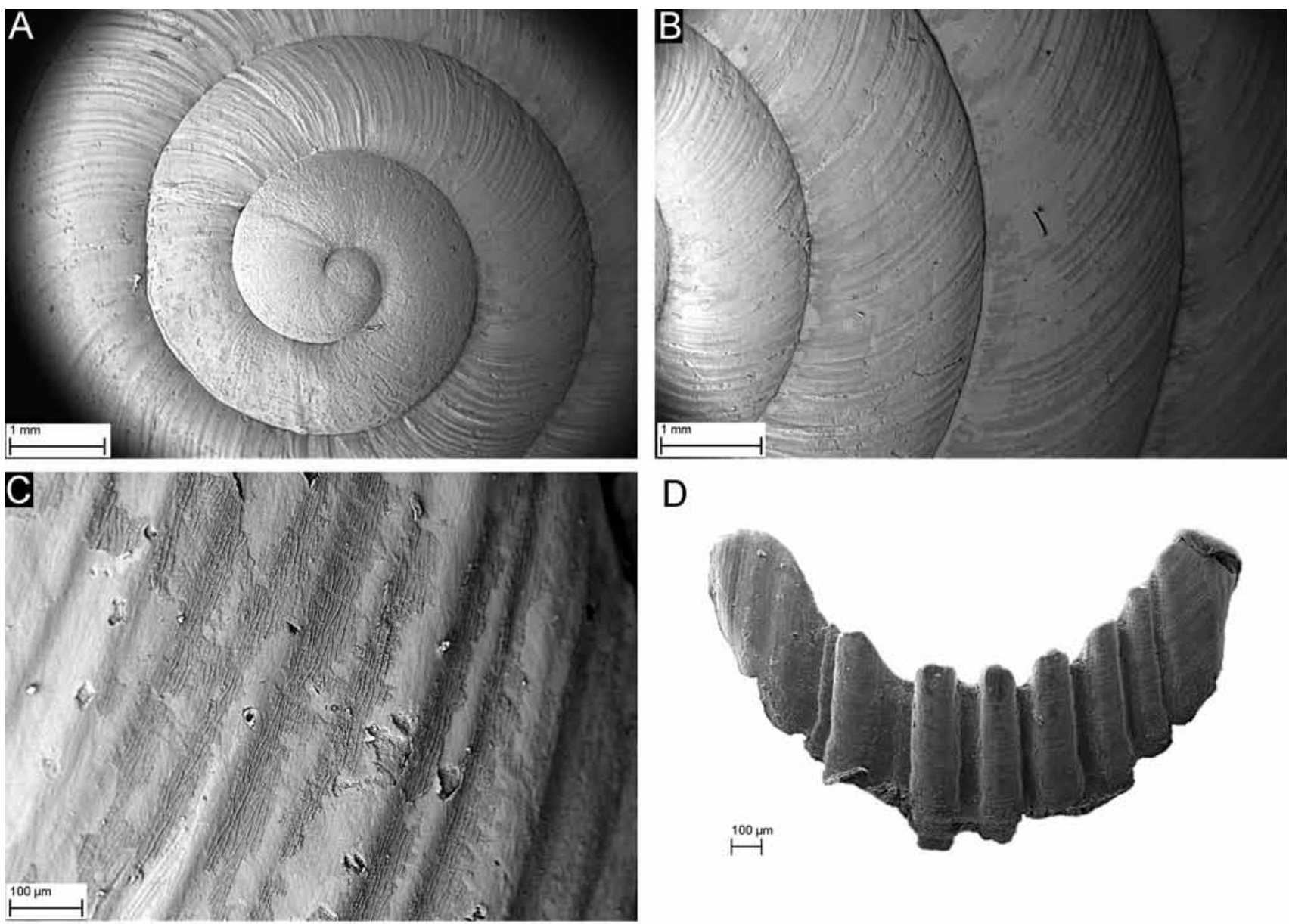

D
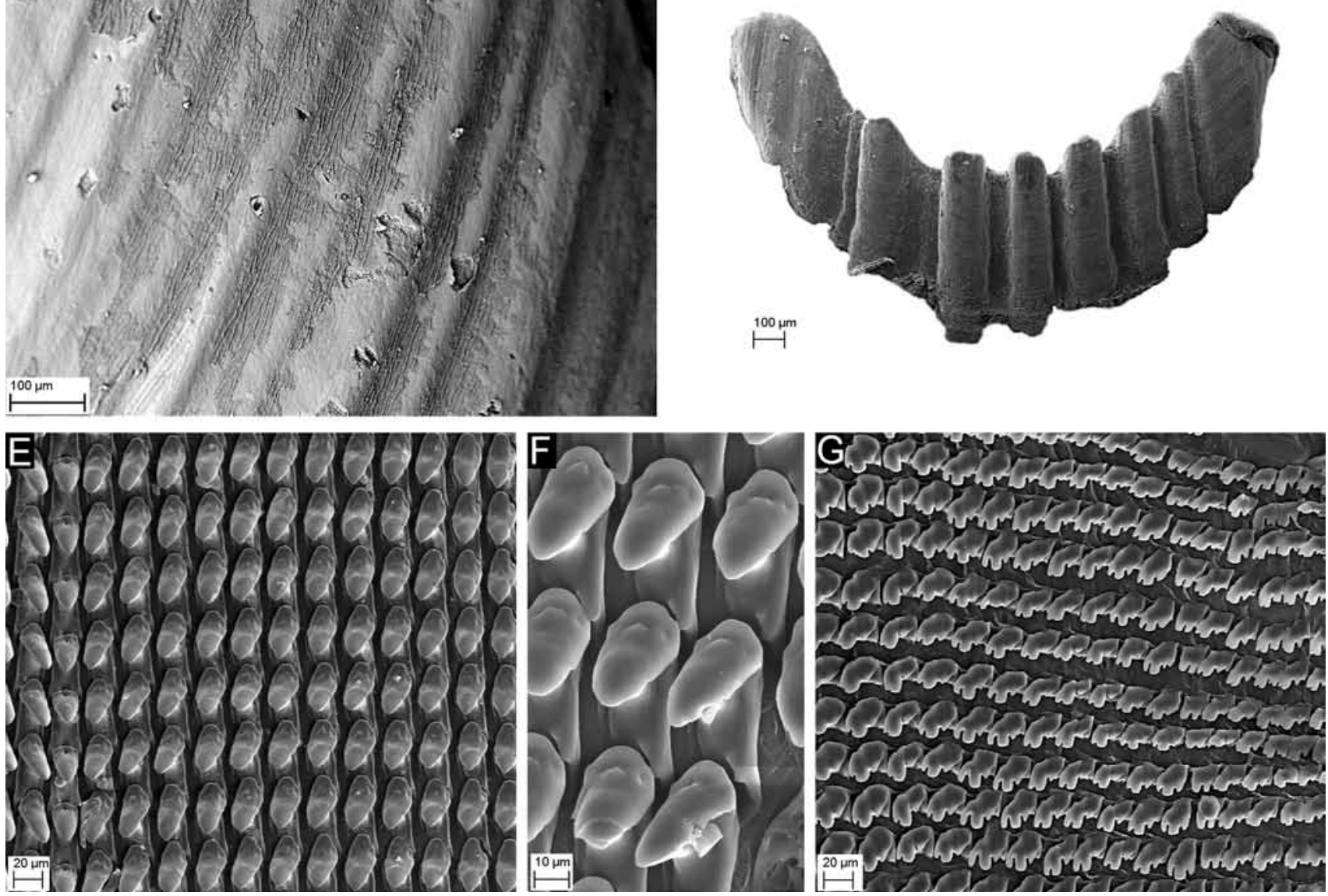

Figure 35. SEM photographs of Amplirhagada decora n.sp. (A-C) Shell, paratype AMS C463700: $(A)$ apical whorl viewed from above (scale $1 \mathrm{~mm}) ;(B)$ sculpture on first three whorls viewed from above (scale $1 \mathrm{~mm}) ;(C)$ sculpture on last whorl (scale $100 \mu \mathrm{m}) .(D) \mathrm{Jaw}$, paratype AMS C463698 (scale $100 \mu \mathrm{m}) .(E-G)$ Radula, paratype AMS C463698: $(E)$ central and lateral teeth (scale $20 \mu \mathrm{m}) ;(F)$ close-up of lateral teeth (scale $10 \mu \mathrm{m}) ;(G)$ inner and middle marginal teeth (scale $20 \mu \mathrm{m}$ ).

in rows over entire length of inner penial wall; partly fused to small elongated ridges. Main stimulatory pilaster well-differentiated, forming a very large cone sculptured by dense ridges comprising apical to median portion of penial chamber; pilaster ridges support little hooks. Vas deferens rather undulated, moderately thick, entering penial sheath in upper third of penis. Vagina short, tubular, posteriorly inflated; inner wall with longitudinal pilasters. Spermathecal duct of medium thickness, internally with smooth longitudinal pilasters. Spermathecal head globular to elongately inflated, connected with oviduct by connective tissue, internally smooth, with thin wall. Free oviduct comprising more than half of anterior part of oviduct, rather straight. Spermoviduct longer than anterior part of oviduct. Talon embedded in albumen gland close to anterior end of albumen gland.

Radular morphology (Fig. 35E-G). Rectangular. Tooth formula $\mathrm{C}+16-18+0-3+20-21$. In average $137.3 \pm 25.4$ rows of teeth, $27.8 \pm 2.7$ rows of teeth $(n=3)$. Central teeth 

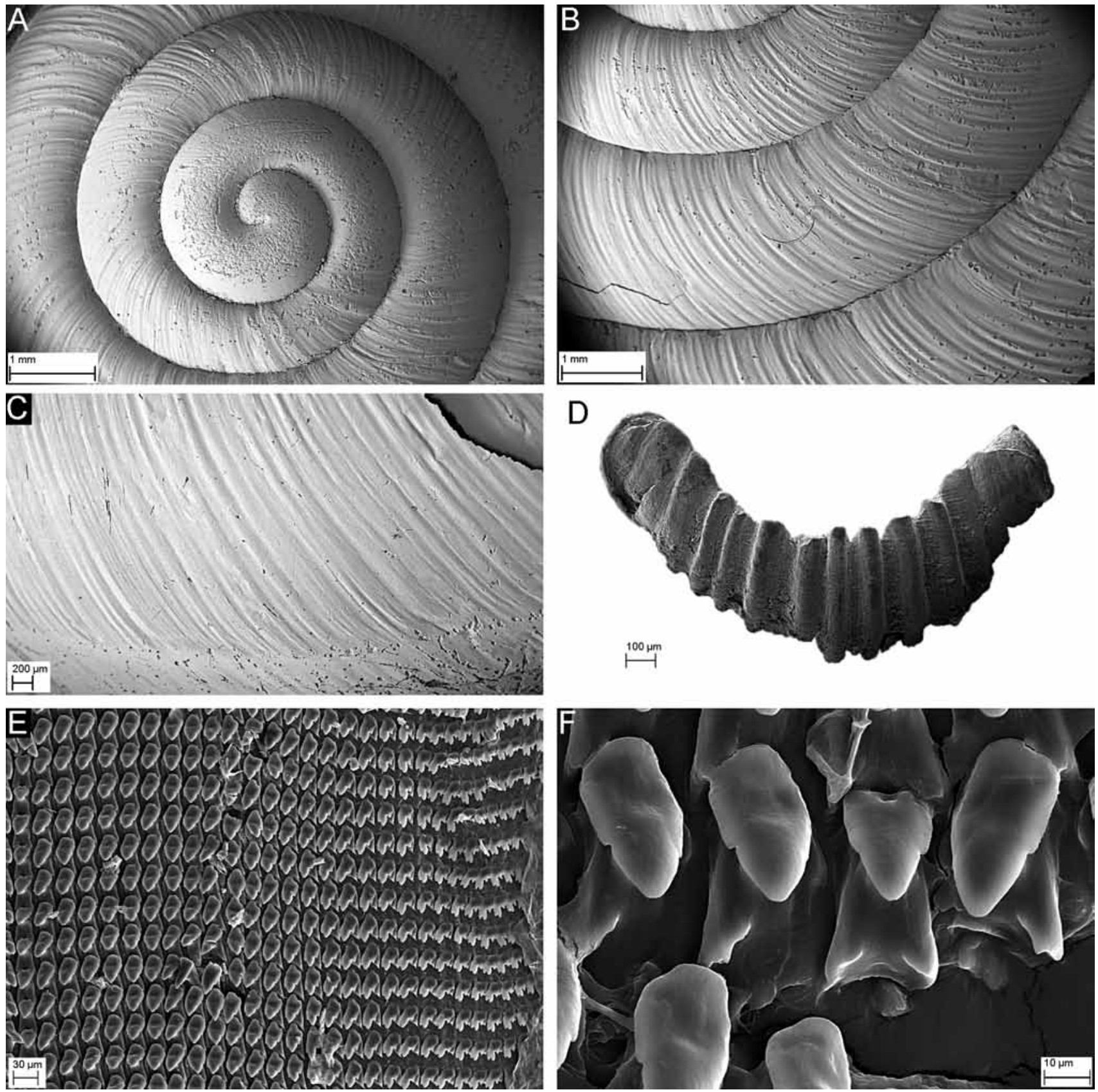

Figure 36. SEM photographs of Amplirhagada kessneri n.sp. (A-C) Shell, paratype AMS C463703: $(A)$ apical whorl viewed from above (scale $1 \mathrm{~mm}) ;(B)$ sculpture on second to forth whorl viewed from above (scale $1 \mathrm{~mm}) ;(C)$ detail of sculpture on mid of last whorl (scale $200 \mu \mathrm{m})$. (D) Jaw, paratype AMS C463701 (scale $100 \mu \mathrm{m})$. $(E-G)$ Radula, paratype AMS C463701: $(E)$ central and lateral teeth (scale $20 \mu \mathrm{m}) ;(F)$ close-up of lateral teeth (scale $10 \mu \mathrm{m}) ;(G)$ inner and middle marginal teeth (scale $20 \mu \mathrm{m})$.

with bluntly pointed, triangular to ovate mesocones, shorter than base of tooth; ectocones vestigial. Lateral teeth with bluntly pointed, triangular to ovate mesocones, shorter than base of tooth; ectocones and endocones vestigial. Marginal teeth with broad, flattened mesocones; ectocones shorter and narrower than mesocones, divided into two denticles, endocones reduced in size.

Comparative remarks. Its highly elevated, dome-shaped shell being characteristic (H/D larger than in many other species with more conical shells). Comparatively large, coneshaped main pilaster, rather large pustules of inner penial wall and tiny verge are diagnostic. This species was referred to as "Amplirhagada sp. 23" by Solem (1991).

\section{Amplirhagada kessneri n.sp.}

Type locality (Fig. 1). Western Australia, northwestern Kimberley, Bonaparte Archipelago, Bigge Island, $4.3 \mathrm{~km}$ north of Savage Hill, $14^{\circ} 35^{\prime} 15^{\prime \prime S} 125^{\circ} 11^{\prime} 05^{\prime \prime E}$; KIS 1-41. Vine thicket on mid slopes north of small stream, dolerite, on trees and bushes in drier sections (leg. V. Kessner, 17 February 2008).

Type material. Holotype WAM S34610 (Pl. 1.16). Paratypes AMS C463701 (4 preserved specimens, as holotype), WAM S36875 (10 preserved specimens, as holotype), WAM S36477 (5 shells, $\left.14^{\circ} 35^{\prime} 16^{\prime \prime S} 125^{\circ} 11^{\prime} 02^{\prime \prime E}\right)$, AMS C463702 (9 preserved specimens, $\left.14^{\circ} 35^{\prime} 16^{\prime \prime S} 125^{\circ} 11^{\prime} 02^{\prime \prime} \mathrm{E}\right)$, AMS C C.463703 ( 2 shells, $14^{\circ} 35^{\prime} 16^{\prime \prime S} 125^{\circ} 11^{\prime}$ '02"E), WAM S36658 (10 preserved specimens, $14^{\circ} 35^{\prime} 16^{\prime \prime S} 125^{\circ} 11^{\prime} 02^{\prime \prime E}$ ), WAM S36876 (16 preserved specimens, $14^{\circ} 35^{\prime} 18.5^{\prime \prime S} 125^{\circ} 10^{\prime} 54.7^{\prime \prime E}$ ), WAM S36475 (3 shells, $14^{\circ} 35^{\prime} 16^{\prime \prime S ~} 125^{\circ} 11^{\prime} 06^{\prime E}$ ), WAM S36476 (6 shells, 14³5'14"S 12511'08"E). 


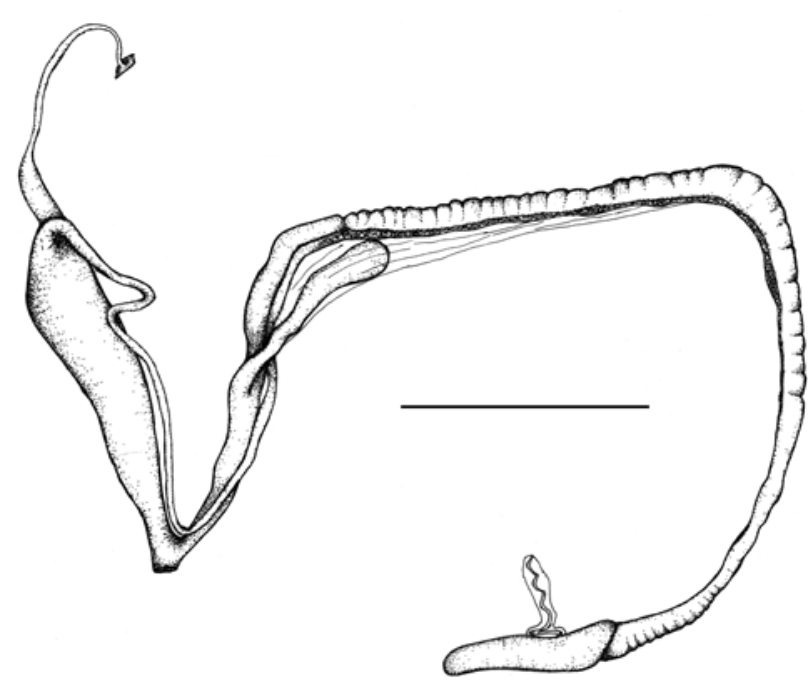

Figure 37. Genitalia of Amplirhagada kessneri n.sp., paratype WAM S36876 (17 February, scale $10 \mathrm{~mm}$ ). Compare with Fig. 3 for labelling of structures.

Etymology. Named in honour of Vince Kessner in recognition of his lasting achievements as one of Australia's finest experts in the field.

Shell (Fig. 36A-C, Pl. 1.16). Semi-globose to conical with low spire; thin to solid (translucent). Periphery evenly rounded to slightly angulate; upper sector of whorls rounded, basal sector somewhat flattened. Umbilicus open, forming a chink or narrowly winding opening, 30-90 percent concealed by columellar reflection. Background colour horn to light brown, exceptionally dark brown; sub-sutural and mid-whorl bands absent or diffuse to well marked, brown, thin to moderately thick, most conspicuous on last whorls; ventral colour horn to light brown; outer lip colour lighter than shell, horn; inner lip translucent. Protoconch c. $2 \mathrm{~mm}$ in diameter, comprising 2 whorls, almost smooth. Teleoconch with regularly spaced axial lirae becoming somewhat oblique on last whorl. Angle of aperture $45^{\circ}$; outer lip rounded, sharp to moderately thick, slightly expanded, not or slightly reflected, basal node absent or very weak, palatal node absent. Parietal wall of inner lip absent.

Pallial morphology. Pallial cavity deep, extending one whorl. Mottled mantle pigmentation dark grey to black. Kidney extending about half of pallial cavity.

Genital morphology (Figs. 37-38). Penis straight, more or less of same length as anterior part of oviduct. Vas deferens forms simple loop before entering penis. Penial retractor muscle longer than penis. Penial sheath evenly thin. Penial verge short $(<1 / 8$ penial chamber), slender to spatulate, with truncated tip. Penial wall pustules small, densely arranged in rows over entire length of inner penial wall. Main stimulatory pilaster well-differentiated, forming a large, elongated cone, sculptured by smooth horizontal ridges, comprising apical to median portion of penial chamber. Vas deferens entering penial sheath in upper third. Vagina rather long, tubular; inner vaginal wall densely covered by tiny pustules. Spermathecal duct moderately thick, internally with longitudinal rows of densely packed ciliae. Spermathecal head globular to elongately inflated, connected with oviduct by connective tissue, internally smooth, densely ciliated, with thin wall. Free oviduct comprising \pm half of anterior part of oviduct, straight. Spermoviduct longer to much longer than anterior

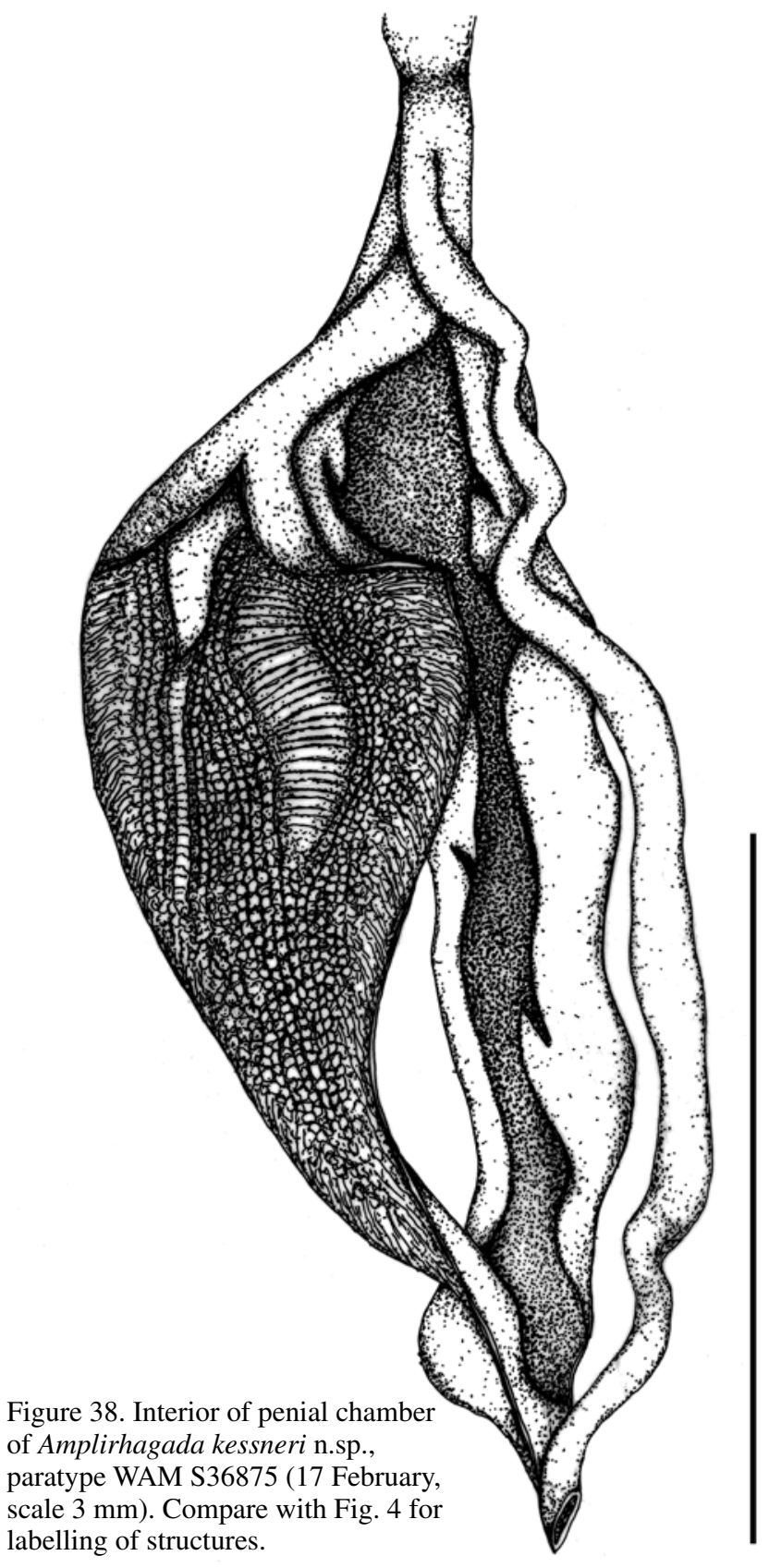

part of oviduct. Talon embedded in albumen gland close to anterior end.

Radular morphology (Fig. 36E-G). Rectangular. Tooth formula $\mathrm{C}+14-17+0-4+18-21$. In average with $117 \pm 2.9$ rows of teeth, $27.6 \pm 0.7$ rows per $\mathrm{mm}(\mathrm{n}=3)$. Central teeth with sharply pointed, triangular mesocones, shorter than base of tooth; ectocones tiny. Lateral teeth with sharply pointed, triangular mesocones, length equal to base of tooth; ectocones tiny, endocones vestigial. Marginal teeth with broad, flattened mesocones; ectocones shorter and narrower than mesocones; endocones reduced in size.

Comparative remarks. Differs from $A$. decora, its congener from Bigge Island, by flatter, uniformly coloured shell, much smaller main pilaster and finer pustulation of inner penial wall. 


\section{Amplirhagada berthierana n.sp.}

Type locality (Fig. 1). Western Australia, northwestern Kimberley, Bonaparte Archipelago, Berthier Island, $14^{\circ} 29^{\prime} 49^{\prime S} \mathrm{~S} 124^{\circ} 59^{\prime} 34.1^{\prime \prime E}$ (leg. C. Whisson, 11 November 2006).

Type material. Holotype WAM S34611 (Pl. 1.17). Paratypes AMS C463754 (8 preserved specimens), WAM S33029 (10 preserved specimens).

Etymology. In reference to Berthier Island, where this species occurs.

\section{Sealing strategy. Rock sealer.}

Shell (Fig. 41A-C, Pl. 1.17). Globose to broadly conical with medium high spire; thick. Whorls evenly rounded. Umbilicus open, forming a chink, 95 percent concealed by columellar reflection. Background and ventral colour cream; banded. Sub-sutural band well defined, red-brown. Mid-whorl band well marked, red brown, moderately broad, visible on entire shell becoming more diffuse on upper whorls, blends with sub-sutural band to cover entire surface of whorl in reddish brown towards tip of shell; outer lip colour white; inner lip translucent, white. Protoconch c. $2.2 \mathrm{~mm}$ in diameter, comprising 1.7 whorls, with fine, indistinct axial lirae. Teleoconch with strong axial growth lines. Angle of aperture $45^{\circ}$; outer lip rounded, moderately thick to thick, slightly expanded, slightly reflected; basal node of lip weak; palatal node absent. Parietal wall of inner lip inconspicuous.

Pallial morphology. Pallial cavity moderately deep, extending $3 / 4$ whorl. Pigmentation on mantle comprising sparsely distributed, dark brown spots. Kidney extending more than half of pallial cavity.

Genital morphology (Figs. 39-40). Penis curved, thick, more or less of same length as anterior part of oviduct. Vas deferens coils once before entering penis. Penial retractor muscle stubby to short. Penial sheath evenly thick. Penial

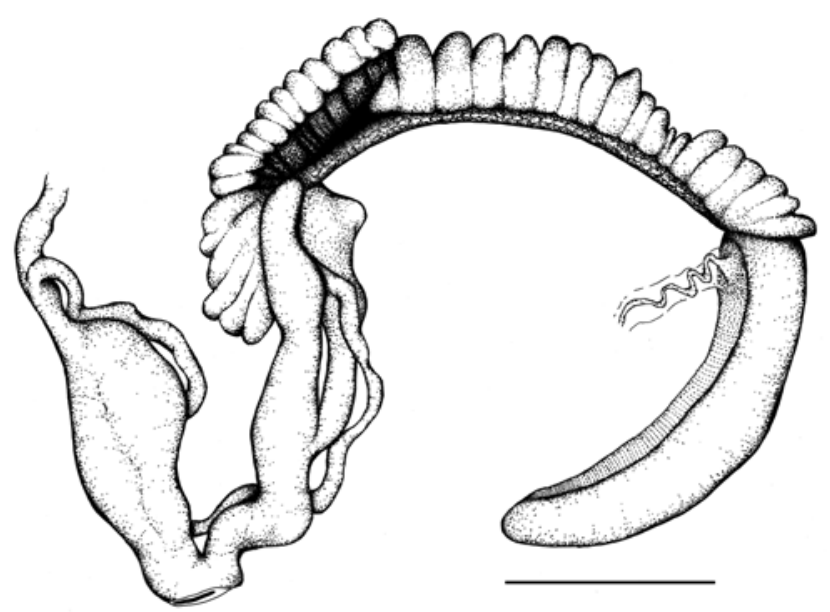

Figure 39. Genitalia of Amplirhagada berthierana n.sp., paratype AMS C463754 (11 November, scale $10 \mathrm{~mm}$ ). Compare with Fig. 3 for labelling of structures. verge short $(<1 / 4$ penial chamber), broad with rounded tip. Penial wall pustules small, arranged in rows over entire length of inner penial wall. Main stimulatory pilaster welldifferentiated, elongated, cone-shaped, sculptured by smooth horizontal ridges, comprising apical two thirds of penial chamber. Vas deferens entering penial sheath in upper third. Vagina moderately thick, medially inflated; inner vaginal wall with undulating longitudinal pilasters. Spermatheca long, clearly extending over base of spermoviduct. Spermathecal duct wide, internally with undulating longitudinal pilasters. Spermathecal head elongately inflated, connected with oviduct by connective tissue, internally smooth with delicate wall. Free oviduct comprising more or less half of anterior part of oviduct, straight. Spermoviduct longer than anterior part of oviduct. Talon embedded in albumen gland at junction with spermoviduct.

Radular morphology (Fig. 41E-G). Rectangular. Tooth formula $C+13-15+3-4+20-24$. In average $133 \pm 5$.0 rows of teeth, $29.2 \pm 0.2$ rows per $\mathrm{mm}(\mathrm{n}=2)$. Central teeth with sharply pointed, triangular to ovate mesocones, shorter than base of tooth; ectocones vestigial. Lateral teeth with sharply pointed, triangular mesocones, length equal to base of tooth; ectocones and endocones vestigial. Marginal teeth with triangular mesocones; ectocones shorter and narrower than mesocones; endocones reduced in size.

Comparative remarks. Distinctive species; its broadly conical, almost dome-like shell with widely rounded, almost depressed last whorl with pronounced spiral banding, and the corrugated, large main pilaster are diagnostic.

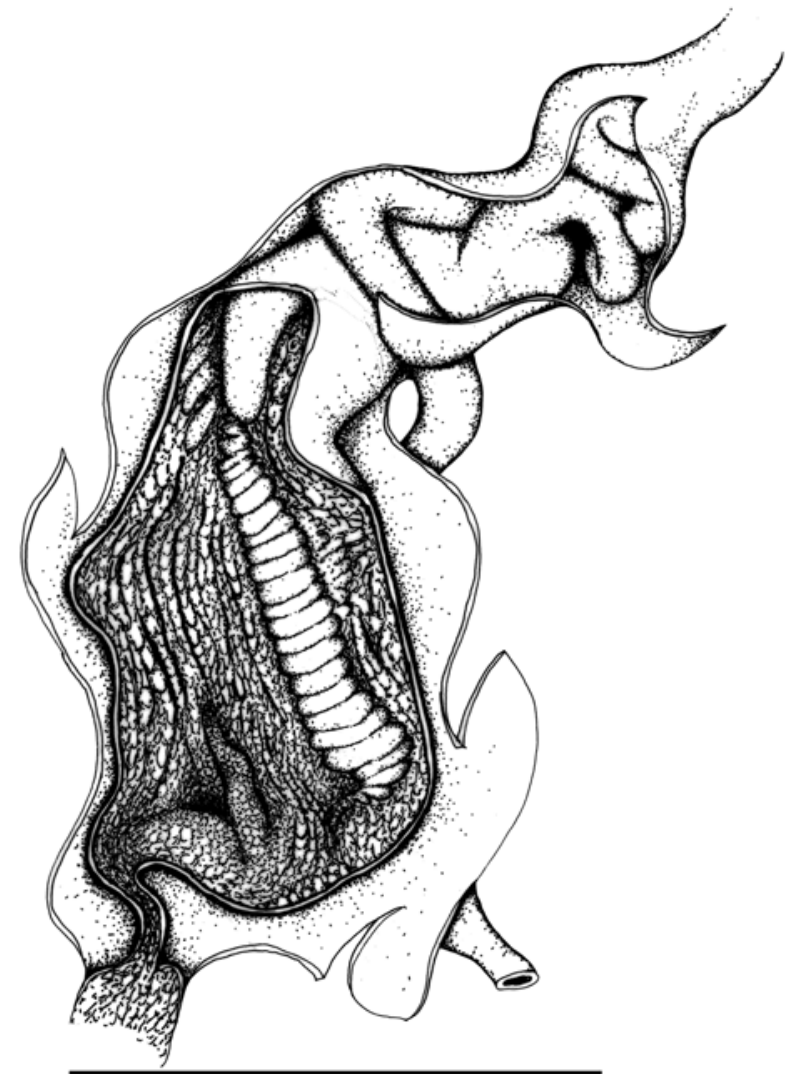

Figure 40. Interior of penial chamber of Amplirhagada berthierana n.sp., paratype AMS C463754 (11 November, scale $5 \mathrm{~mm}$ ). Compare with Fig. 4 for labelling of structures. 

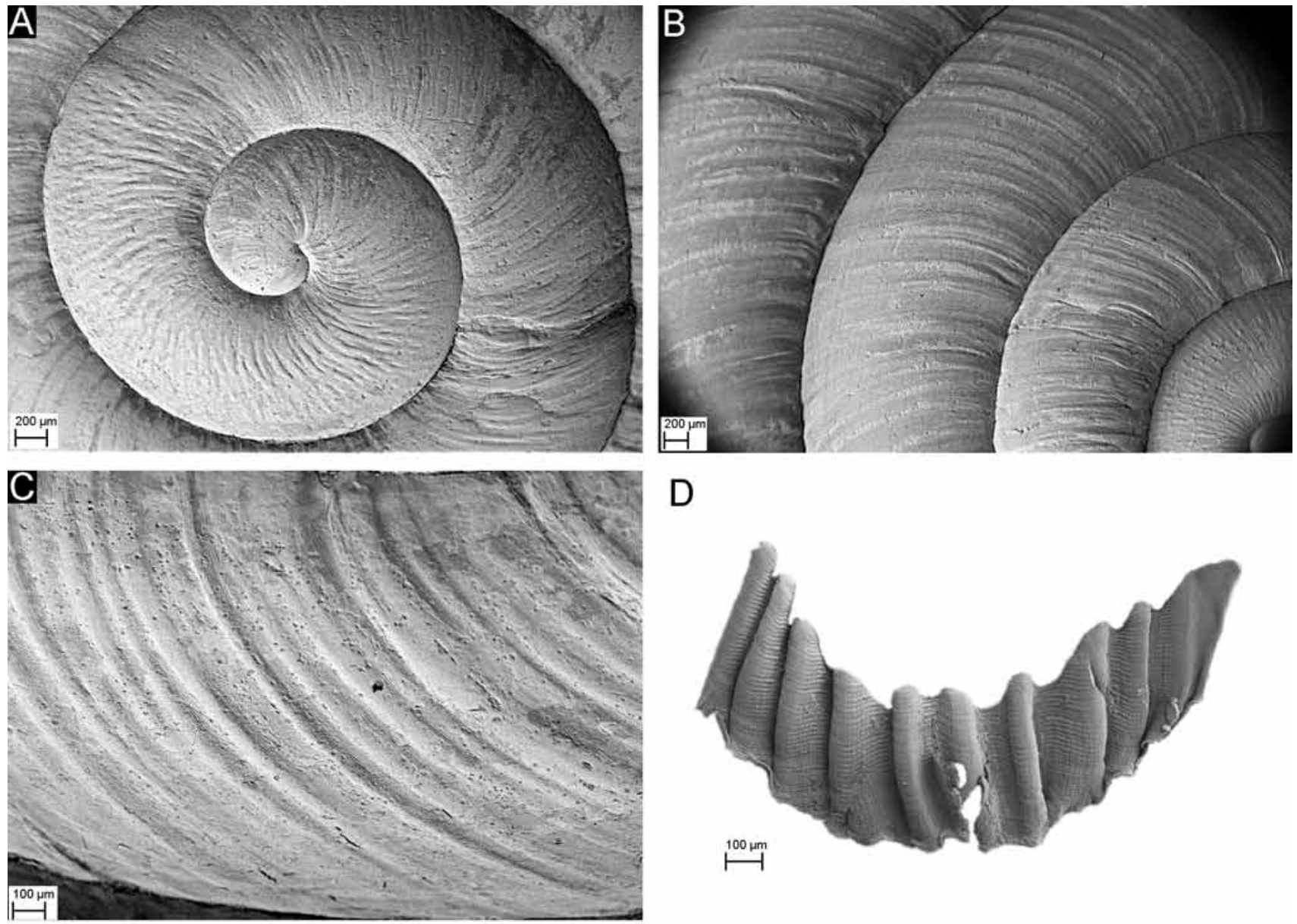

D
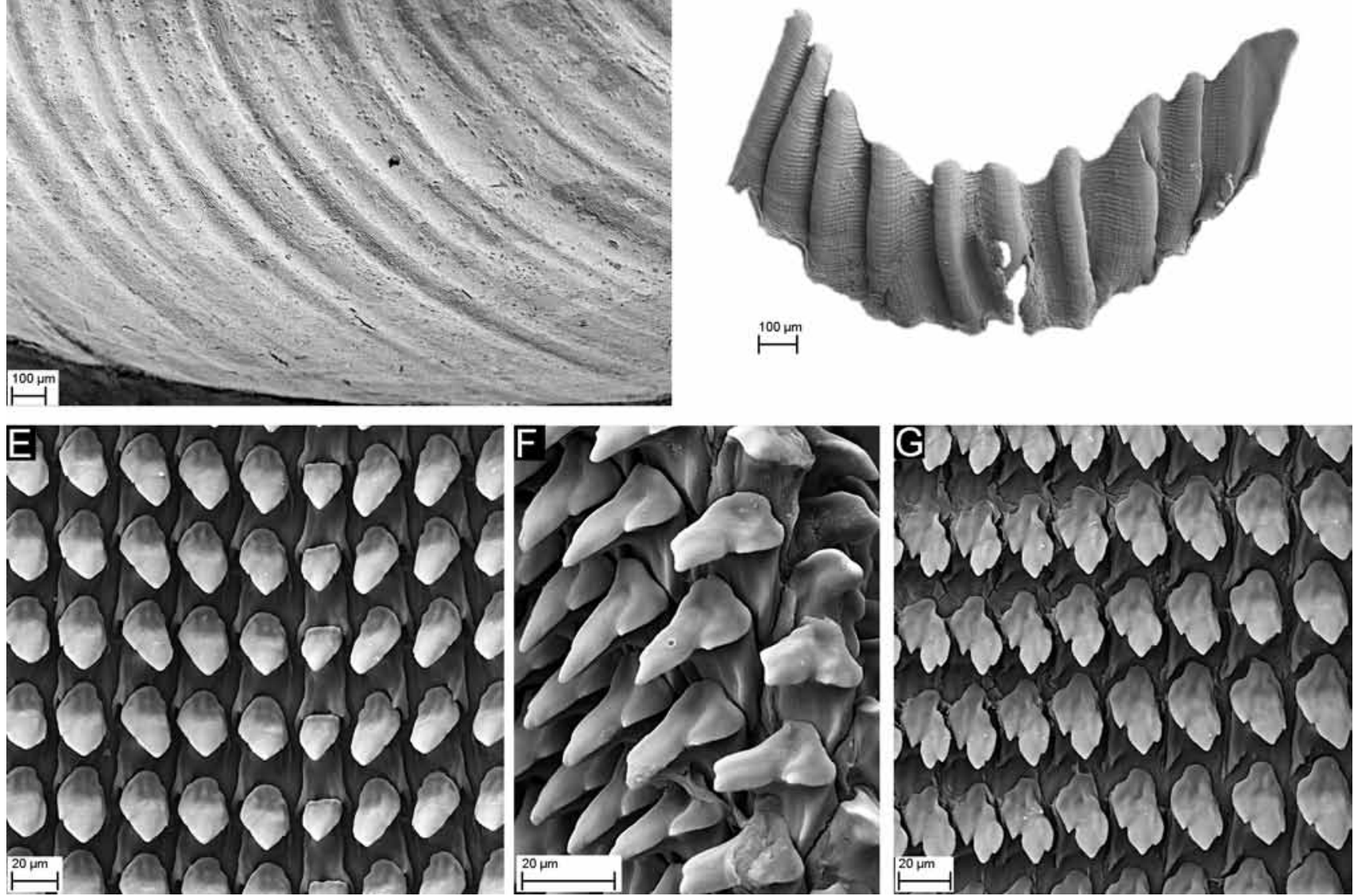

Figure 41. SEM photographs of Amplirhagada berthierana n.sp., paratype AMS C463754. (A-C) Shell: $(A)$ apical whorl viewed from above (scale $200 \mu \mathrm{m}) ;(B)$ sculpture on second to forth whorl viewed from above (scale $200 \mu \mathrm{m}) ;(C)$ sculpture on upper part of last whorl (scale $200 \mu \mathrm{m})$. (D) Jaw (scale $100 \mu \mathrm{m})$. $(E-G)$ Radula: $(E)$ central and lateral teeth (scale $20 \mu \mathrm{m}) ;(F)$ close-up of lateral teeth (scale 20 $\mu \mathrm{m}) ;(G)$ outer lateral and inner marginal teeth (scale $20 \mu \mathrm{m}$ ).

\section{Amplirhagada lamarckiana n.sp.}

Type locality (Fig. 1). Western Australia, Kimberley, Bonaparte Archipelago, York Sound, Lamarck Island, $14^{\circ} 46^{\prime} 50^{\prime \prime S ~} 125^{\circ} 1$ '23"E; KC-042 (leg. V. Kessner \& A. Longbottom, 14 July 1988).

Type material. Holotype WAM S34612 (Pl. 1.18). Paratypes AMS C463755 (5 preserved specimens), FMNH 219163 (15 preserved specimens), WAM S41485 (8 preserved specimens).
Etymology. In reference to Lamarck Island, where this species occurs.

Shell (Fig. 42A-C, Pl. 1.18). Semi-globose to broadly conical, with medium high spire; thin (translucent). Periphery evenly rounded to slightly angulate; upper sector of whorls rather flattened, basal sector rounded. Umbilicus forming a chink, 90-100 percent concealed by columellar reflection. Background colour light brownish horn, banded. Sub-sutural and mid-whorl bands diffuse to well defined, light brown, 

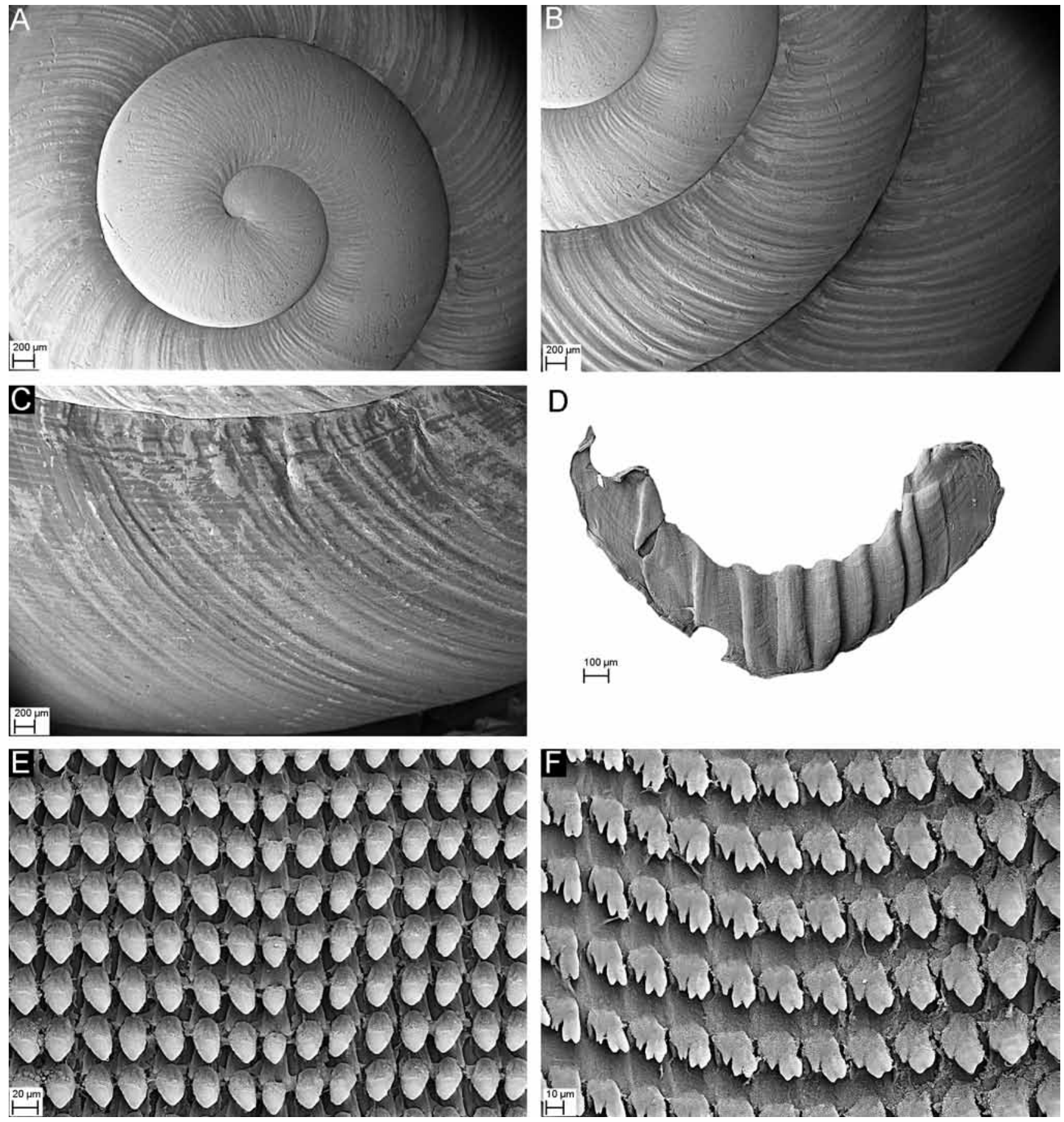

Figure 42. SEM photographs of Amplirhagada lamarckiana n.sp., holotype WAM S34612. $(A-C)$ Shell: $(A)$ apical whorl viewed from above (scale $200 \mu \mathrm{m}) ;(B)$ sculpture on second to forth whorl viewed from above (scale $200 \mu \mathrm{m}) ;(C)$ sculpture on upper part of last whorl (scale $200 \mu \mathrm{m})$. $(D)$ Jaw (scale $100 \mu \mathrm{m})$. $(E-F)$ Radula: $(E)$ central and lateral teeth (scale $20 \mu \mathrm{m}) ;(F)$ middle marginal teeth (scale $10 \mu \mathrm{m})$.

thin, visible on last whorl(s) only; ventral colour horn; outer lip colour same as shell; inner lip translucent. Protoconch c. $3 \mathrm{~mm}$ in diameter, comprising 1.7 whorls, with fine and indistinct lirae. Teleoconch with rather strong axial growth lines. Angle of aperture $45^{\circ}$; outer lip rounded, sharp to moderately thick, slightly expanded, reflected, basal node of lip absent or weak; palatal node absent. Parietal wall of inner lip absent or inconspicuous.

Pallial morphology. Pallial cavity deep, extending $3 / 4$ whorl. Pigmentation on mantle mottled, black. Kidney extending more than half of pallial cavity.
Genital morphology (Figs. 43-44). Penis straight to curved, of about same length as anterior part of oviduct. Vas deferens coils before entering penis. Penial retractor muscle shorter than penis. Penial sheath delicate. Penial verge tiny (barely visible), slender to spatulate, with pointed tip. Penial wall small, arranged in rows over entire length of inner penial wall. Main stimulatory pilaster elongated, sculptured by horizontal ridges that support little hooks, comprising apical to median portion of penial chamber. Two to three additional pilasters are covered by undifferentiated pustules. Vas deferens entering penial sheath half way up. Vagina moderate, posteriorly inflated; inner vaginal wall with 


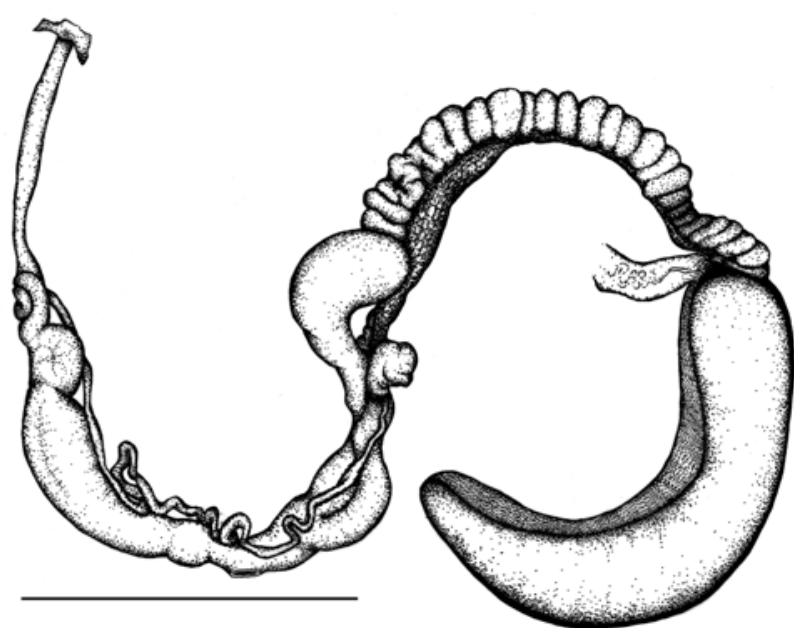

Figure 43. Genitalia of Amplirhagada lamarckiana n.sp., holotype WAM S34612 (14 July, scale 10 mm). Compare with Fig. 3 for labelling of structures.

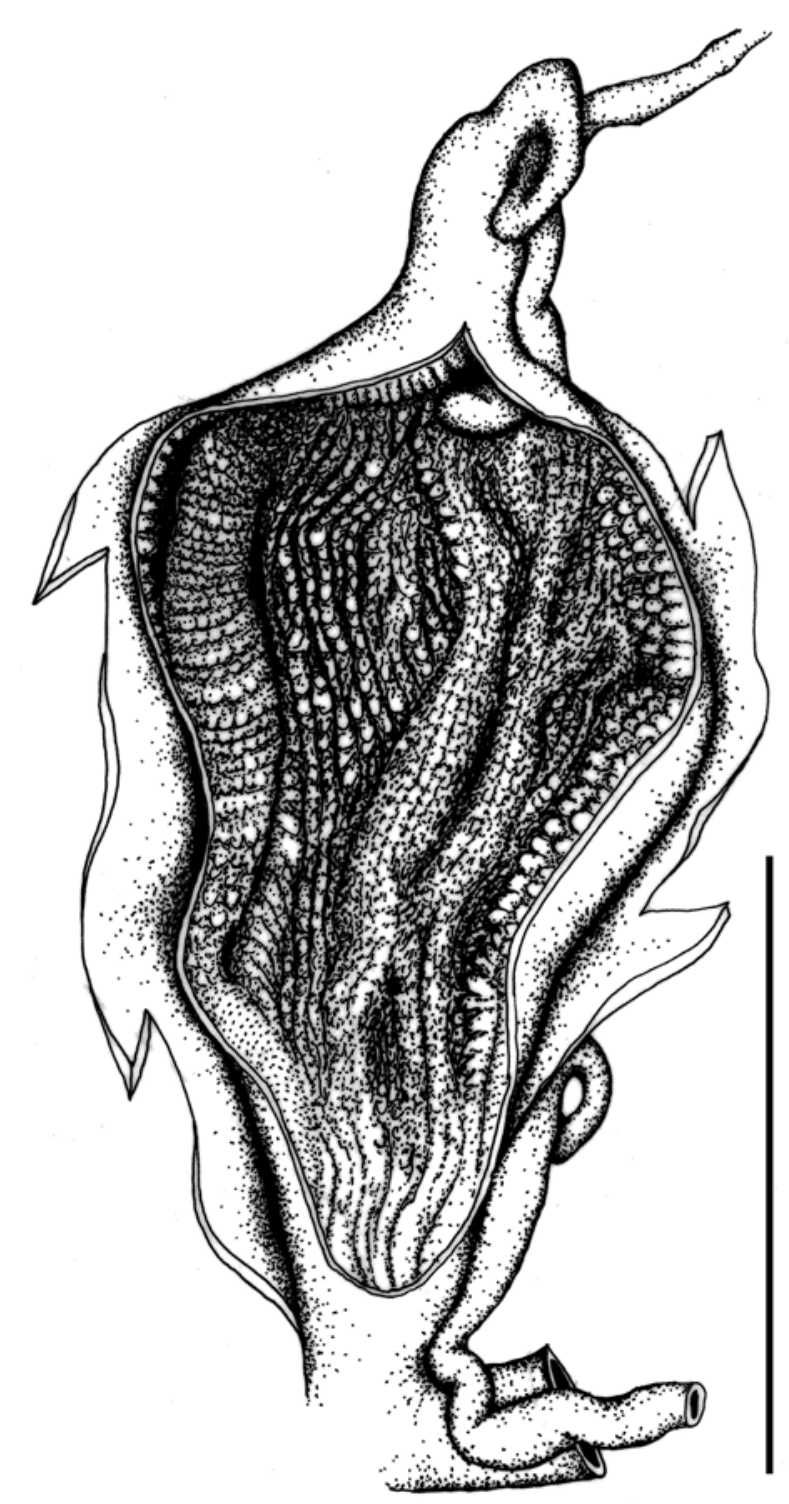

Figure 44. Interior of penial chamber of Amplirhagada lamarckiana n.sp., paratype FMNH 219163 (14 July, scale $5 \mathrm{~mm}$ ). Compare with Fig. 4 for labelling of structures. smooth longitudinal pilasters. Spermathecal duct moderately thick, internally with smooth longitudinal pilasters. Spermathecal head globular, connected with oviduct by connective tissue, internally smooth, with delicate wall. Free oviduct comprises more or less half of anterior part of oviduct, straight. Spermoviduct longer than anterior part of oviduct. Talon embedded in albumen gland at junction with spermoviduct.

Radular morphology (Fig. 42E-F). Rectangular. Tooth formula $\mathrm{C}+14+4+18$. With 157 rows of teeth, 27.9 rows per $\mathrm{mm}(\mathrm{n}=1)$. Central teeth with bluntly pointed, triangular to ovate mesocones, shorter than base of tooth; ectocones vestigial. Lateral teeth with sharply pointed, triangular mesocones, length equal to base of tooth; ectocones and endocones vestigial. Marginal teeth with triangular mesocones; ectocones shorter and narrower than mesocones, occasionally divided into two denticles, endocones reduced in size.

Comparative remarks. Pustulation of inner penial wall somewhat similar to A. indistincta and A. solemiana, which lack a well-differentiated main pilaster and differ by more conical shape of shell. Main pilaster differs in shape and surface pattern from the two species from Bigge Island. Material of the present species has been labelled as "Amplirhagada sp. 68" by Solem.

\section{Amplirhagada anderdonensis n.sp.}

Type locality (Fig. 1). Western Australia, Kimberley, Bonaparte Archipelago, Prince Frederick Harbour, Anderdon Islands, unnamed island c. $8 \mathrm{~km}$ ENE of Cape Torrens,

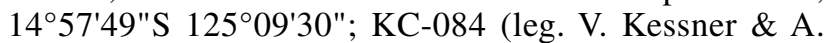
Longbottom, 22 July 1988).

Type material. Holotype WAM S34613 (Pl. 1.19). AMS C463756 (5 preserved specimens), FMNH 219330 (16 preserved specimens), WAM S41492 (10 preserved specimens).

Etymology. In reference to Anderdon Islands, where this species occurs.

Sealing strategy. Rock sealer.

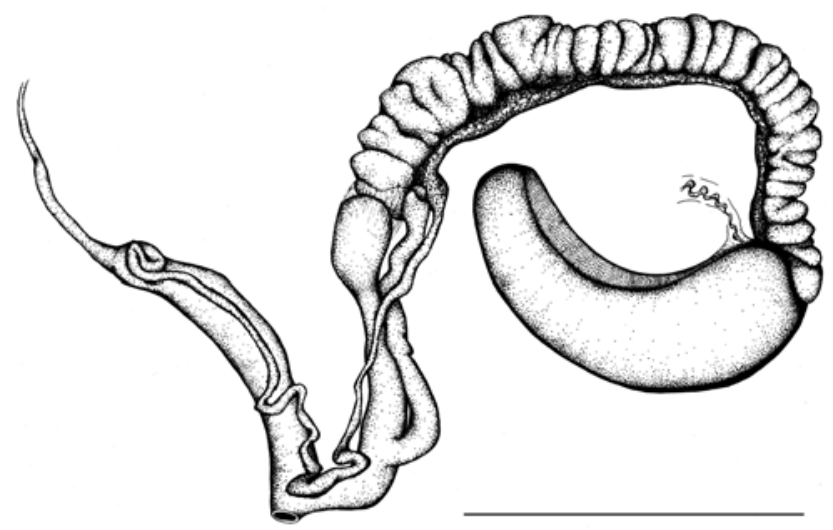

Figure 45. Genitalia of Amplirhagada anderdonensis n.sp., paratype FMNH 219330 (22 July, scale $10 \mathrm{~mm}$ ). Compare with Fig. 3 for labelling of structures. 

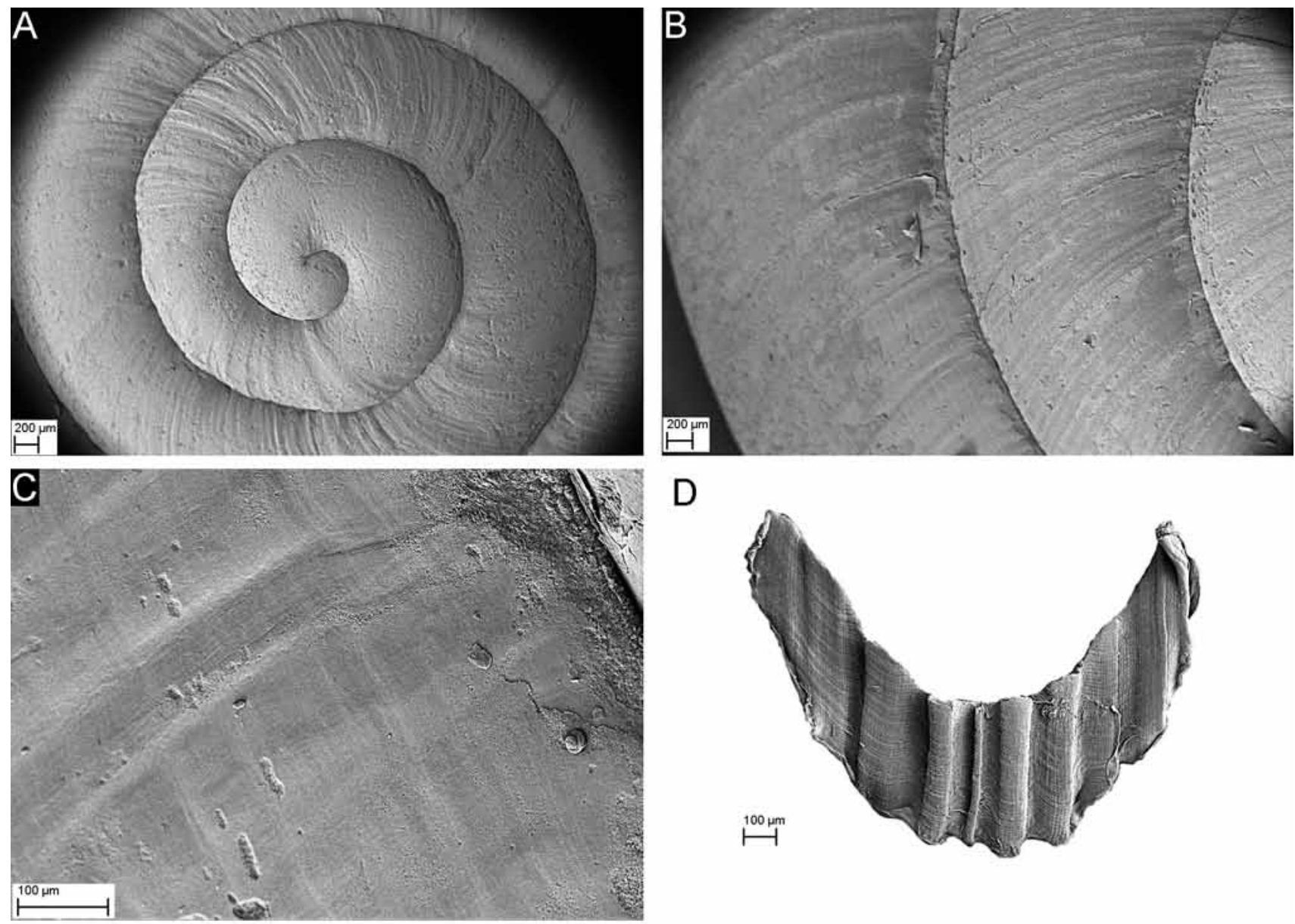

D
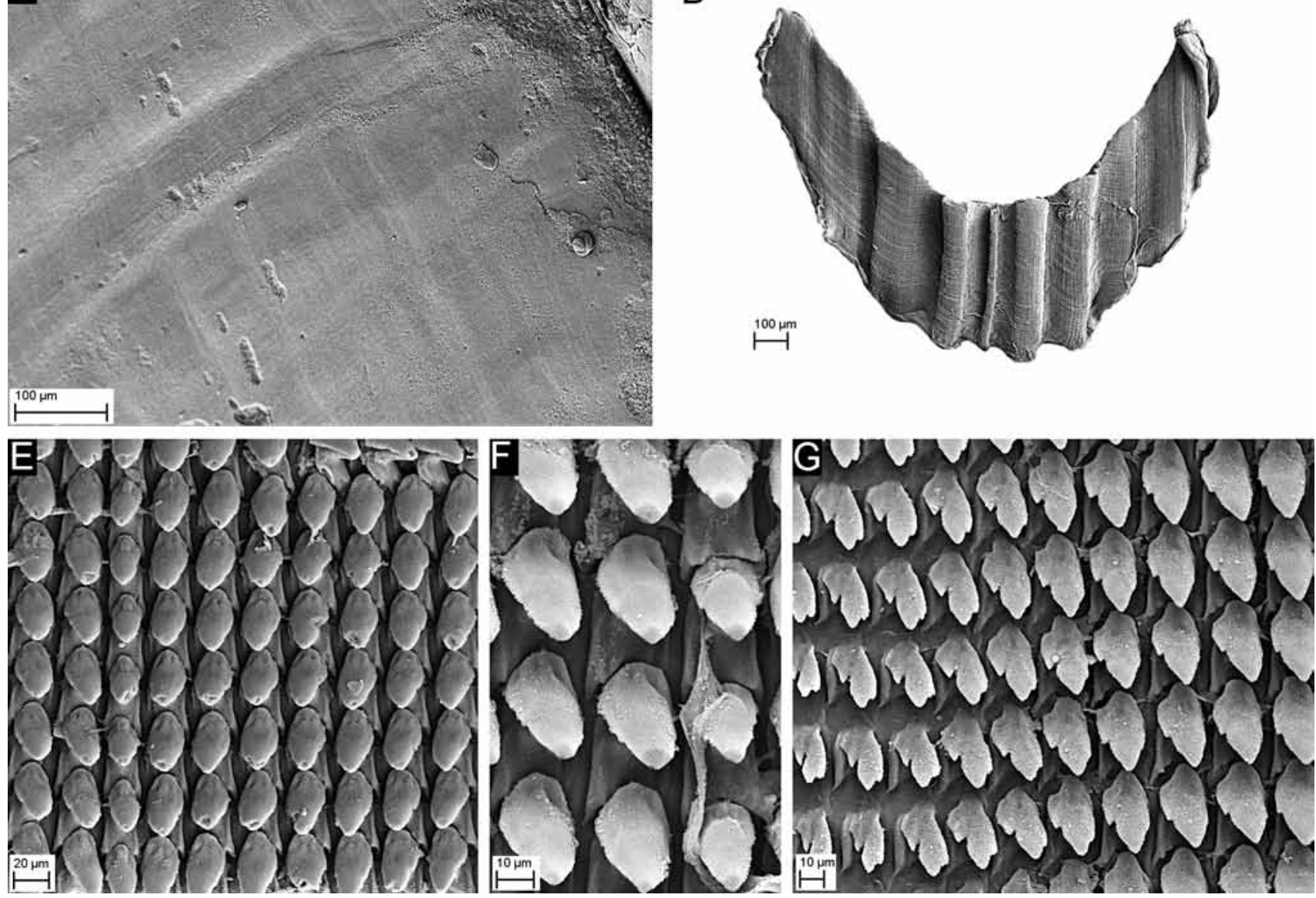

Figure 46. SEM photographs of Amplirhagada anderdonensis n.sp. (A-C) Shell, paratype AMS C463756: $(A)$ apical whorl viewed from above (scale $200 \mu \mathrm{m}) ;(B)$ sculpture on second and third whorl viewed from above (scale $200 \mu \mathrm{m}) ;(C)$ sculpture on upper part of last whorl (scale $100 \mu \mathrm{m})$. (D) Jaw (scale $100 \mu \mathrm{m})$. $(E-G)$ Radula, paratype FMNH 219330: $(E)$ central and lateral teeth $(\mathrm{scale} 20 \mu \mathrm{m}) ;(F)$ close-up of lateral teeth (scale $10 \mu \mathrm{m}) ;(G)$ outer lateral and inner marginal teeth (scale $10 \mu \mathrm{m}$ ).

Shell (Fig. 46A-C, Pl. 1.19). Broadly conical with medium high spire, solid. Periphery evenly rounded to slightly angulate; upper and basal sectors of whorls rounded. Umbilicus forming a chink, 90-100 percent concealed by columellar reflection. Background colour greenish ochre to yellowish brown; sub-sutural and mid-whorl band absent or diffuse, darker than background, thin, most conspicuous on last whorl; ventral colour cream; outer lip colour same as shell; inner lip translucent, whitish. Protoconch c. $2 \mathrm{~mm}$ in diameter, comprising 1.7 whorls, almost smooth. Teleoconch with inconspicuous axial growth lines, last whorl smooth.
Angle of aperture $30^{\circ}$; outer lip rounded, moderate to thick, slightly expanded, slightly reflected; basal node of lip absent or weak; palatal node absent. Parietal wall of inner lip inconspicuous.

Pallial morphology. Pallial cavity deep, extending one whorl. Pigmentation on mantle consists of sparse greyish to brown spots. Kidney extending about half of pallial cavity.

Genital morphology (Figs. 45, 47). Penis straight to slightly curved, more or less of same length as anterior part 


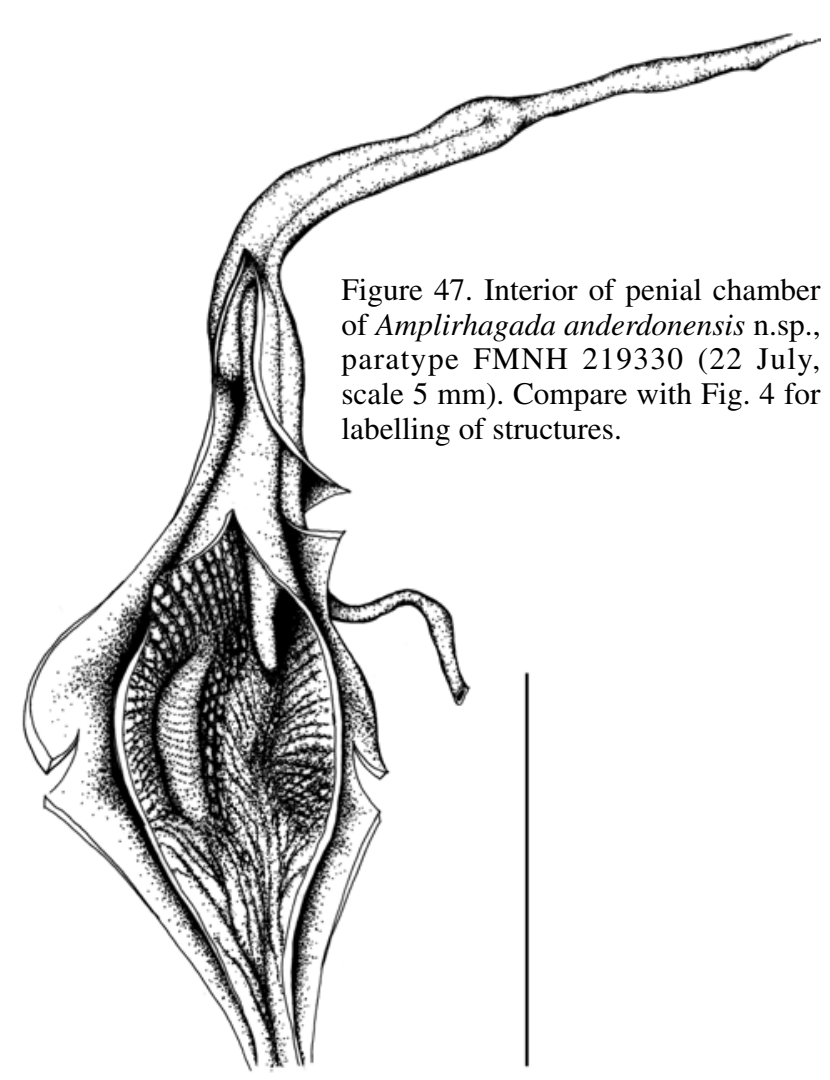

of oviduct. Vas deferens coils once before entering penis. Penial retractor muscle shorter than penis. Penial verge moderately long ( $1 / 8-1 / 4$ penial chamber), slender to spatulate, with pointed tip. Penial wall pustules small, arranged in rows. Main stimulatory pilaster differentiated, relatively thin, cone-shaped, with horizontal ridged that support little hooks, comprising apical to median portion of penial chamber. Vas deferens entering penial sheath in upper third. Vagina moderately long, tubular, posteriorly inflated; inner vaginal wall with smooth longitudinal pilasters. Spermatheca very short, barely reaching base of spermoviduct. Spermathecal duct normal, internally with smooth longitudinal pilasters. Spermathecal head globular, connected with oviduct by connective tissue, internally smooth, with delicate wall. Free oviduct comprising more than half of anterior part of oviduct, more or less straight. Spermoviduct longer than anterior part of oviduct. Talon embedded in albumen gland at junction with spermoviduct.

Radular morphology (Fig. 46E-G). Rectangular. Tooth formula $\mathrm{C}+14-15+2+20-23$. In average with $145 \pm 12.0$ rows of teeth, $31.6 \pm 4.2$ rows per $\mathrm{mm}(\mathrm{n}=2)$. Central teeth with bluntly pointed, ovate mesocones, shorter than base of tooth; ectocones vestigial. Lateral teeth with bluntly pointed, ovate mesocones, length equal to base of tooth; ectocones small, endocones vestigial. Marginal teeth with triangular to rounded mesocones; ectocones shorter and narrower than mesocones; endocones reduced in size.

Comparative remarks. Shell colour very distinctive, similar only to A. tricenaria (see below). Penis proportionally smaller than in other species. In addition, it differs from $A$. lamarckiana by finer pustulation of inner penial wall and smaller main pilaster. Material of the present species has been labelled as "Amplirhagada sp. 75" by Solem.

\section{Amplirhagada tricenaria n.sp.}

Type locality (Fig. 1). Western Australia, Kimberley, Bonaparte Archipelago, Prince Frederick Harbour, north of Hunter River mouth, 1501'54"S 125²3'13"E; KC-080 (leg. V. Kessner \& A. Longbottom, 22 July 1988).

Type material. Holotype WAM S34614 (Pl. 1.20). Paratypes AMS C463757 (2 preserved specimens), FMNH 219322 (6 preserved specimens), WAM S41476 (4 preserved specimens).

Etymology. From tricenaria $($ Latin $=$ thirty), in reference to manuscript name assigned to this species by Solem (“Amplirhagada n.sp. 30").

Shell (Fig. 49A-D, Pl. 1.20). Semi-globose, with medium high spire; thin to solid (translucent). Periphery slightly angulate; upper and basal sectors of whorls rounded. Umbilicus forming a chink, 90-100 percent concealed by columellar reflection. Background colour dark horn to ochre; sub-sutural and mid-whorl bands diffuse to well defined, yellowish brown, thin to moderately broad, most conspicuous on last whorls; ventral colour horn; outer lip colour same as shell; inner lip yellowish white. Protoconch c. $2.6 \mathrm{~mm}$ in diameter, comprising 2 whorls, almost smooth. Teleoconch with pronounced axial growth lines, last whorl almost smooth. Angle of aperture $30^{\circ}$, outer lip rounded, sharp to moderately thick, slightly expanded, slightly reflected, basal

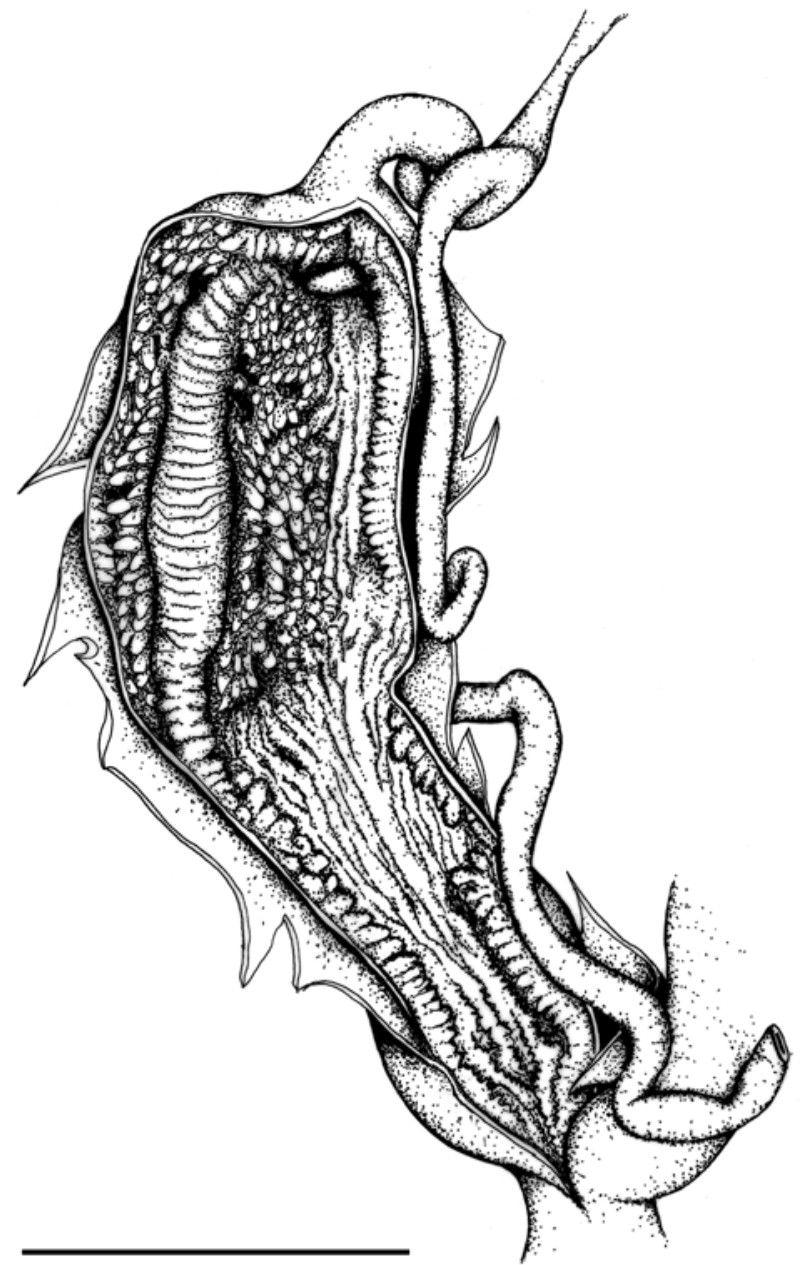

Figure 48. Interior of penial chamber of Amplirhagada tricenaria n.sp., paratype FMNH 219332 (22 July, scale 5 mm). Compare with Fig. 4 for labelling of structures. 

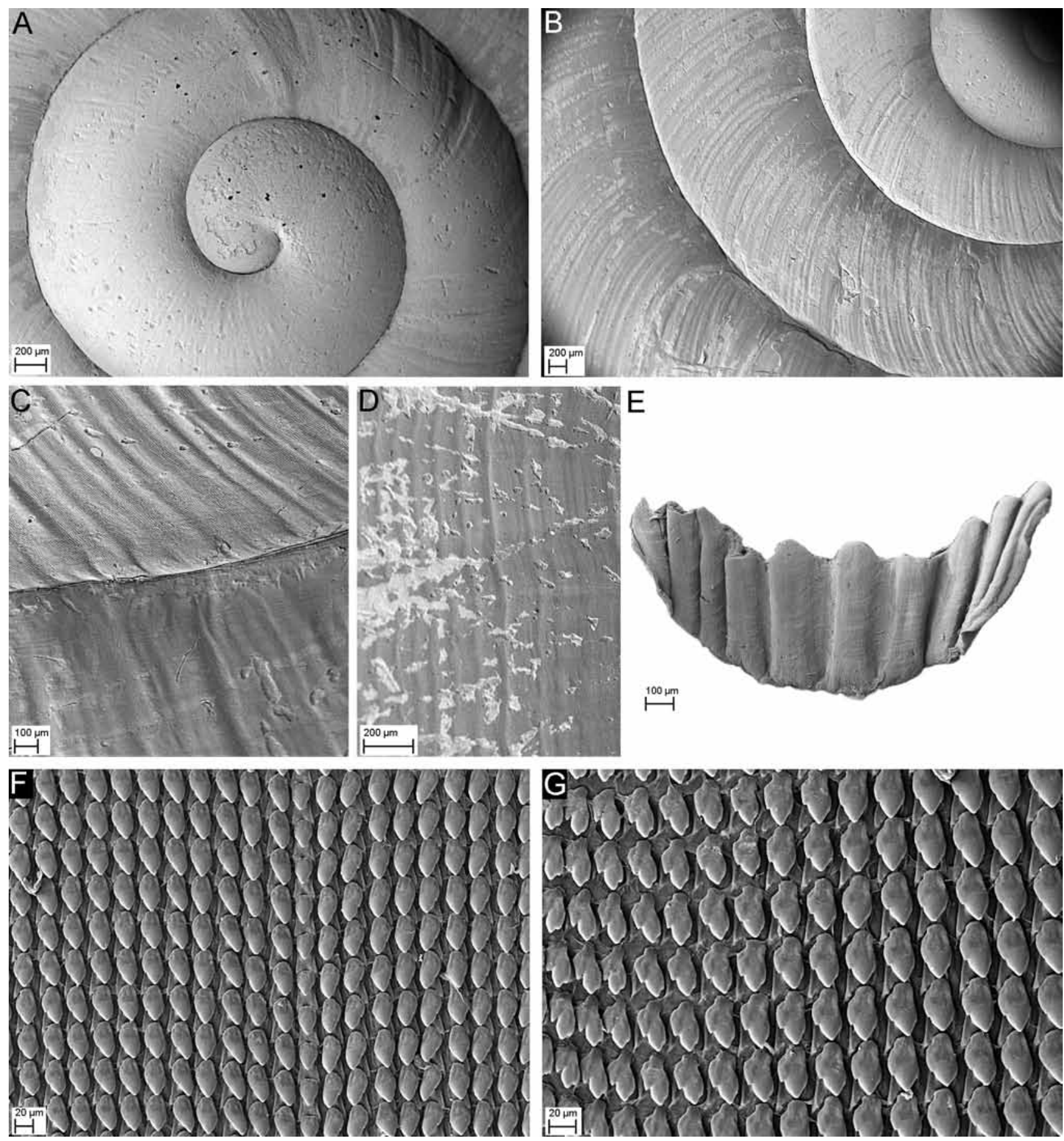

Figure 49. SEM photographs of Amplirhagada tricenaria n.sp. (A-D) Shell, paratype AMS C463757: $(A)$ apical whorl viewed from above (scale $200 \mu \mathrm{m}) ;(B)$ sculpture on second to third whorl viewed from above (scale $200 \mu \mathrm{m}$ ); $(C)$ suture between last and penultimate whorl with details of sculpture (scale $100 \mu \mathrm{m}) ;(D)$ surface of last whorl, viewed rectangularly from above (Scale $200 \mu \mathrm{m})$. (E) Jaw, paratype FMNH 219322 (scale $100 \mu \mathrm{m})$. $(F-G)$ Radula, paratype FMNH 219332: $(F)$ central and lateral teeth (scale $20 \mu \mathrm{m}) ;(G)$ outer lateral and inner marginal teeth (scale $20 \mu \mathrm{m})$.

node of lip absent or weak, palatal node absent. Parietal wall of inner lip inconspicuous.

Pallial morphology. Pallial cavity deep, extending one whorl. Pigmentation on mantle mottled, greyish or brownish (probably leached in actual specimens). Kidney extending about half of pallial cavity.

Genital morphology (Figs. 48, 50). Penis straight, more or less of same length as anterior part of oviduct. Vas deferens forms simple loop before entering penis. Penial retractor muscle shorter than penis. Penial verge very short (barely visible), slender to spatulate with pointed tip. Penial wall pustules small, elongated, arranged in rows on apical to median portion of penial chamber. Base of inner penial walls with many smooth longitudinal pilasters. Main stimulatory pilaster well-differentiated, elongate to cone-shaped, sculptured by smooth ridges, comprising apical to median portion of penial chamber. Vas deferens entering penial sheath in upper third. Vagina of medium length and thickness, tubular, posteriorly slightly inflated. Inner vaginal wall with 


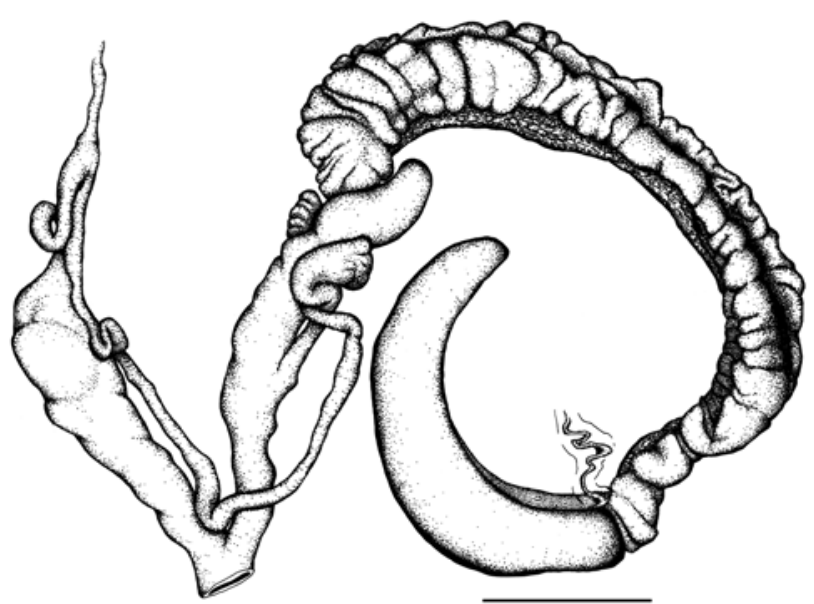

Figure 50. Genitalia of Amplirhagada tricenaria n.sp., paratype AMS C463757 (22 July, scale $10 \mathrm{~mm}$ ). Compare with Fig. 3 for labelling of structures.

smooth longitudinal pilasters. Spermathecal duct moderately thick, internally with smooth longitudinal pilasters. Spermathecal head globular to elongately inflated, connected with oviduct by connective tissue, internally smooth, with thin wall. Free oviduct comprising less than half of anterior part of oviduct, more or less straight. Spermoviduct longer than anterior part of oviduct. Talon embedded in albumen gland at junction with spermoviduct.

Radular morphology (Fig. 49F-G). Rectangular. Tooth formula $C+15-17+3+18-23$. In average with $152 \pm 3.0$ rows of teeth, $28.1 \pm 0.8$ rows per $\mathrm{mm}(\mathrm{n}=2)$. Central teeth with sharply pointed, ovate mesocones, shorter than base of tooth; ectocones vestigial. Lateral teeth with bluntly pointed, ovate mesocones, length equal to base of tooth; ectocones small, endocones vestigial. Marginal teeth with triangular mesocones; ectocones shorter and narrower than mesocones; endocones reduced in size.

Comparative remarks. This species has a very distinctive colour, similar only to A. anderdonensis, which differs by smaller shell size, less globose shell shape, higher position of peripheral angulation. Rather flattened diameter of whorls and very broadly conical shape of shell are diagnostic. Material of the present species has been labelled as “Amplirhagada sp. 30” by Solem.

\section{Amplirhagada regia n.sp.}

Type locality (Fig. 1). Western Australia, Kimberley, Bonaparte Archipelago, central section of Boongaree Island, $15^{\circ} 04^{\prime} 15^{\prime \prime S} 125^{\circ} 11^{\prime} 14^{\prime \prime E}$; KIS 1-30. Dry vine thicket on west facing sandstone scree below escarpment, under rocks (leg. M. Shea, 9.8.2007).

Type material. Holotype WAM S34615 (Pl. 1.21). Paratypes AMS C463705 (4 preserved specimens, as holotype), WAM S36647 (3 preserved specimens, as holotype), WAM S36449 (6 preserved specimens, $15^{\circ} 04^{\prime} 00^{\prime \prime S}$ $125^{\circ} 11^{\prime} 11^{\prime \prime E}$ ), AMS C463704 (6 shells, $15^{\circ} 04^{\prime} 31^{\prime \prime S} 125^{\circ} 11^{\prime} 07^{\prime \prime E}$ ), WAM S36480 (12 shells, $\left.15^{\circ} 04^{\prime} 31^{\prime \prime S} 125^{\circ} 11^{\prime} 07^{\prime \prime E}\right)$.

Additional, non-type material. WAM S36479, WAM S36481-5, WAM S36648 (Boongaree Island).

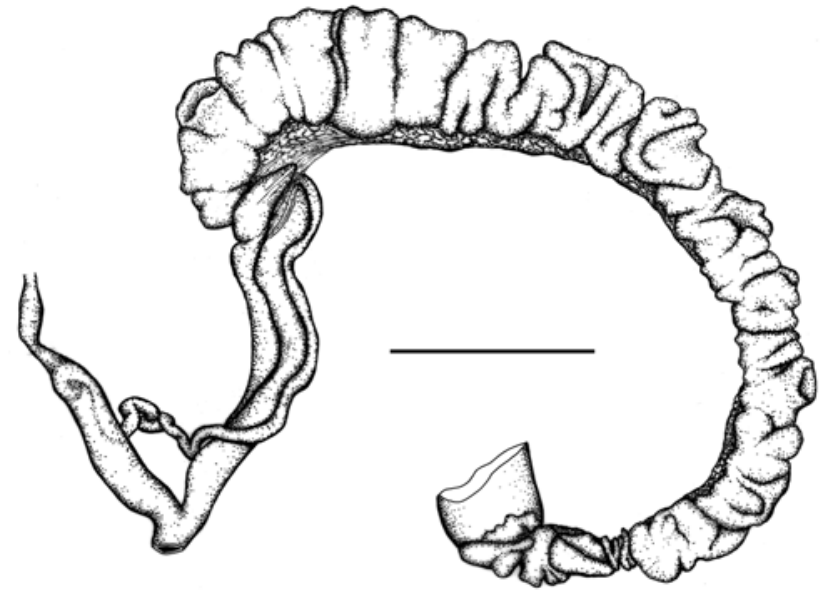

Figure 51. Genitalia of Amplirhagada regia n.sp., paratype WAM S36647 (9 August; scale 10 mm). Compare with Fig. 3 for labelling of structures.

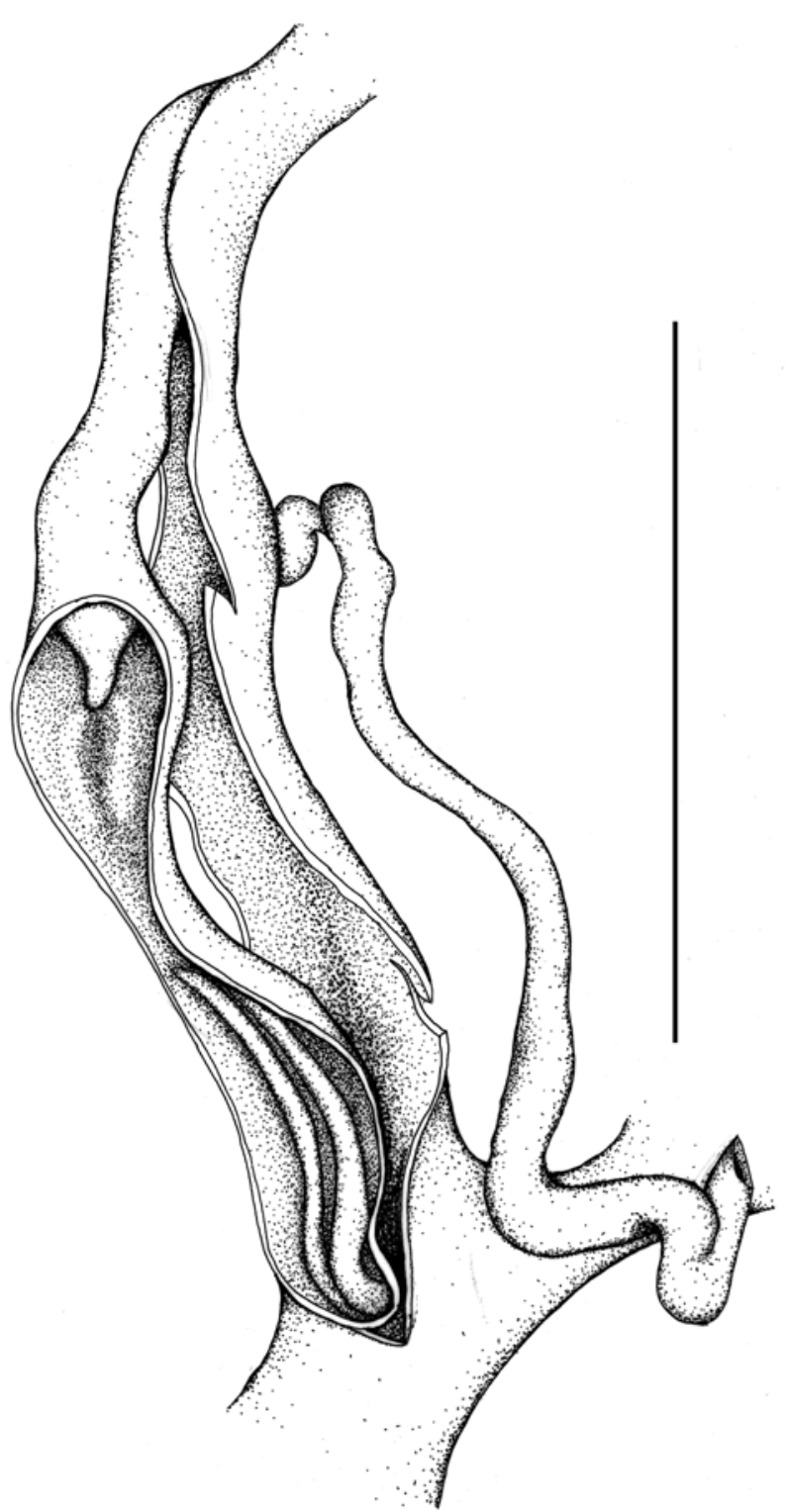

Figure 52. Interior of penial chamber of Amplirhagada regia n.sp., paratype WAM S36647 (9 August; scale $5 \mathrm{~mm}$ ). Compare with Fig. 4 for labelling of structures. 

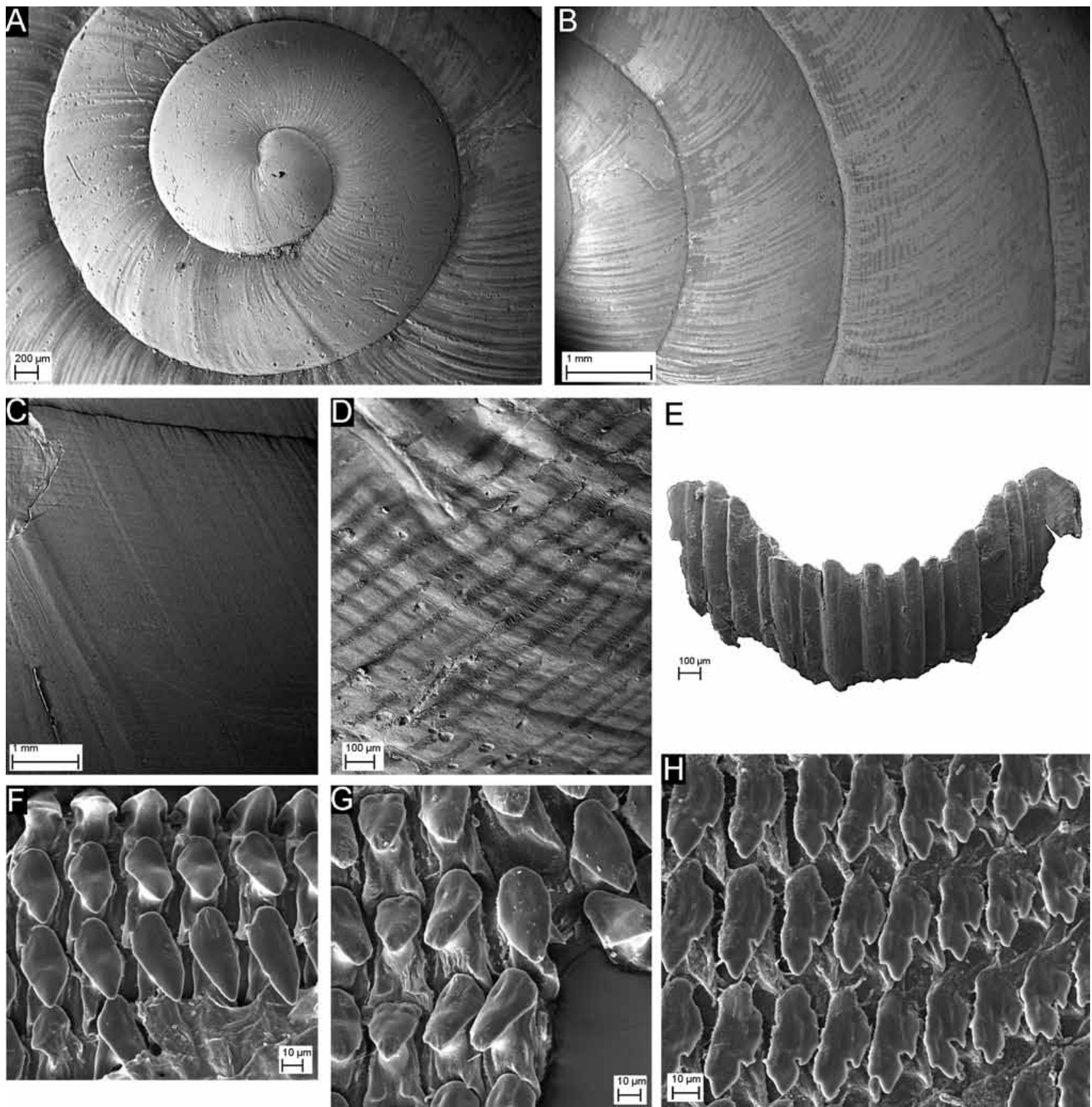

Figure 53. SEM photographs of Amplirhagada regia n.sp. $(A-D)$ Shell, paratype AMS C463704: $(A)$ apical whorl viewed from above (scale $200 \mu \mathrm{m}) ;(B)$ sculpture on second to forth whorl viewed from above (scale $1 \mathrm{~mm}$ ); $(C)$ surface of last whorl (scale $1 \mathrm{~mm}$ ); $(D)$ close-up showing axial growth lines on last whorl (Scale $100 \mu \mathrm{m})$. (E) Jaw, paratype WAM S36647 (scale $100 \mu \mathrm{m})$. (E-G) Radula, paratype WAM S36647: $(E)$ close-up of lateral teeth (scale $10 \mu \mathrm{m}) ;(F)$ close-up of central and inner lateral teeth (scale $10 \mu \mathrm{m}) ;(G)$ close-up of middle marginal teeth (scale $10 \mu \mathrm{m})$.

Etymology. From regia $($ Latin $=$ royal $)$, referring to fact that this species is among the largest of the genus.

\section{Sealing strategy. Free sealer.}

Shell (Fig. 53A-D, Pl. 1.21). Globose with medium high to high spire; solid to thick. Periphery angulated; upper sector of whorls rather flattened, basal sector rounded. Umbilicus forming chink or narrowly winding opening, 60-100 percent concealed by columellar reflection. Background colour uniform, creamish horn; outer lip purple; inner lip pale purple. Protoconch c. $2.2 \mathrm{~mm}$ in diameter, comprising 1.5 whorls, sculpture almost smooth. Teleoconch smooth except for faint axial growth lines. Angle of aperture 45; outer lip simple rounded; moderate; slightly expanded; not reflected, or slightly reflected; basal node of lip present; weak; palatal node absent. Parietal wall of inner lip inconspicuous.

Pallial morphology. Pallial cavity deep, extending one whorl. Pigmentation on mantle comprising brownish grey spots. Kidney extending about half of pallial cavity.

Genital morphology (Figs. 51-52). Penis straight, more or less of same length as anterior part of oviduct. Vas deferens 
forms simple loop before entering penis. Penial retractor muscle shorter than or equal to penis length. Penial sheath evenly thin. Penial verge short ( $<1 / 8$ penial chamber), slender to spatulate, with pointed tip. Penial wall pustules absent. Main stimulatory pilaster absent. Two longitudinal pilasters present at basal portion of penial chamber, two additional weakly developed pilasters visible at apical portion. Vas deferens entering penial sheath in upper third. Vagina short to moderately long, tubular. Inner vaginal wall with smooth longitudinal pilasters. Spermathecal duct moderately wide, internally with smooth longitudinal pilasters. Spermathecal head globular to elongately inflated, connected with oviduct by connective tissue, internally entirely smooth, with delicate wall. Free oviduct comprising about half of anterior part of oviduct, more or less straight. Spermoviduct of same length as anterior part of oviduct. Talon embedded in albumen gland close to anterior end of albumen gland.

Radular morphology (Fig. 53F-H). Rectangular. Tooth formula $\mathrm{C}+20+3+20$. In average with $147 \pm 2.5$ rows of teeth, 29.6 \pm 1.7 rows per $\mathrm{mm}(\mathrm{n}=2)$. Central teeth with sharply pointed, triangular mesocones, shorter than base of tooth; ectocones vestigial. Lateral teeth with sharply pointed, triangular mesocones, length equal to base of tooth; ectocones and endocones vestigial. Marginal teeth with elongate mesocones; ectocones shorter and narrower than mesocones; endocones greatly reduced in size.

Comparative remarks. Diagnostic features are the broadly conical to dome-shaped shell, smooth inner penial wall with lack of pustulation and main pilaster.

\section{Amplirhagada boongareensis n.sp.}

Type locality (Fig. 1). Western Australia, Kimberley, Bonaparte Archipelago, Boongaree Island, central section, $15^{\circ} 04^{\prime} 36^{\prime \prime S} 125^{\circ} 11^{\prime} 12^{\prime \prime E}$; KIS 1-28. Rainforest on north facing sandstone scree below escarpment, under rocks (leg. M. Shea, 8.8.2007).

Type material. Holotype WAM S34616 (Pl. 1.22). Paratypes WAM S36655

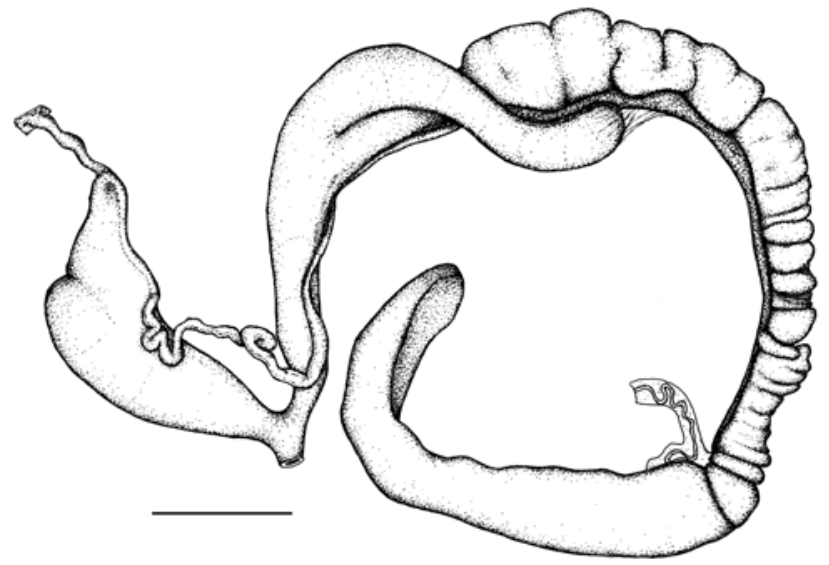

Figure 54. Genitalia of Amplirhagada boongareensis n.sp., paratype WAM S36655 (8 August, scale $10 \mathrm{~mm}$ ). Compare with Fig. 3 for labelling of structures.
( 3 preserved specimens, as holotype), AMS C463707 ( 8 shells, $15^{\circ} 04^{\prime} 31^{\prime \prime S}$ $\left.125^{\circ} 11^{\prime} 07^{\prime \prime E}\right)$, WAM S36455 (12 shells, $\left.15^{\circ} 04^{\prime} 31^{\prime \prime S ~} 125^{\circ} 11^{\prime} 07^{\prime \prime E}\right)$, WAM S36456 (15 shells, $\left.15^{\circ} 04^{\prime} 31^{\prime \prime S} 125^{\circ} 11^{\prime} 07^{\prime \prime E}\right)$, AMS C463706 (6 shells, $\left.15^{\circ} 04^{\prime} 16^{\prime \prime S} 125^{\circ} 10^{\prime} 47^{\prime \prime E}\right)$, WAM S36458 (8 shells, $15^{\circ} 04^{\prime} 16^{\prime \prime S}$ $125^{\circ} 10^{\prime} 47^{\prime \prime E}$ ), WAM S36656 (3 preserved specimens, $15^{\circ} 04^{\prime} 09^{\prime \prime} \mathrm{S}$ $\left.125^{\circ} 10^{\prime} 49^{\prime \prime} \mathrm{E}\right)$.

Additional, non-type material. WAM S36457, WAM S36459-60 (Boongaree Island).

Etymology. In reference to Boongaree Island, where this species occurs.

Shell (Fig. 56A-D, Pl. 1.22). Semi-globose, with rather high spire; solid. Periphery slightly to clearly angulate; upper sector slightly shouldered, basal sector rounded. Umbilicus forming chink or narrowly winding opening, 50-100 percent concealed by columellar reflection. Background colour light brown; sub-sutural and mid-whorl bands may be absent; if present, bands are diffuse to well marked, dark reddish brown, thin to moderately broad, most conspicuous on last whorl; bands may blend into each other and covering entire surface of tip of the shell with purplish brown colour; ventral colour horn; outer lip colour same as shell; inner lip colour blends from reddish brown near parietal wall of shell into horn in outer sections. Protoconch c. $2.3 \mathrm{~mm}$ in diameter, comprising 2 whorls, with fine, indistinct axial lirae. Teleoconch with fine axial lirae, rounded in cross-section, spacing regular, spaces equal to thickness of elements, evenly distributed across shell surface, reduced underneath suture. Angle of aperture $30^{\circ}$; outer lip rounded to slightly angulate, with moderate to thick parietal notch at lower margin, slightly expanded, not or slightly reflected, basal node of lip present, palatal node absent.

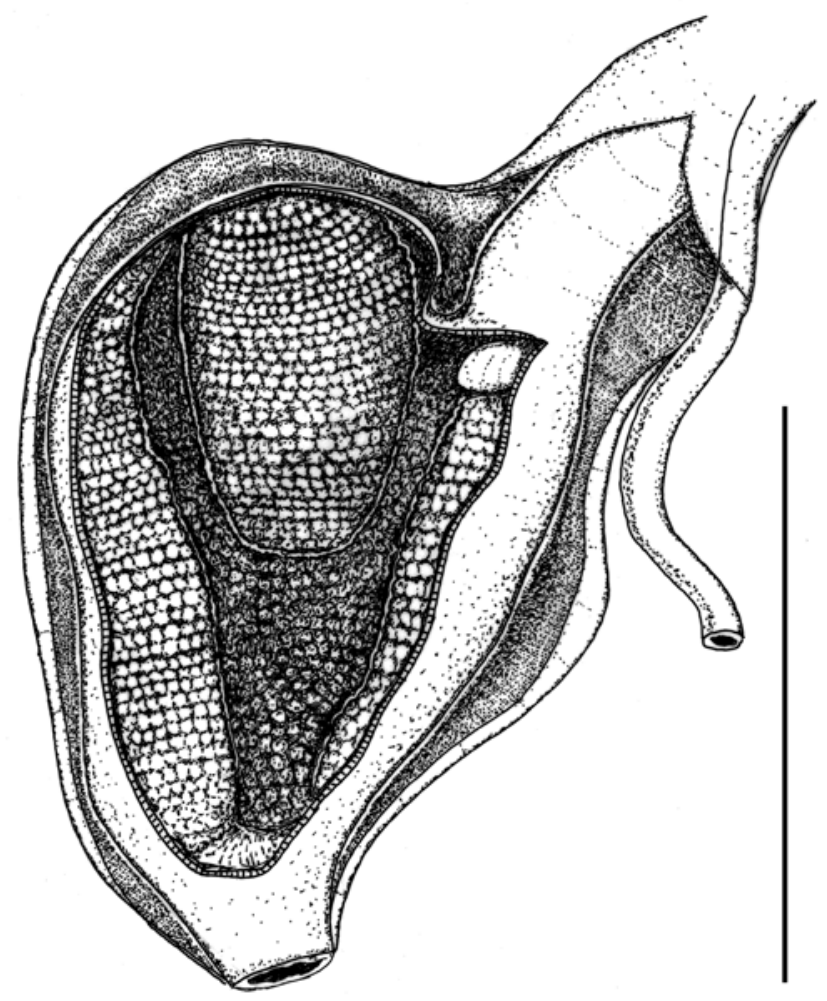

Figure 55. Interior of penial chamber of Amplirhagada boongareensis n.sp., paratype WAM S36655 (8 August, scale $5 \mathrm{~mm}$ ) (drawing by F.K.). Compare with Fig. 4 for labelling of structures. 

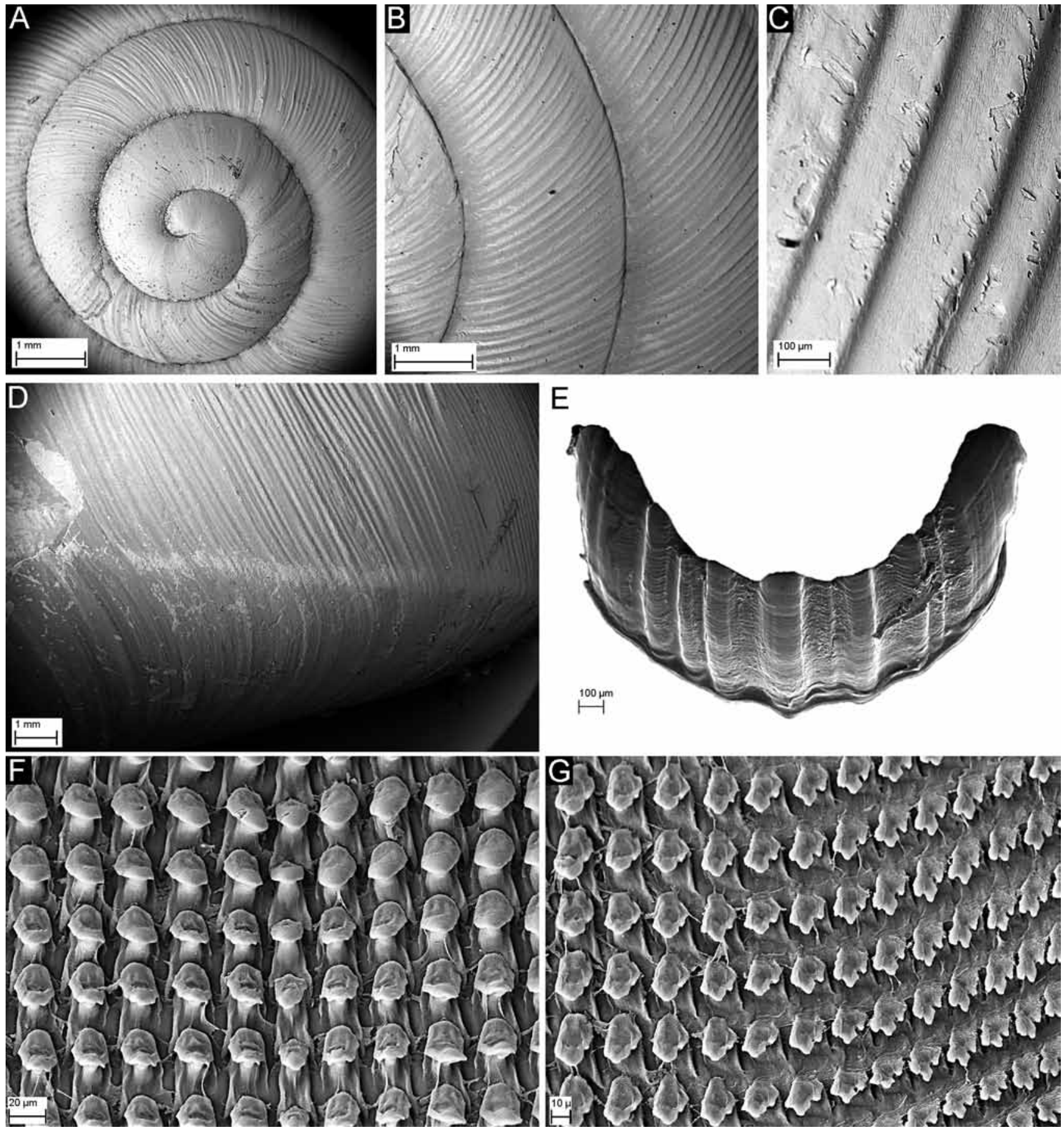

Figure 56. SEM photographs of Amplirhagada boongareensis n.sp. (A-D) Shell, paratype AMS C463706: (A) apical whorl viewed from above (scale $200 \mu \mathrm{m}) ;(B)$ sculpture on second and third whorl viewed from above (scale $1 \mathrm{~mm}$ ); $(C)$ close-up showing axial sculpture on last whorl (scale $100 \mu \mathrm{m}) ;(D)$ close-up showing axial periphery of last whorl (Scale $1 \mathrm{~mm}$ ). (E) Jaw, paratype WAM S36655 (scale 100 $\mu \mathrm{m})$. $(E-G)$ Radula, paratype WAM S36655: $(E)$ central and inner lateral teeth (scale $20 \mu \mathrm{m})$; $(F)$ outer lateral and inner marginal teeth (scale $10 \mu \mathrm{m}) ;(G)$ close-up of inner and middle marginal teeth (scale $10 \mu \mathrm{m}$ ).

Pallial morphology. Pallial cavity deep, extending one whorl; mantle pigmentation mottled, dark grey. Kidney extending about half of pallial cavity.

Genital morphology (Figs. 54-55). Penis straight to curved, more or less of same length as anterior part of oviduct. Vas deferens forms simple loop before entering penis. Penial retractor muscle shorter than penis. Penial verge very short (barely visible), spatulate, with pointed tip. Penial wall pustules of average size, dense, randomly arranged on entire length of inner penial wall. Main stimulatory pilaster well-differentiated; large, cone-shaped, covered by smooth, flattened pustules arranged in horizontal rows, comprising apical to median portion of penial chamber. Two additional pilasters comprise entire length of penial chamber, supporting undifferentiated pustulation. Vas deferens entering penial sheath in upper third. Vagina moderately wide, tubular; inner vaginal wall with smooth longitudinal pilasters. Spermathecal duct of medium width, internally with smooth longitudinal pilasters. Spermathecal head elongately inflated, 
connected with oviduct by connective tissue, internally entirely smooth, with delicate wall. Free oviduct comprising more than half of anterior part of oviduct, zig-zag-folded underneath entrance to spermoviduct. Spermoviduct longer than anterior part of oviduct. Talon embedded in albumen gland close to anterior end of albumen gland.

Radular morphology (Fig. 56F-G). Rectangular. Tooth formula $\mathrm{C}+16+3+20$. With 165 rows of teeth, 19.9 rows per $\mathrm{mm}(\mathrm{n}=1)$. Central teeth with sharply pointed, triangular mesocones, shorter than base of teeth; ectocones vestigial. Lateral teeth with sharply pointed, triangular to ovate mesocones; ectocones and endocones vestigial. Marginal teeth with triangular mesocones; ectocones smaller and narrower than mesocones; endocones smaller than ectocones.

Comparative remarks. His report that it also occurs on the opposite mainland requires confirmation. The bee-hive shape of the shell and its dark purplish brown colour are diagnostic. Amplirhagada regia from Boongaree Island also differs by absence of penial wall pustules or main pilaster. This species was referred to as "Amplirhagada sp. 27" by Solem (1991).

\section{Amplirhagada gibsoni n.sp.}

Type locality (Fig. 1). Western Australia, Kimberley, Bonaparte Archipelago, Boongaree Island, central section, $15^{\circ} 04^{\prime} 15^{\prime \prime S} 125^{\circ} 11^{\prime} 14^{\prime \prime} \mathrm{E}$; KIS 1-30. Dry vine thicket on west facing sandstone scree below escarpment, under rocks (leg. M. Shea, 09 August 2007).

Type material. Holotype WAM S34617 (Pl. 2.1). Paratypes AMS C463709 (1 preserved specimen, as holotype), WAM S36650 (2 preserved specimens, as holotype), WAM S36468 (6 shells, $15^{\circ} 04^{\prime} 15^{\prime \prime} \mathrm{S}$ $125^{\circ} 11^{\prime} 14^{\prime \prime E}$ ), AMS C463708 (4 shells, $15^{\circ} 04^{\prime} 36^{\prime \prime S ~} 125^{\circ} 11^{\prime} 18^{\prime \prime E}$ ), WAM S36469 (10 shells, $15^{\circ} 04^{\prime} 36^{\prime \prime S} 125^{\circ} 11^{\prime} 18^{\prime \prime E}$ ), WAM S36651 (1 preserved specimen, $\left.15^{\circ} 04^{\prime} 36^{\prime \prime} \mathrm{S} 125^{\circ} 11^{\prime} 18^{\prime \prime} \mathrm{E}\right)$.

Etymology. Named in honour of Lesley Gibson, Western Australian Department of Environment and Conservation, in recognition of her support for my work.

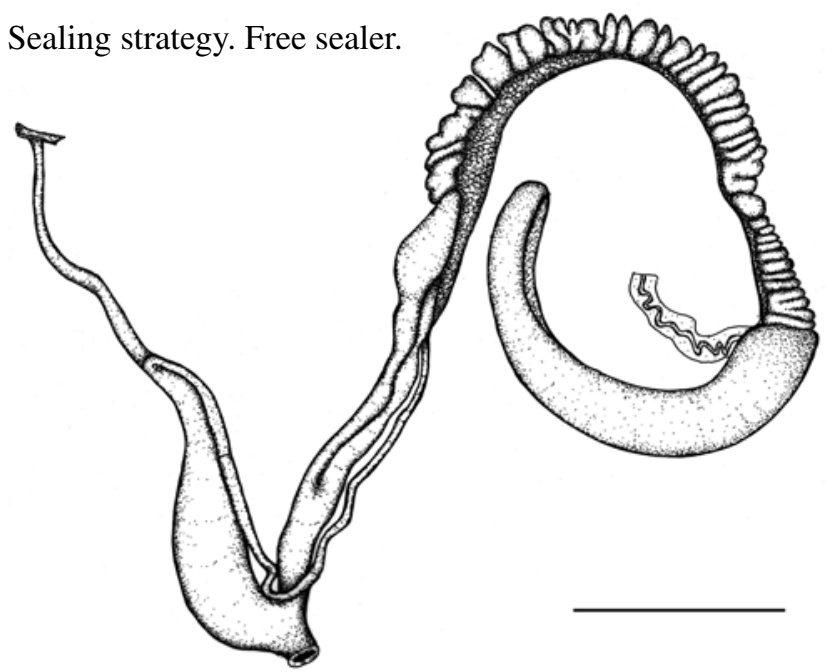

Figure 57. Genitalia of Amplirhagada gibsoni n.sp., paratype AMS C463709 (8 August, scale $10 \mathrm{~mm}$ ). Compare with Fig. 3 for labelling of structures.

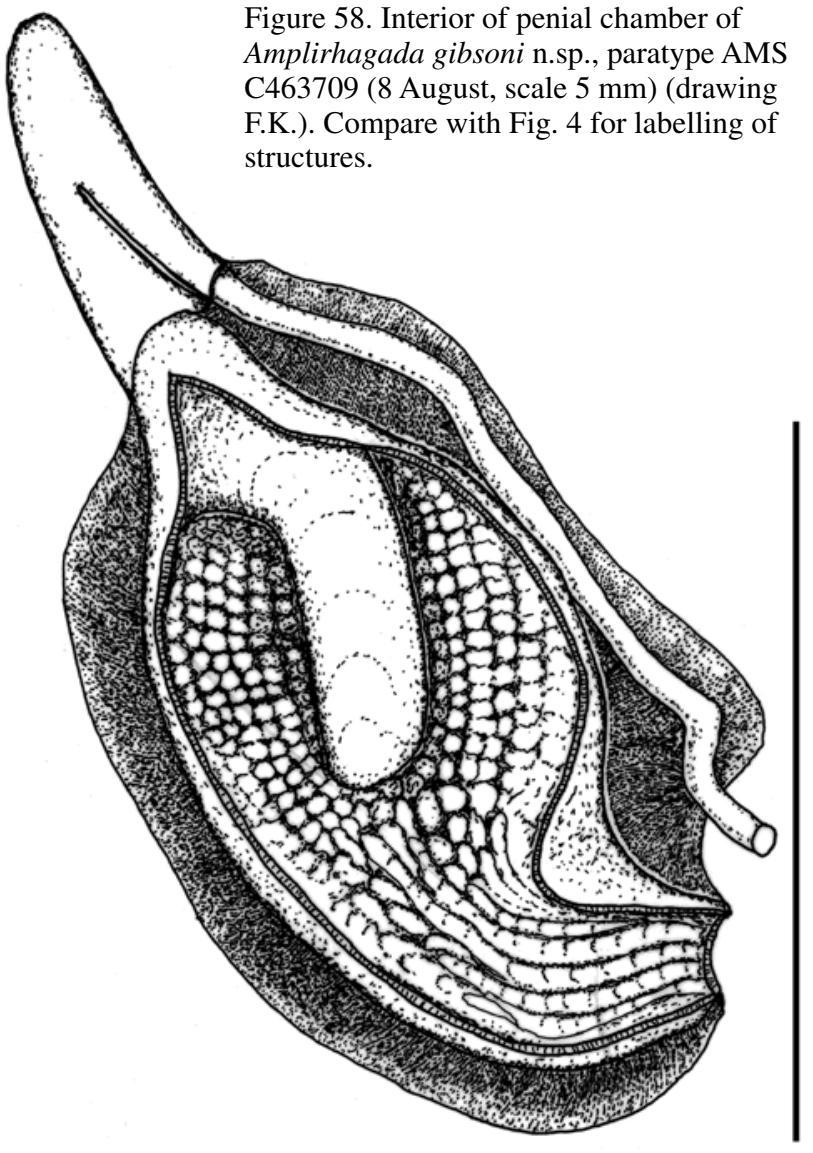

Shell (Fig. 59A-C, Pl. 2.1-2). Semi-globose to conical with medium high spire; thin (translucent) to solid. Periphery evenly rounded to slightly angulate; upper and basal sectors of whorls rounded. Umbilicus open, forming a narrowly winding chink, about 90 percent concealed by columellar reflection. Background colour light brownish to horn; uniform. Outer lip colour same as shell, inner lip colour white. Protoconch c. $2.2 \mathrm{~mm}$ in diameter, comprising 2 whorls, with fine and distinct axial lirae. Teleoconch with fine axial lirae, rounded in cross-section, regularly spaced, spaces equal to thickness of lirae, evenly distributed across shell surface, reduced underneath suture; across whorls of shell. Angle of aperture $30^{\circ}$; outer lip rounded, sharp to moderately thick, slightly expanded, slightly reflected; basal node absent or very weak, palatal node absent. Parietal wall of inner lip inconspicuous.

Pallial morphology. Pallial cavity deep, extending one whorl; mantle pigmentation mottled, black. Kidney extending about half of pallial cavity.

Genital morphology (Figs. 57-58). Penis straight, more or less of same length as anterior part of oviduct. Vas deferens forms simple loop before entering penis. Penial retractor muscle as long as penis. Penial sheath evenly thick. Penial verge very long (c. $1 / 3$ penial chamber), broad, with pointed tip. Penial wall pustules of normal size, randomly and densely arranged over entire length of inner penial wall. At base of penial chamber fused rows of pustules form 3-4 smooth longitudinal pilasters. Main stimulatory pilaster absent. Vas deferens entering penial sheath in upper third. Vagina 

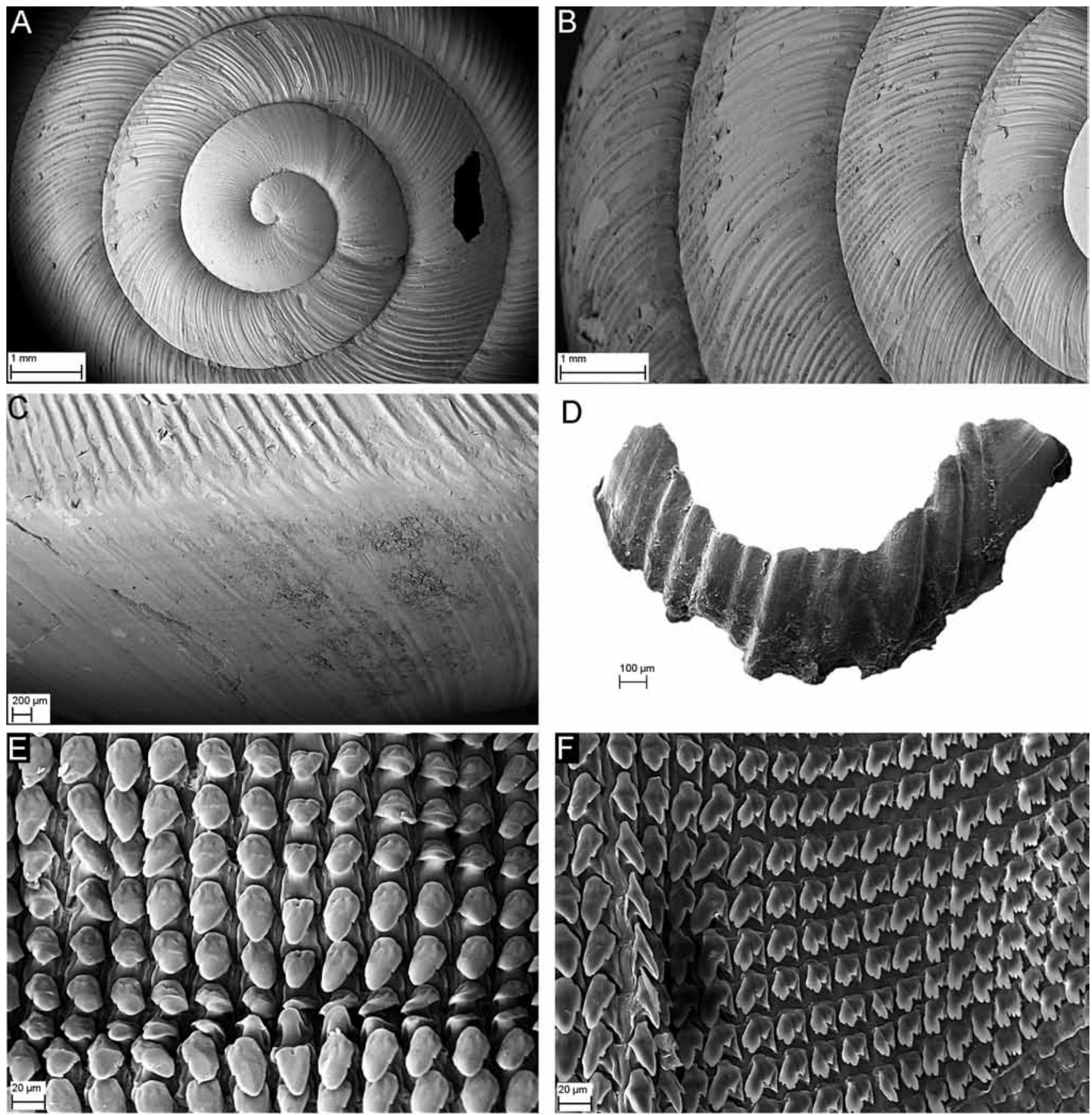

Figure 59. SEM photographs of Amplirhagada gibsoni n.sp. (A-D) Shell, paratype AMS C463708: $(A)$ apical whorl viewed from above (scale $1 \mathrm{~mm}) ;(B)$ sculpture on second to forth whorl viewed from above (scale $1 \mathrm{~mm}$ ); $(C)$ close-up showing axial periphery of last whorl (Scale $200 \mu \mathrm{m}) ;(D)$ Jaw, paratype AMS C463709 (scale $100 \mu \mathrm{m})$. $(E-F)$ Radula, paratype AMS C463709: $(E)$ central and inner lateral teeth (scale $20 \mu \mathrm{m}) ;(F)$ outer lateral and inner marginal teeth (scale $20 \mu \mathrm{m}$ ).

tubular; inner vaginal wall with smooth longitudinal pilasters. Spermathecal duct moderately wide, internally with smooth longitudinal pilasters. Spermathecal head elongately inflated, connected with oviduct by connective tissue, internally smooth, with delicate wall. Free oviduct comprising about half of anterior part of oviduct, more or less straight. Spermoviduct longer than anterior part of oviduct. Talon embedded in albumen gland close to anterior end of albumen gland.

Radular morphology (Fig. 59E-F). Rectangular. Only a partial fragment was studied with 32 rows per mm. Central teeth with sharply pointed, triangular mesocones, shorter than base of teeth. Central ectocones reduced. Lateral teeth with sharply pointed, triangular to ovate mesocones. Lateral ectocones tiny, endocones reduced. Marginals with triangular mesocones. Marginal ectocones smaller and narrower than mesocones, endocones smaller than ectocones.

Comparative remarks. Shell smaller in size, not as elevated in shape as in congeners from the same island. Large pustules and very large penial verge are also diagnostic. A lateral pocket off the penial chamber as mentioned by Solem (1991) was not observed. This species was referred to as “Amplirhagada sp. 32” by Solem (1991). 

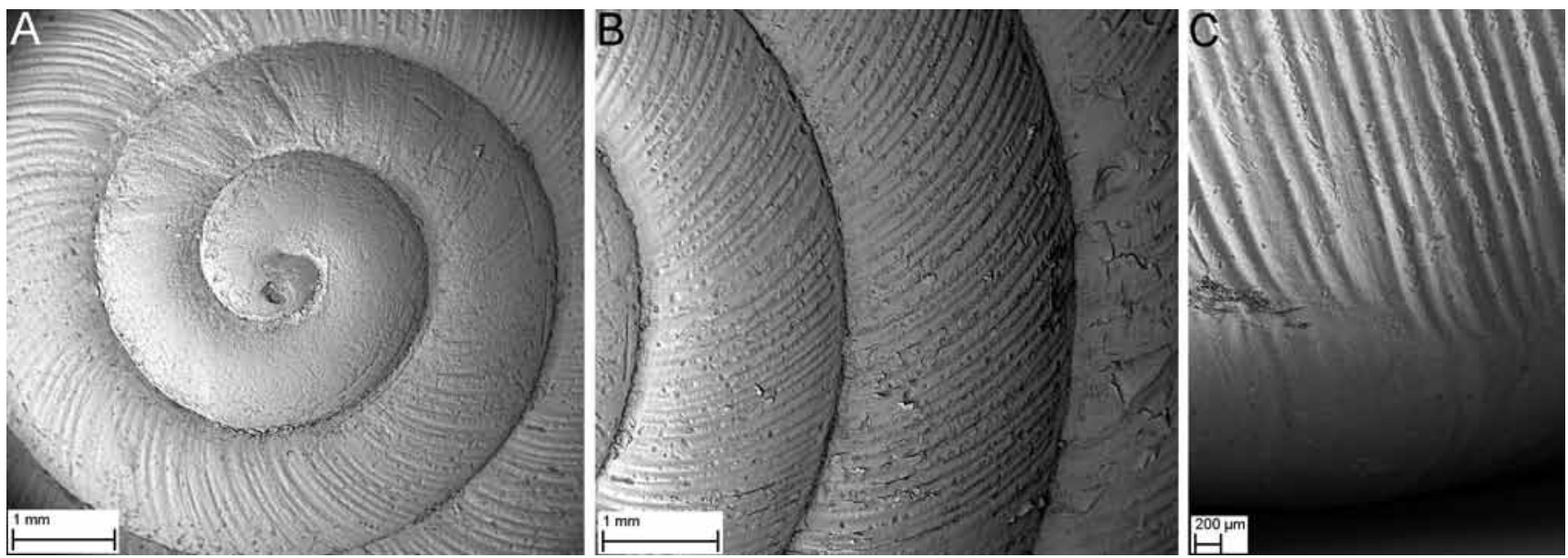

Figure 60. SEM photographs of the shell of Amplirhagada sp. AMS C463710: $(A)$ apical whorl viewed from above (scale $1 \mathrm{~mm}) ;(B)$ sculpture on second and third whorl viewed from above (scale $1 \mathrm{~mm}) ;(C)$ close-up showing axial sculpture and keel on periphery of last whorl (scale $200 \mu \mathrm{m})$.

\section{Amplirhagada sp.}

Material studied. WAM S36953 (Pl. 2.3), AMS C463710 (shells, central section of Boongaree Island, $\left.15^{\circ} 04^{\prime} 00^{\prime \prime} \mathrm{S} 125^{\circ} 11^{\prime} 11^{\prime \prime} \mathrm{E}\right)$, WAM S36740 (2 shells, $\left.15^{\circ} 04^{\prime} 36^{\prime \prime} \mathrm{S} 125^{\circ} 11^{\prime} 18 " \mathrm{E}\right)$

Shell (Fig. 60A-C, Pl. 2.3). Semi-globose with medium to high spire; solid. Whorls evenly rounded in cross-section. Umbilicus completely concealed by columellar reflection. Background colour brownish horn (shells worn); with well defined, chestnut brown, moderately broad sub-sutural and mid-whorl bands, most conspicuous on last whorl(s); ventral colour horn; outer lip colour lighter than shell. Protoconch c. $2.2 \mathrm{~mm}$ in diameter, comprising 1.7 whorls, almost smooth. Teleoconch with fine axial lirae, rounded in cross-section, regularly spaced, spaces narrower than thickness of ribs, distributed evenly across shell surface, reduced underneath suture. Angle of aperture $30^{\circ}$, outer lip rounded, moderately thick, expanded, slightly reflected, basal node of lip weak, palatal node absent. Parietal wall of inner lip inconspicuous.

Comparative remarks. Of this species, only five dry shells from Boongaree island are available. Although these shells differ clearly from those of all other species on this island, the limited data available are considered insufficient to justify formal description of this species. Amplirhagada regia and A. boongareensis have much larger and more dome-shaped shells. Amplirhagada gibsoni differs by having a flatter shell. Adult shells of the present species are generally higher than $14.7 \mathrm{~mm}$, those of $A$. gibsoni are lower.

\section{Amplirhagada yorkensis n.sp.}

Type locality (Fig. 1). Western Australia, northwestern Kimberley, Bonaparte Archipelago, York Sound, Coronation Island, southern section, $15^{\circ} 01^{\prime} 52^{\prime \prime S} 124^{\circ} 56^{\prime} 56^{\prime \prime E}$; KIS3-085. Vine thicket on upper slopes of a volcanic hill behind mangroves, under rocks (leg. V. Kessner, 30 May 2008).

Type material. Holotype WAM S34619 (P1. 2.4). Paratypes AMS C463711 (24 preserved specimens), WAM S36979 (42 preserved specimens).

Additional, non-type material. WAM S41477, FMNH 219151 (12 preserved specimens, Port Nelson, $5 \mathrm{~km} \mathrm{~N}$ of Mt. Knight, c. $3 \mathrm{~km}$ E of
Careening Bay; $15^{\circ} 06^{\prime} 41^{\prime \prime S} 125^{\circ} 01^{\prime} 53^{\prime \prime E}$; KC-040), WAM S37376-8, WAM S36980-6, WAM S37394-404, AMS C463712-4 (Coronation Island, southern section).

Etymology. In reference to York Sound, where this species occurs on islands and likely adjacent mainland.

Sealing strategy. Free sealer.

Shell (Fig. 62A-B, Pl. 2.4-5). Broadly conical to almost flat with low spire; thin (translucent). Periphery evenly rounded to slightly angulate; upper and basal sectors of whorls rounded. Umbilicus open, narrowly winding, 30-90 percent concealed by columellar reflection. Background and ventral colour brownish horn; sub-sutural band absent; mid-whorl band absent or diffuse, light yellowish brown, thin, generally not very pronounced, only visible on last whorl(s); outer lip colour same as shell; inner lip translucent, whitish. Protoconch c. $2.7 \mathrm{~mm}$ in diameter, comprising 2 whorls, with fine, indistinct axial lirae. Teleoconch smooth except of axial growth lines. Angle of aperture $30^{\circ}$; outer lip rounded, sharp, expanded to largely expanded, reflected; basal and palatal node absent. Parietal wall of inner lip inconspicuous.

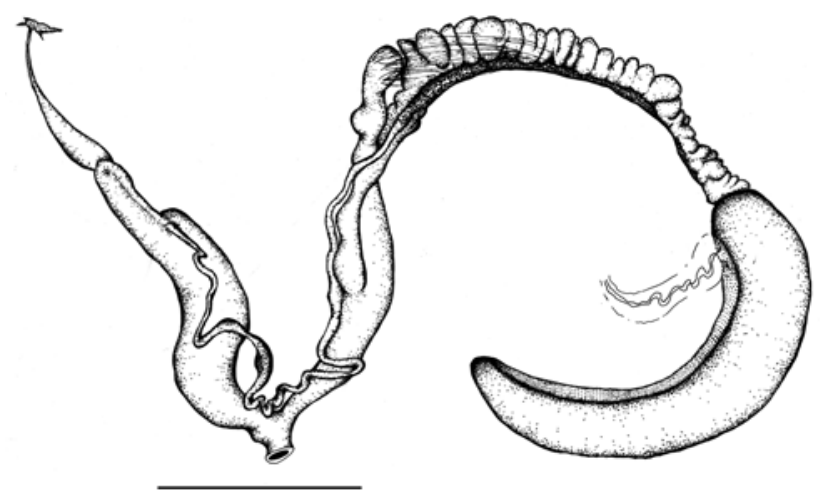

Figure 61. Genitalia of Amplirhagada yorkensis n.sp., paratype AMS C463711 (30 May, scale 5 mm). Compare with Fig. 3 for labelling of structures. 

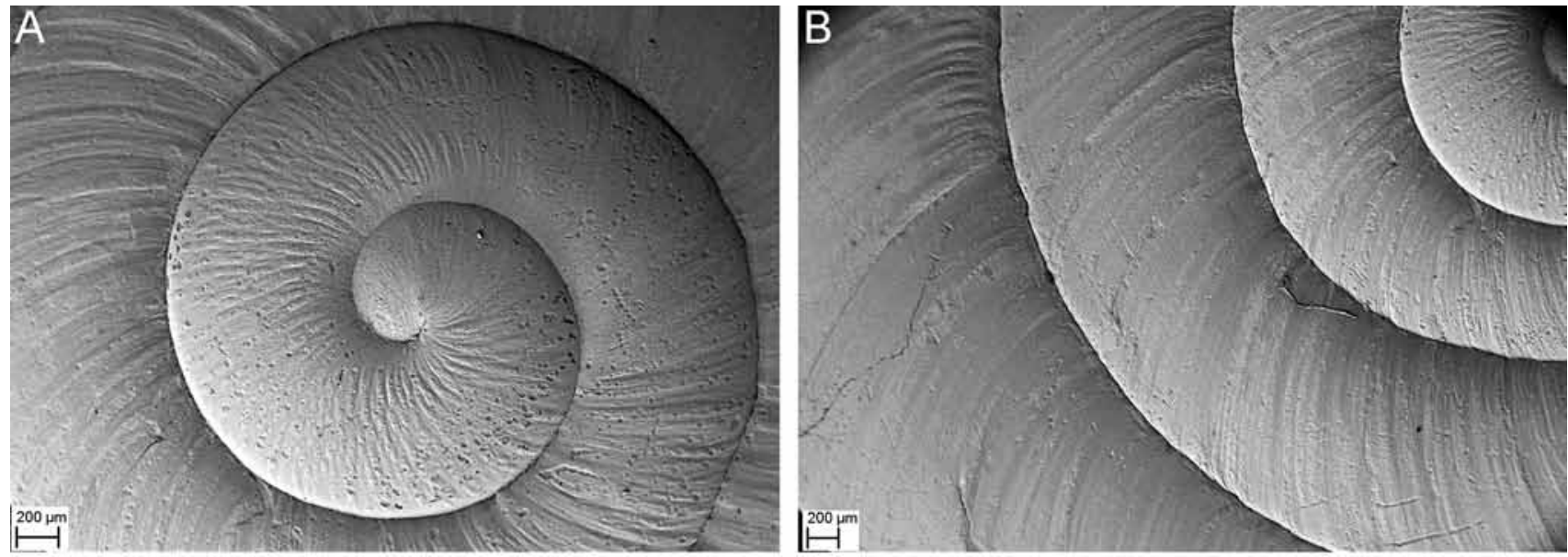

C
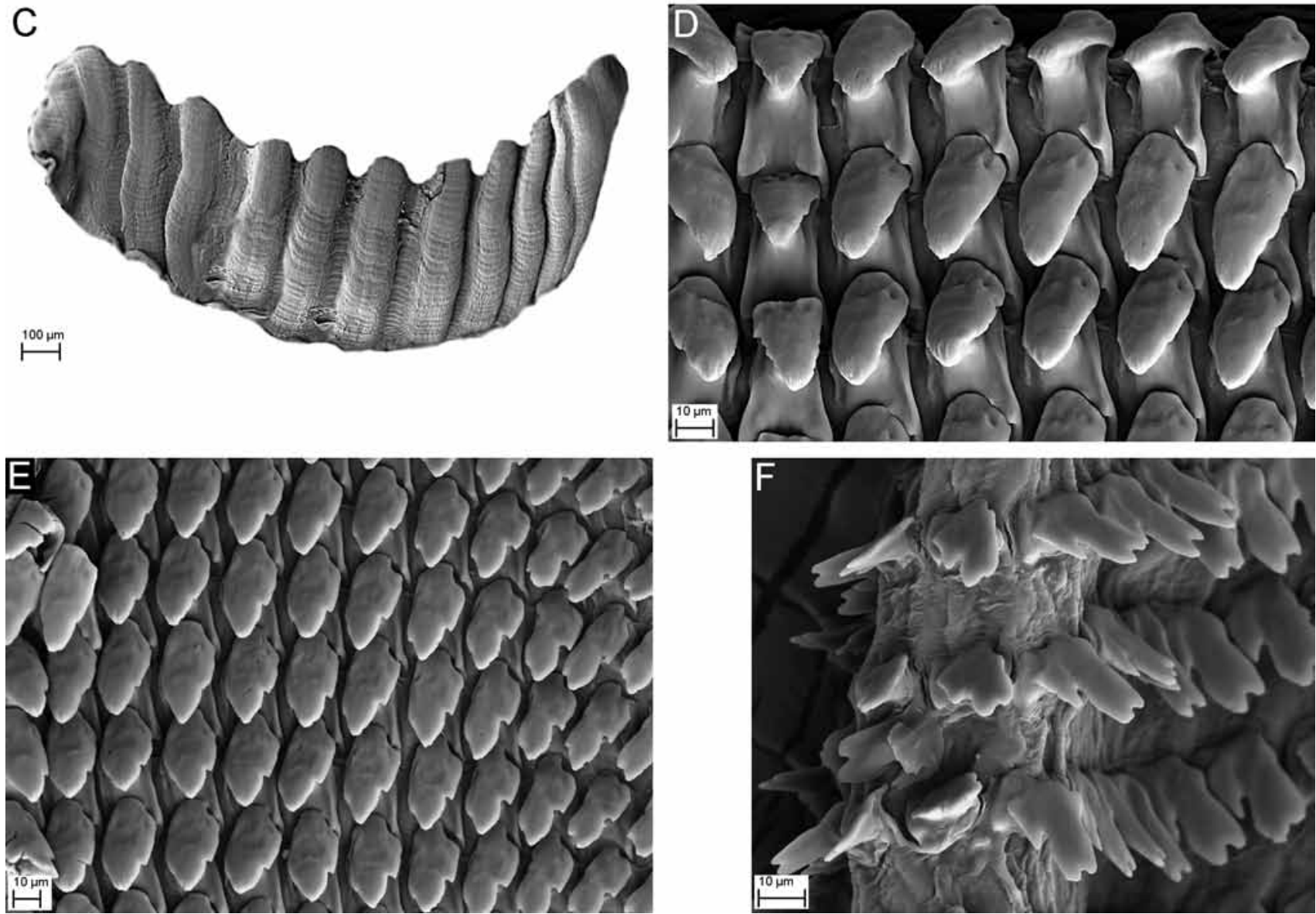

Figure 62. SEM photographs of shell, jaw and radula of Amplirhagada yorkensis n.sp., paratype AMS C463711: $(A)$ apical whorl viewed from above (scale $200 \mu \mathrm{m}) ;(B)$ sculpture on second to forth whorl viewed from above (scale $200 \mu \mathrm{m}) ;(C)$ jaw $(\mathrm{scale} 100 \mu \mathrm{m}) ;(D)$ close-up of central and inner lateral teeth (scale $10 \mu \mathrm{m}) ;(E)$ outer lateral and inner marginal teeth (scale $10 \mu \mathrm{m}) ;(F)$ close-up of middle marginal teeth (scale $10 \mu \mathrm{m})$.

Pallial morphology. Pallial cavity moderately deep, extending $3 / 4$ whorl; mantle pigmentation spotted, black. Kidney extending about half of pallial cavity.

Genital morphology (Figs. 61, 63). Penis curved to sharply bent, more or less of same length as anterior part of oviduct. Vas deferens coils once before entering penis. Penial retractor muscle very short, stubby. Penial verge very short, slender to spatulate, with pointed tip. Penial wall pustules of average size, arranged in rows over entire length of inner penial wall. Main stimulatory pilaster well-differentiated, large, cone-shaped, sculptured by horizontal ridges that support little hooks, comprising about $3 / 4$ of length of penial chamber. Vas deferens entering penial sheath in upper third. Vagina moderately wide, posteriorly inflated; inner vaginal wall with smooth longitudinal pilasters. Spermathecal duct wide, internally with smooth longitudinal pilasters. Spermathecal head pyriform, connected with oviduct by connective tissue, internally smooth with thing wall. Free oviduct comprising about half of anterior part of oviduct, more or less straight. Spermoviduct longer than anterior part of oviduct. Talon embedded in albumen gland at junction with spermoviduct. 


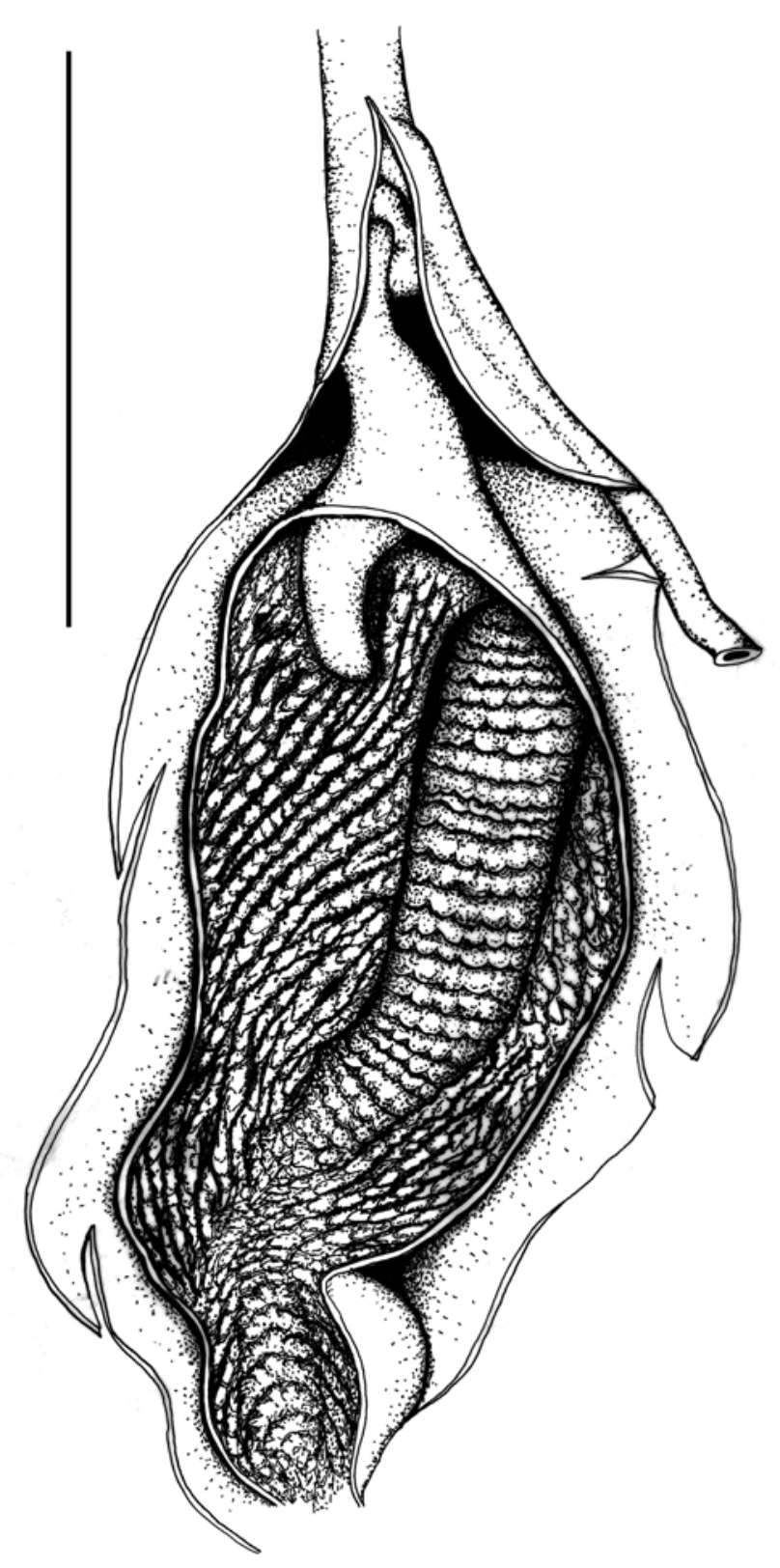

Figure 63. Interior of penial chamber of Amplirhagada yorkensis n.sp., paratype AMS C463711 (30 May, scale 3 mm). Compare with Fig. 4 for labelling of structures.

Radular morphology (Fig. 62D-F). Rectangular. Tooth formula $\mathrm{C}+13-14+3+18$. In average with $122 \pm 1.5$ rows of teeth, $32.4 \pm 2.0$ rows per $\mathrm{mm}(\mathrm{n}=2)$. Central teeth with sharply pointed, triangular mesocones, shorter than base of tooth; ectocones vestigial. Lateral teeth with bluntly pointed, triangular to ovate mesocones, length equal to base of tooth; ectocones and endocones vestigial. Marginal teeth with triangular to elongate mesocones; ectocones shorter and narrower than mesocones; endocones reduced in size.

Comparative remarks. The shell is low spired with a rounded periphery and light colouration; penis with a comparatively large main pilaster. This species was referred to as "Amplirhagada sp. 34" by Solem (1991).

\section{Amplirhagada buffonensis n.sp.}

Type locality (Fig. 1). Western Australia, Kimberley, Bonaparte Archipelago, Buffon Island, $14^{\circ} 54^{\prime} 40^{\prime \prime} \mathrm{S}$ $124^{\circ} 44^{\prime} 13$ "S; KC-086 (leg. V. Kessner \& A. Longbottom, 23 July 1988).

Type material. Holotype WAM S34620 (Pl. 2.6). Paratypes AMS C463758 ( 2 preserved specimens, as holotype), FMNH 219337 (8 preserved specimens, same as holotype), WAM S41482 (5 preserved specimens, as holotype), FMNH 219365 (8 preserved specimens, unnamed islet W of Buffon Island, $14^{\circ} 54^{\prime} 29^{\prime \prime S} 124^{\circ} 43^{\prime 2} 28^{\prime \prime}$ ), AMS C463759 (2 preserved specimens, as FMNH 219365), WAM S41483 (5 preserved specimens, same as FMNH 219365).

Additional, non-type material. FMNH 219374, WAM S41484 (preserved specimens, unnamed island S of Buffon Island, $14^{\circ} 57^{\prime} 07^{\prime \prime S} 124^{\circ} 44^{\prime} 50^{\prime \prime E}$ ).

Etymology. In reference to Buffon Island, where this species occurs.

Shell (Fig. 65A-C, Pl. 2.6). Broadly conical to almost flat with low spire; thin (translucent). Periphery evenly rounded to slightly angulate; upper and basal sectors of whorls rounded. Umbilicus open, forming narrowly winding opening, 10-20 percent concealed by columellar reflection. Background and ventral colour greyish horn to slightly beige, whitish cracks and growth lines visible; sub-sutural band absent; mid-whorl band absent or diffuse, yellowish brown, thin, only visible on last whorl; outer and inner lip whitish. Protoconch c. $2.7 \mathrm{~mm}$ in diameter, comprising 1.7 whorls, smooth. Teleoconch with faint axial growth lines only. Angle of aperture $45^{\circ}$, outer lip rounded, sharp to moderately thick, expanded, slightly reflected, basal node of lip absent to weak, palatal node absent. Parietal wall of inner lip inconspicuous.

Pallial morphology. Pallial cavity moderately deep, extending $3 / 4$ whorl; mantle pigmentation comprises densely packed black spots or patches. Kidney extending about half of pallial cavity.

Genital morphology (Figs. 64, 66). Penis straight to slightly curved, more or less of same length as anterior part of oviduct. Vas deferens forms simple loop or coils before

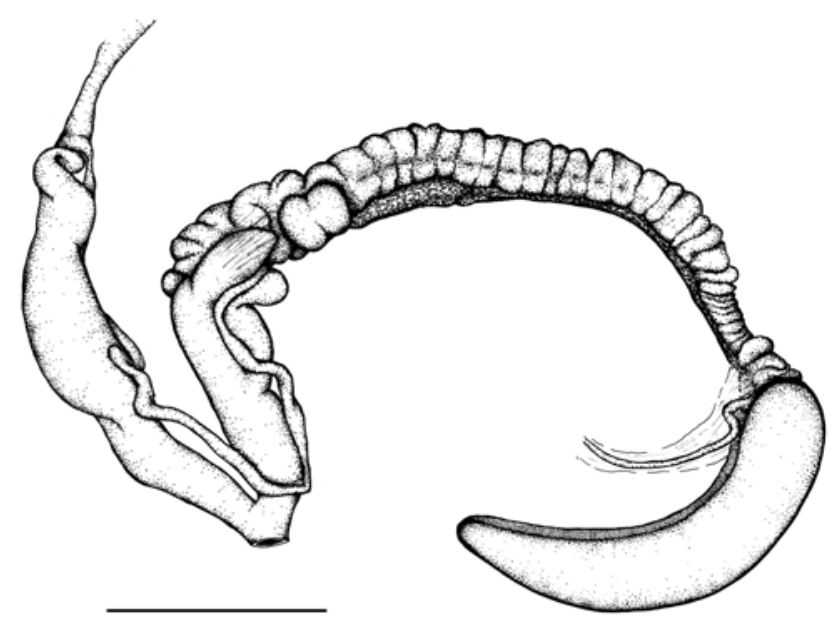

Figure 64. Genitalia of Amplirhagada buffonensis n.sp., paratype AMS C463758 (23 July, scale $10 \mathrm{~mm}$ ). Compare with Fig. 3 for labelling of structures. 

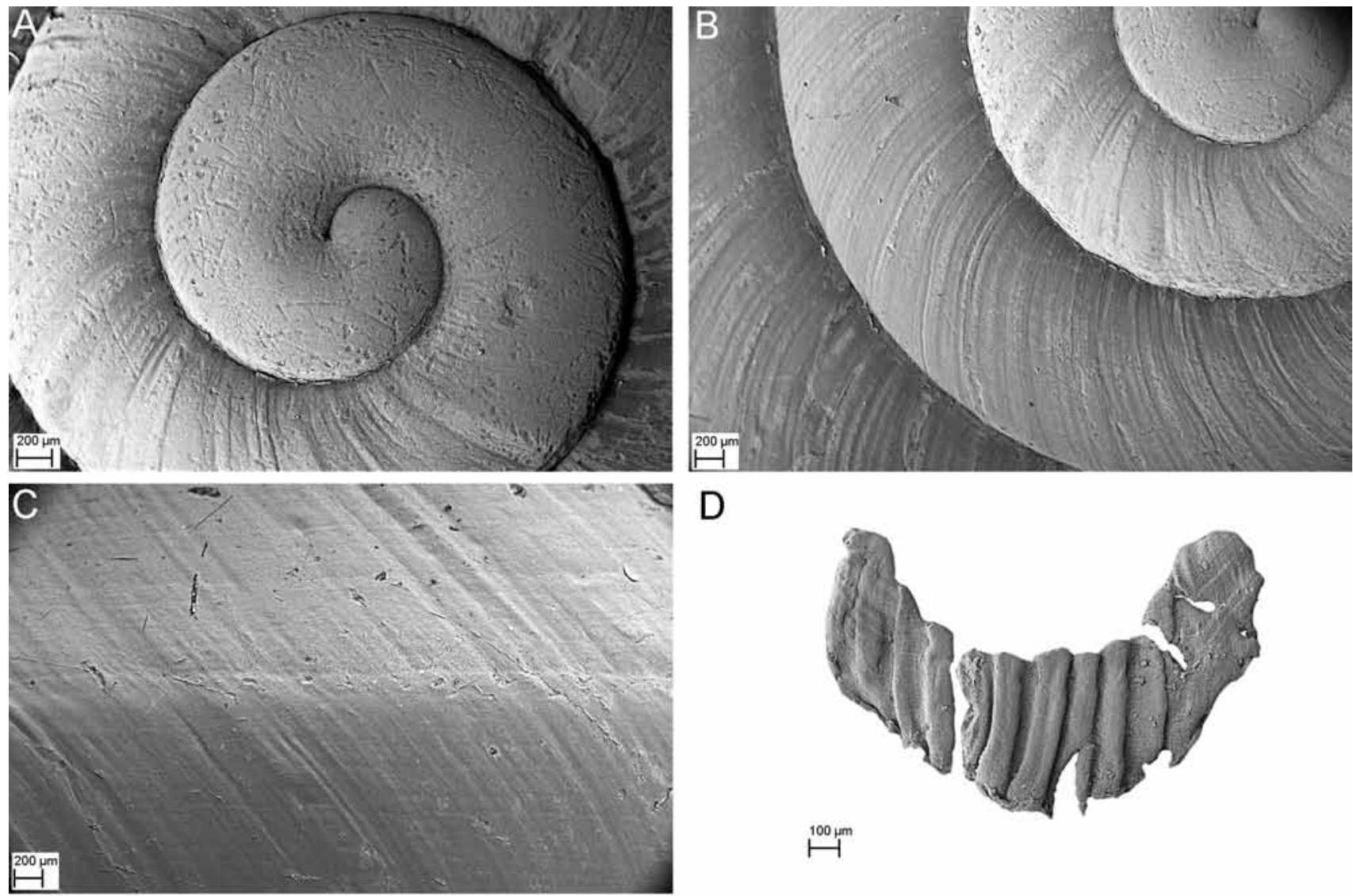

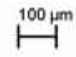
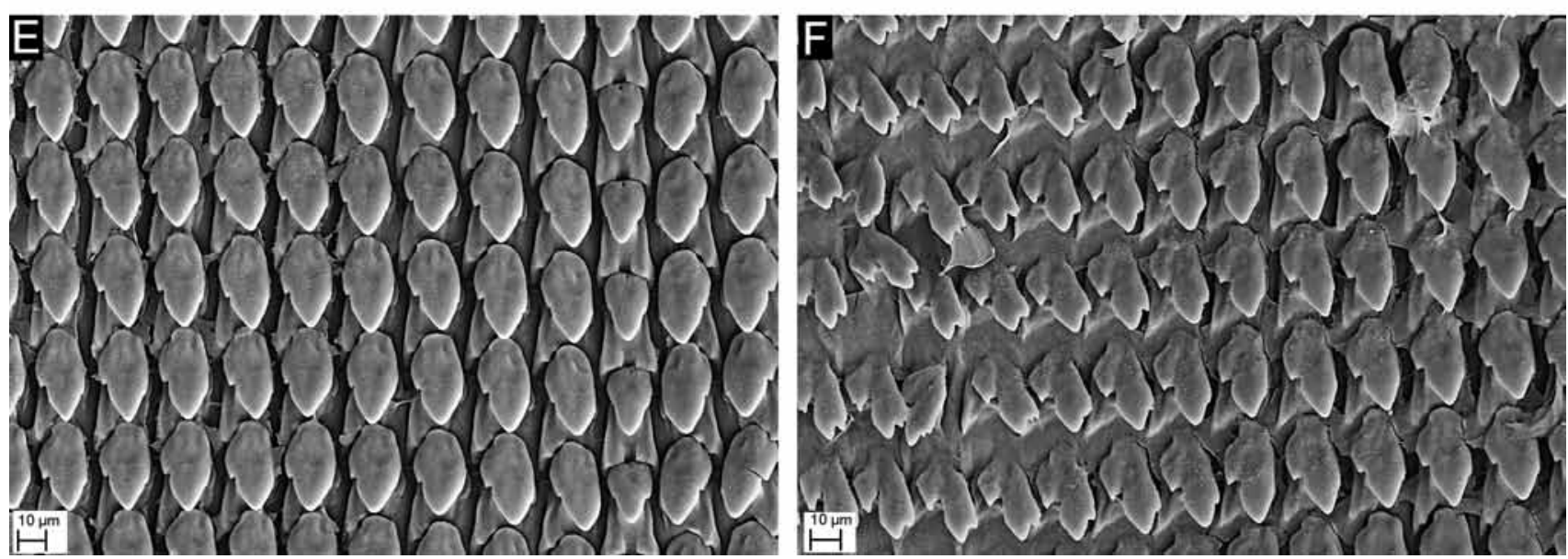

Figure 65. SEM photographs of shell, jaw and radula of Amplirhagada buffonensis n.sp., paratype AMS C463759: (A) apical whorl viewed from above (scale $200 \mu \mathrm{m}) ;(B)$ sculpture on first three whorls viewed from above (scale $200 \mu \mathrm{m}) ;(C)$ close-up of periphery of last whorl (scale $200 \mu \mathrm{m}) ;(D)$ jaw (scale $100 \mu \mathrm{m}) ;(E)$ central and inner lateral teeth (scale $10 \mu \mathrm{m}) ;(F)$ outer lateral and inner marginal teeth (scale $10 \mu \mathrm{m})$.

entering penis. Penial retractor muscle shorter than penis. Penial verge very short (barely visible), slender to spatulate, with pointed to rounded tip. Penial wall pustules very small, densely arranged in rows on apical to median portion of penial chamber, becoming oblique towards base of penial chamber. Main stimulatory pilaster well-differentiated, large, cone-shaped, sculptured by horizontal ridges that support little hooks, comprising almost entire length of penial chamber. Vas deferens entering penial sheath in upper third of penis. Vagina moderately wide, posteriorly inflated; inner vaginal wall with smooth longitudinal pilasters. Spermatheca of long, clearly extending over base of spermoviduct.
Spermathecal duct rather wide, internally with smooth longitudinal pilasters. Spermathecal head elongately inflated with extended tubular or pyriform tip, connected with oviduct by connective tissue, internally smooth, with delicate wall. Free oviduct comprising less than half of anterior part of oviduct, more or less straight. Spermoviduct longer than anterior part of oviduct. Talon embedded in albumen gland close to anterior end of albumen gland.

Radular morphology (Fig. 65E-F). Rectangular. Tooth formula $\mathrm{C}+14-15+3-4+18-22$. In average $153 \pm 17.5$ rows of teeth, $27.4 \pm 0.1$ rows per $\mathrm{mm}(\mathrm{n}=2)$. Central teeth with 


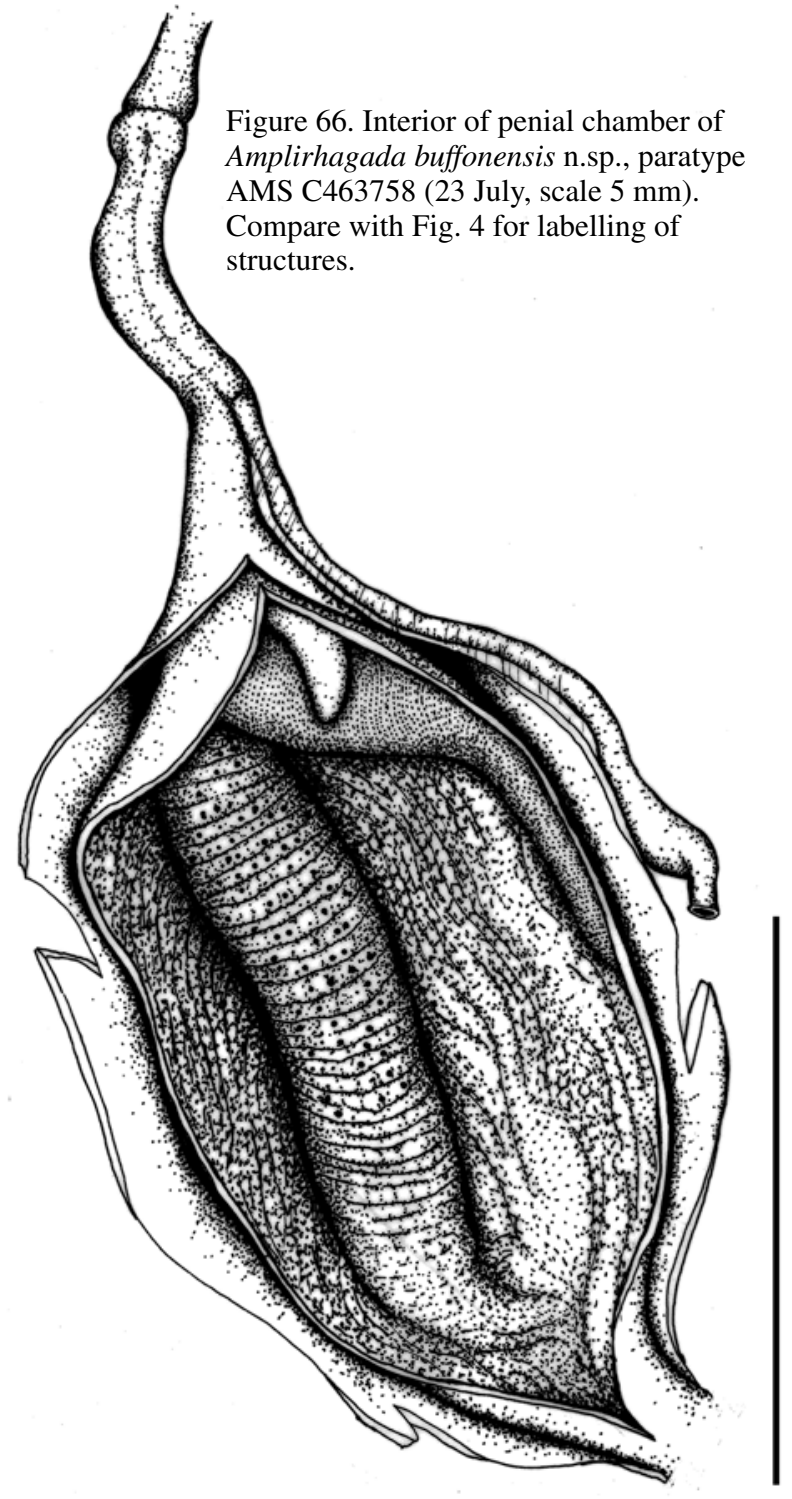

bluntly pointed, triangular mesocones, shorter than base of tooth; ectocones vestigial. Lateral teeth with sharply pointed, triangular to ovate mesocones, length equal to base of tooth; ectocones well developed, endocones vestigial. Marginal teeth with triangular mesocones; ectocones shorter and narrower than mesocones; endocones reduced in size.

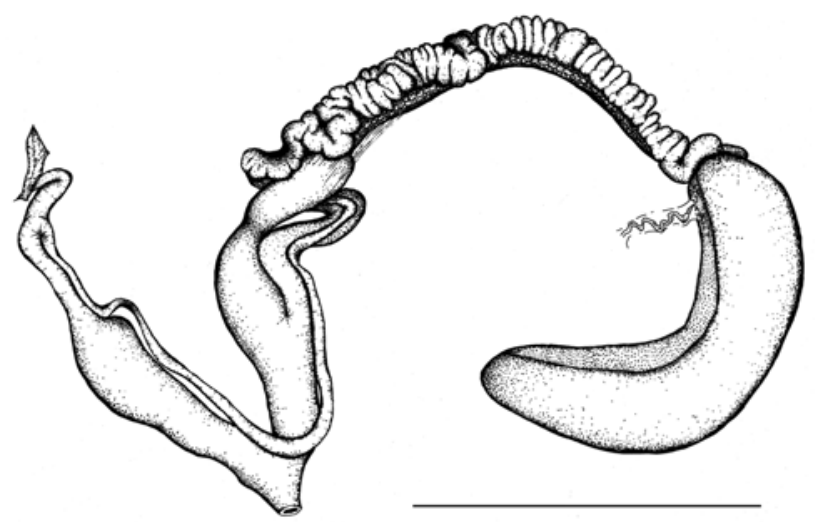

Figure 67. Genitalia of Amplirhagada uwinsensis n.sp., paratype AMS C463715 (7 August, scale $10 \mathrm{~mm}$ ). Compare with Fig. 3 for labelling of structures.
Comparative remarks. It has a low spired shell with reduced banding pattern. Differs from its sister species in the phylogeny, A. yorkensis, by angulate periphery, slightly larger shell size (Table 1), and smaller verge. Material of this species has been labelled as "Amplirhagada sp. 67" by Solem.

\section{Amplirhagada uwinsensis n.sp.}

Type locality (Fig. 1). Western Australia, Kimberley, Bonaparte Archipelago, Hanover Bay, Uwins Island, $15^{\circ} 15^{\prime} 32^{\prime \prime S} 124^{\circ} 46^{\prime} 08^{\prime \prime E}$; KIS-3-106. Vine thicket and large fig trees on upper slopes, piles of sandstone rocks, under large slabs. (leg. V. Kessner, 09 June 2006).

Type material. Holotype WAM S34621 (Pl. 2.7). Paratypes AMS C463715 (15 preserved specimens, as holotype), WAM S36991 (35 preserved specimens, as holotype), AMS C463716 (15 shells, $15^{\circ} 15^{\prime} 25^{\prime \prime} \mathrm{S}$ $124^{\circ} 48^{\prime} 04^{\prime \prime E}$ ), WAM S37441 (30 shells, $\left.15^{\circ} 15^{\prime} 25^{\prime \prime} \mathrm{S} 124^{\circ} 48^{\prime} 04^{\prime \prime E}\right)$.

Additional, non-type material. WAM S36987-90, WAM S37440, WAM S37442-4, AMS C463717 (Uwins Island).

Etymology. In reference to Uwins Island, where this species occurs.

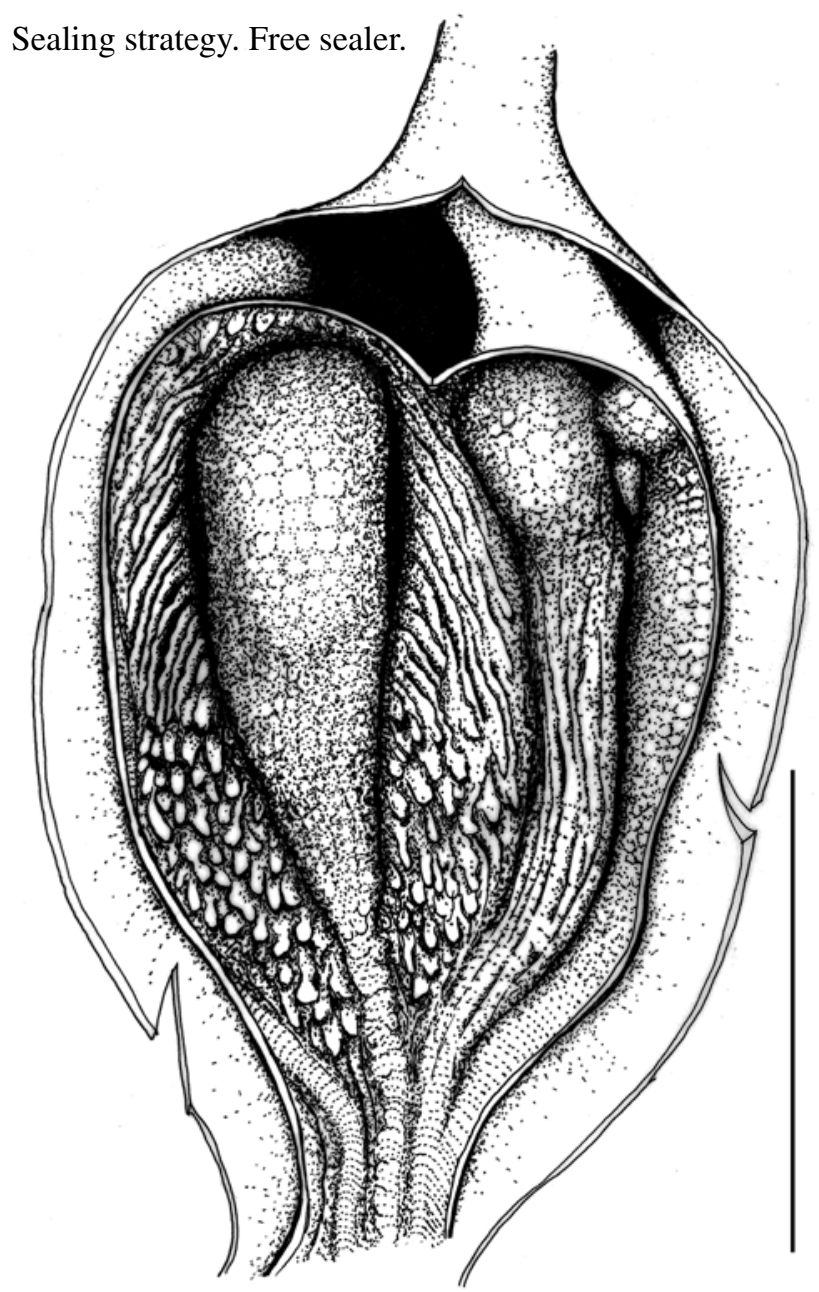

Figure 68. Interior of penial chamber of Amplirhagada uwinsensis n.sp., paratype AMS C463715 (7 August, scale 5 mm). Compare with Fig. 4 for labelling of structures. 

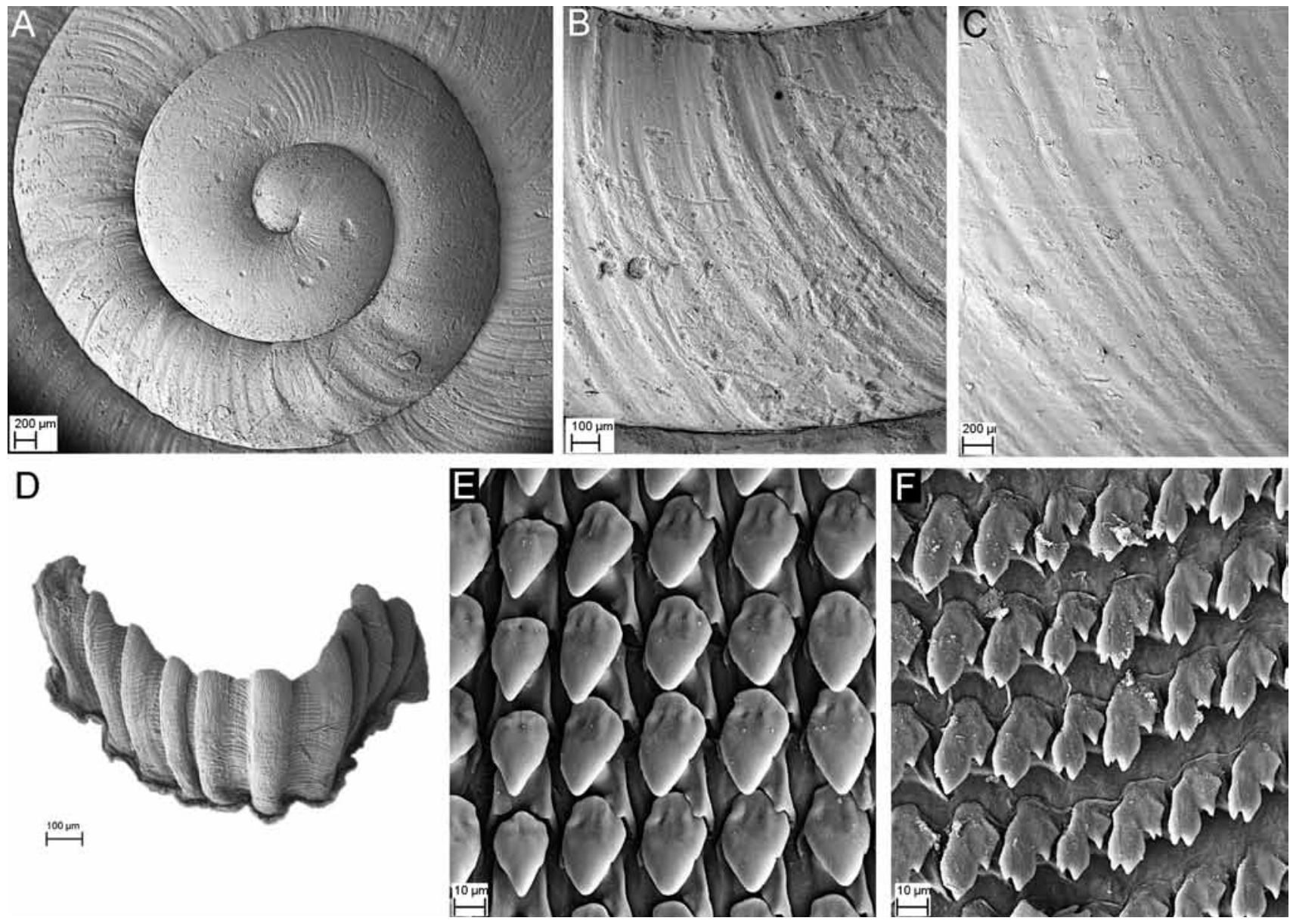

Figure 69. SEM photographs of Amplirhagada uwinsensis n.sp. $(A-C)$ Shell, paratype AMS C463716: $(A)$ apical whorl viewed from above (scale $200 \mu \mathrm{m}) ;(B)$ sculpture penultimate whorl viewed rectangularly from above (scale $100 \mu \mathrm{m})$; $(C)$ close-up of periphery of last whorl (scale $200 \mu \mathrm{m})$. (D) Jaw, paratype AMS C463715 (scale $100 \mu \mathrm{m})$. (E-F) Radula, paratype AMS C463715: $(E)$ close-up of central and inner lateral teeth (scale $10 \mu \mathrm{m}$ ); $(F)$ close-up of inner to middle marginal teeth (scale $10 \mu \mathrm{m}$ ).

Shell (Fig. 69A-C, Pl. 2.7-9). Semi-globose with medium high spire; solid. Periphery angulate; upper and basal sectors of whorls rounded. Umbilicus completely concealed by columellar reflection. Background colour light reddish brown; sub-sutural band diffuse to well defined, light brown to chestnut brown, varies greatly in thickness and contrast; mid-whorl band diffuse, brownish to chestnut brown, thin, varies greatly in contrast and thickness, visible on last whorl(s) only; bands may blend into each other across whorl surface; ventral colour yellowish-greenish brown to ochre; outer lip colour blending into chestnut brown; inner lip blending into dark ochre to chestnut brown. Protoconch c. 2.7 $\mathrm{mm}$ in diameter, comprising 1.7 whorls, with fine, indistinct axial lirae. Teleoconch with marked growth lines, becoming oblique towards base of shell. Angle of aperture $45^{\circ}$; outer lip rounded, slightly expanded, not reflected, basal node of lip weak, palatal node absent. Parietal wall of inner lip absent.

Pallial morphology. Pallial cavity short, extending $1 / 2$ to $3 / 4$ whorls; mantle pigmentation consists of indistinctive, sparsely distributed brown spots. Kidney extending about half or more than half of pallial cavity.

Genital morphology (Figs. 67-68). Penis rather straight, more or less of same length as anterior part of oviduct. Vas deferens coils once before entering penis. Penial retractor muscle very short to stubby. Penial verge very short (barely visible), slender to spatulate, with pointed tip. Penial wall pustules comparatively large, elongated, arranged in rows on median and basal portion of penial chamber, forming densely packed, narrow longitudinal pilasters at apical end of penial chamber. Main stimulatory pilaster welldifferentiated, large, cone-shaped, covered with flattened pustules, comprising anterior to median portion of penial chamber. Two additional pilasters are formed that are covered by flattened pustules or smooth narrow ridges. Vas deferens entering penial sheath in upper third. Vagina moderately wide, tubular to posteriorly inflated; inner vaginal wall with weakly developed longitudinal pilasters. Spermathecal duct wide, internally with smooth longitudinal pilasters. Spermathecal head globular, connected with oviduct by connective tissue, internally smooth, with delicate wall. Free oviduct comprising less than half to about half of anterior part of oviduct, more or less straight. Spermoviduct of same length as anterior part of oviduct or longer. Talon embedded in albumen gland close to anterior end of albumen gland.

Radular morphology (Fig. 69E-F). Rectangular. Tooth formula $C+14-16+4+22$. In average $149 \pm 16.0$ rows of teeth, $29.5 \pm 1.0$ rows per $\mathrm{mm}(\mathrm{n}=2)$. Central teeth with sharply pointed, triangular mesocones, shorter than base of teeth; ectocones vestigial. Lateral teeth with sharply 

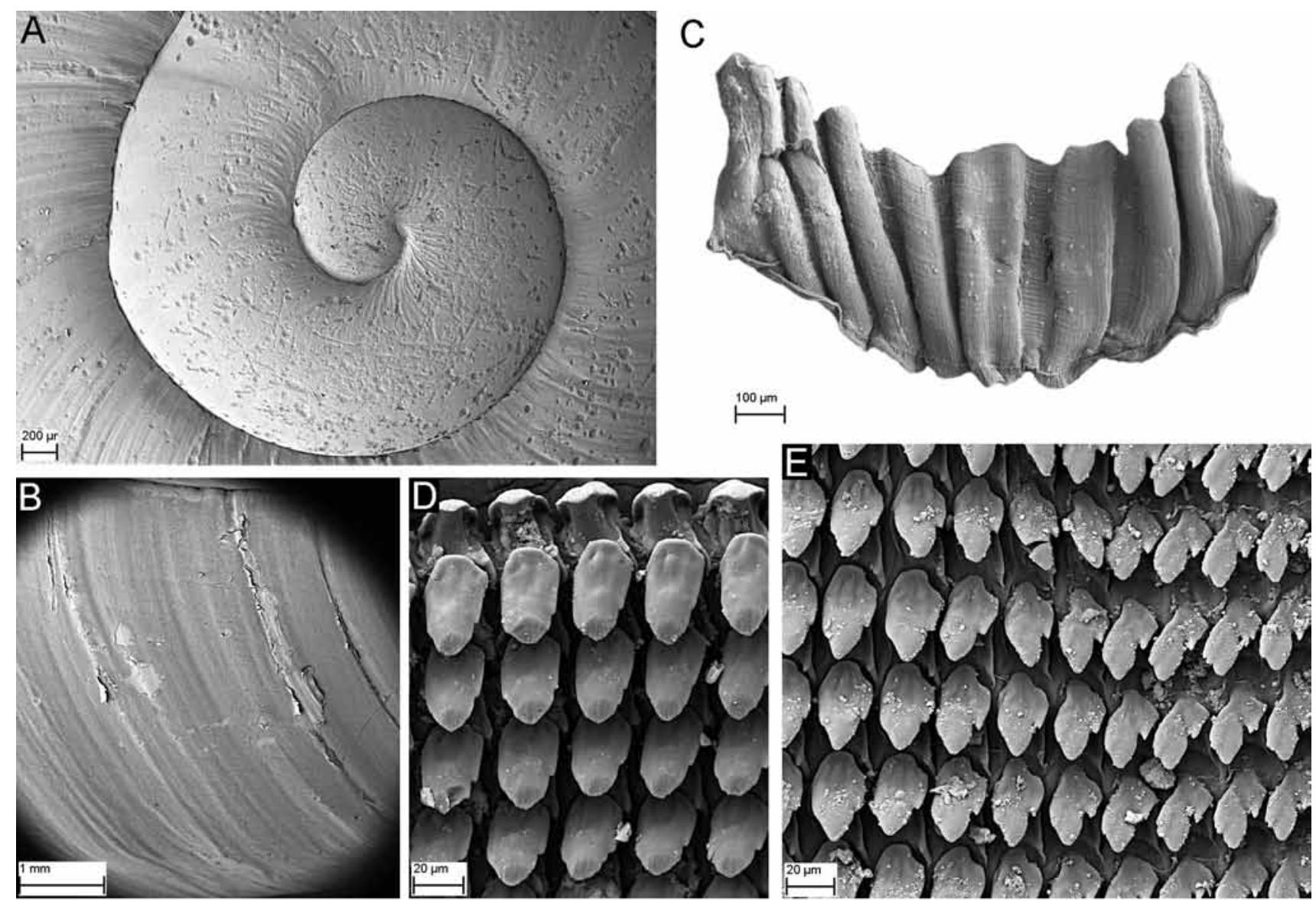

Figure 70. SEM photographs of Amplirhagada sphaeroidea n.sp. $(A-B)$ Shell, paratype AMS C463719: $(A)$ apical whorl viewed from above (scale $200 \mu \mathrm{m}) ;(B)$ close-up of periphery of last whorl (scale $1 \mathrm{~mm}) ;(C)$ jaw, paratype WAM S37027 (scale $100 \mu \mathrm{m})$. $(D-E)$ Radula, paratype WAM S37027: $(D)$ close-up of inner lateral teeth (scale $20 \mu \mathrm{m}) ;(E)$ Close-up of outer lateral and inner marginal teeth (scale $20 \mu \mathrm{m}$ ).

pointed, triangular mesocones, length equal to base of teeth; ectocones and endocones vestigial. Marginal teeth with elongate mesocones; ectocones smaller and narrower than mesocones; endocones shorter than ectocones.

Comparative remarks. One of the few species with large, dome-shaped shells. Differs from A. tricenaria and A. regia by conspicuously dark brown outer lip colour and by huge, cone-shaped main pilaster, presence of additional pilasters and characteristically elongated pustules of inner penial wall.

\section{Amplirhagada sphaeroidea n.sp.}

Type locality (Fig. 1). Western Australia, Kimberley, Saint George Basin, St. Andrews Island, 15²1'24"S 12459'46"E; KIS-2-40. Volcanic boulder scree, vine thicket, under rocks (leg. R. Teale, 25 May 2008).

Type material. Holotype WAM S34622 (Pl. 2.10). Paratypes AMS C463718 (2 preserved specimens, same as holotype), WAM S37029 (7 preserved specimens, same as holotype), AMS C463719 (shell, 15²1'34"S $125^{\circ} 00^{\prime} 07^{\prime \prime E}$ ), WAM S37027 (3 preserved specimens, $15^{\circ} 21^{\prime} 34^{\prime \prime S}$ $125^{\circ} 00^{\prime} 07^{\prime \prime E}$ ), WAM S37411 (1 dry shell, $15^{\circ} 21^{\prime} 34^{\prime \prime S} 125^{\circ} 00^{\prime} 07^{\prime \prime E}$ ).

Additional, non-type material. WAM S37028, WAM S37030, WAM S37410, WAM S37412 (St. Andrews Island).

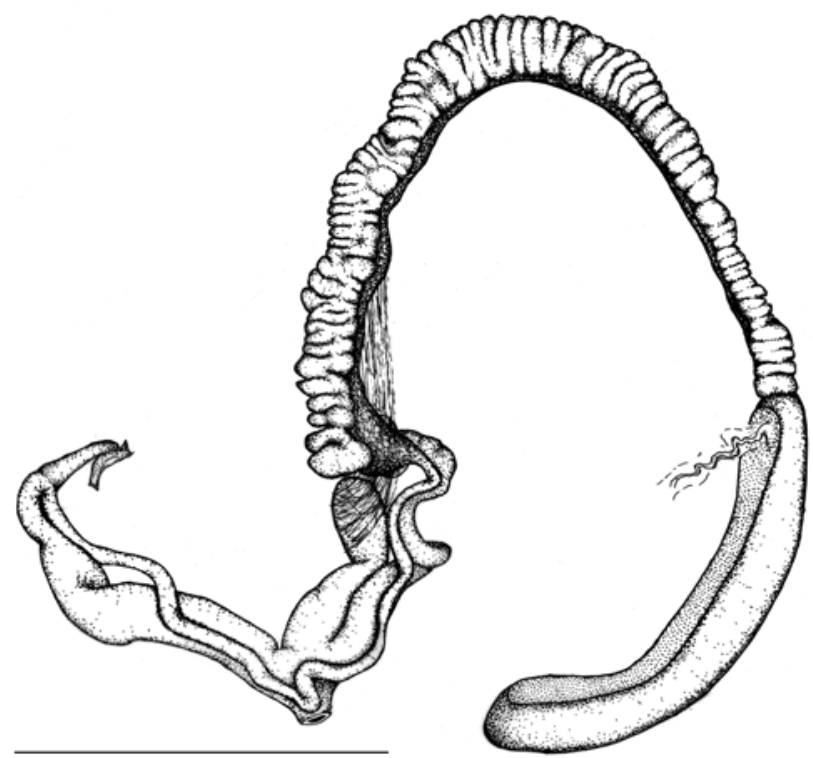

Figure 71. Genitalia of Amplirhagada sphaeroidea n.sp., paratype WAM S37027 (24 May, scale 10 mm). Compare with Fig. 3 for labelling of structures.

Etymology. From sphaeroeides $($ Greek $=$ globular, spherical), referring to globular shape of shell.

Sealing strategy. Free sealer. 
Shell (Fig. 70A-B, Pl. 2.10). Globose to semi-globose, with medium high spire; solid to thick. Periphery angulate; upper sector of whorls rather flattened, basal sector rounded. Umbilicus forming a chink, 90-100 percent concealed by columellar reflection. Background colour blends from horn at base to lightly brownish at top of shell; sub-sutural band absent or diffuse, indistinct, brownish; mid-whorl band absent or diffuse, brownish, thin, indistinct, visible on last whorl(s) only; ventral colour cream; outer lip colour differs from shell, dark brownish-purple; inner lip blends from dark pink outside to horn deeper inside. Protoconch c. $2.4 \mathrm{~mm}$ in diameter, comprising 1.7 whorls, smooth. Teleoconch smooth, except of faint growth lines. Angle of aperture $45^{\circ}$; outer lip rounded, thick, slightly expanded to expanded, slightly reflected, basal node of lip weak, palatal node absent. Parietal wall of inner lip absent or inconspicuous.

Pallial morphology. Pallial cavity moderately deep, extending $\pm 3 / 4$ whorl; mantle pigmentation mottled, diffuse dark grey. Kidney extending about half of pallial cavity.

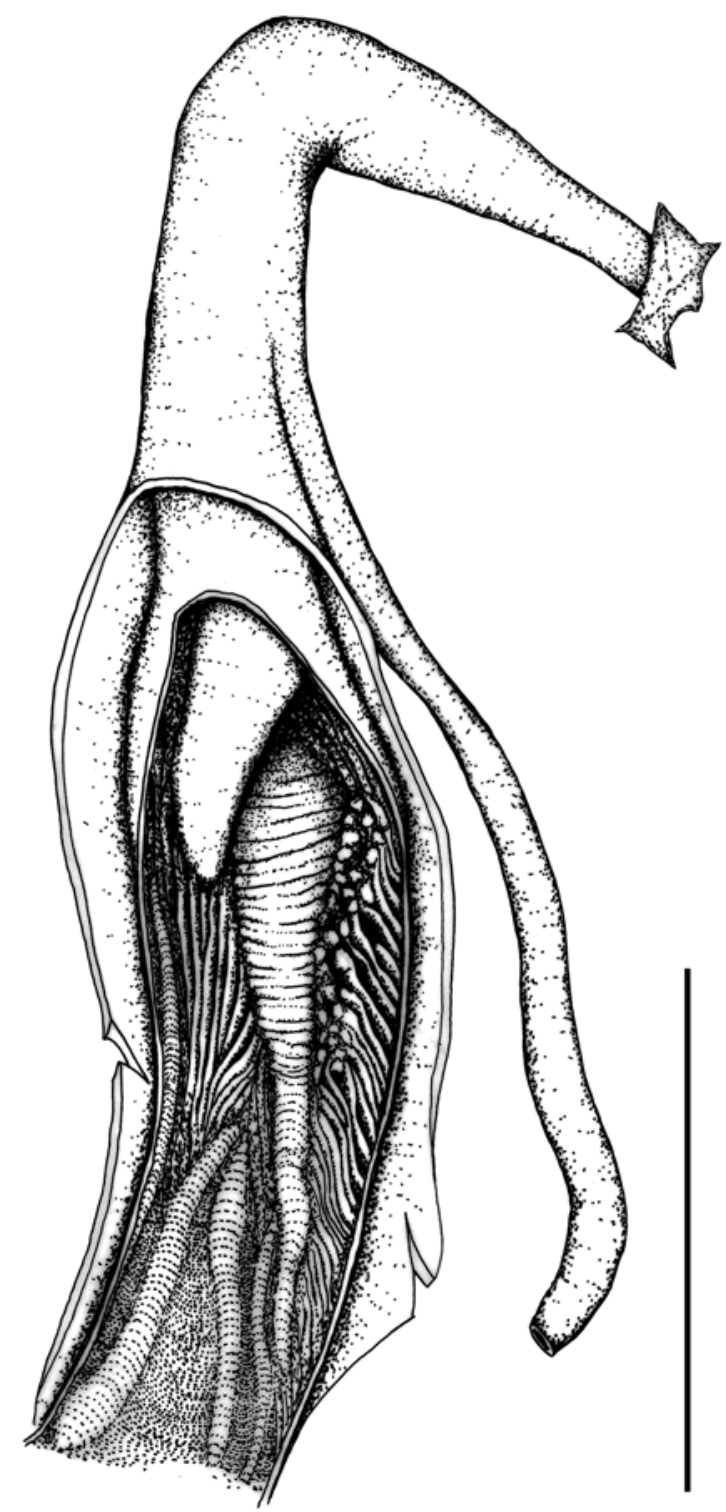

Figure 72. Interior of penial chamber of Amplirhagada sphaeroidea n.sp., paratype WAM S37027 (24 May, scale 3 mm). Compare with Fig. 4 for labelling of structures.
Genital morphology (Figs. 71-72). Penis straight, more or less of same length as anterior part of oviduct. Vas deferens forms simple loop before entering penis. Penial retractor muscle very short, stubby. Penial sheath evenly thick. Penial verge short ( $<1 / 8$ penial chamber), slender to spatulate, with pointed tip. Penial wall pustules fused to regular, smooth, diagonal and delicate lamellae on apical portion, becoming more and more oblique towards base of penial chamber. Main stimulatory pilaster well-differentiated; elongated, large, cone-shaped, corrugated, comprising mainly the apical portion of penial chamber and gradually decreasing in size towards base. Three additional, smooth, narrow, rather indistinct pilasters are formed at base of penial chamber. Vas deferens entering penial sheath apically. Vagina rather short, posteriorly inflated; inner vaginal wall with smooth longitudinal pilasters. Spermathecal duct moderately wide, internally with smooth longitudinal pilasters. Spermathecal head globular, connected with oviduct by connective tissue, internally entirely smooth, wall delicate. Free oviduct comprising about half of anterior part of oviduct, or more than half of anterior part of oviduct; more or less straight. Spermoviduct much longer than anterior part of oviduct. Talon embedded in albumen gland anteriorly.

Radular morphology (Fig. 70D-E). Rectangular. Tooth formula $\mathrm{C}+15+4+18$. With 118 rows of teeth, 26.0 rows per $\mathrm{mm}(\mathrm{n}=1)$. Central teeth with bluntly pointed, broadly elongate mesocone, length equal to base of teeth; ectocones vestigial. Lateral teeth with bluntly pointed, broadly elongate mesocone, length equal to base of teeth; ectocones small, endocones vestigial. Marginal teeth with broadly elongate mesocones; ectocones smaller and narrower than mesocones; endocones greatly reduced.

Comparative remarks. One of the few species with large, dome-shaped shells. Differs from A. tricenaria and A. regia by dark outer lip and from $A$. uwinsensis purplish colour of outer lip. Covering of inner penial wall with lamellae, elongate-conical, corrugated main pilaster, and relatively large verge are diagnostic.

\section{Amplirhagada basilica n.sp.}

Type locality (Fig. 1). Western Australia, Kimberley, Bonaparte Archipelago, Augustus Island, southern section,

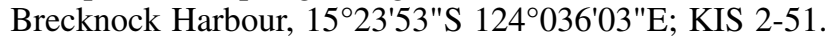
Weathered south facing sandstone scree in deep gorge, under rocks (leg. R. Teale, 1 June 2008).

Type material. Holotype WAM S34623 (Pl. 2.11). Paratypes AMS C463720 (4 preserved specimens, same as holotype), WAM S37004 (11 preserved specimens, same as holotype), AMS C463721 (3 shells, 15²2'54"S $124^{\circ} 35^{\prime} 24^{\prime \prime E}$ ), WAM S37414 (4 shells, $15^{\circ} 22^{\prime} 54^{\prime \prime S} 124^{\circ} 35^{\prime} 24^{\prime \prime E}$ ).

Additional, non-type material. WAM S37000-3, WAM S37413 (Augustus Island).

Etymology. From basilica (Latin = royal, splendid, magnificent), referring to its large shell. Amplirhagada regia is among the largest species of the genus.

Sealing strategy. Free sealer. 

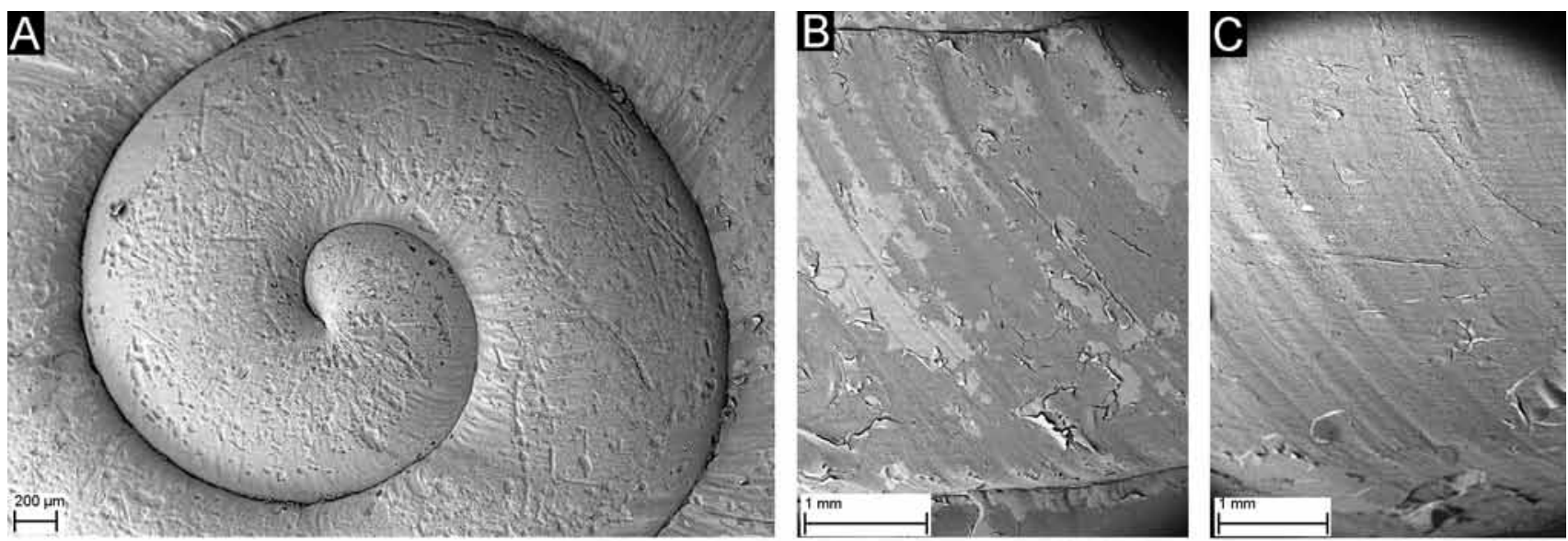

D
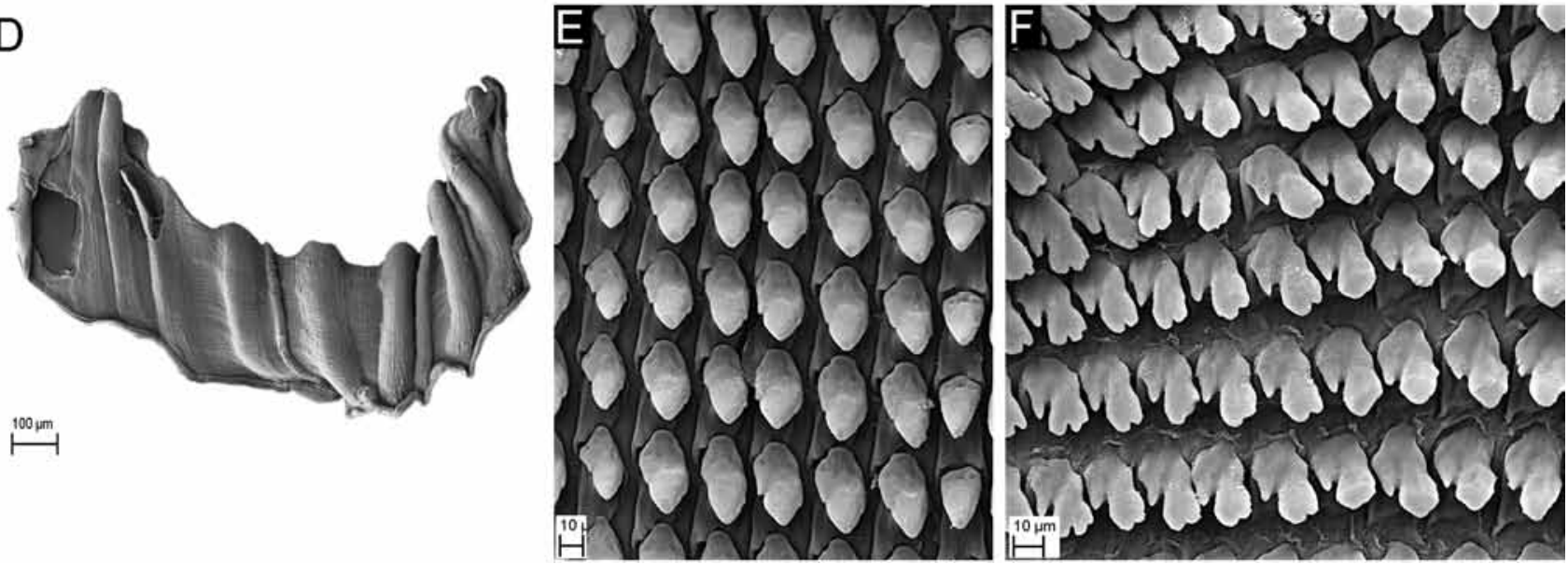

Figure 73. SEM photographs of Amplirhagada basilica n.sp. (A-C) Shell, paratype AMS C463721: (A) apical whorl viewed from above $($ scale $200 \mu \mathrm{m}) ;(B)$ close-up of periphery of penultimate whorl (scale $1 \mathrm{~mm}) ;(C)$ close-up of periphery of last whorl $(\mathrm{scale} 1 \mathrm{~mm})$. $(D)$ Jaw, paratype AMS C463720 (scale $100 \mu \mathrm{m})$. $(E-F)$ Radula, paratype AMS C463720: $(E)$ central and inner lateral teeth (scale $10 \mu \mathrm{m})$; $(F)$ outer lateral and inner marginal teeth (scale $10 \mu \mathrm{m})$.

Shell (Fig. 73A-C, Pl. 2.11). Semi-globose, with medium high spire; solid to thick. Periphery slightly angulate; upper and basal sectors of whorls rounded. Umbilicus open, forming a chink to narrowly winding opening, 80-95 percent concealed by columellar reflection. Background colour blends from cream into brownish (upper sector of lower whorls darker); sub-sutural band diffuse, light brownish; mid-whorl band diffuse, thin, brownish, most pronounced, visible on last whorls only, blurring towards tip of shell; ventral colour horn; outer lip colour differs from shell, brownish purple; inner lip colour pinkish. Protoconch 2.4 $\mathrm{mm}$ in diameter, comprising 1.7 whorls, smooth. Teleoconch smooth except of indistinct growth lines. Angle of aperture $45^{\circ}$; outer lip rounded, moderate to thick, expanded, slightly reflected, basal node of lip weak, palatal node absent. Parietal wall of inner lip absent.

Pallial morphology. Pallial cavity moderately deep, extending $3 / 4$ whorl; mantle pigmentation mottled, dark grey. Kidney extending about half of pallial cavity.

Genital morphology (Figs. 74-75). Penis straight, shorter than anterior part of oviduct, very thin. Vas deferens forms simple loop before entering penis. Penial retractor muscle of same length as penis. Penial sheath evenly thick. Penial verge comprising $1 / 8-1 / 4$ of penial chamber, slender to spatulate, with rounded tip. Penial wall pustules absent. Main stimulatory pilaster absent. Two smooth, narrow longitudinal pilasters comprise entire length of penial chamber; two additional smooth, narrow pilasters develop at base of penial chamber. Vas deferens rather thick, entering penial sheath apically. Vagina rather short, posteriorly inflated; inner vaginal wall densely covered by tiny pustules and smooth longitudinal pilasters. Spermatheca long, extending over base of spermoviduct. Spermathecal duct moderately

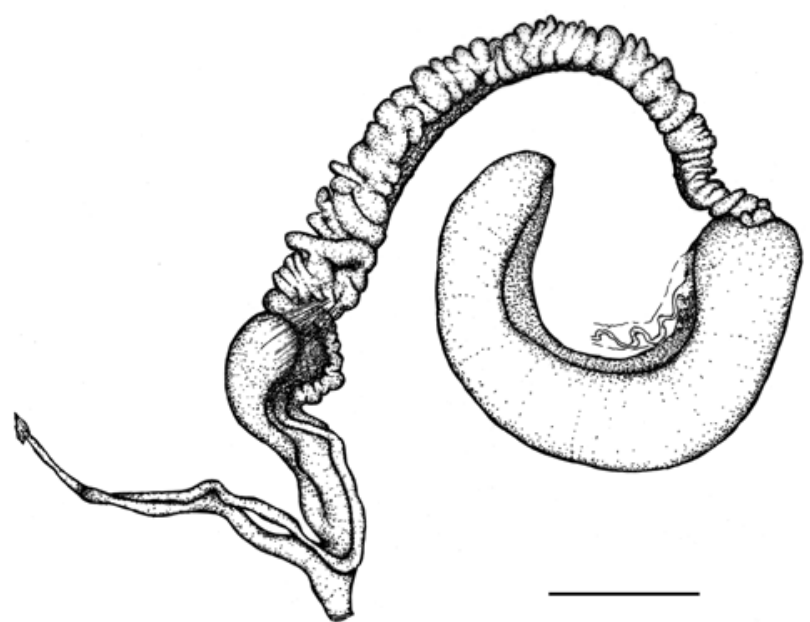

Figure 74. Genitalia of Amplirhagada basilica n.sp., paratype AMS C463720 (1 June, scale 10 mm). Compare with Fig. 3 for labelling of structures. 


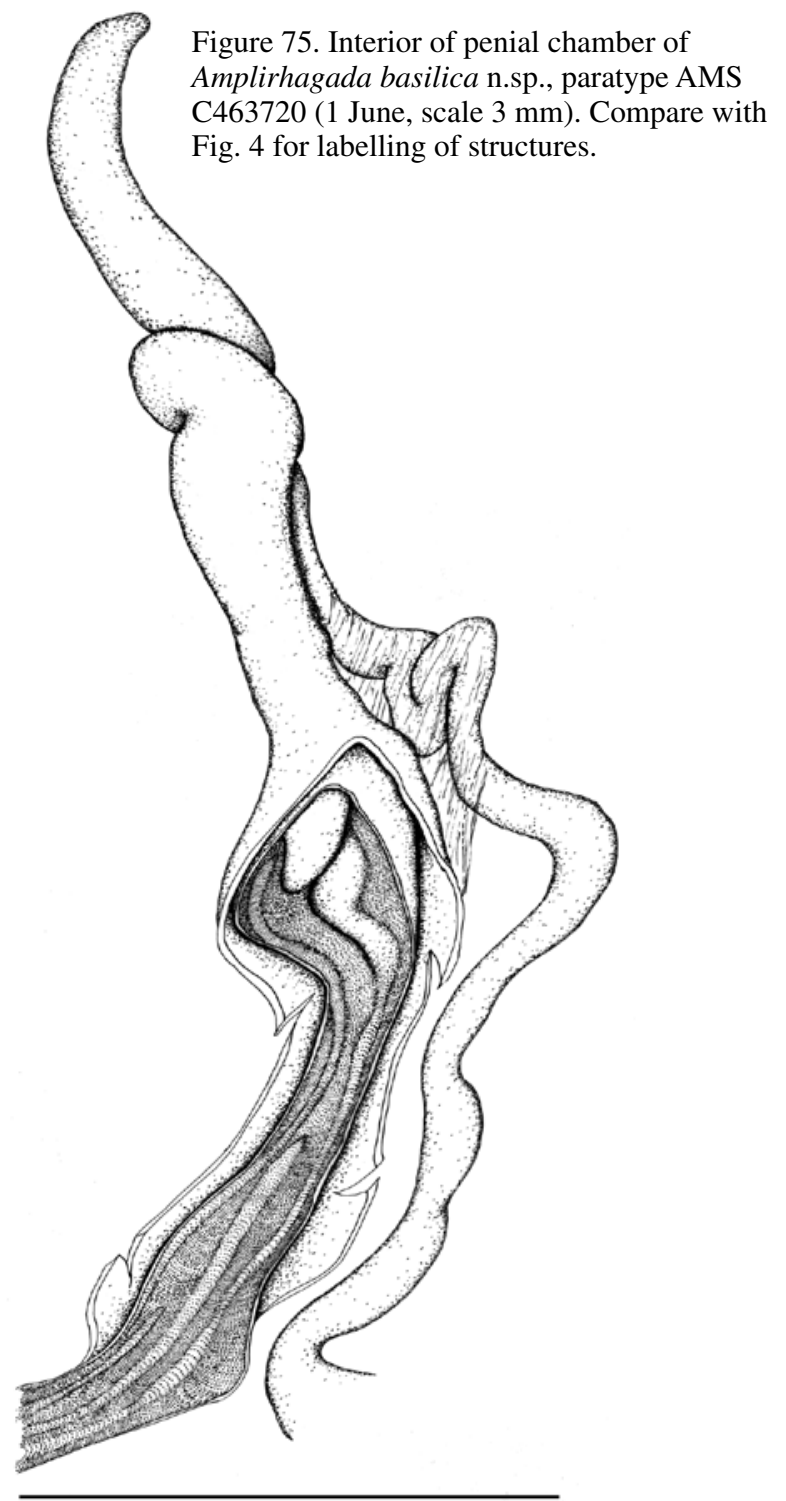

wide, internally with pustules. Spermathecal head globular, connected with oviduct by connective tissue, internally smooth, with thin wall. Free oviduct comprising half of anterior part of oviduct or more; more or less straight. Spermoviduct much longer than anterior part of oviduct. Talon embedded in albumen gland anteriorly.

Radular morphology (Fig. 73E-F). Rectangular. Tooth formula $\mathrm{C}+14+4+22$. In average $119 \pm 19.0$ rows of teeth, $28.0 \pm 0.4$ rows per $\mathrm{mm}(\mathrm{n}=2)$. Central teeth with bluntly pointedovate mesocone, shorter than base of teeth; ectocones vestigial. Lateral teeth with bluntly pointed, ovate mesocones, shorter than base of teeth; ectocones and endocones vestigial. Marginal teeth with broadly rounded mesocones; ectocones pointed, much smaller and narrower than mesocones; endocones vestigial.

Comparative remarks. One of the few species with large, dome-shaped shells. Differs from A. tricenaria and A. regia by dark outer lip. Purplish colour of outer lip similar to $A$. sphaeroidea. Absence of penial wall pustules is characteristic for this species.

\section{Amplirhagada camdenensis n.sp.}

Type locality (Fig. 1). Western Australia, Kimberley, Bonaparte Archipelago, Camden Sound, Augustus Island, northwestern section, $15^{\circ} 20^{\prime} 16^{\prime S}$ 12431'16"E; KIS 1-49. Vine thicket amongst boulders at base of sandstone cliffs, under rocks (leg. M. Shea, 25 May 2008).

Type material. Holotype WAM S34624 (Pl. 2.12). AMS C463722 (3 preserved specimens, as holotype), WAM S37006 (5 preserved specimens, as holotype), WAM S37005 (3 preserved specimens, $15^{\circ} 20^{\prime} 59^{\prime \prime} \mathrm{S}$ $\left.124^{\circ} 31^{\prime} 30^{\prime \prime} \mathrm{E}\right)$.

Additional, non-type material. WAM S37007-8, WAM S37445-50, WAM S41481, FMNH 219063 (Augustus Island).

Etymology. In reference to Camden Sound, in which Augustus Island is situated.

Sealing strategy. Free sealer.

Shell (Fig. 77A-B, Pl. 2.12). Globose, with medium to high spire; solid. Periphery evenly rounded to slightly angulate; upper sector of whorl flattened to slightly shouldered, basal sector rounded. Umbilicus forming a chink to narrowly winding opening, 40-100 percent concealed by columellar reflection. Background colour yellowish brown to horn; sub-sutural band diffuse, dark to chestnut brown, becomes more indistinct or blurs towards tip of whorl, may fuse with mid-whorl band to cover shell in light brown colour;

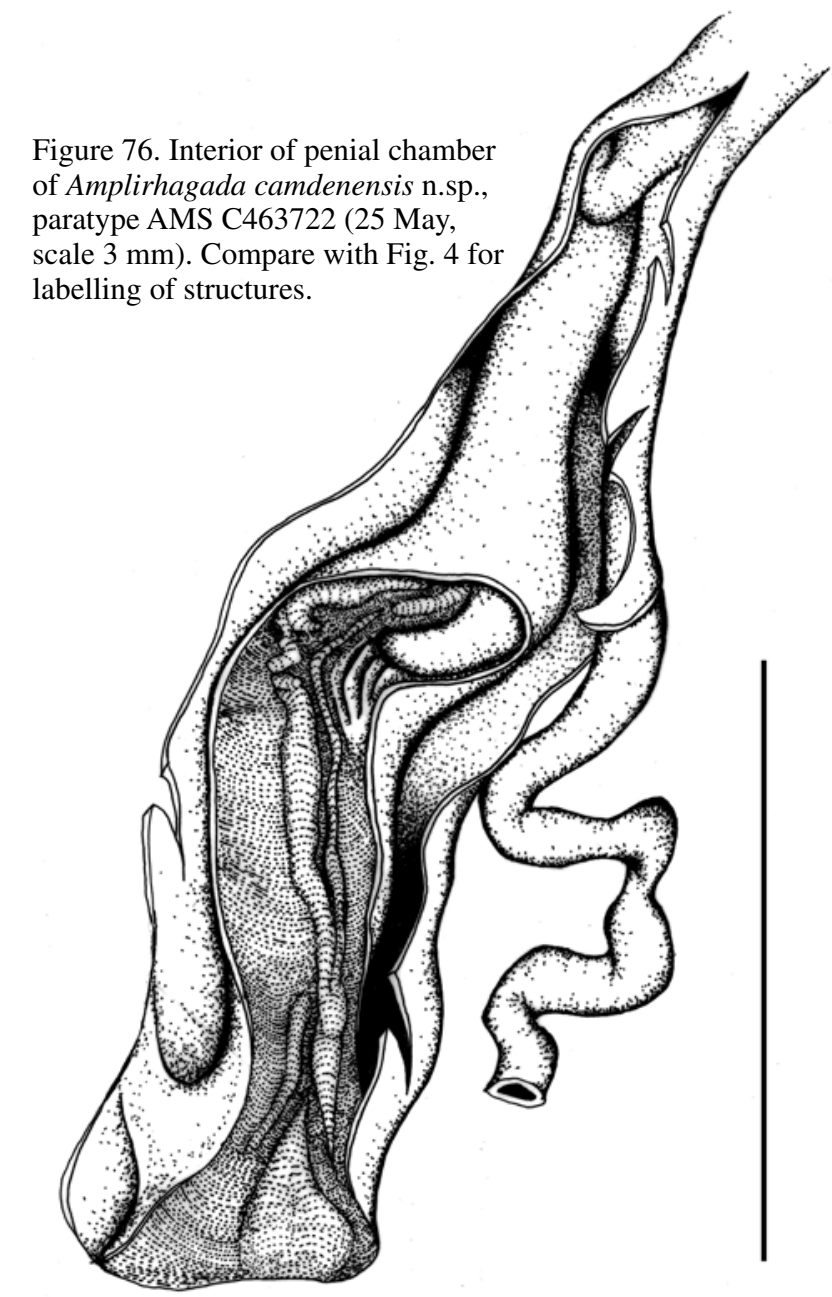



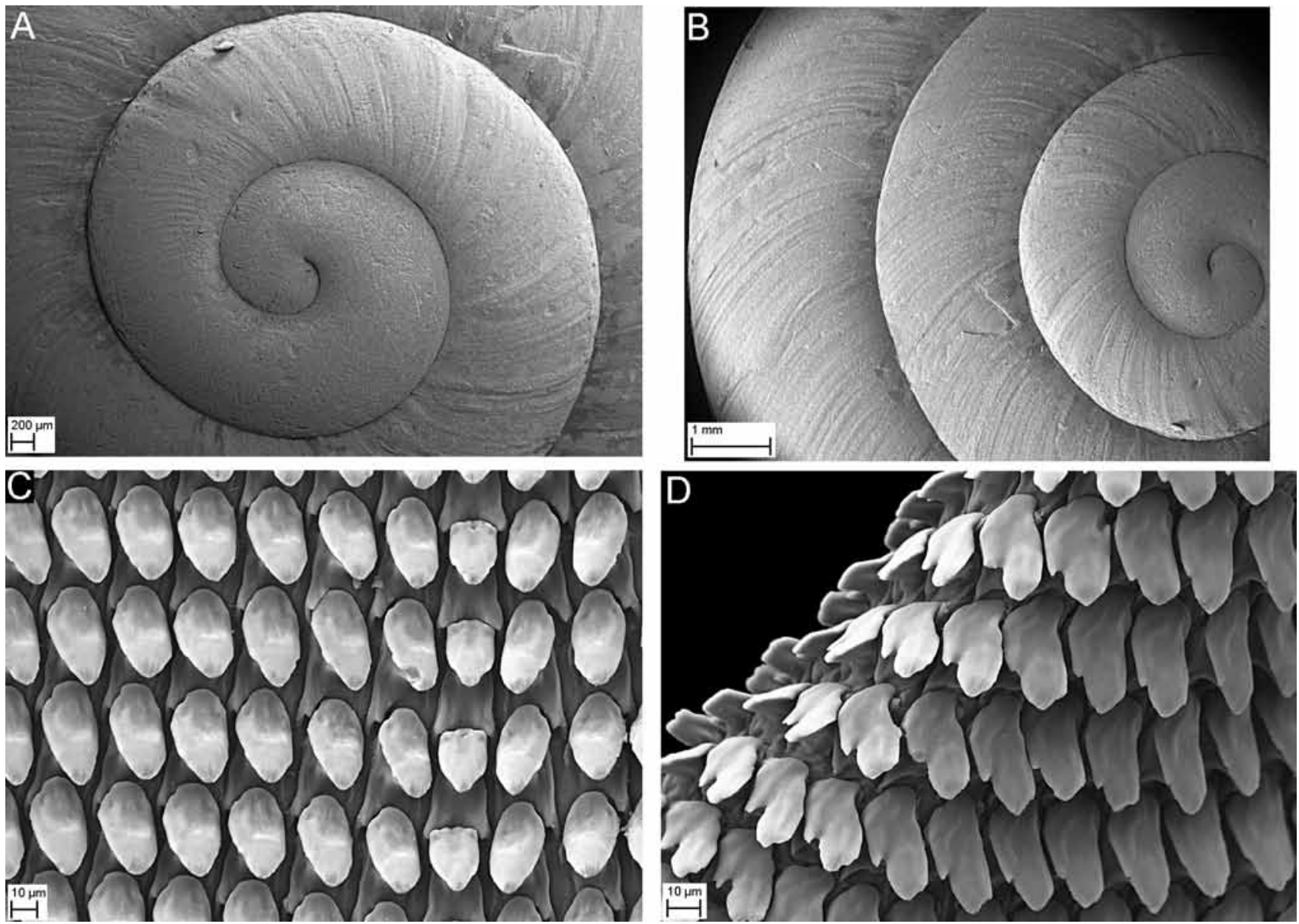

Figure 77. SEM photographs of shell and radula of Amplirhagada camdenensis n.sp., paratype AMS C463722: (A) apical whorl viewed from above (scale $200 \mu \mathrm{m}) ;(B)$ sculpture on first three whorls viewed from above (scale $1 \mathrm{~mm}$ ); $(C)$ close-up showing central and inner lateral teeth (scale $10 \mu \mathrm{m}) ;(D)$ close-up showing inner and middle marginal teeth (scale $10 \mu \mathrm{m})$.

mid-whorl band diffuse, dark to chestnut brown, thin to moderately broad, visible on last whorl(s) only; ventral colour whitish cream to yellowish brown; outer and inner lip colour differs from shell, pinkish brown. Protoconch c. 3.5 $\mathrm{mm}$ in diameter, comprising 2 whorls, smooth. Teleoconch smooth except of faint axial growth lines. Angle of aperture $30^{\circ}$; outer lip rounded, moderately thick, expanded, not or slightly reflected, basal and palatal node absent. Parietal wall of inner lip absent.

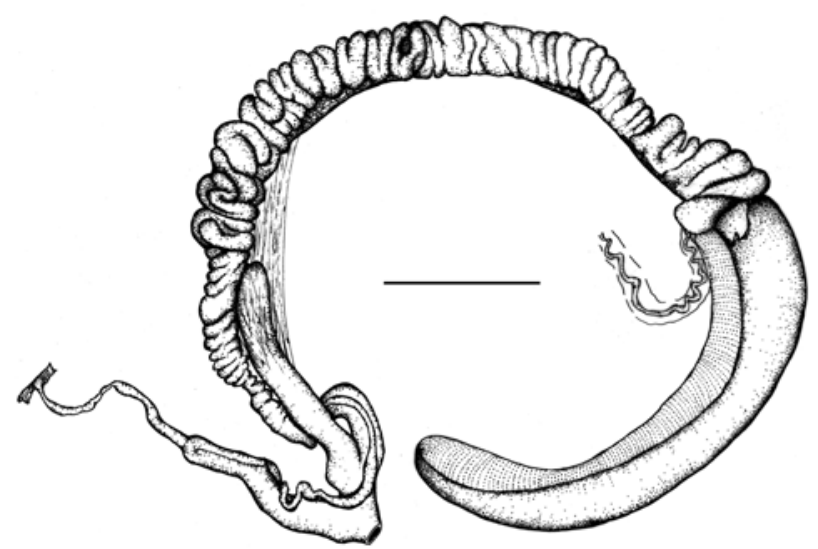

Figure 78. Genitalia of Amplirhagada camdenensis n.sp., paratype AMS C463722 (25 May, scale $10 \mathrm{~mm}$ ). Compare with Fig. 3 for labelling of structures.
Pallial morphology. Pigmentation on mantle mottled, dark grey. Kidney extending about half of pallial cavity.

Genital morphology (Figs. 76, 78). Penis straight, shorter than anterior part of oviduct, very thin. Vas deferens forms simple loop before entering penis. Penial retractor muscle as long as penis. Penial verge rather short (1/8-1/4 of length of penial chamber), broad, with pointed to rounded tip. Penial wall pustules absent. Main stimulatory pilaster not well differentiated, narrow, smooth, on apical to median portion of penial chamber. One to three additional, smooth, narrow pilasters on apical portion. Vas deferens entering penial sheath in upper third. Vagina rather short, medially to posteriorly inflated; inner vaginal wall predominantly smooth, with few weakly developed longitudinal pilasters. Spermathecal duct moderately wide, internally smooth. Spermathecal head globular to elongately inflated, connected with oviduct by connective tissue, internally smooth, with thin wall. Free oviduct comprising about half of anterior part of oviduct; more or less straight. Spermoviduct much longer than anterior part of oviduct. Talon embedded in albumen gland at junction with spermoviduct.

Radular morphology (Fig. 77C-D). Rectangular. Tooth formula $\mathrm{C}+16+4+$ ? With 122 rows of teeth, 27.4 rows per $\mathrm{mm}(\mathrm{n}=1)$. Central teeth with sharply pointed, triangular mesocones, shorter than base of tooth; ectocones vestigial. Lateral teeth with sharply pointed, triangular to ovate 

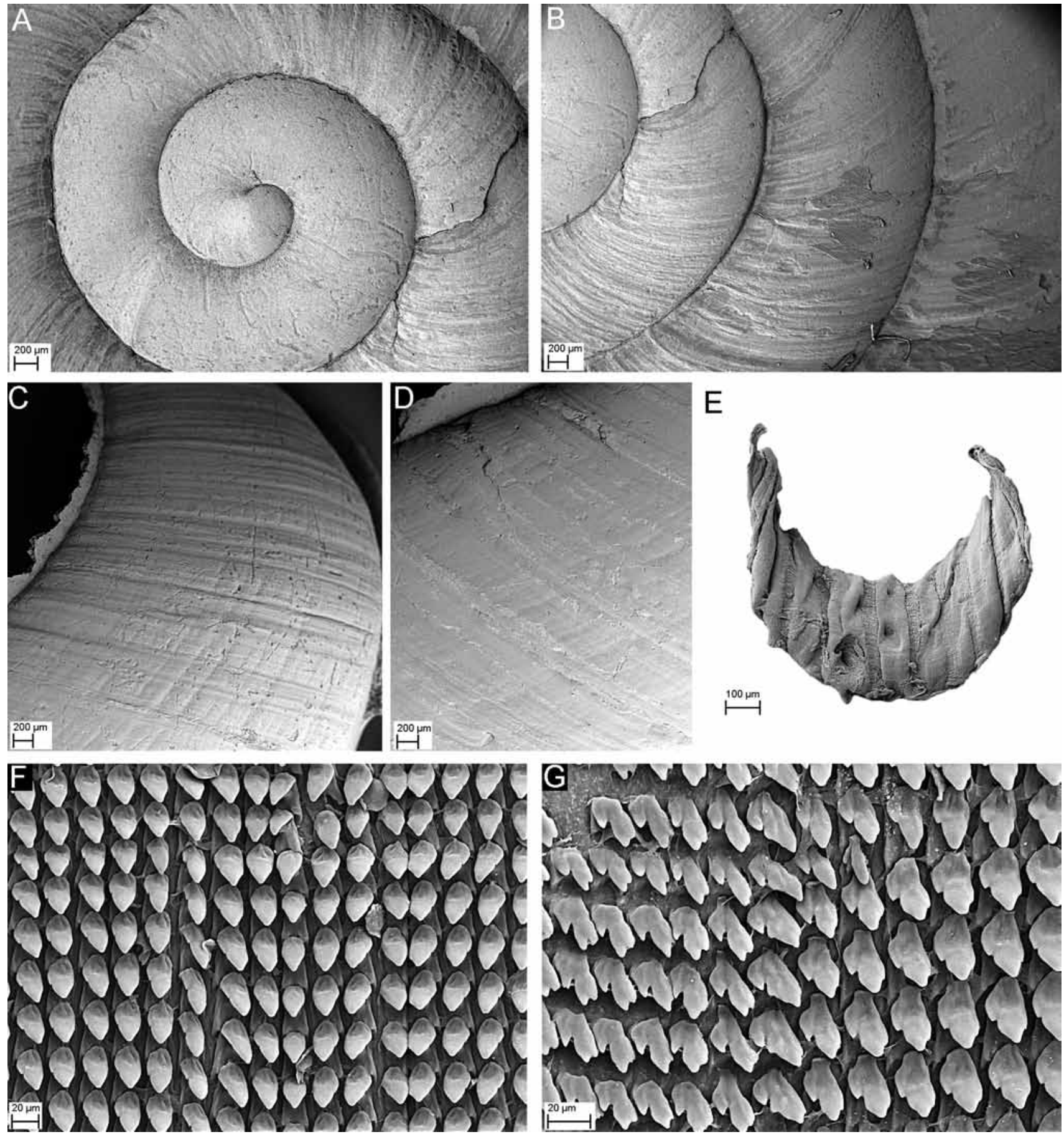

Figure 79. SEM photographs of Amplirhagada kimberleyana n.sp. (A-D) Shell, paratype FMNH 219055: $(A)$ apical whorl viewed from above (scale $200 \mu \mathrm{m}) ;(B)$ sculpture on first three whorls viewed from above (scale $1 \mathrm{~mm}$ ); $(C)$ close-up showing sculpture on penultimate whorl (scale $200 \mu \mathrm{m}) ;(D)$ close-up showing surface of last whorl (scale $200 \mu \mathrm{m})$. (E) Jaw, paratype AMS C463760 (scale $100 \mu \mathrm{m})$. ( $F-G)$ Radula, paratype AMS C463760: $(F)$ central and lateral teeth (scale $20 \mu \mathrm{m}) ;(G)$ outer lateral and inner marginal teeth (scale $20 \mu \mathrm{m})$.

mesocones, length equal to base of tooth; ectocones and endocones vestigial. Marginal teeth with triangular to broadly flattened mesocones; ectocones shorter and narrower than mesocones; endocones vestigial.

Comparative remarks. Material of this species has been labelled as "Amplirhagada sp. 65" by Solem. It has the smallest of all dome-shaped shells with a significantly higher $\mathrm{H} / \mathrm{D}$ ratio as most other species (Table 1). Absence of penial wall pustules and pattern of smooth, longitudinal pilasters are diagnostic.

\section{Amplirhagada kimberleyana n.sp.}

Type locality (Fig. 1). Western Australia, Kimberley, Bonaparte Archipelago, Camden Sound, northern Slate Islands, $2.4 \mathrm{~km}$ NW of Wilson Point, 15³2'10"S 124²3'56"E; KC-005 (leg. V. Kessner \& A. Longbottom, 09 July 1988).

Type material. Holotype WAM S34625 (Pl. 2.13). Paratypes AMS C463760 (5 preserved specimens), FMNH 219055 (21 preserved specimens), WAM S41480 (15 preserved specimens). 


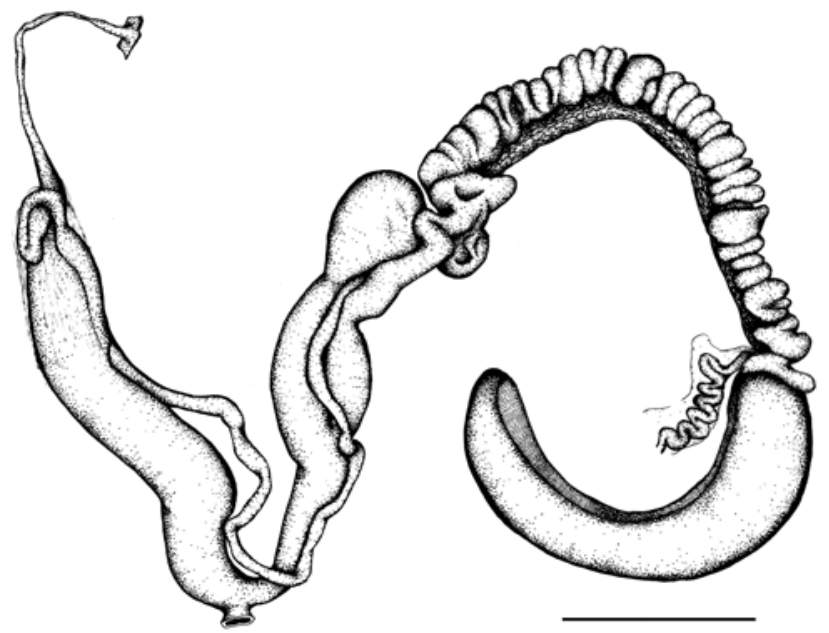

Figure 80. Genitalia of Amplirhagada kimberleyana n.sp., paratype AMS C463760 (9 July, scale 10 mm). Compare with Fig. 3 for labelling of structures.

Etymology. In reference to the Kimberley region.

Shell (Fig. 79A-D, Pl. 2.13). Semi-globose to broadly conical, with medium high spire; thin to solid (translucent). Periphery evenly rounded to slightly angulate; upper sector of whorl and basal sector rounded. Umbilicus forming a chink to narrowly winding opening, $60-100$ percent concealed by columellar reflection. Background colour beige-brown; subsutural band absent or diffuse, brown; mid-whorl band absent or diffuse, brown, thin, visible on last whorl only; ventral colour lighter, horn or whitish; outer lip colour differs from shell, light brown to whitish; inner lip whitish. Protoconch c. $3 \mathrm{~mm}$ in diameter, comprising 2 whorls, smooth. Teleoconch smooth except of axial growth lines. Angle of aperture $45^{\circ}$; outer lip rounded, moderately thick, slightly expanded, not or slightly reflected, basal and palatal node absent. Parietal wall of inner lip inconspicuous.

Pallial morphology. Pallial cavity moderately deep, extending $3 / 4$ whorl. Pigmentation on mantle mottled, black. Kidney extending about half of pallial cavity.

Genital morphology (Figs. 80-81). Penis straight, more or less of same length as anterior part of oviduct or longer. Vas deferens coils once before entering penis. Penial retractor muscle shorter than penis. Penial verge moderately long $(1 / 8-1 / 4$ penial chamber), slender to spatulate, with pointed tip. Penial wall pustules large, arranged in rows on apical to median portion of the penial chamber. Main stimulatory pilaster undifferentiated, formed by few rows of slightly enlarged, hooked pustules. Base of penial wall smooth, supporting two smooth and narrow pilasters. Vas deferens entering penial sheath in upper third. Vagina moderately long, tubular to posteriorly slightly inflated; inner vaginal wall with smooth longitudinal pilasters. Spermathecal duct wide, internally with corrugated longitudinal pilasters. Spermathecal head globular, connected with oviduct by connective tissue, internally smooth, with thin wall. Free oviduct comprising about half of anterior part of oviduct, more or less straight. Spermoviduct of same length as anterior part of oviduct. Talon embedded in albumen gland at junction with spermoviduct.

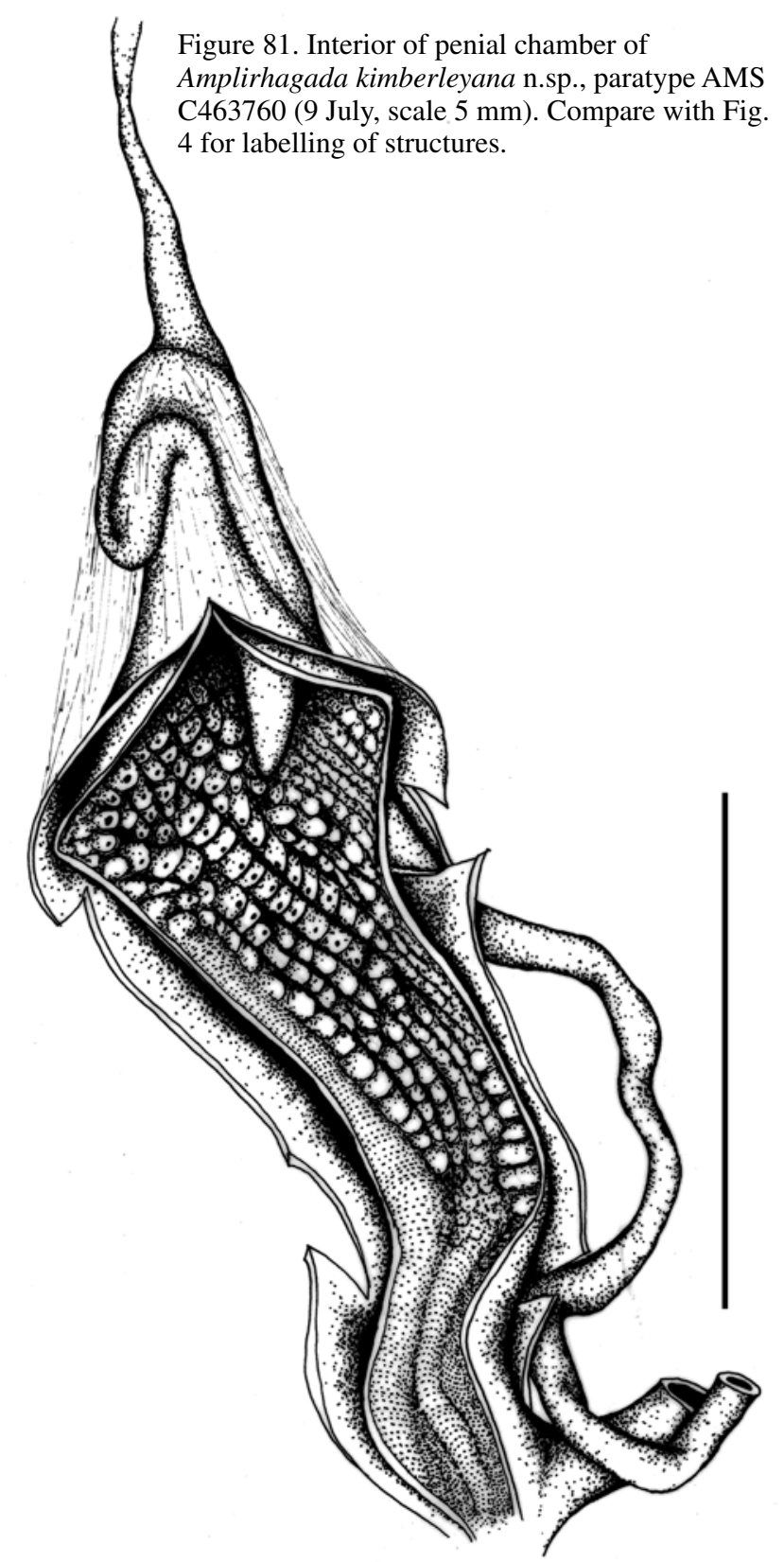

Radular morphology (Fig. 79F-G). Rectangular. Tooth formula $\mathrm{C}+16+3+22$. With 147 rows of teeth, 31.9 rows per $\mathrm{mm}(\mathrm{n}=1)$. Central teeth with sharply pointed, triangular mesocones, shorter than base of tooth; ectocones vestigial. Lateral teeth with sharply pointed, triangular mesocones, length equal to base of tooth; ectocones small, endocones vestigial. Marginal teeth with elongate to triangular mesocones; ectocones shorter and narrower than mesocones, divided into two denticles; endocones greatly reduced.

Comparative remarks. Shell broadly conical to domeshaped but smaller than species with similar shell shape. Inner penial wall with strong developed pustulation and undifferentiated main pilaster is diagnostic. Material of the present species has been labelled as "Amplirhagada sp. 64" by Solem. 

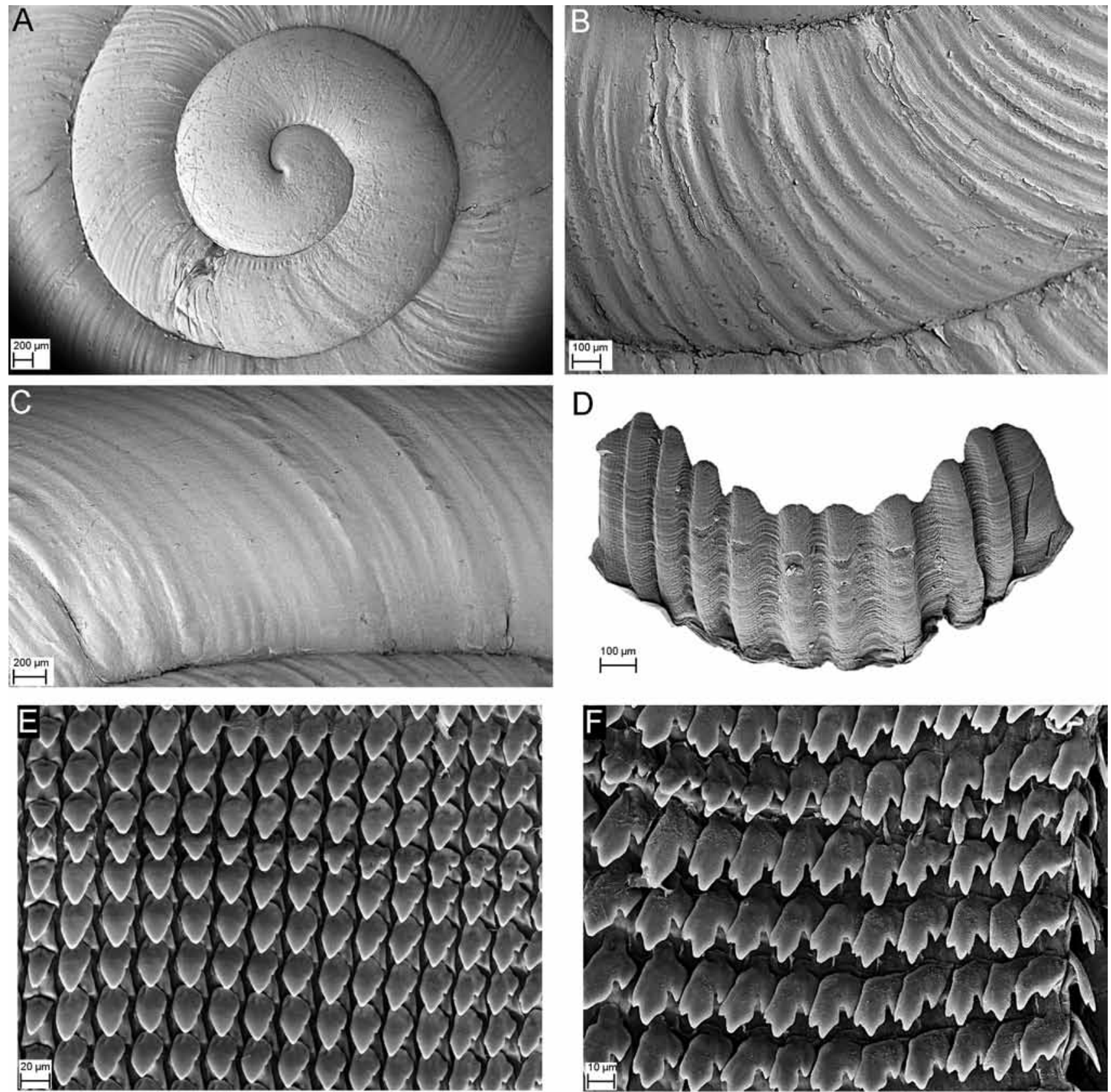

Figure 82. SEM photographs of Amplirhagada gemina n.sp. (A-B) Shell, holotype WAM S34626: $(A)$ apical whorl viewed from above (scale $200 \mu \mathrm{m}$ ); $(B)$ sculpture on second whorl viewed from above (scale $100 \mu \mathrm{m}$ ); $(C)$ close-up showing sculpture on penultimate whorl (scale $200 \mu \mathrm{m})$. (D) Jaw (scale $100 \mu \mathrm{m})$, paratype FMNH 219049. $(E-F)$ Radula, paratype FMNH 219049: $(E)$ central and lateral teeth (scale $20 \mu \mathrm{m}) ;(F)$ middle marginal teeth (scale $10 \mu \mathrm{m}$ ).

\section{Amplirhagada gemina n.sp.}

Type locality (Fig. 1). Western Australia, Kimberley, Bonaparte Archipelago, Camden Sound, mainland $4.5 \mathrm{~km}$ $\mathrm{N}$ of Prior Point, $1.5 \mathrm{~km}$ SE of Hall Point; KC-005 (leg. V. Kessner \& A. Longbottom, 09 July 1988).

Type material. Holotype WAM S34626 (Pl. 2.14). Paratypes AMS C463761 (preserved specimen), FMNH 219049 (5 preserved specimens), WAM S41479 (3 preserved specimens).

Etymology. From gemina $($ Latin $=$ twin-born $)$, in reference to its close overall similarity with its sibling species $A$. kimberleyana.
Shell (Fig. 82A-C, Pl. 2.14). Semi-globose to broadly conical, with medium spire, thin to solid (translucent). Periphery evenly rounded to slightly angulate; upper and basal sectors of whorls rounded. Umbilicus forming a chink to narrowly winding opening, 60-100 percent concealed by columellar reflection. Background colour beige brown sub-sutural band absent or diffuse, brown; mid-whorl band absent or diffuse, brown, thin, visible on last whorl only; ventral colour lighter, horn or whitish; outer lip colour differs from shell, light brown to whitish; inner lip whitish. Angle of aperture $45^{\circ}$, outer lip moderately thick, slightly expanded, not or slightly reflected, basal and palatal node absent. Teleoconch with pronounced axial growth lines 


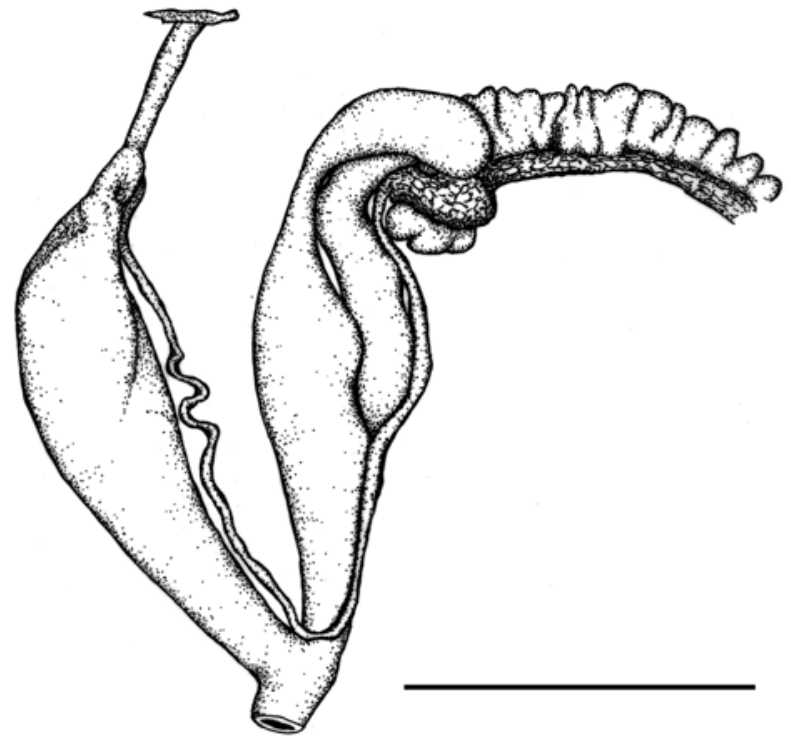

Figure 83. Genitalia of Amplirhagada gemina n.sp., holotype WAM S34626 (9 July, scale $10 \mathrm{~mm}$ ). Compare with Fig. 3 for labelling of structures.

which become more oblique towards the base of the shell. Parietal wall of inner lip inconspicuous.

Pallial morphology. Pallial cavity moderately deep, extending $3 / 4$ whorl; mantle pigmentation mottled, black. Kidney extending about half of pallial cavity.

Genital morphology (Figs. 83-84). Penis straight, more or less of same length as anterior part of oviduct. Vas deferens coils once before entering penis. Penial retractor muscle shorter than penis. Penial verge short $(<1 / 8$ penial chamber), slender to spatulate, with pointed tip. Penial wall pustules rather large, arranged in rows on entire wall of penial chamber, becoming more oblique towards base. Main stimulatory pilaster not well differentiated, covered by undifferentiated pustules, comprising apical to median portion of penial chamber. Vas deferens entering penial sheath in upper third. Vagina moderately long, tubular to posteriorly inflated. Inner vaginal wall with smooth longitudinal pilasters. Spermathecal duct wide, inflated, internally with smooth longitudinal pilasters. Spermathecal head elongately inflated, connected with oviduct by connective tissue, internally smooth, with delicate wall. Free oviduct comprising about half of anterior part of oviduct, more or less straight. Posterior parts of genital system unknown.

Radular morphology (Fig. 82E-F). Rectangular. Tooth formula $\mathrm{C}+16+4+20$. With 150 rows of teeth, 34.2 rows per $\mathrm{mm}(\mathrm{n}=1)$. Central teeth with sharply pointed, triangular mesocones, shorter than base of tooth; ectocones vestigial. Lateral teeth with sharply pointed, triangular mesocones, length equal to base of tooth; ectocones tiny, endocones vestigial. Marginal teeth with elongate to triangular mesocones; ectocones shorter and narrower than mesocones; endocones smaller than ectocones.

Comparative remarks. Smaller than other species with broadly conical to dome-shaped. Inner penial wall pustules

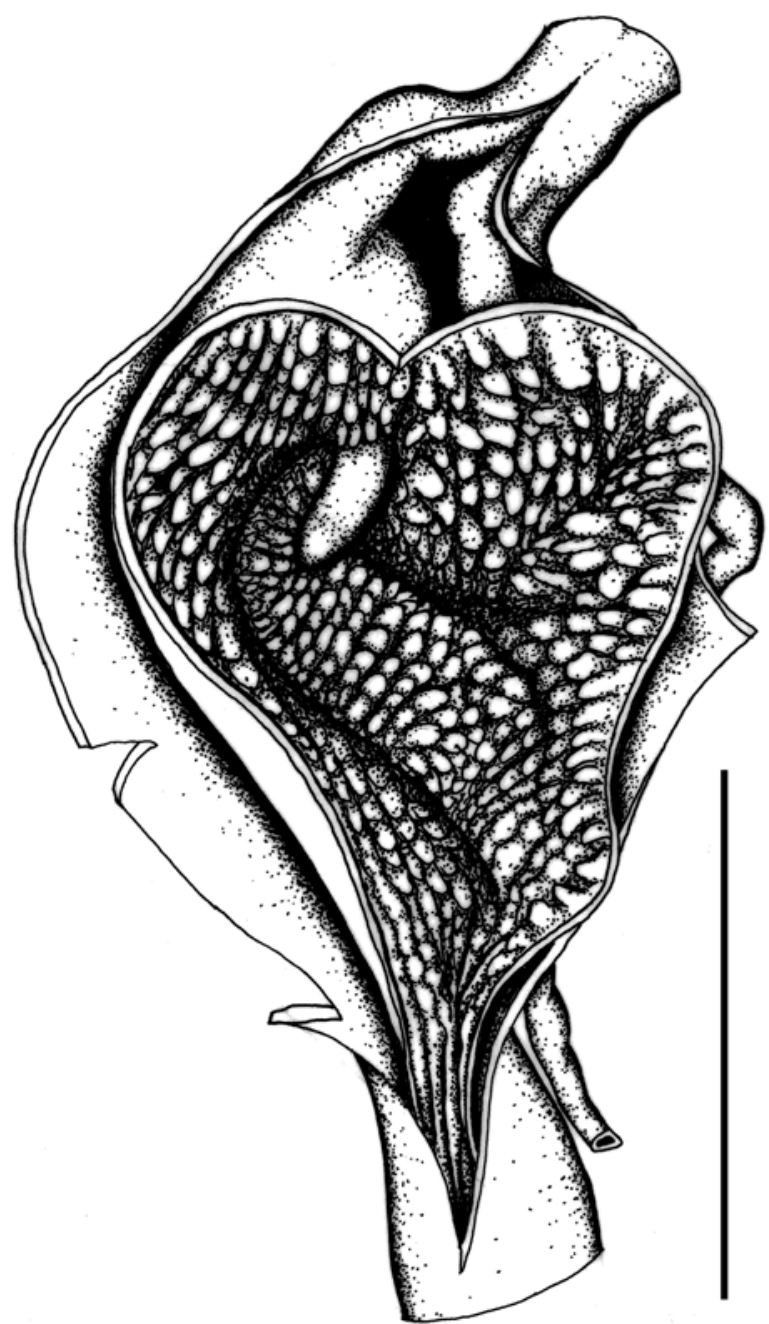

Figure 84. Interior of penial chamber of Amplirhagada gemina n.sp., holotype WAM S34626 (9 July, scale $3 \mathrm{~mm}$ ). Compare with Fig. 4 for labelling of structures.

larger and denser than in A. kimberleyana. Although morphologically similar, both species are genetically welldifferentiated. Material of the present species has been labelled as "Amplirhagada sp. 64" by Solem together with material of A. kimberleyana, which has a similar shell.

\section{Amplirhagada dubitabile n.sp.}

Type locality (Fig. 1). Western Australia, Kimberley, Bonaparte Archipelago, Doubtful Bay, Steep Island, $2.3 \mathrm{~km}$ NE of Raft Point, $16^{\circ} 03^{\prime} 36^{\prime \prime S} 124^{\circ} 22^{\prime} 03^{\prime \prime E}$; KC-002 (leg. V. Kessner \& A. Longbottom, 08 July 1988).

Type material. Holotype WAM S34627 (Pl. 2.15). Paratypes AMS C463762 (3 preserved specimens), FMNH 219047 (8 preserved specimens), WAM S41478 (5 preserved specimens).

Etymology. From dubitabile $($ Latin $=$ doubtful), in reference to Doubtful Bay, where this species occurs on Steep Island.

Shell (Fig. 85A-C, Pl. 2.15). Semi-globose to broadly conical, with medium high spire; solid. Periphery slightly angulate; upper and basal sectors of whorls rounded. Umbilicus open, forming narrowly winding opening, 30-70 

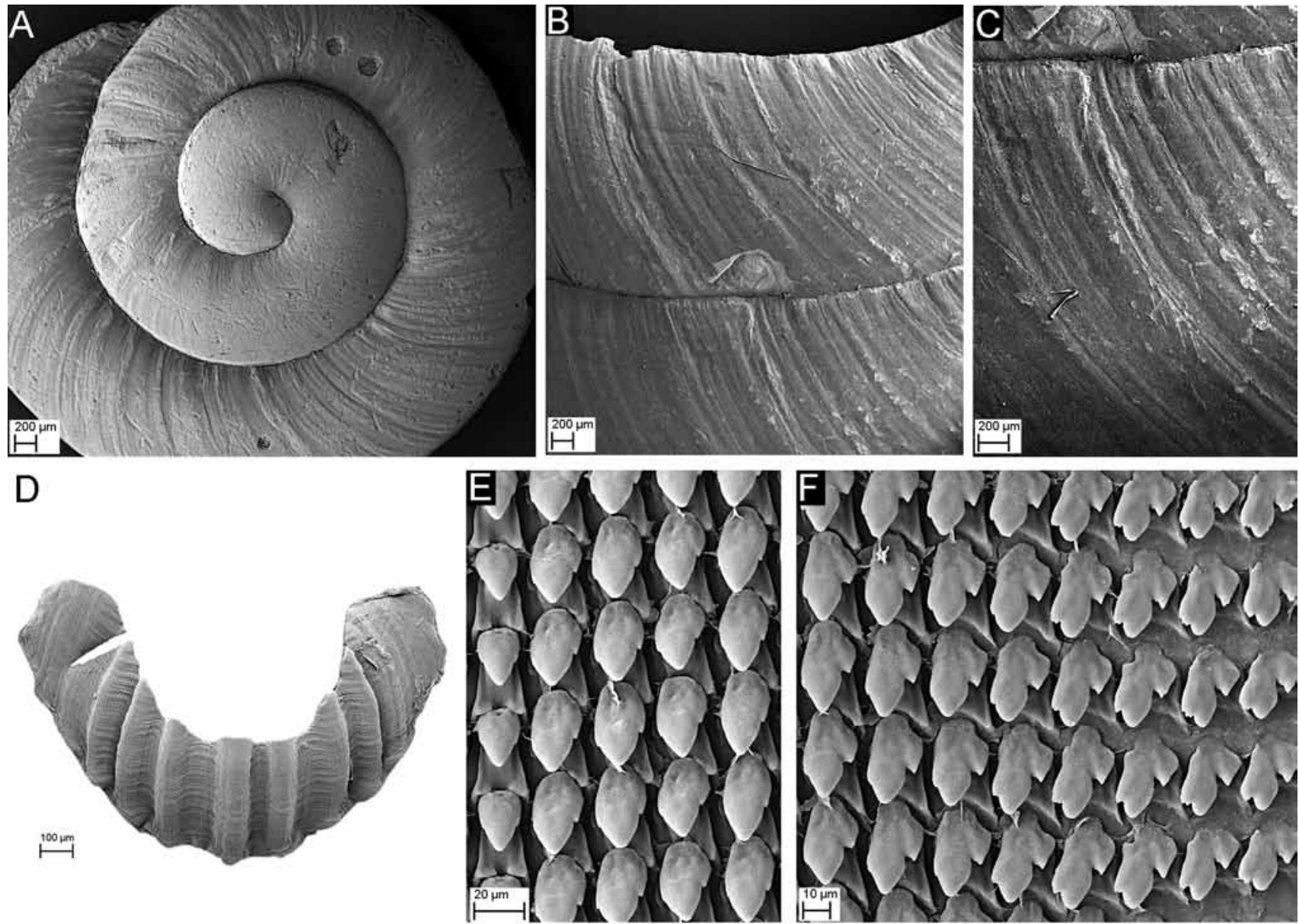

Figure 85. SEM photographs of shell, jaw and radula of Amplirhagada dubitabile n.sp., paratype FMNH 219047: (A) apical whorl viewed from above (scale $200 \mu \mathrm{m}$ ); $(B)$ sculpture on penultimate whorl viewed rectangular from above (scale $200 \mu \mathrm{m}$ ); $(C)$ close-up showing growth lines on last whorl (scale $200 \mu \mathrm{m}) ;(D)$ jaw (scale $100 \mu \mathrm{m}) ;(E)$ central and inner lateral teeth (scale $20 \mu \mathrm{m}) ;(F)$ outer lateral and inner marginal teeth (scale $20 \mu \mathrm{m}$ ).

percent concealed by columellar reflection. Background colour brownish beige, may display irregular pattern of hornish growth lines; sub-sutural band absent; mid-whorl band absent or diffuse, yellowish brown, thin, visible on last whorl only; ventral colour horn; outer lip colour differs from shell, horn; inner lip whitish. Protoconch c. $2.8 \mathrm{~mm}$ in diameter, comprising 2 whorls, smooth. Teleoconch with pronounced axial growth lines. Angle of aperture $45^{\circ}$; outer lip rounded, moderately thick, slightly expanded, not or slightly reflected, basal and palatal node absent. Parietal wall of inner lip inconspicuous.

Pallial morphology. Pallial cavity short, extending half a whorl; mantle pigmentation mottled, greyish black. Kidney extending about half of pallial cavity.

Genital morphology (Figs. 86-87). Penis straight, more or less of same length as anterior part of oviduct. Vas deferens coils once before entering penis. Penial retractor muscle shorter than penis. Penial verge short $(<1 / 8$ penial chamber), broad, pointed. Penial wall pustules absent; wall covered by delicate, narrow, longitudinal pilasters. Main stimulatory pilaster well-differentiated; smooth undulating, well developed at apical portion, decreasing in size in median portion, largely reduced at basal portion of penial chamber. Vas deferens entering penial sheath in upper third.
Vagina rather short, posteriorly inflated; inner vaginal wall with weakly developed longitudinal pilasters. Spermatheca slightly extending over base of spermoviduct. Spermathecal duct wide, internally with smooth longitudinal pilasters. Spermathecal head globular, connected with oviduct by connective tissue, internally smooth, with delicate wall. Free oviduct comprising about half of anterior part of oviduct, more or less straight. Spermoviduct longer than anterior part of oviduct. Talon embedded in albumen gland close to anterior end of albumen gland.

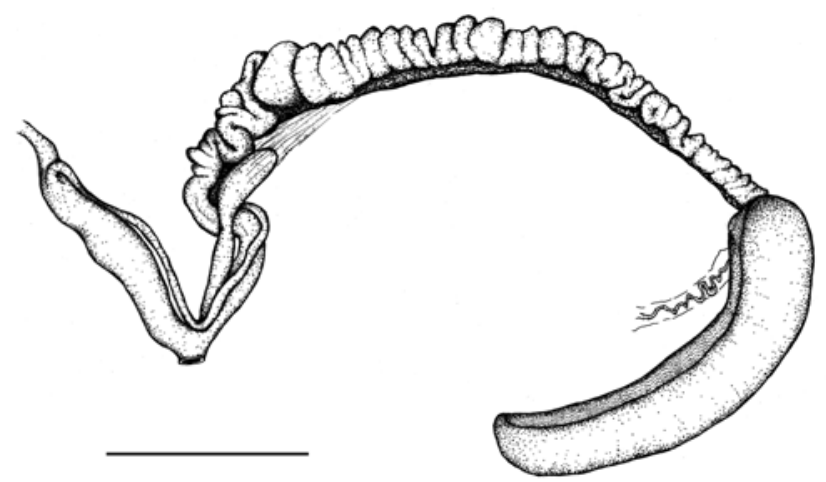

Figure 86. Genitalia of Amplirhagada dubitabile n.sp., paratype FMNH 219047 (8 July, scale 10 mm). Compare with Fig. 3 for labelling of structures. 


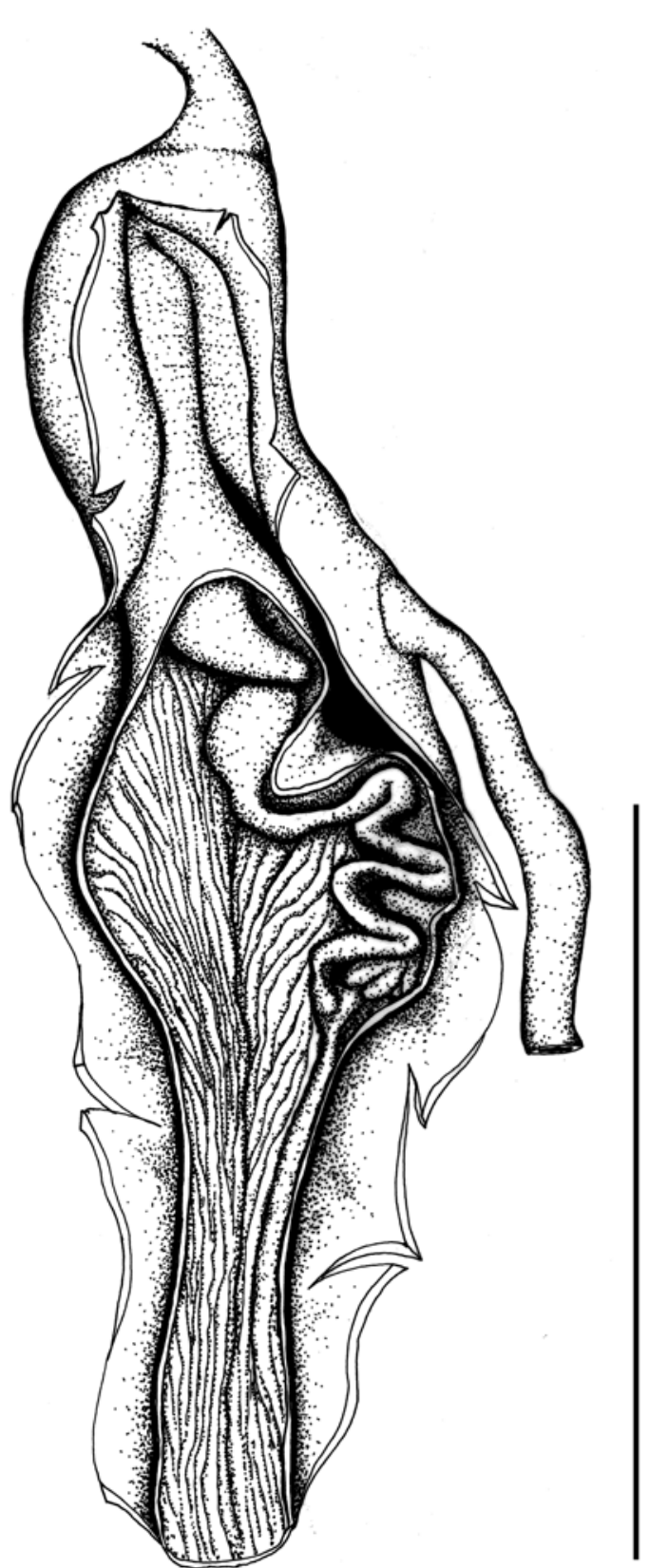

Figure 87. Interior of penial chamber of Amplirhagada dubitabile n.sp., paratype FMNH 219047 (8 July, scale 3 mm). Compare with Fig. 4 for labelling of structures.

Radular morphology (Fig. 85E-F). Rectangular. Tooth formula $\mathrm{C}+16+3+22$. With 139 rows of teeth, 32.3 rows per $\mathrm{mm}(\mathrm{n}=1)$. Central teeth with sharply pointed, triangular mesocones, shorter than base of tooth; ectocones vestigial. Lateral teeth with sharply pointed, triangular to ovate mesocones, length equal to base of tooth; ectocones small; endocones vestigial. Marginal teeth with elongate to triangular mesocones; ectocones shorter and narrower than mesocones; endocones smaller than ectocones.

Comparative remarks. Material of this species has been labelled as "Amplirhagada sp. 63" by Solem. Shell similar to A. kimberleyana and A. gemina in shape, size, and colouration. Inner penial wall structure (lamellae, no pustules with long, undulating main pilaster) very characteristic.

\section{Amplirhagada napierana Solem, 1981}

Amplirhagada napierana Solem, 1981a: 225-232, pl. 14d, figs. 36b, 48a-b, 50, 51a (Barker Gorge, Napier Range).

Material examined. AMS C150457 (Western Australia, Napier Range, E side, $1.2 \mathrm{~km} \mathrm{~N}$ of Napier Downs, $17^{\circ} 19.5^{\prime} \mathrm{S} 124^{\circ} 48.0^{\prime} \mathrm{E}$ ) (Fig. 1, Pl. 2.16).

Remarks. This species was described from various localities in the Napier Range, where it occurs in three disjunct areas in close proximity but not sympatrically with $A$. percita. The anatomy was described by Solem (1981a). The penial morphology of the present sample corresponds with the original description. This species is represented in the molecular tree shown below.

\section{Amplirhagada percita (Iredale, 1939)}

Tenuigada percita Iredale, 1939: 68, pl. V, fig. 14 (northern end of Napier Range), Solem, 1981a: 211-225, pl. 14e-f, figs. $47 \mathrm{a}-\mathrm{j}, 50 \mathrm{c}, 51 \mathrm{~b}-\mathrm{c}$.

Tenuigada ignara Iredale, 1939: 68, pl. V, fig. 13 (north end of Napier Range).

Nomenclatural remarks. Iredale (1939) described the two species, A. percita and A. ignara, based on series of dry shells. Subsequently, the two names were synonymized by Solem (1981a), who revised the genus, on the grounds that no significant difference in the shells were found, which would justify treatment as distinct species. However, Solem (1981a) also stated that he found distinct differences between allopatric populations of this species. Hence, it remains to be critically tested whether the taxon as currently delimited by Solem (1981a) encompasses more than a single species.

Material examined. AMS C144028 (Western Australia, Napier Range, 24 $\mathrm{km} \mathrm{N}$ of Wagon Pass, $17^{\circ} 04.5^{\prime \prime S} 124^{\circ} 34^{\prime} \mathrm{E}$ ) (Fig. 1, Pl. 2.17).

Remarks. A sample of this species is represented in the molecular tree shown below.

\section{Amplirhagada varia Solem, 1981}

Amplirhagada varia varia Solem, 1981a: 294-300, pl. 13c, figs. 36e, 65b, 66a, 67a-b, 69a-d (Mitchell Plateau, AMAX port, Warrender Road).

Material examined. AMS C460963 (track to Crystal Creek, $1.5 \mathrm{~km}$ from Walsh Point, $14.446^{\circ} \mathrm{S} 125.792^{\circ}$ E) (Fig. 1, Pl. 2.18).

Remarks. Solem (1981a) described two subspecies, A. varia varia and $A$. varia depressa, which essentially differ in the length of the penial verge. Both taxa are found in very close geographical proximity. They were apparently treated as subspecies because of their otherwise very close anatomy. However, as they do not meet the criteria of geographical races that replace each other, I suggest elevating both to the rank of distinct species. Consequently, herein I refer to the species name $A$. varia for the so-called nominate form. The penis anatomy of the present sample corresponds with the figures shown by Solem (1981a). This species is represented in the molecular tree shown below. 


\section{Amplirhagada mitchelliana Solem, 1981}

Amplirhagada mitchelliana Solem, 1981a: 272-280, pl. 13b, figs. 37i, 55c-d, 61c-e, 62a-b, 64a (Mitchell Plateau, Warrender Road).

Material examined. WAM S41462 (lookout on track between Mitchell Plateau camp and Walsh Pool) (Fig. 1, Pl. 2.19), AMS C144039 (Mitchell Plateau, Mitchell Plateau Road, 43.6 km W of Gibb Road-Kalamburu turnoff).

Remarks. Found in the same area as A. varia, this species differs most significantly from the former by a distinct anatomy of the interior penial wall. The penis anatomy of the present sample corresponds with that shown by Solem (1981a). This species is represented in the molecular tree shown below. The two samples sequenced herein do not form a monophyletic cluster but are separated by a considerable uncorrected pair-wise genetic distance of $17 \%$ and are shown as non-monophyletic with respect to $A$. varia. This indicates problems with the species recognition and probably the presence of an unidentified species.

\section{Amplirhagada castra Solem, 1981}

Amplirhagada castra Solem, 1981a: 286-293, pl. 13d, figs. 37h, 63a-b, 64b, 67e-f, 68 (Mitchell Plateau, Camp Creek).

Material examined. AMS C460966 (track to Mitchell Plateau ranger Station, 14.821 S 125.721 E) (Fig. 1, Pl. 2.20).

Remarks. Found in the same area as $A$. varia and $A$. mitchelliana this species differs most significantly from the former two by a distinct anatomy of the interior penial wall. The penis anatomy of the present sample corresponds with that shown by Solem (1981a). This species is represented in the molecular tree shown below.

\section{Molecular phylogeny}

Phylogenetic trees were reconstructed for a sequence data set with a length of 655 bp that comprised 53 sequences representing 28 species of Amplirhagada and two out-group sequences of Carinotrachia. DNA was successfully extracted from up to 20 years old museum samples but it was not possible to amplify the mitochondrial COI fragment from all studied Amplirhagada species because DNA quality was sometimes low. Nevertheless, the phylogeny contains a representative subsample of the species treated in this paper.

Rates of transitions and transversions were plotted against sequence divergence (corrected after Tamura \& Nei, 1993) by use of DAMBE (Xia \& Xie, 2001) in order to test for substitution saturation. Both curves showed nearly linear relationships indicating no significant levels of saturation. A hierarchical likelihood ratio test implemented in Treefinder revealed the generally time reversible model of sequence evolution $(\mathrm{GTR}+\mathrm{I}+\Gamma)$ as the best-fit model. Settings were adjusted accordingly in the following ML and BI analyses.

Trees obtained by the three different analytical techniques (MP, ML, BI) revealed widely congruent topologies that differed only in minor aspects. The maximum parsimony tree found by the MP Ratchet (length 2052 steps, $\mathrm{Ci}=25$, $\mathrm{Ri}=66)$ showed A. napierana as the most basal offshoot within the genus (Fig. 88). By contrast, the BI tree (Fig. 89) and the ML trees (not depicted) showed this species in an unresolved relationship with respect to the out-group and all other Amplirhagada species. Next to A. napierana, all trees reveal essentially five species clusters (Figs. 88-89). The basal relationships between these clusters are not well supported in terms of branch support values and are unresolved in the Bayesian tree (Fig. 89). Nodal support within the clusters, however, is usually high. The sister pair of A. buffonensis and A. yorkensis (Cluster 1) is consistently shown in a position basal to all other clades. Monophyly of this species pair receives high nodal support. The four other clusters contain species that do not always restricted to certain geographical areas. Cluster 2 (A. kimberleyana and other species) encompasses taxa from Boongaree Island and all coastal areas south of it. Most of these species have rather dome-shaped shells (except for A. kimberleyana) and are free sealers; the branching order is consistently revealed by all three trees. Cluster 3 contains species that are distributed to areas between the Napier Ranges in the hinterland (A. percita) to islands of the central Kimberley coast (A. katerana, A. berthierana). The MP cladogram indicates that species of Cluster 4 from the Mitchell Plateau (A. castra, A. mitchelliana) and A. kessneri from Bigge Island are more closely related to Cluster 2 , while the BI shows the relationships between them and A. tricenaria as unresolved. Cluster 5 contains species from islands in the Admiralty Gulf and the Mitchell Plateau (A. varia and others).

Pair-wise genetic distances within species did not exceed the maximum of $4 \%$ found between the two sequences of A. combeana. Average pair-wise distances between species usually range between 26 and $35 \%$ (corrected sequence divergence, Tamura \& Nei, 1993) or 16 and 23\% of uncorrected p-distance. Average interspecific distances between some species, which are very close to each other in the phylogenetic tree were not lower than 10\% (Tamura-Nei distances) or $8 \%$ (p-distances). 


\section{Discussion}

\section{Species delimitation by means of morphology and molecules}

Solem (1981a) established that the most informative and convenient source of information for identifying species of Amplirhagada is the genital anatomy, particularly the structure of the inner penial wall and development of the main stimulatory pilaster. Naturally, the development and relative size of some genital structures depends on the maturity of the animal and on its actual reproductive state. Among fully mature specimens (with adult shell features and fully developed albumen gland), a simple pattern of seasonal variation is found with the genitalia being inactive and reduced in size during the early to middle dry season between May and August (Solem \& Christensen, 1984). As figures and descriptions of genital features herein are based exclusively on the examination of adult specimens collected at the end of the dry or during the wet season (November to April), this phenomenon should not seriously affect the assessment of these features with respect to the delimitation of taxa.

The marked interspecific differentiation in the reproductive anatomy and the observation that differences are greater when species occur in sympatry led Solem (1981a) to argue that the structure of penial and vaginal walls may have a significant function in mate recognition. Recent findings of reproductive character displacement in genital morphology of Asian camaenids (Satsuma) seem to provide evidence in support of this idea (Kameda et al., 2009).

Contrasting the significance of reproductive anatomy, Solem (1981a) found that shell features often are of limited value for the recognition of species. Species that occur under allopatric conditions may exhibit quite similar shells while conversely species found in sympatry are usually well recognisable by their shells. Radulae and jaws have been considered rather useless for the differentiation of taxa at species level by Solem (1981a). Similar assessments of anatomical characters have been made also with regard to other Australian (Willan et al., 2009; Köhler, 2010), Asian (e.g., Chiba, 1999a; Kameda et al., 2007; Chiba \& Davison, 2008) and New Guinean Camaenidae (e.g., Jordaens et al., 2009).

In the present study, the observations and conclusions of Solem (1981a) with regard to the significance of morphological characters for the recognition of species are generally confirmed. The considerable genetic differentiation of species supports the appraisal of reproductive features. Species delimited by their anatomy are differentiated on average by Tamura-Nei distances of about $30 \%$ in the mitochondrial marker COI. In the few exceptions to this general rule, species were found to be separated by as little as $10 \%$ sequence divergence (such as $A$. combeana and A. montesquieuana). However, even these rates of genetic differentiation do not seriously contradict the supposed status as distinct species. Corresponding with Solem's (1981a) statements on Amplirhagada (see also Solem, 1979, 1981b, 1984, 1985, 1988, 1993; 1997 for other camaenid groups from Western Australia), the anatomy of the penis (i.e., the structure and development of inner penial wall, main stimulatory pilaster, and penial verge) is most informative on the species level. Differentiation within populations was generally negligible compared to the well-marked differences between species. Also, the differences in the genital anatomy between sympatric species (e.g., A. kessneri and A. decora on Bigge Is., A. boongareensis, A. gibsoni, A. regia on Boongaree Is) are often pronounced - well in agreement with the statement of Solem (1981a). Only in one allopatric species pair, A. solemiana and A. indistincta, were virtually no differences observed in the genital anatomy. Both species occur on neighbouring islands and form a sister pair. They are genetically well-differentiated and can be distinguished by their shell size (Fig. 8).

Shell characters have otherwise been revealed as being of limited value for the discrimination of Amplirhagada species. Shells of most species are within a size range of 15 to $25 \mathrm{~mm}$ in diameter with few exceptions from this rule (Table 1). The general shape of the shell (i.e., broadly conical or dome-shaped) is a feature often found in a clade with little differentiation among the constituent species. This is illustrated by the example of the clade of dome-shaped species (A. uwinsensis, A. sphaeroidea, A. regia, and A. camdenensis), all of which have very similar shells. It is correct, though, that sympatric species tend to show more pronounced differences in the shell, which may facilitate species recognition even without examination of the genitalia. This is exemplified by the sympatric (an in part closely related) species on Boongaree and Bigge islands, which are readily recognisable by their remarkably different shells.

\section{Patterns of endemism and diversity among Kimberley camaenids}

In the Kimberley Rainforest Survey (1987-1988) large numbers of camaenid species were found only in one or two rainforest patches (Solem, 1991; Solem \& McKenzie, 1991). These patches and similarly suitable habitats are usually surrounded by areas that are uninhabitable for the snails. Most camaenid land snails have limited dispersal abilities. For snails, these patches function as islands just as the "real islands" of the Bonaparte Archipelago off the mainland coast, which are also inhabited by these camaenids. If islands are simply seen as areas surrounded by hostile environments (Gittenberger, 2007), from a biogeographical point of view the entire Kimberley region is best understood as a huge island archipelago. Camaenid land snails in the Kimberley therefore exhibit distributions that are similar with to those found in snails on oceanic islands. Most camaenid species in the Kimberley have very short ranges with a calculated median range of only $20 \mathrm{~km}$ This holds true not only for species of Amplirhagada, but also for many other genera with few notable exceptions, such as species of Xanthomelon inhabiting open woodland (Solem, 1991). This highly insular distribution is inevitably connected with narrow-range endemism in many camaenids groups in the Kimberley. Documenting these patterns will provide the basis for a better understanding of the biogeography of the region and the evolution of its biota and facilitate the development of appropriate conservation strategies (e.g., Willan et al., 2009; Köhler, 2010).

Solem \& McKenzie (1991) concluded that camaenid land snails reveal geographic patterns, which reflect their low dispersal abilities and multiple centres of endemism; the phylogeographic relationships within Amplirhagada are fully consistent with this. The mitochondrial phylogeny reveals a basal polytomy, which is not caused by sequence saturation and hence considered as a "hard polytomy". The branching pattern of the tree corresponds closely with geographical 


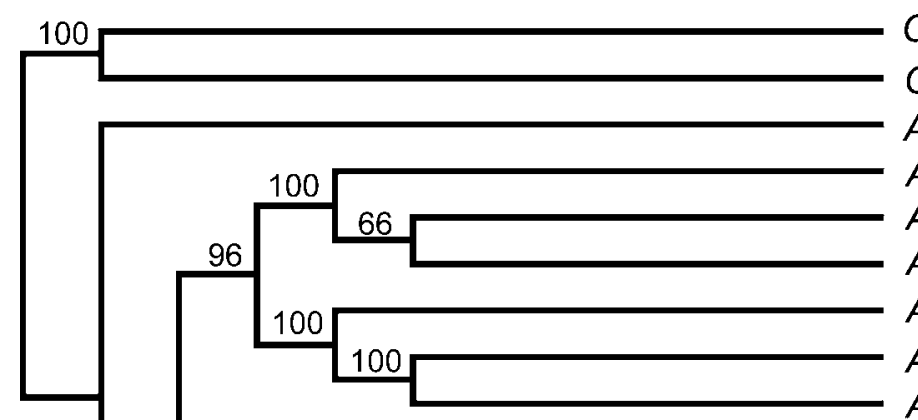
Carinotrachia sp. WAM S36600 Carinotrachia sp. AM C.463606 A. napierana AM C.150457 A. yorkensis FMNH 219151 A. yorkensis WAM S36976 A. yorkensis AM C.463711 A. buffonensis WAM S41484 A. buffonensis WAM $\mathrm{S} 41483$ A. buffonensis FMNH 219365

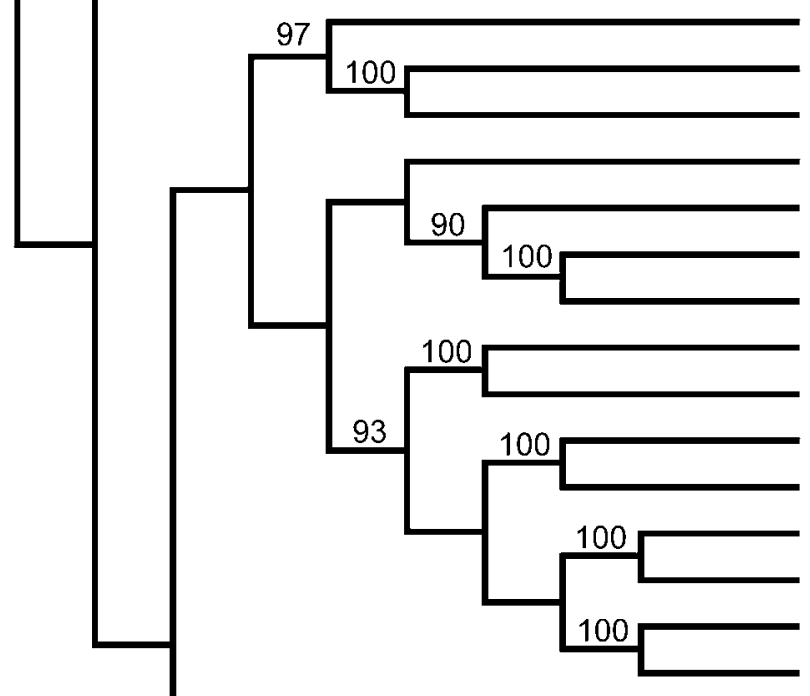

A. kimberleyana AM C.463760

A. gemina WAM S41479

A. gemina FMNH 219049

A. basilica AM C.463720

A. boongareensis AM C.463706

A. gibsoni WAM $\mathrm{S} 36650$

A. gibsoni WAM S36651

A. camdenensis WAM 537005

A. camdenensis AM C.463722

A. regia WAM $S 36647$

A. regia WAM $\mathrm{S} 36648$

A. uwinsensis WAM $\mathrm{S} 36991$

A. uwinsensis AM C. 463715

A. sphaeroidea AM C. 463718

A. sphaeroidea WAM $\mathrm{S} 37030$

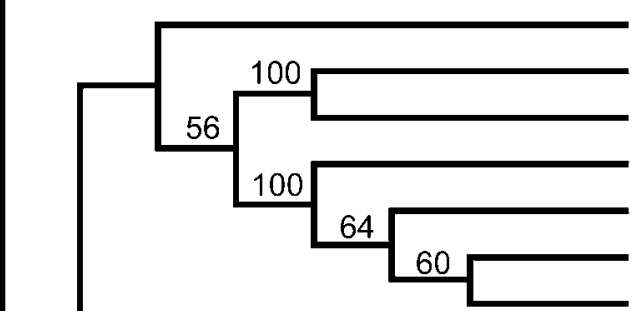

A. percita AM C.144028

A. berthierana AM C.463754

A. berthierana WAM $\$ 33029$

A. katerana AM C.463692

A. katerana WAM S36879

A. katerana WAM $\$ 36603$

A. katerana AM C.463696

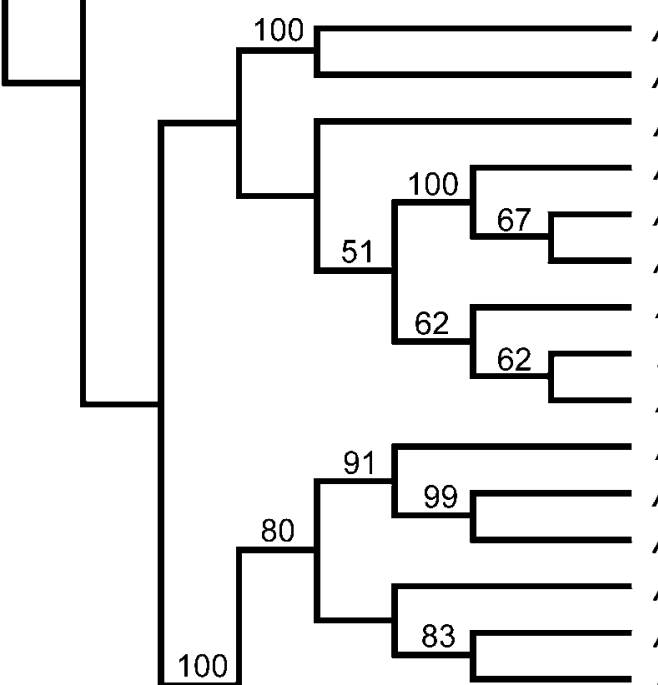

A. euroa AM C. 463680

A. euroa WAM S37083

A. tricenaria AM C.463757

A. kessneri WAM S36876a

A. kessneri WAM S36876b

A. kessneri AM C.463701

A. mitchelliana WAM S41462

A. mitchelliana AM C.144039

A. castra AM C.460966

A. montesquieuana AM C.463748

A. descartesana WAM S41491

A. descartesana FMNH 219276

A. mckenziei FMNH 219250

A. combeana AM C.463725

A. combeana WAM $\$ 41455$

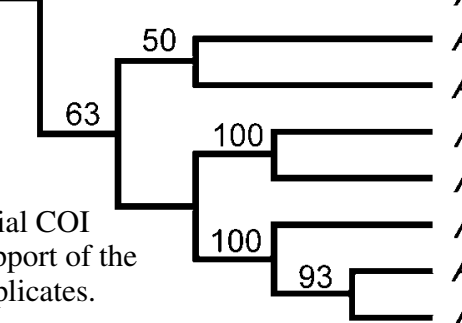

A. ponderi FMNH 219268

A. varia AM C. 460963

A. solemiana WAM $\$ 36595$

A. solemiana AM C. 463681

Figure 88. Strict consensus of three most parsimonious MP trees for the mitochondrial COI data set. Numbers on branches indicate support of the shown topology by 1,000 MP bootstrap replicates.
A. indistincta AM C.463724

A. indistincta AM C.463686

A. indistincta WAM $\$ 36864$ 
\begin{tabular}{|c|l}
100 & Carinotrachia sp. WAM $\$ 36600$ \\
Carinotrachia sp. AM C.463606
\end{tabular}

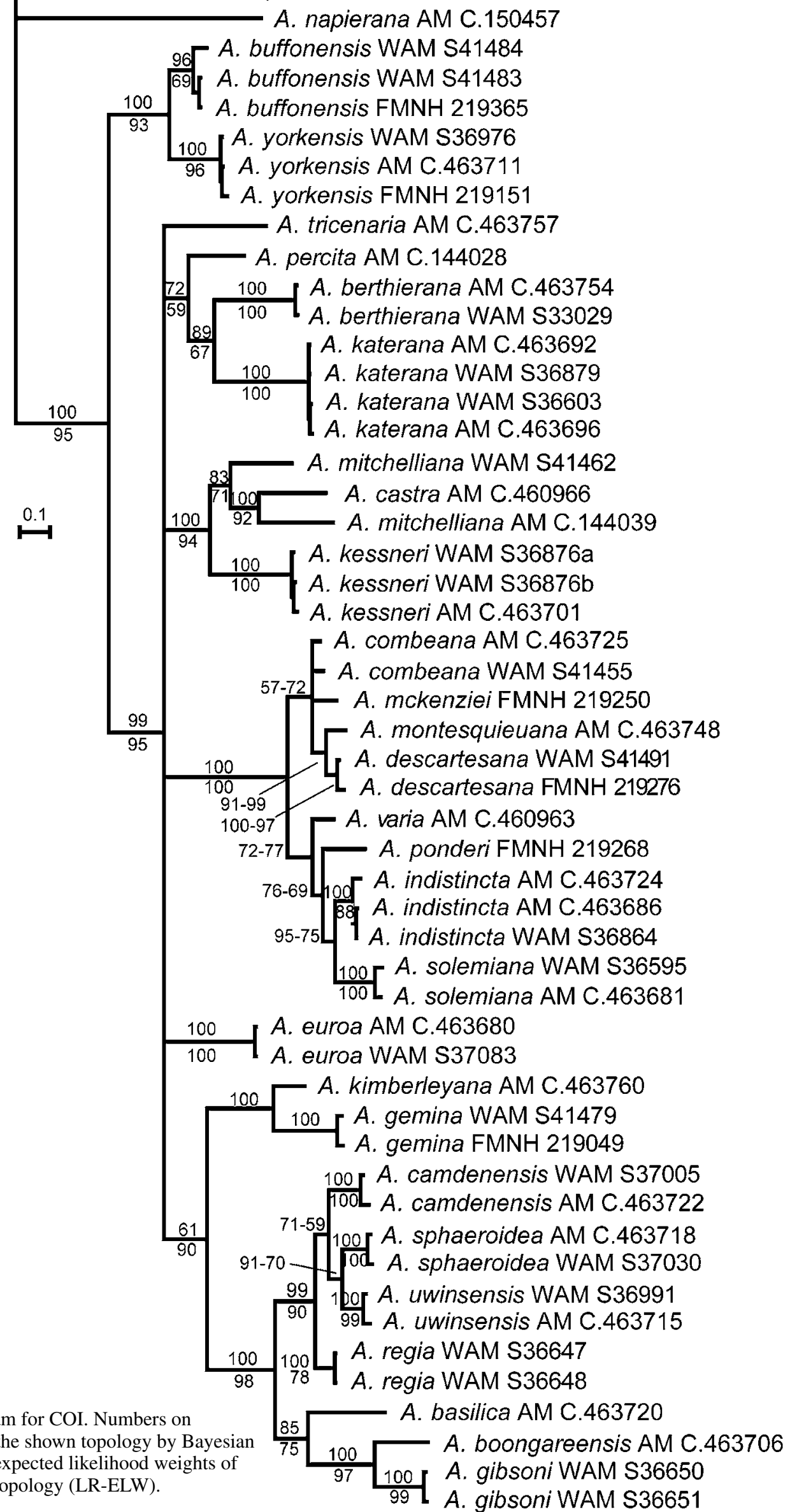

Figure 89. Bayesian phylogram for COI. Numbers on branches indicate support of the shown topology by Bayesian posterior clade probabilities/expected likelihood weights of local rearrangements of tree topology (LR-ELW).

\section{A. napierana AM C. 150457}

A. buffonensis $\mathrm{FMNH} 219365$

A. yorkensis WAM $\$ 36976$

A. yorkensis AM C. 463711

yorkensis FMNH 219151

A. percita AM C. 144028

A. berthierana AM C. 463754

A. katerana AM C.463692

A. katerana WAM $\mathrm{S} 36879$

A. katerana WAM S36603

A. katerana AM C.463696

A. kessneri WAM S36876a

A. kessneri WAM S36876b

A. kessneri AM C. 463701

A. combeana AM C.463725

A. descartesana WAM $\mathrm{S} 41491$

A. descartesana FMNH 219276

A indistincta AM C.463724

A. indistincta AM C. 463686

A. indistincta WAM S36864

A. A. solemiana WAM $\$ 36595$

A. solemiana AM C. 463681

A. euroa AM C. 463680

A. gemina WAM S41479

$\$ 37005$

A. camdenensis AM C.463722

A. sphaeroidea AM C.463718 


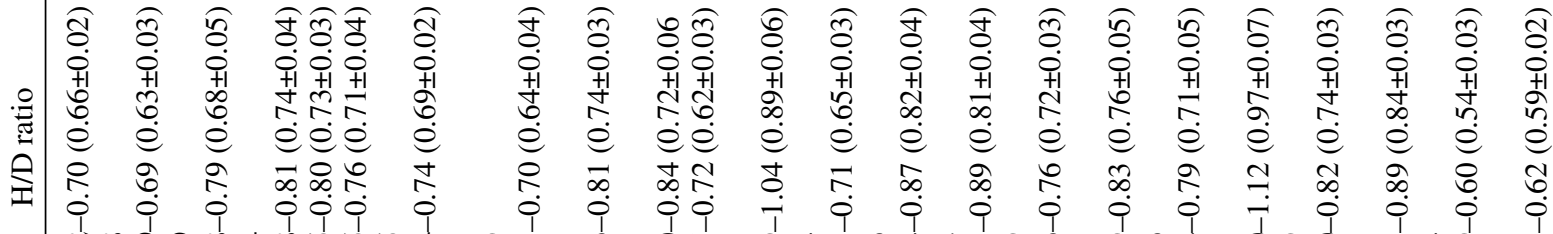
元

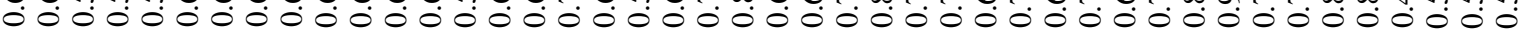

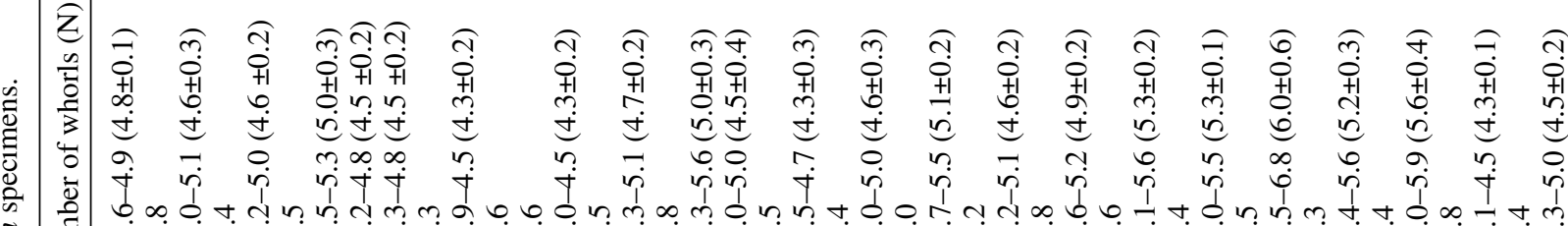

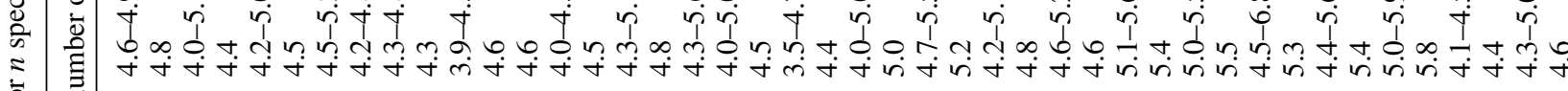

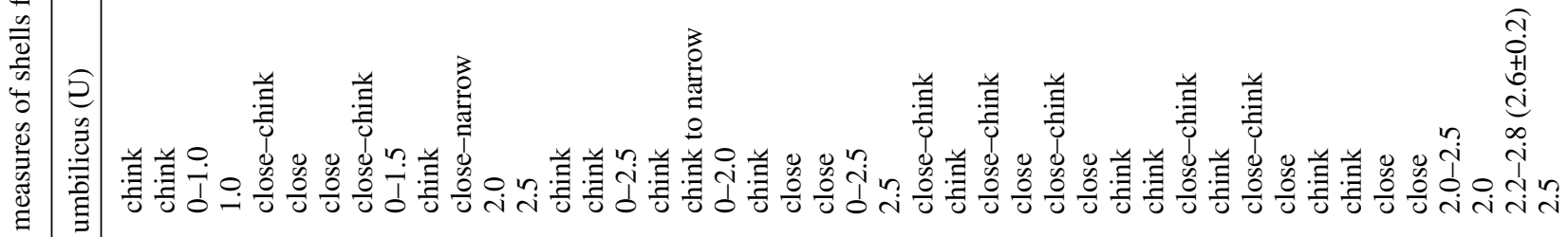 \\ กิ?}

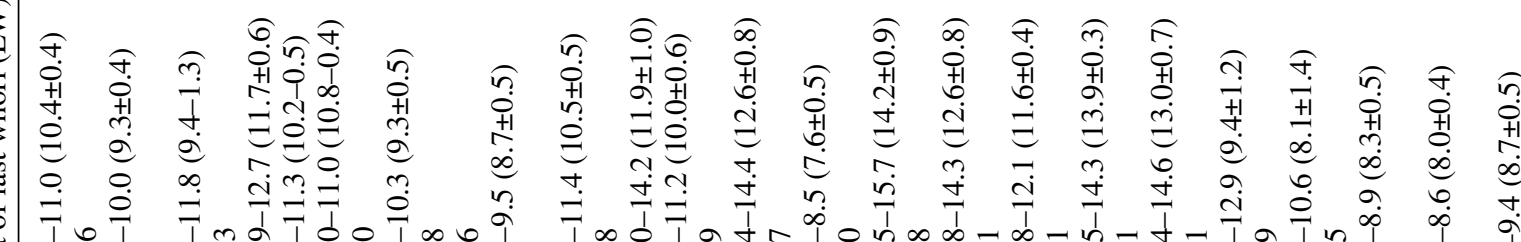

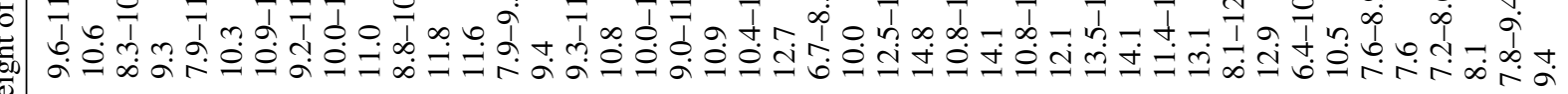

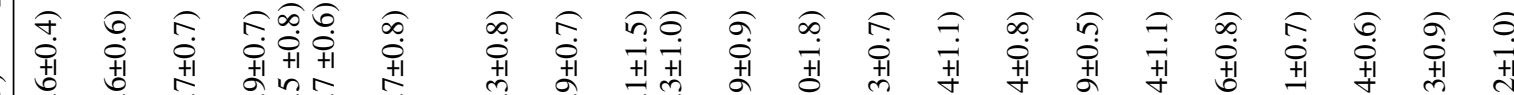

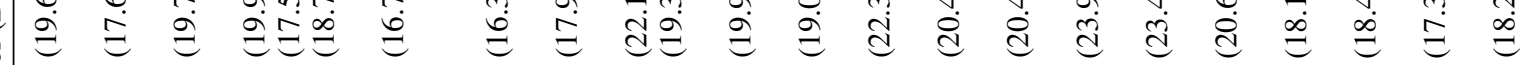

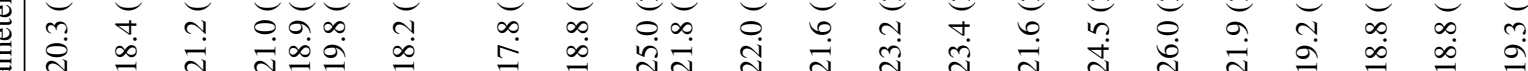

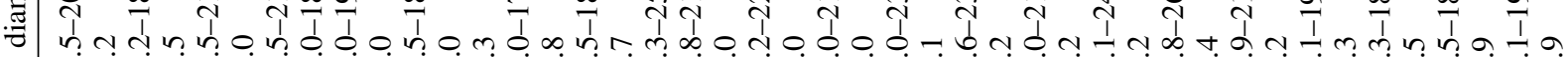

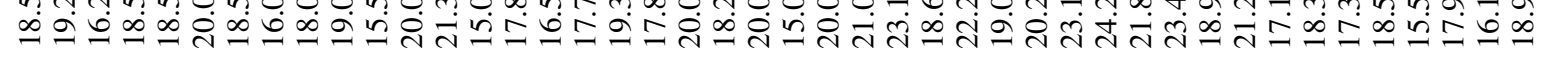

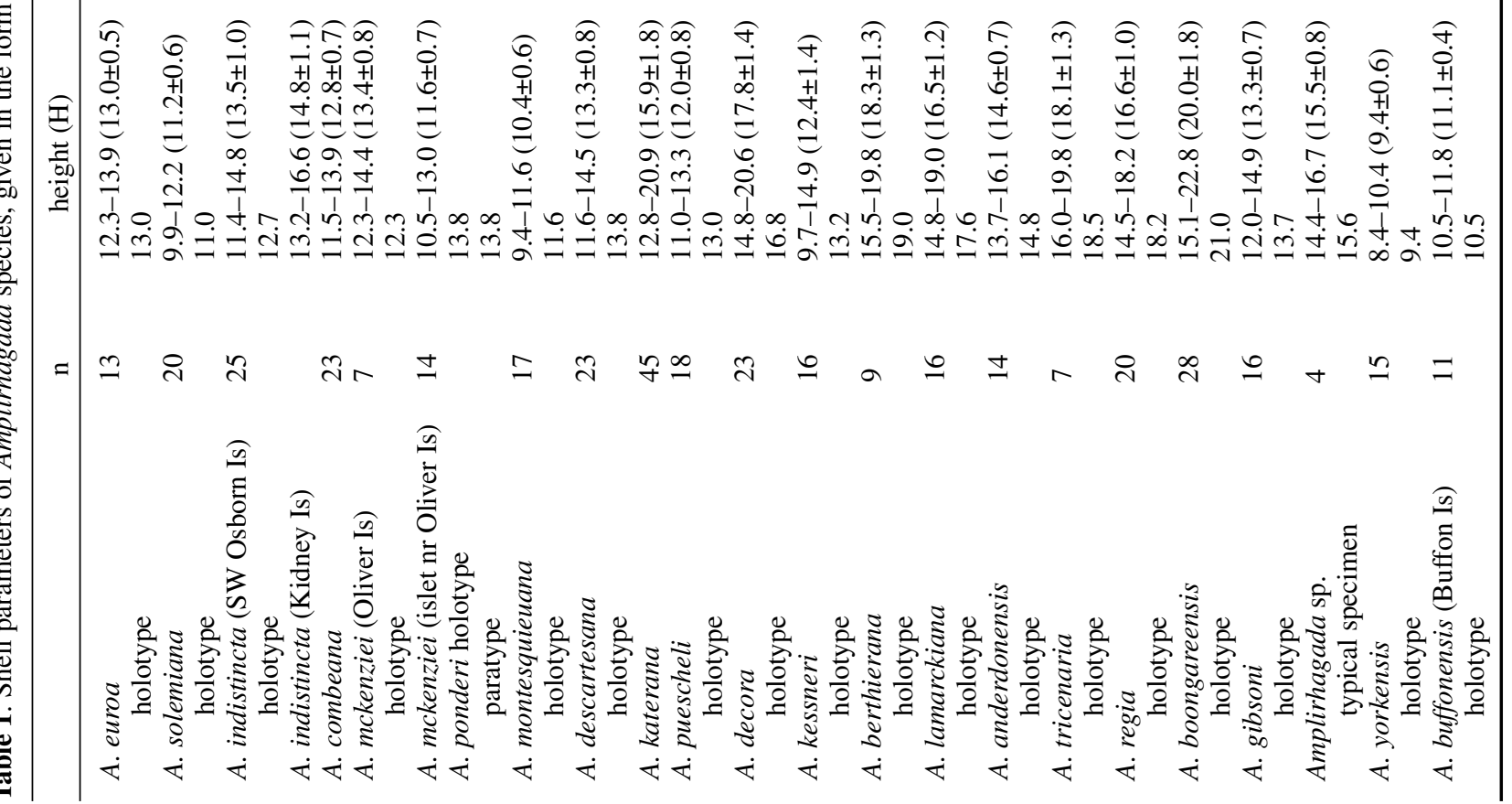




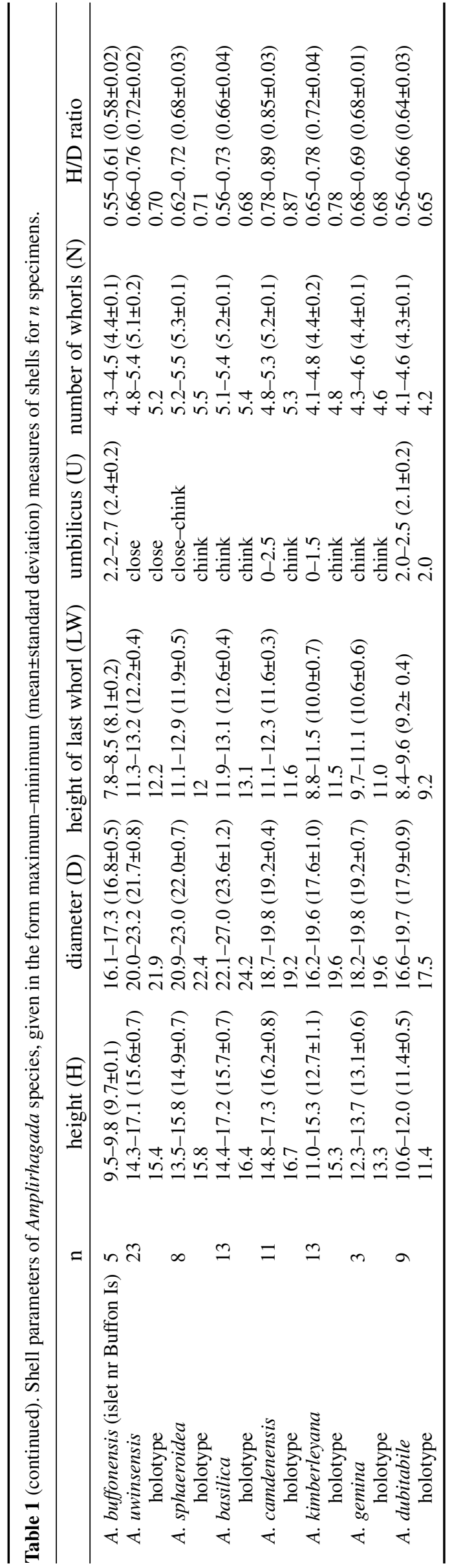

distributions, with clades comprising species from regional island groups plus the adjacent mainland. This is consistent with several clades having colonized islands more or less simultaneously from different centres of origin along the mainland coast. Rates of genetic differentiation between species are generally high, suggesting that species became separated a long time ago. Moreover, genetic distances between the mainland species are not significantly different from those between the island species or between species from islands and mainland. This seems to indicate that for the evolution of these snails it is not relevant whether their insular habitats are isolated by means of surrounding sea or other hostile environments.

It would be helpful to know when exactly the islands of the Bonaparte Archipelago were colonized by Amplirhagada snails in order to understand whether dispersal or vicariance played a major role. However, attempting to deduce the age of the group from estimated rates of sequence evolution, would be an arbitrary endeavour. Wilke et al., (2009) have suggested the applicability of a local molecular clock for small invertebrates. However, it has also been demonstrated that evolutionary rates on islands may be accelerated (Chiba, 1999b; Millien, 2006). In addition, it remains unclear whether the clock suggested by Wilke et al. (2009) for freshwater caenogastropods would be applicable to pulmonates, which were stated to show accelerated rates of molecular evolution (Thomaz et al., 1996; Chiba, 1999b; Watanabe \& Chiba, 2001; Pinceel et al., 2005). The latter two phenomena undermine the reliability of a molecular clock approach by assuming rates similar to those in caenogastropods. When a very coarse general estimate of 1 to $2 \%$ substitution rates per million years in the COI gene of invertebrates was considered (Wilke et al., 2009), observed substitution rates of around 30\% were taken to indicate divergence times for most species of several million years and that sea level changes during the Pleistocene, which may have periodically re-connected islands with the mainland, did not have a great impact on the patterns that may well have evolved prior to these events.

Johnson et al. (2010) studied Amplirhagada species on 16 Kimberley islands that are only partly covered by the present study on a finer spatial scale and came to very similar conclusions. They showed that the mitochondrial variation across the populations on the 16 islands correlates tightly with the geographical patterns. Genetic divergence was generally found to be low within local populations but much higher when populations from different islands were compared. Unfortunately, this study remained inconclusive with respect to the number of species involved. The authors found 16-27\% sequence divergence in a small fragment of the 16S rRNA gene between major clades of Amplirhagada that are separated by 10 to $160 \mathrm{~km}$ It is demonstrated herein that such distances are equivalent to the differentiation at the species level, which implies that Johnson et al. (2010) dealt indeed with several distinct, yet mostly unrecognized species. The phylogeographic patterns further revealed that species are restricted to single islands or smaller groups of closely adjacent islands. This finding corresponds well with the results of the present study. Johnson et al. (2010) concluded that even when accelerated evolutionary rates of 10 to $12.9 \%$ per million years were considered, as reported from some land snails (Thomaz et al., 1996; Chiba, 1999b; Thacker \& Hadfield, 2000), the amount of differentiation found in Amplirhagada would indicate divergence times of species of at least 1.5 to 
1
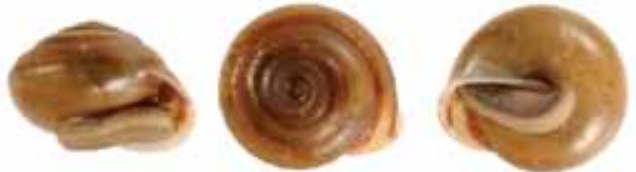

2

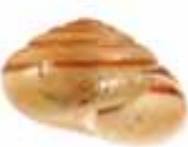

3
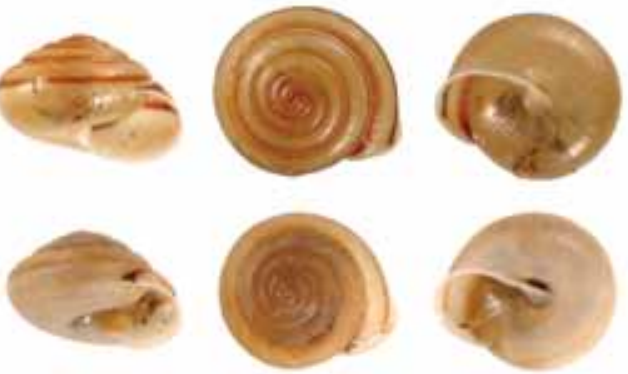

4
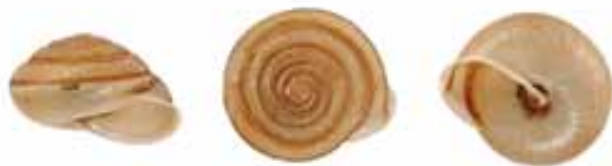

5
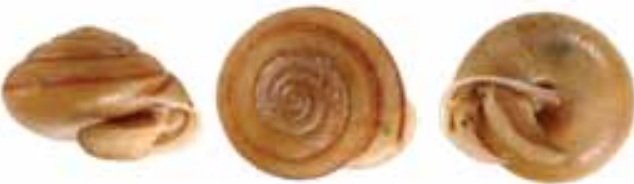

6
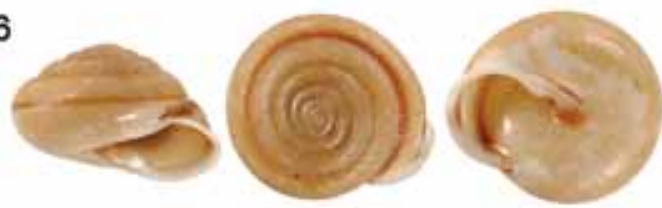

7
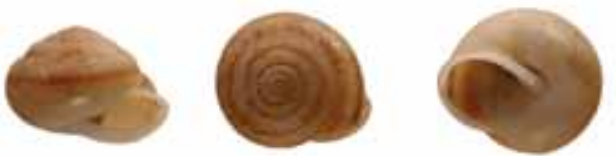

8
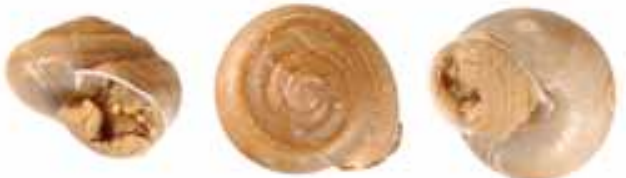

9
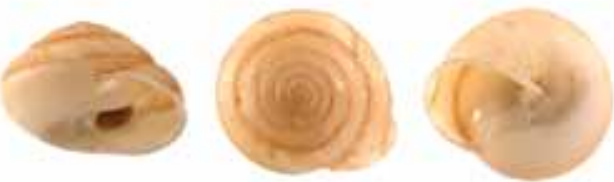

10
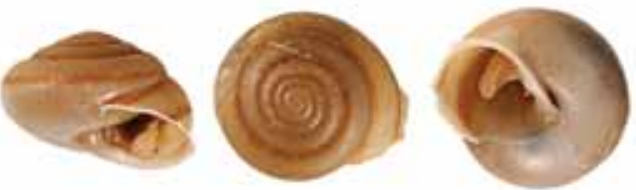

11
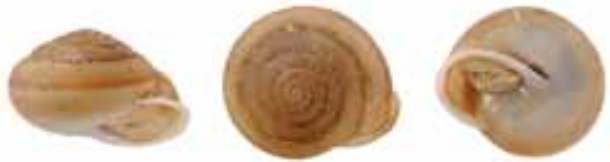

12
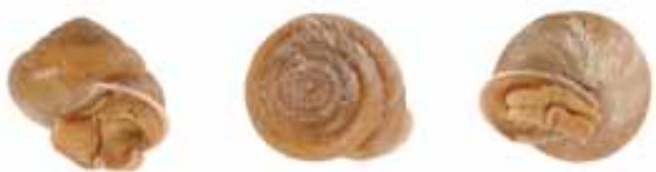

13
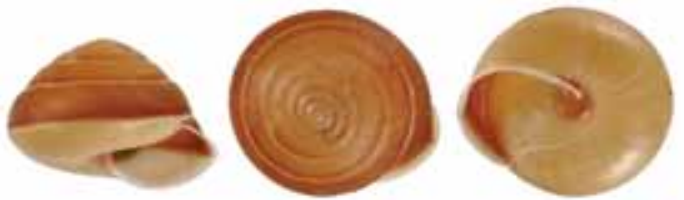

14
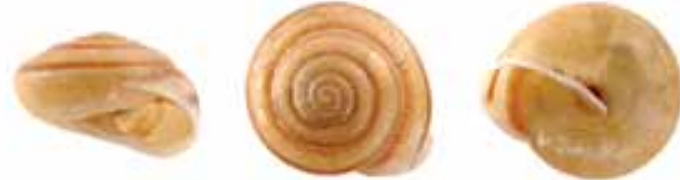

15
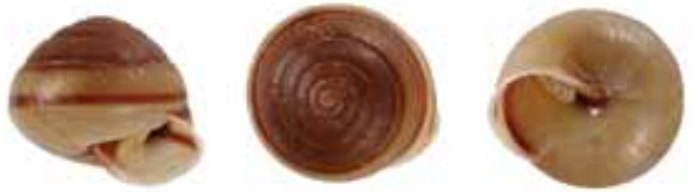

16
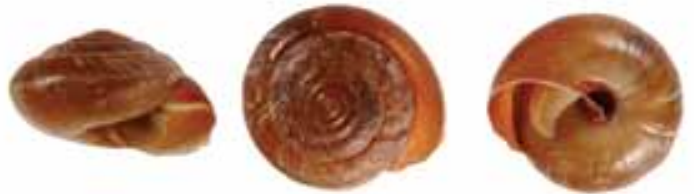

17
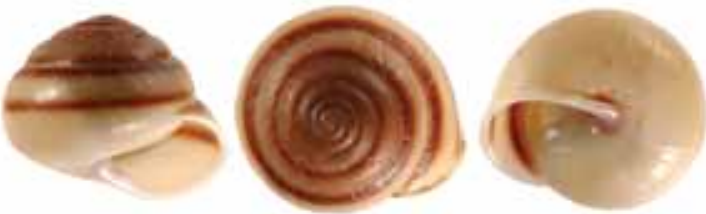

18
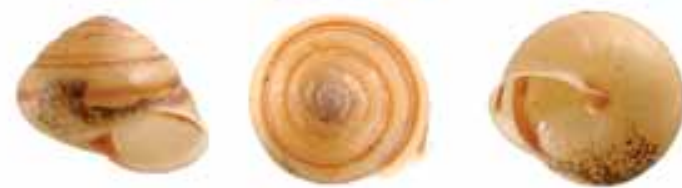

19
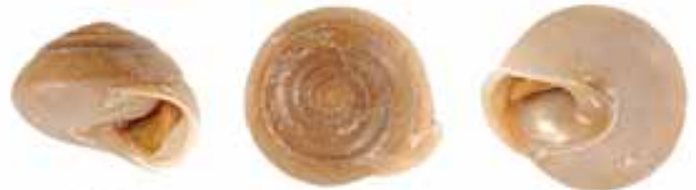

20
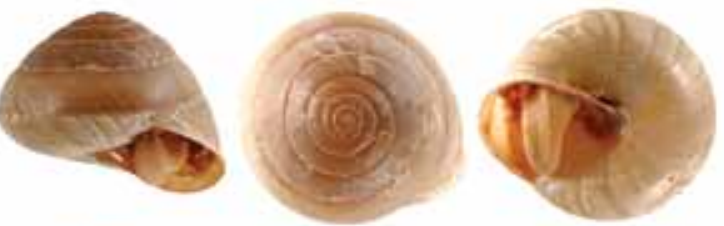

21
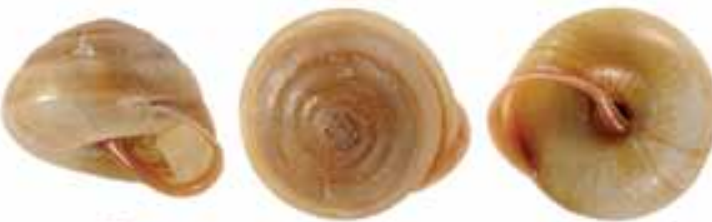

22
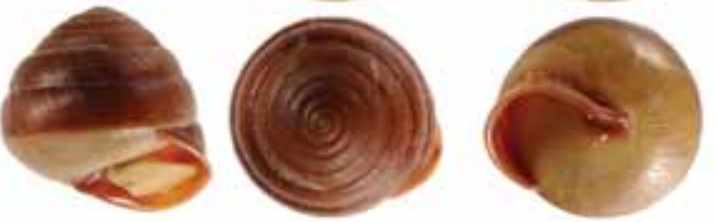

Plate 1. [Shells of Amplirhagada species (natural size, scale bar $=10 \mathrm{~mm}$ ). Caption given on page 282]. 
1

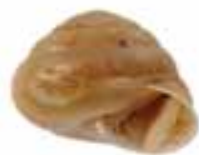

2

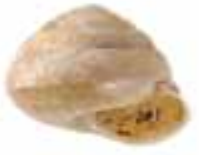

3

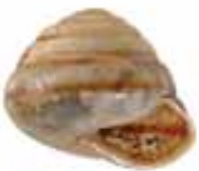

4

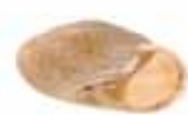

5

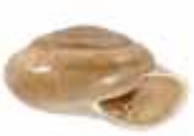

6

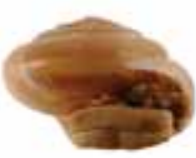

7

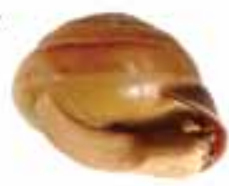

8

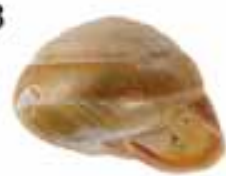

9

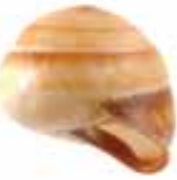

10

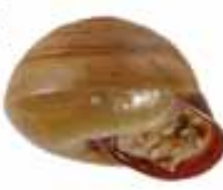

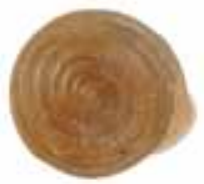
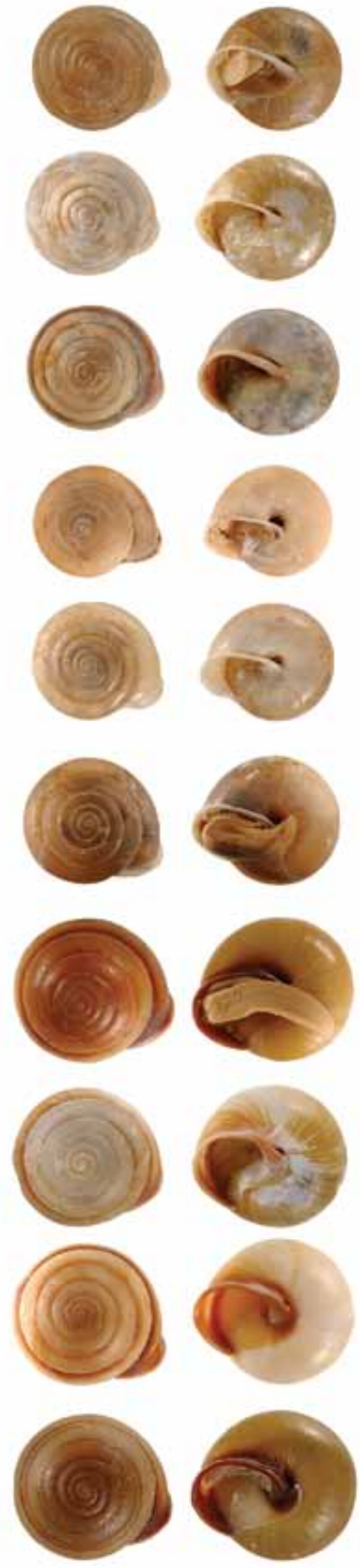

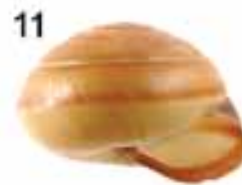

12

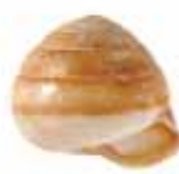

13

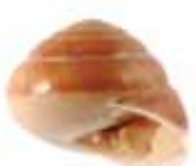

14

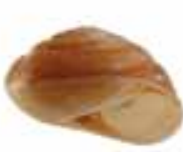

15
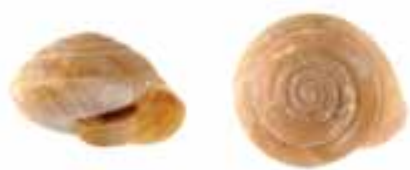

16
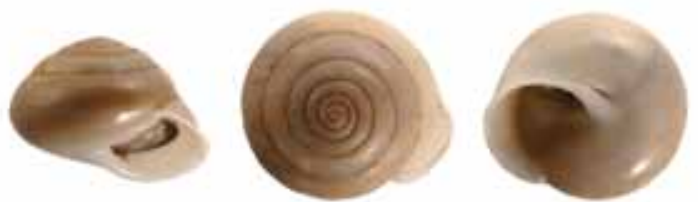

17
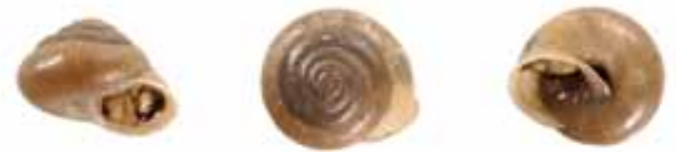

18
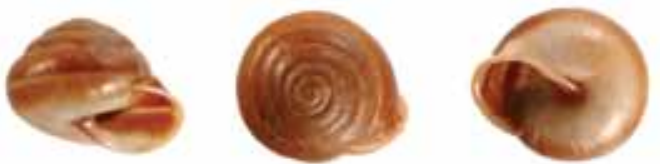

19
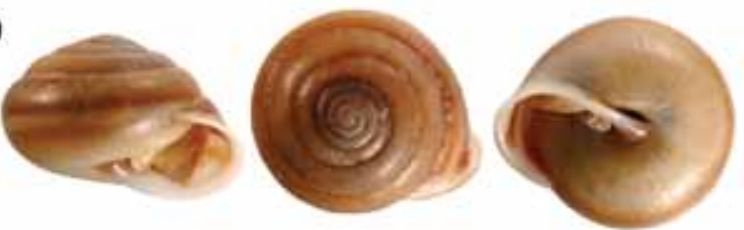

20
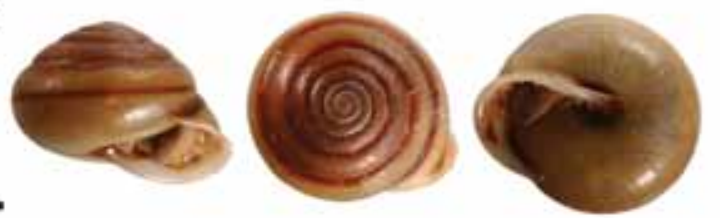

Plate 2. [Shells of Amplirhagada species (natural size, scale bar $=10 \mathrm{~mm}$ ). Caption given on page 282]. 
Plate 1 (page 280). Shells of Amplirhagada species (natural size, scale bar $=10 \mathrm{~mm}$ ). (1.1) A. euroa n.sp. holotype WAM S34601. (1.2) A. euroa $\mathrm{n}$.sp. paratype WAM S37392. (1.3) A. solemiana $\mathrm{n} . \mathrm{sp}$. holotype WAM S34602. (1.4) A. solemiana n.sp. paratype WAM S36572. (1.5) A. indistincta n.sp. holotype WAM S34603. (1.6) A. indistincta n.sp. paratype WAM S36499. (1.7) A. combeana WAM S41450. (1.8) A. mckenziei n.sp. holotype WAM S34604. (1.9) A. mckenziei n.sp. paratype FMNH 219253. (1.10) A. ponderi n.sp. holotype WAM S34605. (1.11) A. montesquieuana n.sp. holotype WAM S34606. (1.12) A. descartesana holotype WAM S34607. (1.13) A. katerana WAM S36580. (1.14) A. puescheli n.sp. holotype WAM S34608. (1.15) A. decora n.sp. holotype WAM S34609. (1.16) A. kessneri n.sp. holotype WAM S34610. (1.17) A. berthierana n.sp. holotype WAM S34611. (1.18) A. lamarckiana n.sp. holotype WAM S34612. (1.19) A. anderdonensis n.sp. holotype WAM S34613. (1.20) A. tricenaria n.sp. holotype WAM S34614. (1.21) A. regia n.sp. holotype WAM S34615. (1.22) A. boongareensis n.sp. holotype WAM S34616. Note that foot protrudes from shell in some cases.

Plate 2 (page 281). Shells of Amplirhagada species (natural size, scale bar $=10 \mathrm{~mm}$ ). (2.1) A. gibsoni n.sp. holotype WAM S34617. (2.2) A. gibsoni n.sp. paratype AMS C463708. (2.3) Amplirhagada sp. Bigge Island, WAM S36953. (2.4) A. yorkensis n.sp. holotype WAM S34619. (2.5) A. yorkensis n.sp. paratype WAM S37401. (2.6) A. buffonensis n.sp. holotype WAM S34620. (2.7) A. uwinsensis n.sp. holotype WAM S34621. (2.8) A. uwinsensis n.sp. paratype WAM S37441. (2.9) A. uwinsensis n.sp. paratype AMS C463716. (2.10) A. sphaeroidea n.sp. holotype WAM S34622. (2.11) A. basilica n.sp. holotype WAM S34623. (2.12) A. camdenensis n.sp. holotype WAM S34624. (2.13) A. kimberleyana n.sp. holotype WAM S34625. (2.14) A. gemina n.sp. holotype WAM S34626. (2.15) A. dubitabile n.sp. holotype WAM S34627. (2.16) A. napierana AMS C150457. (2.17) A. percita AMS C144028. (2.18) A. varia AMS C460963. (2.19) A. mitchelliana WAM S41462. (2.20) A. castra AMS C460966. Note that foot protrudes from shell in some cases.

2 million years. In this period of time, particularly during the Pleistocene, the studied islands were repeatedly interconnected due to periodically lowered sea levels. However, the species have maintained distinctiveness on a small geographical scale over this period of time, which implies that fluctuating sea levels during Pleistocene did not influence the processes of genetic differentiation or allopatric speciation.

In general, narrow-range endemics, such as the Kimberley camaenids, are promising candidates for the study of speciation and adaptation. While the isolated occurrence of most species may suggest allopatric speciation as the predominant mode, Schilthuizen \& Scott (2004) have stressed that for a number of model cases including Western Australian camaenids, a strong ecological component may also be involved. Observed cases of character displacement in sympatric species also points towards the relevance of ecological factors and sexual selection in these species. Hence, further studies are needed that address aspects of speciation, adaptation and radiation in Amplirhagada in more detail. Markedly different patterns of morphological versus genetic differentiation were found in the camaenid snail Rhagada in Dampierland, Western Australia. In these snails, high levels of morphological differentiation were accompanied by generally very low levels of genetic differentiation (Johnson et al., 2004). A comparative study of the contrasting patterns in these two Western Australian camaenid genera may help to better understand the factors that drive the evolution of Australian Camaenidae.

With respect to overall species diversity, the Kimberley with its approximately 180 known camaenid species (Solem, 1998) is comparable with many textbook cases of mega- diverse island faunas (Whittaker, 1998). Moreover, given the large number of still unsurveyed islands off the mainland coast and other equally inaccessible regions on the mainland, the number of yet undiscovered species in the Kimberley is without doubt considerable. Amplirhagada may be taken as a prime example to estimate the proportion of yet undescribed species in relation to what is already known. Thirty species are currently considered as valid (Solem, 1981a, 1988). However, museum material examined by Solem contains some further 35 Amplirhagada species to be described, which includes the 25 unnamed species reported by Solem (1991). Here, only eleven of these species are described. Additional species descriptions are based on materials collected during the ongoing Kimberley Island Survey in 2007-2008 on eight larger islands. During survey work conducted in 2009 we found probably another six currently unknown species of Amplirhagada, which are not included here. Consequently, at this stage there are 57 named plus 30 yet to be described Amplirhagada species. These numbers include species collected on approximately 25 islands of the Bonaparte Archipelago, which includes the 19 largest islands of this archipelago. However, the snail fauna of at least 50 larger islands in this region remains entirely unknown. If only every second island supports an endemic Amplirhagada species, which is probably a conservative estimate, than there might be 25 undiscovered species on top of the numbers given above. It can only be speculated, how many species await discovery on the mainland but less than half of the species diversity in Amplirhagada is likely documented so far. There is no reason to assume that these figures are different for other camaenid genera in the area. 
ACKNOWLEDGMENTS. This work has been conducted as part of the Kimberley Island Survey of the Western Australian Department of Environment and Conservation (DEC), a project jointly funded by the Commonwealth of Australia and the Western Australian Government. I owe a debt of gratitude to Marlene Vial, Sue Lindsay and Martin Püschel for their help with sample processing, SEM work, anatomical drawings and photography. I further wish to thank Shirley Slack-Smith and Corey Whisson (WAM), Jochen Gerber (FMNH) as well as Alison Miller and Janet Waterhouse (AM) for most effectively handling extensive loans from or to their respective museums. Special thanks are due to Winston Ponder and Norm McKenzie for encouraging me to work with Kimberley camaenids. Thanks are also due to everybody who contributed to the successful implementation of the survey work on the Kimberley Islands. This includes traditional landowners of the Malaya, Dambimangari, and Bardi-Jawi people, the Kimberley Land Council and staff of the DEC and the Australian Museum. Last but not least, I am indebted to two anonymous reviewers for their constructive and helpful comments on the submitted version of the manuscript.

\section{References}

Barker, G.M., 1999. Naturalised terrestrial Stylommatophora (Mollusca: Gastropoda). Fauna of New Zealand, vol. 38. Canterbury, New Zealand: Lincoln.

Cameron, R.A.D., B.M. Pokryszko \& F.E. Wells, 2005. Alan Solem's work on the diversity of Australasian land snails: an unfinished project of global significance. Records of the Western Australian Museum, Supplement 68: 1-10.

Chiba, S., 1999a. Character displacement, frequency-dependent selection, and divergence of shell colour in land snails Mandarina (Pulmonata). Biological Journal of the Linnean Society 66: 465-479.

Chiba, S., 1999b. Accelerated evolution of land snails Mandarina in the oceanic Bonin Islands: Evidence from mitochondrial DNA sequences. Evolution 53: 460-471.

http://dx.doi.org/10.2307/2640782

Chiba, S., \& A. Davison, 2008. Anatomical and molecular studies reveal several cryptic species of the endemic genus Mandarina (Pulmonata: Helicoidea) in the Ogasawara Islands. Journal of Molluscan Studies 74: 373-382.

http://dx.doi.org/10.1093/mollus/eyn029

Felsenstein, J., 1985. Confidence limits on phylogenies: an approach using the bootstrap. Evolution 39: 783-791. http://dx.doi.org/10.2307/2408678

Folmer, O., M. Black, W. Hoeh, R. Lutz \& R. Vrijenhoek, 1994. DNA primers for amplification of mitochondrial cytochrome c oxidase subunit I from diverse metazoan invertebrates. Molecular Marine Biology and Biotechnology 3: 294-299.

Gittenberger, E., 2007. Islands from a snail's perspective. In Biogeography, Time, and Place: Distributions, Barriers, and Islands, ed. W. Renema, pp. 347-363. Heidelberg: Springer-Verlag. http://dx.doi.org/10.1007/978-1-4020-6374-9_11

Iredale, T., 1933. Systematic notes on Australian land shells. Records of the Australian Museum 19: 37-59. http://dx.doi.org/10.3853/..0067-1975.19.1933.690

Iredale, T., 1938. A basic list of the land Mollusca of AustraliaPart III. Australian Zoologist 9: 83-124.

Iredale, T., 1939. A review of the land Mollusca of Western Australia. Journal of the Royal Society of Western Australia 25: $1-88$

Jobb, G., A. v. Haeseler \& K. Strimmer, 2004. TREEFINDER: a powerful graphical analysis environment for molecular phylogenetics. BMC Evolutionary Biology 4: 18.

http://dx.doi.org/10.1186/1471-2148-4-18
Johnson, M.S., Z.R. Hamilton, C.E. Murphy, C.A. MacLeay, B. Roberts \& P.G. Kendrick, 2004. Evolutionary genetics of island and mainland species of Rhagada (Gastropoda: Pulmonata) in the Pilbara Region, Western Australia. Australian Journal of Zoology 52: 341-355.

http://dx.doi.org/10.1071/ZO04027

Johnson, M.S., E.K. O’Brien \& J.J. Fitzpatrick, 2010. Deep, hierarchical divergence of mitochondrial DNA in Amplirhagada land snails (Gastropoda: Camaenidae) from the Bonaparte Archipelago, Western Australia. Biological Journal of the Linnean Society 100: 141-153. http://dx.doi.org/10.1111/j.1095-8312.2010.01407.x

Jordaens, K., L. Bruyndoncx, J. Van Goethem \& T. Backeljau, 2009. Morphological and anatomical differentiation of three land snails of the genus Rhynchotrochus (Gastropoda: Pulmonata: Camaenidae). Journal of Molluscan Studies 75: 1-8. http://dx.doi.org/10.1093/mollus/eyn035

Kameda, Y.C., A. Kawakita \& M. Kato, 2007. Cryptic genetic divergence and associated morphological differentiation in the arboreal land snail Satsuma (Luchuhadra) largillierti (Camaenidae) endemic to the Ryukyu Archipelago, Japan. Molecular Phylogenetics and Evolution 45: 519-533. http://dx.doi.org/10.1016/j.ympev.2007.03.021

Kameda, Y.C., A. Kawakita \& M. Kato, 2009. Reproductive character displacement in genital morphology in Satsuma land snails. The American Naturalist 173: 689-697. http://dx.doi.org/10.1086/597607

Köhler, F., 2010. Three new species and two new genera of land snails from the Bonaparte Archipelago in the Kimberley, Western Australia (Pulmonata, Camaenidae). Molluscan Research 30: 1-16.

Larget, B., \& D.L. Simon, 1999. Markov chain Monte Carlo algorithms for the Bayesian analysis of phylogenetic trees. Molecular Biology and Evolution 16: 750-759.

Millien, V., 2006. Morphological evolution is accelerated among island mammals. PLoS Biology 4: 1863-1868.

Nixon, K.C., 1999. The Parsimony Ratchet, a new method for rapid parsimony analysis. Cladistics 15 : 407-414. http://dx.doi.org/10.1111/j.1096-0031.1999.tb00277.x

Pinceel, J., K. Jordaens \& T. Backeljau, 2005. Extreme mtDNA divergences in a terrestrial slug (Gastropoda, Pulmonata, Arionidae): accelerated evolution, allopatric divergence and secondary contact. Journal of Evolutionary Biology 18: $1264-1280$.

http://dx.doi.org/10.1111/j.1420-9101.2005.00932.x

Ronquist, F., \& J.P. Huelsenbeck, 2003. MRBAYES 3: Bayesian phylogenetic inference under mixed models. Bioinformatics 19: $1572-1574$.

http://dx.doi.org/10.1093/bioinformatics/btg180

Smith, E.A., 1894. On the land-shells of Western Australia. Proceedings of the Malacological Society of London 1: 84-99.

Solem, A., 1979. Camaenid land snails from Western and central Australia (Mollusca: Pulmonata: Camaenidae). I. Taxa with trans-Australian distribution. Records of the Western Australian Museum Supplement 10: 5-142.

Solem, A., 1981a. Camaenid land snails from Western and central Australia (Mollusca: Pulmonata: Camaenidae). II. Taxa from the Kimberley, Amplirhagada Iredale 1933. Records of the Western Australian Museum Supplement 11: 147-320.

Solem, A., 1981b. Camaenid land snails from Western and central Australia (Mollusca: Pulmonata: Camaenidae). III. Taxa from the Ningbing Ranges and nearby areas. Records of the Western Australian Museum, Supplement 11: 321-425.

Solem, A., 1984. Camaenid land snails from Western and central Australia (Mollusca: Pulmonata: Camaenidae). IV. Taxa from the Kimberley, Westraltrachia Iredale, 1933 and related genera. Records of the Western Australian Museum, Supplement 17: 427-705. 
Solem, A., 1985. Camaenid land snails from Western and central Australia (Mollusca: Pulmonata: Camaenidae). V. Remaining Kimberley genera and addenda to the Kimberley. Records of the Western Australian Museum, Supplement 20: 707-981.

Solem, A., 1988. New camaenid land snails from the northeast Kimberley, Western Australia. Journal of the Malacological Society of Australia 9: 27-58.

Solem, A., 1991. Land snails of Kimberley rainforest patches and biogeography of all Kimberley landsnails. In Kimberley rainforests of Australia, ed. N.L. McKenzie, R.B. Johnston, \& P.G. Kendrick, pp. 145-246. Canberra: Surrey Beatty \& Sons and Department of Conservation and Land Management Western Australia.

Solem, A., 1993. Camaenid land snails from Western and central Australia (Mollusca: Pulmonata: Camaenidae). VI. Taxa from the Red Centre. Records of the Western Australian Museum, Supplement 43: 983-1489.

Solem, A., 1997. Camaenid land snails from Western and central Australia (Mollusca: Pulmonata: Camaenidae). VII. Taxa from Dampierland trough the Nullabor. Records of the Western Australian Museum, Supplement 50: 1461-1906.

Solem, A., 1998. Family Camaenidae. In Mollusca: The Southern Synthesis, ed. P.L. Beesley, G.J.B. Ross, \& A. Wells. pp. 1112-1113. Melbourne: CSIRO Publishing.

Solem, A., \& C. Christensen, 1984. Camaenid land snail reproductive cycle and growth patterns in semiarid area of north-western Australia. Australian Journal of Zoology 32: 471-491. http://dx.doi.org/10.1071/ZO9840471

Solem, A., \& N.L. McKenzie, 1991. The composition of land snail assemblages in Kimberley rainforests. In Kimberley Raonforests of Australia, ed. N.L. McKenzie, R.B. Johnston \& P.G. Kendrick, pp. 247-263. Canberra: Surrey Beatty \& Sons and Department of Conservation and Land Management Western Australia.

Strimmer, K., \& A. Rambaut, 2002. Inferring confidence sets of possibly misspecified gene trees. Proceedings of the Royal Society of London B Biological Sciences 269: 137-142. http://dx.doi.org/10.1098/rspb.2001.1862
Tamura, K., \& M. Nei, 1993. Estimation of the number of nucleotide substitutions in the control region of mitochondrial DNA in humans and chimpanzees. Molecular Biology and Evolution 10: 512-526.

Thacker, R.W., \& M.G. Hadfield, 2000. Mitochondrial phylogeny of extant Hawaiian tree snails (Achatinellidae). Molecular Phylogenetics and Evolution 16: 263-270. http://dx.doi.org/10.1006/mpev.2000.0793

Thomaz, D., A. Guiller \& B. Clarke, 1996. Extreme divergence of mitochondrial DNA within species of pulmonate land snails. Proceedings of the Royal Society of London B Biological Sciences 263: 363-368. http://dx.doi.org/10.1098/rspb.1996.0056

Watanabe, Y., \& S. Chiba, 2001. High within-population mitochondrial DNA variation due to microvicariance and population mixing in the land snail Euhadra quaesita (Pulmonata: Bradybaenidae). Molecular Ecology 10: 2635-2645. http://dx.doi.org/10.1046/j.0962-1083.2001.01388.x

Whittaker, R.J., 1998. Island Biogeography. Ecology, Evolution and Conservation. Oxford, NY: Oxford University Press.

Wilke, T., R. Schultheiß \& C. Albrecht, 2009. As time goes by: A simple fool's guide to molecular clock approaches in invertebrates. American Malacological Bulletin 27: 25-45. http://dx.doi.org/10.4003/006.027.0203

Willan, R.C., F. Köhler, V., Kessner \& M.F. Braby. 2009. Description of four new species of limestone associated Torresitrachia land snails (Mollusca: Pulmonata: Camaenidae) from the Katherine District of the Northern Territory, with comments on their conservation. The Beagle. Records of the Museums and Art Galleries of the Northern Territory 25: $85-98$.

Xia, X., \& Z. Xie, 2001. DAMBE: Data analysis in molecular biology and evolution. Journal of Heredity 92: 371-373. http://dx.doi.org/10.1093/hhered/92.4.371

Manuscript submitted 3 August 2009, revised 30 December 2009, and accepted 31 December 2009. 